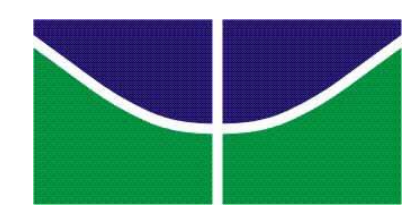

UNIVERSIDADE DE BRASÍLIA

Instituto de Ciências Biológicas

Instituto de Física

Instituto de Química

Faculdade UnB Planaltina

Programa de Pós-Graduação em Ensino de Ciências

Mestrado Profissional em Ensino de Ciências

\title{
Avaliação do Uso de Modelagem Qualitativa com Apoio de Agentes Aprendizes Virtuais na Compreensão da Dinâmica de Sistemas por Alunos do Ensino Fundamental
}

Tarcisio Ferreira Cavalcante

Brasília, DF

2015 


\section{Tarcisio Ferreira Cavalcante}

\section{Avaliação do Uso de Modelagem Qualitativa com Apoio de Agentes Aprendizes Virtuais na Compreensão da Dinâmica de Sistemas por Alunos do Ensino Fundamental}

Dissertação realizada sob orientação do Prof. Dr. Paulo Sérgio Bretas de Almeida Salles, apresentada à banca examinadora como requisito parcial para a obtenção do título de Mestre em Ensino de Ciências pelo Programa de Pós-Graduação em Ensino de Ciências da Universidade de Brasília.

Brasília, DF

2015 


\section{TARCISIO FERREIRA CAVALCANTE}

\section{Avaliação do Uso de Modelagem Qualitativa com Apoio de Agentes Aprendizes Virtuais na Compreensão da Dinâmica de Sistemas por Alunos do Ensino Fundamental}

Dissertação apresentada à banca examinadora como requisito parcial para a obtenção do título de Mestre em Ensino de Ciências, pelo Programa de Pós-Graduação em Ensino de Ciências da Universidade de Brasília.

Aprovada em 03 de agosto de 2015.

BANCA EXAMINADORA

Prof. Dr. Paulo Sérgio B. de Almeida Salles

(Presidente)

Prof. ${ }^{\text {a }}$ Dr. ${ }^{a}$ Alice Melo Ribeiro

(Membro Interno - IB/PPGEC/UnB)

\begin{tabular}{c}
\hline Prof. $^{\text {a }}$ Dr. \\
(Membro Nara Maria Pimentel \\
\\
\hline Prof. $^{\text {a }}$ Dr. ${ }^{a}$ Maria Márcia Murta \\
(Suplente - IQ/PPGEC/UnB).
\end{tabular}


Dedico este trabalho aos meus filhos, João Eduardo e Maria Eduarda. 


\section{AGRADECIMENTOS}

No percurso deste trabalho, muitos cruzaram o meu caminho e todos deram um pouco de seu tempo, conhecimentos e experiência, que contribuíram para a realização do mesmo. Agradeço...

- a Deus, pela força e iluminação, para eu que tomasse as melhores decisões;

- à minha mãe, Teresinha, que me criou com função de pai e mãe, e sempre me motivou nos estudos, e à minha esposa, Rayanne, que me acompanhou de perto, teve paciência nos momentos mais críticos e me incentivou a não desistir no meio do caminho;

- à minha sogra Joana, a quem tenho confiado o cuidado dos meus filhos;

- ao meu grande parceiro, aquele que me orientou antes mesmo do início do mestrado, mostrando as melhores opções e caminhos a seguir, de grande experiência acadêmica, Paulo Salles;

- aos professores do Centro de Ensino em que esta pesquisa foi realizada, em especial à professora Caline, dedicada e compromissada, à professora e coordenadora Raquel, atenciosa e esforçada, sempre acessível e pronta nos momentos em que fora solicitada, à supervisora pedagógica Conceição e à diretora, Maria Lourdes, pelo apoio;

- aos colegas Fabrício, Adriano, Geane e Rejane, com quem dividi momentos de troca de conhecimentos, aflições e alegrias nos últimos 2 anos e meio. Aos amigos Airton e Israel, pela revisão ortográfica;

- aos professores Ricardo Gauche, Marcelo Bizerril, Mariana Zancul, Gerson Mól, Maria Rita Avanzi, Renata Razuck, Roseline Strieder, Wildson Santos e Maria Luiza Gastal, pelos ensinamentos;

- aos componentes da minha banca examinadora, professoras Alice Ribeiro, Nara Pimentel e Márcia Murta, pelas sugestões que enriqueceram o meu trabalho;

- à secretária do PPGEC, Luciene, à secretária do IQ, Caroline, e à secretária do NECBIO, Jesa, pela atenção no atendimento, nas inúmeras vezes em que foram solicitadas. 


\section{RESUMO}

A presente Dissertação apresenta proposta de intervenção pedagógica baseada no uso da modelagem qualitativa, apoiada por agentes aprendizes virtuais (teachable agent ou TA), funcionalidade disponível no software DynaLearn (www.dynalearn.eu), como ferramenta facilitadora da compreensão da dinâmica de sistemas para alunos de uma turma do $8^{\circ}$ ano do Ensino Fundamental de uma escola pública do Distrito Federal. O agente aprendiz virtual, que assume a figura de um Pet (animal de estimação), tem como função principal fazer com que o aluno sinta que está 'ensinando-lhe' novos conhecimentos. O aluno aprende enquanto ensina o Pet durante a construção de modelos qualitativos de simulação. Estes são modelos construídos de acordo com técnicas desenvolvidas em uma área da Inteligência Artificial conhecida como Raciocínio Qualitativo, na qual funções matemáticas e informações sobre quantidades são representadas qualitativamente, sem o uso de dados numéricos. Mais especificamente, a modelagem adotada segue princípios estabelecidos na Teoria Qualitativa dos Processos de Forbus, para representar a estrutura e o funcionamento de sistemas. Durante a construção do modelo, o aluno pode chamar um segundo agente, apresentado como um animal semelhante ao primeiro, porém adulto, e caracterizado como um animador de auditório (Quizmaster), que faz perguntas para o Pet sobre o conteúdo do modelo. Ao final de cada consulta ao Quizmaster, é gerada uma tabela com os acertos e erros cometidos pelo aluno. A partir da interação com o Pet e com a dinâmica do quiz, e da análise dos relatórios gerados por DynaLearn, os alunos são incitados a refletir e retornar à leitura de textos para reconstruir seus modelos. Desse modo, eles melhoraram o 'desempenho de seus Pets' (que, afinal, representa o desempenho dos próprios alunos), em um processo iterativo até que todas as respostas do Pet estejam corretas. Nossa hipótese é a de que o uso de modelos qualitativos apoiados por agentes aprendizes virtuais aumenta a motivação e, consequentemente, o desempenho dos alunos na compreensão da estrutura e funcionamento do sistema em estudo, quando comparado a situações nas quais fazem a leitura de textos sem modelos, e modelam sem o apoio do TA. A metodologia utilizada consistiu de abordagens qualitativa e quantitativa, respectivamente estudo de caso, no qual opiniões de alunos e da professora de Ciências da turma foram registradas em entrevistas, questionários, observações e anotações, e análise dos relatórios gerados pelos quizes, e por meio de estudo experimental no qual foi analisado, estatisticamente, o desempenho dos alunos em pré e pós-testes. Os resultados mostram que o uso dos agentes virtuais pelos alunos pesquisados melhorou significativamente a compreensão da dinâmica dos sistemas de interesse, comparado a estudos baseados na leitura de textos sem o apoio de modelos, e à modelagem sem o TA. Os alunos se sentiram mais motivados para o estudo dos conceitos de ciências, e a professora considerou muito produtivo o uso dos agentes virtuais para seu trabalho docente. As atividades e experiências aqui descritas levaram à formulação de uma proposta de intervenção pedagógica, apresentada como material suplementar desta Dissertação.

Palavras-chave: Agentes Aprendizes Virtuais, Modelagem Qualitativa, DynaLearn. 


\begin{abstract}
This Dissertation presents a pedagogical intervention proposal based on the use of qualitative modelling, supported by virtual teachable agents (or TA) functionality available in the workbench DynaLearn (www.dynalearn.eu), a tool designed to facilitate understanding of the systems dynamics by students in a class of 8th grade of elementary school at a public school in the Federal District. The virtual teachable agent takes the figure of a Pet whose main function is to make the students feel as if they are 'teaching him' new knowledge. The student learn while teaching the pet during the construction of qualitative simulation models. These models are built in accordance with techniques developed in an area of Artificial Intelligence known as Qualitative Reasoning, in which mathematical functions and knowledge about quantities are represented qualitatively, whitout using numerical data. More specifically, the modelling approach follows the Qualitative Process Theory by Forbus, to represent systems structure and functioning. During the modelling activity, the student can call a second agent, presented as an adult animal similar to the Pet, featured as a quiz show animator (Quizmaster), which asks questions to the Pet about the model contents. At the end of each interaction with the Quizmaster, a table is generated to reporting correct and wrong answers given by the student. From the interaction with the Pet and with the dynamics of the quiz, and the analysis of reports generated by DynaLearn, students are encouraged to reflect and return to reading texts to reconstruct their models. This way, they improve the 'performance of their Pets' (that, after all, is the students' performance themselves), in an iterative process until all the answers of the Pets are correct. Our hypothesis is that the use of qualitative models supported by virtual teachable agents increases motivation and consequently the performance of students in understanding the system structure and function compared to situations in which students learn by reading texts without the use of models, and build models without the support of TA. The methodology consisted of qualitative and quantitative approaches, respectively a case study in which opinions of students and their Science teacher were recorded in interviews, questionnaires and observations, in analyses of quiz reports, and by means of experimental studies with statistical analyses of the performance of students in pre and post-tests. The results show that the use of the virtual agents significantly improved the students' understanding of the dynamics of the systems of interest, compared to reading texts without the support of models and modeling without TA. Students felt more motivated to study science concepts, and the teacher considered very productive the use of virtual agents for her teaching work. The activities and experiments described here led to the formulation of a proposal for a pedagogical intervention, presented as supplementary material to this dissertation.
\end{abstract}

Keywords: Teachable Agent, Qualitative Modeling, DynaLearn. 


\section{LISTAS DE ILUSTRAÇÕES}

\section{Lista de Figuras}

Figura 1: Modelo no qual "Ingestão de colesterol ruim influencia Ateromas, que por sua vez influenciam passagem de sangue.

Figura 2a: Cenário LS2, com Ateromas diminuindo.

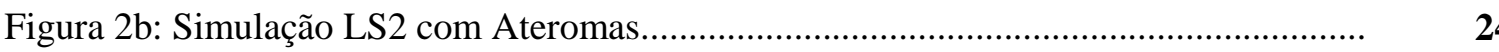

Figura 3: O agente aprendiz (Yoka) observando o modelo sendo construído pelo

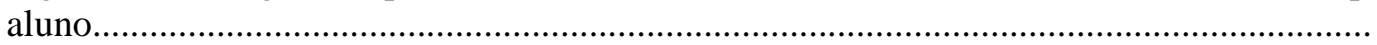

Figura 4: O relatório de desempenho, mostrando tabela com os erros e acertos sendo apresentado após consulta ao Quizmaster (Harry) pelo aluno

Figura 5: O Quizmaster fazendo uma pergunta ao agente aprendiz virtual, que a responde. 


\section{Lista de Quadros}

Quadro 1 - Resumo das atividades realizadas.

Quadro 2 - Respostas dos alunos ao questionário de avaliação do software $(\mathrm{n}=31)$....

Quadro 3 - Respostas dos alunos ao questionário de avaliação da modelagem conceitual $(\mathrm{n}=32$ e 33$)$.......

Quadro 4 - Respostas dos alunos ao questionário sobre o Pet- perguntas 1 e 2 $(\mathrm{n}=31)$.

Quadro 5 - Respostas dos alunos ao questionário sobre o Pet- perguntas 3 e 4 $(\mathrm{n}=31)$.

Quadro 6 - Respostas dos alunos ao questionário sobre o Pet- perguntas 5 e 6 $(\mathrm{n}=31)$.

Quadro 7 - Respostas dos alunos ao questionário sobre o Pet- perguntas 7 e 8 $(\mathrm{n}=31)$.

Quadro 8 - Respostas dos alunos ao questionário sobre o Pet- perguntas 9 e 10 $(\mathrm{n}=31)$.

Quadro 9 - Respostas dos alunos ao questionário sobre o Quizmaster- perguntas 1 e 2 $(\mathrm{n}=32)$

Quadro 10 - Respostas dos alunos ao questionário sobre o Quizmaster- perguntas 3 e 4 $(\mathrm{n}=32)$.

Quadro 11 - Respostas dos alunos ao questionário sobre o Quizmaster- pergunta 5 $(n=32)$.

Quadro 12 - Respostas dos alunos ao questionário sobre o Quizmaster- perguntas 6 e 7 $(\mathrm{n}=31)$.

Quadro 13 - Respostas dos alunos ao questionário sobre o Quizmaster- perguntas 8 e 9 $(\mathrm{n}=32)$

Quadro 14 - Respostas dos alunos ao questionário sobre o Quizmaster-perguntas 10 e 11 $(\mathrm{n}=32)$

Quadro 15 - Respostas dos alunos ao questionário sobre o Quizmaster- perguntas 12 e 13 $(\mathrm{n}=31)$

Quadro 16 - Respostas dos alunos ao questionário sobre o Quizmaster-perguntas 14 e 15 $(n=33)$ 


\section{Lista de Tabelas}

Tabela 1: Resultados dos testes estatísticos aplicados à amostra de alunos em relação ao pré teste x pós-teste em cada uma das atividades 1 (sem uso do TA), 2, 3 e 5 (com uso do TA)

Tabela 02: Resultados dos testes estatísticos aplicados à amostra de alunos em relação ao pós-teste da primeira atividade x pós-testes nas atividades dois, três e cinco 


\section{LISTA DE SIGLAS E ABREVIATURAS}

I- e I+ Influências diretas (negativa e positiva) causadas por processos

LS Learning space (espaço de aprendizagem) em DynaLearn

$\mathrm{P}-\mathrm{e} \mathrm{P}+\quad$ Proporcionalidades qualitativas negativa e positiva

RQ Raciocínio Qualitativo

TA Teachable agent (agente aprendiz virtual)

TQP Teoria Qualitativa dos Processos 


\section{SUMÁRIO}

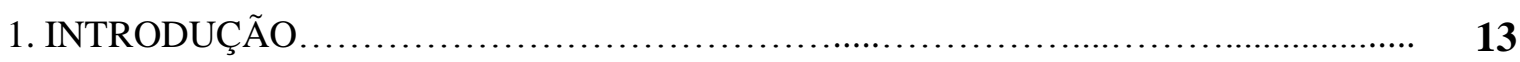

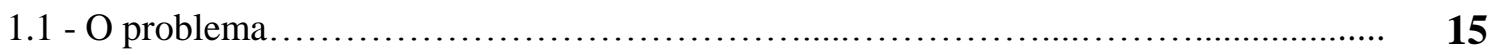

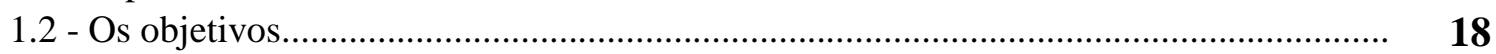

1.3 - Estruturação deste trabalho.................................................................................. 19

2. MODELAGEM QUALITATIVA FUNDAMENTADA NA TEORIA QUALITATIVA DOS PROCESSOS.

2.1 - Raciocínio qualitativo e modelagem qualitativa.......................................................... $\mathbf{2 0}$

2.2 - Teoria Qualitativa dos Processos............................................................................. $\quad 20$

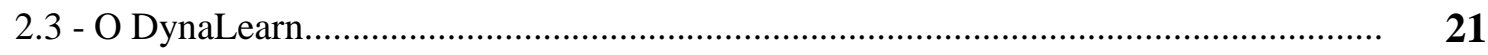

2.4 - Modelos Causais Básicos (LS2) .................................................................. 24

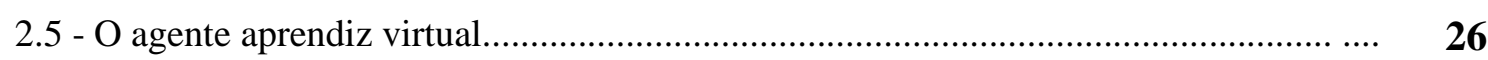

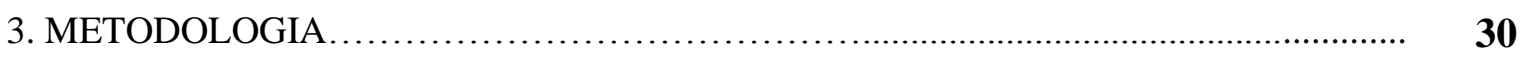

3.1 - Implementação do material didático e dos conteúdos............................................ 31

3.2 - Instrumentos utilizados na coleta de dados........................................................ $\quad 31$

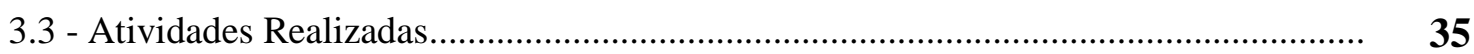

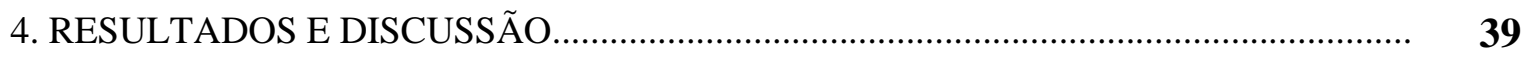

4.1 - Resultados obtidos com os questionários ………....................................................... 39

4.2 - Resultados obtidos com as entrevistas .................................................................... 56

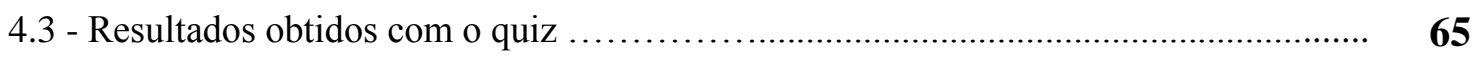

4.4 -Análises estatísticas dos estudos comparativos ................................... 73

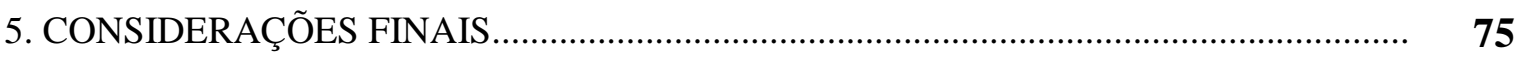

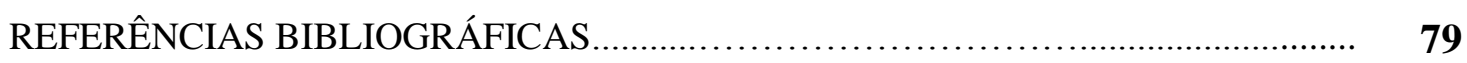

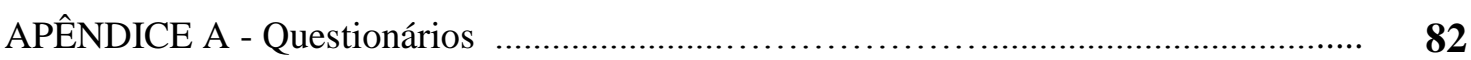

APÊNDICE B - Roteiro para as entrevistas com a professora............................................. $\quad \mathbf{8 8}$

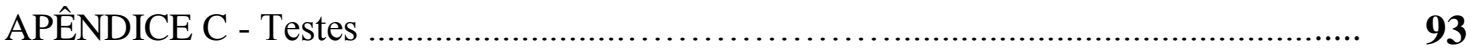

APÊNDICE D - Materiais didáticos produzidos........................................................... 102

APÊNDICE E - Proposição ................................................................................. 126 


\section{INTRODUÇÃO}

O agente aprendiz virtual (teachable agent ou TA) que assume a figura de um Pet (animal de estimação), é uma tecnologia desenvolvida para ambientes virtuais de aprendizagem que usa a figura de agentes pedagógicos capazes de realizar tarefas complexas, aumentam a motivação dos alunos para as atividades educacionais, e estão em constante desenvolvimento e aprimoramento de suas interfaces e funcionalidades (JOHNSON et al., 2000; MEHLMANN et al., 2010; ZHAO; AILIYA; SHEN, 2012; MIODUSER et al., 2012).

A tecnologia que envolve o agente aprendiz virtual difere de outros tipos de tecnologia apoiadas por agentes virtuais, pelo fato de que estes são apresentados aos estudantes para que estes lhes "ensinem" conceitos. Portanto, o seu foco é principalmente fazer com que o aluno aprenda enquanto ensina o agente aprendiz virtual, um princípio conhecido por aprender ensinando (learning by teaching) (WIßNER et al., 2010; ZHAO et al., 2012).

Nesta tecnologia, existem basicamente três tipos de agentes virtuais que assumem papéis metafóricos: o agente aprendiz - que é o que solicita ser ensinado pelo aluno e sua aprendizagem representa a aprendizagem do aluno. O agente professor (Mr. Davis) - que representa a figura do professor, ou seja, aquele que detém conhecimentos confiáveis e fornece explicações ao aluno e o agente Quizmaster (mestre do quiz) que representa a figura de um animador de plateia, cuja função é fazer perguntas e apontar erros e acertos nas perguntas que o mesmo faz. O presente trabalho foca nas contribuições didáticas do agente aprendiz.

$\mathrm{O}$ agente aprendiz virtual tem como função principal fazer com que o aluno sinta que esteja 'ensinando-o' novos conhecimentos. Tem a capacidade de aplicar o conhecimento 'aprendido' ao responder perguntas tanto ao aluno quanto ao Quizmaster sobre o conteúdo aprendido. Outra função deste agente virtual é a de estabelecer bom relacionamento com os alunos (por exemplo, o programa permite que o aluno dê um nome ao seu Pet) e incentivá-los a ensinar bem, a fim de estimular o aluno a assumir a responsabilidade de aprendizagem (ZHAO et al., 2012).

O Quizmaster assume papel importante ao analisar-se o agente aprendiz: ele é o responsável por fazer um jogo de perguntas - um quiz interativo - em que o agente aprendiz virtual testa seus conhecimentos (que, na verdade, são os conhecimentos do estudante) e recebe um relatório final (que é um feedback indireto, já que, metaforicamente, quem comete 
os erros é o agente aprendiz virtual) com o seu desempenho a cada nova consulta ao Quizmaster.

As respostas certas e erradas são mostradas ao fim da série de perguntas, para que o aluno tenha ciência de seus erros e acertos e possa se preparar melhor (preparar melhor o agente aprendiz virtual) e submeter seu agente aprendiz virtual a novas consultas ao quiz. Esse é o princípio da representação compartilhada, citada no Cérebro de Betty (LEELAWONG \& BISWAS, 2008).

Estudantes que usam o TA podem ver como eles descobrem as respostas e como organizam seu conhecimento, pois o conhecimento é organizado e representado por modelos qualitativos, ao contrário de outros softwares nesta área, nos quais o aluno recebe a resposta certa ou errada, mas ele pode ter "chutado" essa resposta ou ter dado uma resposta "decorada" (DORIS et al., 2013).

Em 2008, Leelawong e Biswas (2008) apresentam um software (o "Cérebro de Betty") baseado no uso de mapas conceituais. Neste programa, um agente aprendiz virtual permite a combinação de ensino e aprendizagem com auto regulação da aprendizagem e feedbacks para promover a aprendizagem e domínio de conhecimentos científicos.

Em 2009, tem início o projeto DynaLearn, cujo objetivo foi a implementação e aprimoramento de um software baseado no Raciocínio Qualitativo - em que não há uso de aparatos matemáticos. O software denomina-se DynaLearn (www.dynalearn.eu) e tem se mostrado, por meio de pesquisas, com enorme potencial para uso em atividades educacionais (Bredeweg et al. 2013). Este software apresenta um ambiente de aprendizagem inteligente, que permite que os alunos adquiram conhecimentos conceituais por meio da construção de modelos qualitativos e simulação de como os sistemas se comportam. Neste programa, representações diagramáticas devem ser criadas pelos alunos para expressarem suas ideias. $\mathrm{O}$ ambiente é equipado com componentes de tecnologia semântica ${ }^{1}$ capazes de gerarem um feedback baseado no conhecimento, e personagens virtuais (dentre os quais o agente aprendiz virtual) aumentam a interação com os alunos, aumentando a motivação destes (BREDEWEG et al., 2013).

\footnotetext{
${ }^{1}$ A tecnologia semântica tem como finalidade atribuir significados aos conteúdos publicados na Web, de modo que o os mecanismos de busca por computador possam ser feitos pelo significado, em contraposição à busca exclusiva por palavras, tal como ocorre, por exemplo, com o Google e outras ferramentas de busca.
} 
O uso de modelagem qualitativa por meio de programas computacionais com base no Raciocínio Qualitativo tem mostrado ser uma abordagem interessante para uso em atividades educacionais (BASTOS, 2014; FELTRINI, 2009; SALLES \& BREDEWEG, 2006).

A Teoria Qualitativa dos Processos (FORBUS, 1984) oferece base conceitual para a elaboração dos modelos a serem utilizados como instrumentos de ensino-aprendizagem, que serão apresentados mais adiante. O software DynaLearn é baseado nesta Teoria e será apresentado com mais detalhes e proposto para ser utilizado na formulação e manipulação dos modelos qualitativos que servirão como instrumento de ensino-aprendizagem.

\section{1 - O problema}

Devido às limitações de recursos tecnológicos disponíveis para a elaboração de materiais didáticos que representem a dinâmica de sistemas, os professores de ciências do Ensino Fundamental e os alunos não conseguem compreender aspectos dessa dinâmica. Os materiais didáticos tradicionais tratam sobre o funcionamento de sistemas de forma limitada e inadequada e pouco atuam no campo da criatividade e motivação de alunos e professores. São pouco estimulantes e apresentam fenômenos e experimentos de forma estática, às vezes visual, mas pouco interativa. Diante do exposto, a criatividade e a motivação de alunos e professores são limitadas pela falta de materiais e atividades estimulantes. Salienta-se que os problemas apresentados não se dissociam de outros como a falta de formação inicial e continuada e reflexão crítica dos docentes. Nóvoa (1999, p.10) discorrendo sobre as mudanças necessárias na atual educação, em que há excesso de discursos e pobreza de práticas, diz que "é impossível imaginar alguma mudança que não passe pela formação de professores". Valente (1997, p.02), diz que

O mundo atualmente exige um profissional crítico, criativo, com capacidade de pensar, de aprender a aprender, de trabalhar em grupo e de conhecer o seu potencial intelectual, com capacidade de constante aprimoramento e depuração de idéias e ações... E o computador pode ser um importante aliado nesse processo.

Nesse contexto, é de extrema importância encontrar ferramentas capazes de subsidiar a produção de materiais didáticos, representar e replicar fenômenos científicos e experimentos e permitir ao aluno expressar seus próprios conhecimentos. As técnicas desenvolvidas na área da Inteligência Artificial conhecida como Raciocínio Qualitativo, por meio do uso de modelos de simulação, construídos a partir de linguagem formal (com significados comuns a professores e alunos), em ambiente interativo são fatores que podem contribuir para 
solucionar os problemas descritos. $\mathrm{O}$ uso desses modelos pode garantir a coerência entre o conhecimento representado e as consequências dele derivado e contribuir para que objetivos educacionais relacionados ao pensamento sistêmico e ao raciocínio científico sejam atingidos, mas alguns requisitos são necessários: tais modelos devem ser simples, que permitam a generalização e aplicabilidade a uma grande diversidade de situações familiares aos usuários; devem ser de fácil manipulação, de modo que possam ser explorados na sua totalidade; motivadores, para que possam prender a atenção dos usuários; desafiadores, capazes de estimular a criatividade. O potencial do uso de modelos qualitativos em atividades pedagógicas deve fazer parte da rotina de práticas de reflexão e pensamento crítico em cursos de formação inicial e continuada de professores e que não haja distância entre o que os docentes aprendem e dizem e o que praticam em sala de aula (NÓVOA, 1999). De nada adianta o desenvolvimento de recursos tecnológicos e materiais didáticos inovadores e úteis, produzidos de maneira crítica e reflexiva, se os docentes não se apropriarem de tais ferramentas em suas práticas docentes cotidianas.

Existem poucas pesquisas com modelos de simulação que representem os sistemas estudados nos conteúdos de ciências para o Ensino Fundamental e, quando existem, infelizmente, são de difícil replicação e compreensão para os professores e alunos e pouco estimulantes e motivadores. Muitas vezes esses modelos são baseados em fórmulas matemáticas que não estão ao alcance do desenvolvimento cognitivo dos alunos. Outros modelos utilizados para representar estes sistemas são os experimentais, com uso de animais, que não são viáveis em salas de aula do Ensino Fundamental (DORNAS et al., 2010). Logo, é de extrema importância encontrar ferramentas capazes de representar e replicar fenômenos científicos e experimentos relacionados ao funcionamento de sistemas, que sejam motivadoras e que possam motivar jovens estudantes.

Como serão detalhadas ao longo deste trabalho, as técnicas desenvolvidas na área da Inteligência Artificial conhecida como Raciocínio Qualitativo (SALLES \& BREDEWEG, 2006) é capaz de expor, de maneira diagramática e sem o uso de aparato matemático, vários fenômenos sistêmicos, que podem ser visualizados, interpretados, compreendidos e internalizados de maneira didática, assim como usados como ferramentas na tomada de decisões. A modelagem qualitativa permite trabalhar sobre: dinâmica de sistemas, relações causais, representação de fenômenos que seriam improváveis de outra forma e expansão da criatividade do aluno e professor.

A modelagem qualitativa já provou que apresenta bons resultados em atividades educacionais (por exemplo, Mioduser et al. 2012). Em 2004, uma pesquisa realizada com 
alunos surdos do Ensino Médio, mostrou que a modelagem qualitativa causou efeitos positivos nos alunos na aquisição do português no contexto do desenvolvimento de conceitos científicos, assim como na aprendizagem sobre sistemas dinâmicos. Estes alunos foram capazes de aplicar os conhecimentos adquiridos na resolução de diferentes situaçõesproblema (SALLES, H.; SALLES, P.; BREDEWEG, B, 2004).

Salles, H. \& Salles, P. (2005) descrevem um experimento baseado no uso de modelos qualitativos cujos resultados deram indícios de que esta abordagem é capaz de subsidiar a aquisição de segunda língua por alunos surdos, sendo capaz também de apoiar a capacidade dos alunos de fazer inferências (SALLES, H.; SALLES, P.; BREDEWEG, B, 2005).

Salles (2007) lança a obra "Bilinguismo dos surdos: questões linguísticas e educacionais" que apresenta os resultados encontrados em estudos anteriores (e recentes) que mostraram que o uso de modelos qualitativos oferece subsídios para que estudantes surdos façam uso do raciocínio inferencial em produções linguísticas.

Feltrini (2009) propõe o desenvolvimento de instrumentos didático-pedagógicos para o ensino de português como segunda língua para alunos surdos na aplicação do conhecimento científico. Tal trabalho culminou com a produção de um material didático bilíngue voltado para a formação de conceitos científicos, compreensão de sistemas e o desenvolvimento do raciocínio lógico de estudantes surdos.

Resende (2010) avaliou a influência de modelos qualitativos, utilizados como material didático sobre a aprendizagem de conceitos relacionados à Biologia por alunos surdos e ouvintes de uma escola pública do ensino médio. A partir deste trabalho, o DynaLearn começa a ser utilizado em pesquisas de mestrado na área de ensino de ciências no Brasil. Este software foi testado e aprimorado durante o desenvolvimento do Projeto DynaLearn, em estudos realizados no Brasil, na Áustria, na Inglaterra, em Israel e na Bulgária. A abordagem adotada neste projeto é "aprender modelando". "Para isso, os alunos devem primeiro entender os modelos e aprender a usar o software para depois construir seus próprios modelos" (REZENDE, 2010, p.78).

Bastos (2014), por meio de um estudo de caso com alunos de um curso de licenciatura em Ciências Biológicas produz e apresenta uma proposta de disciplina a distância focada na Dinâmica de Sistemas para o referido curso.

Modelos qualitativos representam bem a dinâmica de sistemas, relações causais e fenômenos que seriam impossíveis de representar de outra forma, além disso, contribuem para desenvolver o raciocínio hipotético-dedutivo e promovem a expansão da criatividade de alunos e professores. Existem poucos trabalhos que abordem os efeitos na aprendizagem de 
alunos sobre o funcionamento de sistemas, com o uso de agentes aprendizes virtuais apoiando a modelagem qualitativa. No Brasil, trabalhos com essa abordagem não foram explorados.

\section{2 - Os objetivos}

O objetivo geral deste trabalho foi formular e apresentar uma proposta de intervenção pedagógica no ensino de Ciências para alunos de uma turma do $8^{\circ}$ ano do Ensino Fundamental, baseada em material didático construído a partir de modelos qualitativos apoiados por agentes aprendizes virtuais.

Os objetivos específicos foram:

$\checkmark$ Elaborar e implementar o material didático necessário para a formulação da proposta;

$\checkmark$ Verificar os efeitos da modelagem qualitativa apoiada por agentes aprendizes virtuais sobre a compreensão da estrutura e da dinâmica de sistemas biológicos e sobre a motivação de alunos de uma turma do $8^{\circ}$ ano do Ensino Fundamental de uma escola pública do DF.

$\checkmark$ Coletar opiniões da professora de Ciências da turma e dos alunos sobre diversos aspectos do uso dos modelos qualitativos apoiados por agentes aprendizes virtuais.

Para que os objetivos deste projeto fossem alcançados, foi necessário:

$\checkmark$ Realizar experimentos controlados com o objetivo de se testar hipóteses sobre os efeitos da modelagem apoiada por agentes aprendizes virtuais na contribuição da compreensão dos sistemas em estudo.

Observar, relatar e discutir o comportamento e a opinião da professora e dos alunos participantes da pesquisa, diante das intervenções pedagógicas e do uso dos materiais produzidos e implementados com base em modelos qualitativos.

As perguntas de pesquisa deste trabalho buscam responder basicamente três questões:

a) Como professores poderiam representar conceitos sobre a dinâmica de sistemas em modelos conceituais qualitativos, apoiados por agentes aprendizes virtuais, de maneira adequada para alunos do $8^{\circ}$ ano do Ensino Fundamental? 
b) Qual é o efeito dos agentes aprendizes virtuais sobre a motivação dos alunos para participarem de práticas de modelagem?

c) Existe diferença estatisticamente significativa no desempenho dos alunos em relação à compreensão do funcionamento de sistemas, comparando-se o uso de modelos qualitativos com e sem o apoio de agentes aprendizes virtuais?

\section{3 - Estruturação deste trabalho}

Este trabalho de Mestrado está estruturado em cinco seções, incluindo esta primeira, que é a Introdução. A seção 2 apresenta o Raciocínio Qualitativo e a modelagem qualitativa que são dois conceitos importantes para o entendimento da base conceitual que fundamenta este trabalho, que é a Teoria Qualitativa dos Processos (FORBUS, 1984). Descreve o software utilizado nesta pesquisa, o DynaLearn (BREDEWEG et al., 2013), particularmente o nível LS2 (modelos causais básicos), e traz informações sobre os agentes aprendizes virtuais.

A metodologia utilizada para a preparação do trabalho e para a coleta, a tabulação, a descrição e a análise dos dados é descrita na seção 3. Nesta seção, são descritas também, as atividades realizadas para que o presente trabalho pudesse se concretizar. Os resultados preliminares e a discussão dos mesmos são apresentados na seção 4 e as considerações finais, na seção 5. A proposta de intervenção pedagógica é apresentada em anexo. 


\section{MODELAGEM QUALITATIVA FUNDAMENTADA NA TEORIA QUALITATIVA DOS PROCESSOS}

\section{1 - Raciocínio Qualitativo e Modelagem Qualitativa}

O Raciocínio Qualitativo é uma área da Inteligência Artificial adotada em estudos e representações de propriedades contínuas de sistemas físicos, sobre os quais os dados disponíveis são incompletos ou imprecisos, sem o uso de cálculos matemáticos (FORBUS, 1984). Este tipo de raciocíno é muito útil nos casos em que não se exige respostas exatas e baseia-se em observações. É muito usado no estudo da predição do comportamento de sistemas físicos com base na representação da estrutura dos sistemas modelados.

A modelagem qualitativa é fundamentada no Raciocínio Qualitativo. O foco desse tipo de modelagem é desenvolver e implementar técnicas que permitam representar e facilitar a compreensão da estrutura e dinâmica de sistemas (FORBUS, 1984).

\section{2 - Teoria Qualitativa dos Processos}

A abordagem que fundamenta este trabalho baseia-se na Teoria Qualitativa dos Processos, representada pela sigla TQP (FORBUS, 1984). Segundo esta teoria, sistemas são conjuntos constituídos por objetos que formam uma unidade bem delimitada. Estes objetos se relacionam de tal modo que os estados de cada objeto dependem dos estados dos outros objetos. Objetos e relações entre eles constituem a estrutura de um sistema. Assim, os sistemas são capazes de realizar funções específicas, em que algum input é transformado em um output determinado. Limites física ou arbitrariamente estabelecidos definem o que faz parte ou não do sistema (BOSSEL, 1986).

De acordo com esta teoria, as mudanças nos sistemas são sempre iniciadas por processos. Estes são modelados por influências diretas, que são representadas por um "I" (podem ser I+ ou I-). Os efeitos das mudanças iniciadas pelos processos são propagadas para outras partes do sistema por meio de proporcionalidades qualitativas, que são representados pela letra "P" (podem ser P+ ou P-). Influências diretas e proporcionalidades expressam relações causais, como mostram a Figura demonstrativa abaixo e vários modelos comentados abaixo. 
Os objetos de um sistema (representados pelas entidades) têm suas relações estabelecidas por configurações e possuem certas "quantidades" ou "variáveis". Os valores das variáveis são definidos por uma combinação de magnitude e derivada. A magnitude se refere à 'quantidade' da 'coisa' e a derivada descreve a direção de mudança. Os valores que as variáveis podem assumir constituem um conjunto chamado espaço quantitativo. Por exemplo: a derivada de todas as variáveis está associada ao espaço quantitativo $\{+, 0,-\}$, indicando que as variáveis podem estar crescendo, estáveis ou diminuindo. A informação completa sobre o valor de uma quantidade (variável), em um determinado período de tempo, é <pequena, crescendo> (FORBUS, 1984).

No presente trabalho foram usadas apenas as derivadas das quantidades, e as relações entre variáveis estabelecidas por sinais positivo (+) e negativo (-), uma simplificação das proporcionalidades qualitativas (Ps), o chamado nível LS2 (veja abaixo). Como exemplo, vejamos o sistema representado em um dos modelos discutidos neste trabalho, na Figura demonstrativa abaixo. O sistema pode ser representado pelo "Ser humano", definido como uma entidade do modelo que pode ter relação com outra entidade, como por exemplo, "Artéria" e, neste caso, uma configuração ('Possui') irá mostrar esta relação: "ser humano" possui “Artéria". A entidade "ser humano" possui algumas propriedades definidas como variáveis, dentre as quais podemos citar a Ingestão de colesterol ruim que é representada no modelo exatamente pelo mesmo nome. "Artéria” possui as variáveis Ateromas e Passagem de sangue. Os valores dessas variáveis são representados apenas pelas derivadas. A cadeia causal representada é: se Ingestão aumenta, Ateomas aumentam e Passagem de sangue diminui.

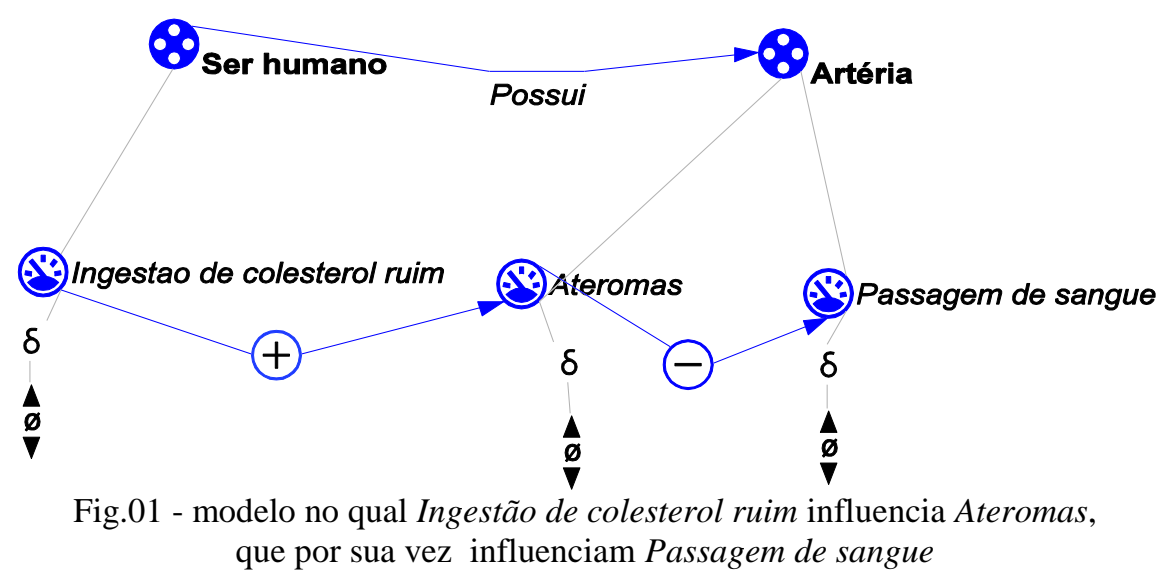

Fonte: Imagem produzida automaticamente pelo software DynaLearn 


\section{3 - DynaLearn}

O simulador utilizado no presente trabalho foi o DynaLearn, na versão 1.0.5 (BREDEWEG et al., 2013). O download deste software para uso acadêmico pode ser feito a partir do sítio http://hcs.science.uva.nl/projects/DynaLearn/software/\#download.

Este programa apresenta um ambiente de aprendizagem inteligente, que possibilita aos alunos a aquisição de conhecimentos conceituais por meio da construção de modelos qualitativos e simulação de como os sistemas se comportam. Neste programa, representações diagramáticas devem ser criadas pelos alunos para expressarem suas ideias. O ambiente é equipado com componentes de tecnologia semântica capazes de gerar um feedback baseado no conhecimento, e personagens virtuais aumentam a interação com os alunos, aumentando a motivação destes (BREDEWEG et al., 2013).

Este programa permite que os alunos construam sua interpretação conceitual do comportamento dos sistemas estudados e ao mesmo tempo aprender conceitos de diversas disciplinas. Por meio dos modelos construídos, os alunos podem fazer simulações e elaborar explicações sobre os conteúdos estudados e ainda, guardar seus modelos em um repositório on line e compará-los a outros modelos (BREDEWEG et al., 2013).

O DynaLearn é um software projetado para atender, principalmente, necessidades para uso em atividades educacionais. O comportamento de sistemas de interesse do usuário pode ser representado por esquemas visuais, e simulações podem prever mudanças no comportamento do sistema. Por meio de adição, retirada ou mudança de conteúdos do modelo, é possível prever estados futuros do sistema ou alterar as condições do cenário inicial e explorar simulações do tipo "o que aconteceria se...".

$\mathrm{O}$ ambiente inteligente de aprendizagem de DynaLearn permite aos alunos externalizarem suas ideias e abstrações, tornando-as visíveis. Essas abstrações, uma vez visualizadas por expressões diagramáticas, podem ser melhor organizadas, o que permite um melhor entendimento, aprofundamento e reflexão, tanto individual quanto coletiva, em prol da construção de conhecimentos e entendimento de fenômenos abstratos ou de difícil compreensão se apresentados apenas em linguagem verbal ou escrita.

Este software faz parte de uma categoria que, além de gerar feedbacks em relação ao tema que o usuário modela, cria situações de interatividade por meio de sua interface, com ícones autoexplicativos e agentes aprendizes virtuais, que beneficia os alunos modeladores e 
os incentiva a desenvolver sua autonomia. Desse modo, os alunos vivem situações em que são "autores" da representação que constroem de conceitos científicos e sujeitos ativos no processo de desenvolvimento de conhecimento conceitual.

O DynaLearn tem sido utilizado em cursos de formação de professores e preparação de atividades didáticas com alunos surdos e ouvintes e inclusive em educação a distância (BASTOS, 2014; RESENDE, 2010). O programa é versátil e permite a manipulação e a criação de modelos conceituais, que são aqueles capazes de abordar conteúdos diversos, desde que contemplem a visão sistêmica e contribuam para a compreensão dos conteúdos modelados (SALLES \& BREDEWEG, 2006). Com DynaLearn, é possível capturar imagens das telas em qualquer etapa da modelagem. O que, juntamente com as características já descritas, permite a criação de materiais didáticos inovadores.

Dynalearn oferece a seus usuários seis níveis de espaços de aprendizagem, crescentes e complementares de complexidade (representados pela sigla LS que em inglês significa Learning Space), projetados para serem usados independentemente, ou como degraus na aprendizagem dos alunos, já que cada um dos primeiros cinco níveis serve de preparação para que o aluno possa utilizar os níveis subsequentes. Desse modo, cada espaço de aprendizagem funciona como uma etapa na sequência da aprendizagem iniciada nos níveis anteriores, com maior aprofundamento na exploração de conteúdos, o que exige maior esforço de modelagem.

O nível de menor complexidade do DynaLearn é o LS1 - ("Mapas conceituais"), que permite a construção de diagramas formando nós (representando conceitos) e ligados entre si por meio de setas (descrevendo a ligação entre dois nós), conhecidos como mapas conceituais. Nesse ambiente, há uma grande liberdade na hora da modelagem, o que dá algumas vantagens, como a facilidade de manipulação por usuários com o mínimo de experiência com o software e a linguagem da modelagem. Porém, traz limitações em relação ao aprofundamento dos modelos construídos e dos conteúdos de aprendizagem. Neste espaço de aprendizagem, não existem cadeias de causalidade e não é possível fazer simulações, como ocorre nos outros cinco níveis subsequentes. Mapas conceituais são muito úteis para alunos e professores, para a organização de ideias, planejamento de ações e avaliação. Apesar das limitações descritas para o contexto deste trabalho, serve de ancoragem para o uso do nível dois (LS2).

O LS2 ("Modelo Causal Básico") tem como objetivo fazer com que os alunos adquiram uma compreensão global das relações de causa e efeito que regem o comportamento de um sistema (BREDEWEG et al., 2013). Permite aos alunos aprenderem sobre a distinção entre entidades e variáveis, e que os alunos expressem relações de dependência entre as 
variáveis que carregam a informação causal (sempre na direção da variável origem para a variável destino). Este nível será melhor detalhado ainda nesta seção.

No nível LS3 de complexidade ("Modelo Causal com Grafo de Estados"), o usuário pode analisar mais de um estado de comportamento do sistema. Além de permitir a comparação entre estados diferentes, o LS3 introduz as magnitudes das variáveis, com seus respectivos espaços quantitativos. Por exemplo, \{zero, pequeno, médio, grande, máximo\}. O aluno modelador pode estabelecer relações entre as magnitudes, aumentando o nível de profundidade e melhorando compreensão do comportamento do sistema modelado.

O objetivo do LS4 ("Diferenciação Causal") é refinar a noção de causalidade nos alunos modeladores pela diferenciação das influências direta e indireta (BREDEWEG et al., 2013), comentada na seção 2.2. Nesse nível, é possível representar melhor processos com efeitos opostos (por exemplo, encher $\mathrm{X}$ esvaziar containers; emitir poluentes $\mathrm{X}$ despoluir; natalidade $\mathrm{X}$ mortalidade), criar todos os tipos de mecanismos de retroalimentação e considerar, nos modelos, a ação de agentes externos ao sistema.

O objetivo do nível de complexidade LS5 ("Conhecimento Condicional") é que os alunos adquiram uma compreensão mais refinada das condições para que processos comecem ou terminem seus efeitos sobre o comportamento do sistema (BREDEWEG et al., 2013). Em relação ao LS4, a diferença é considerar conhecimento condicional aquele segundo o qual alguns fatos modelados só produzirão efeitos sobre o sistema em determinadas condições. Este nível pode ser considerado uma versão simplificada do LS6.

O LS6 ("Conhecimentos genéricos e reusáveis") é o nível mais complexo. Os alunos criam cenários (descrevem estados iniciais do sistema) e, em lugar de construir todo o modelo em uma única tela, utilizam fragmentos de modelos, pequenas partes de um modelo que capturam representações de processos ou de situações, e que podem ser reutilizadas (por exemplo, a descrição do processo natalidade pode ser usada na mesma simulação em duas ou mais populações diferentes), e que podem trazer algumas regras para as simulações realizadas a partir de cenários diferentes (BREDEWEG et al., 2013).

\section{4 - Modelos Causais Básicos (LS2)}

Os modelos utilizados no presente trabalho foram construídos no LS2, comumente chamados de diagramas de influência, e os conhecimentos utilizados para a construção dos mesmos foram obtidos a partir da literatura e em conversa com especialistas. Nível mais 
complexo que os mapas conceituais, diagramas de influência podem ser utilizados comunicar noções da estrutura e do funcionamento de sistemas. Por meio de cadeias de causalidade em que um objeto A influencia um B e este um C, por exemplo, produz dinâmica. Os diagramas de influência podem ser úteis na representação de conteúdos sobre sistemas dinâmicos pela representação de quais quantidades recebem influência e quais são influenciadas por elas em determinado sistema.

Este nível de aprendizagem costumar ser utilizado por modeladores que desejam aperfeiçoar seus modelos, em busca de representação de diferentes sistemas e de representação das dinâmicas dos sistemas modelados. Este nível de aprendizagem pode ser preferido em relação aos seus níveis subsequentes em atividades que requerem modelos de menor complexidade, e em atividades de introdução de conceitos elementares sobre estrutura e funcionamento de sistemas dinâmicos. Para as atividades propostas no presente trabalho, este nível de complexidade pareceu ser o mais próximo do nível de maturidade dos alunos, jovens de $8^{\circ}$ ano do Ensino Fundamental, e foi suficiente para a aplicação das análises.

Por último, mas não menos importante, este nível é, na versão corrente de DynaLearn, o único que permite o uso de agentes aprendizes virtuais personalizados e ensináveis que auxiliam na construção de modelos e despertam o estímulo e motivação dos alunos durante a modelagem.

O modelo é constituído por entidades interligadas por configurações que representam a estrutura do sistema e por variáveis relacionadas por setas positivas e negativas que representam cadeias de causa e efeito. A cadeia de causalidade é representada por meio de setas, que partem da variável $A$ no sentido da variável $B$. As setas são identificadas pelo sinal positivo (+) ou pelo sinal negativo (-). A situação momentânea de um sistema, considerando as variáveis e as cadeias de causalidade agindo entre elas é dito um estado do sistema. A representação de uma situação inicial de um sistema, pronto para rodar uma simulação, denomina-se cenário.

Uma das limitações do LS2 é que, em geral, permite a análise de um único estado do comportamento do sistema em estudo e por isso não é indicado para a análise do comportamento do sistema considerando a passagem do tempo, como nos níveis subsequentes do DynaLearn.

Para que simulações sejam realizadas no LS2, marca-se o valor inicial da(s) derivada(s) de uma ou mais variáveis que iniciam uma cadeia de causalidade. A partir desse cenário, a mudança no sistema se propaga pela alteração dos valores das derivadas das demais quantidades, por meio das influências positiva ou negativa, da variável A para a variável B, de 
B para a $\mathrm{C}$, e assim por diante, até que a última influência aja sobre a última variável da cadeia de causalidade.

Se a relação entre as duas quantidades é mediada por uma influência de sinal negativo $(-)$, as duas quantidades variam em direções opostas. Veja-se as figuras abaixo:

\section{Influência negativa:}

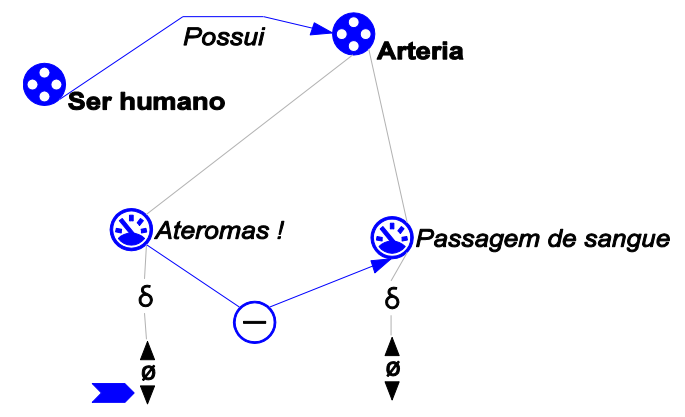

Figura 2a. Cenário LS2, com Ateromas diminuindo

Fonte: Imagem produzida automaticamente pelo software DynaLearn

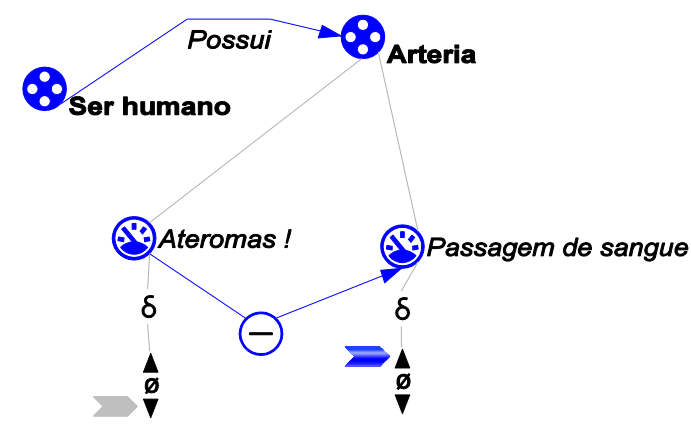

Figura 2b. Simulação LS2 com Ateromas diminuindo e influenciando Passagem de sangue

Fonte: Imagem produzida automaticamente pelo software DynaLearn

Se Ateromas estiver diminuindo (Figura 1a), sua influencia negativa sobre Passagem de sangue fará com que esta quantidade aumente (Figura 1b). Se Ateromas estiver aumentando, sua influência negativa sobre Passagem de sangue fará com que esta quantidade diminua. Ou seja, se a variável A estiver crescendo, a variável B estará diminuindo; se A estiver diminuindo, B aumentará; e se A estiver estável, b também se manterá estável.

Por outro lado, se a relação entre as duas quantidades é mediada por uma influência de sinal positivo (+), as duas quantidades variam na mesma direção (ambas crescem, permanecem estáveis ou diminuem).

\section{5 - O Agente Aprendiz Virtual}

O Agente aprendiz virtual é uma das funcionalidades presentes no nível LS2 do software DynaLearn. A proposta é que o aluno simule o "ensino" de um Pet (que é o agente aprendiz virtual) que tem a capacidade de "aprender", adicionando conteúdos (representados por elementos de modelagem como entidades, configurações, quantidades e influências) a um modelo. Este Pet é capaz de responder a questões do tipo "aumenta" ou "diminui", de acordo 
com a montagem do modelo pelo aluno. Durante o processo de modelagem, sempre que o aluno julgar necessário, o Pet aprendiz virtual é submetido a um pequeno teste, por meio de questionamentos feitos pelo mestre do quiz (Quizmaster). Os acertos ou erros cometidos pelo Pet aprendiz virtual são demonstrados por meio de um relatório. As figuras 3, 4 e 5 mostram algumas situações de modelagem com uso do agente aprendiz virtual.

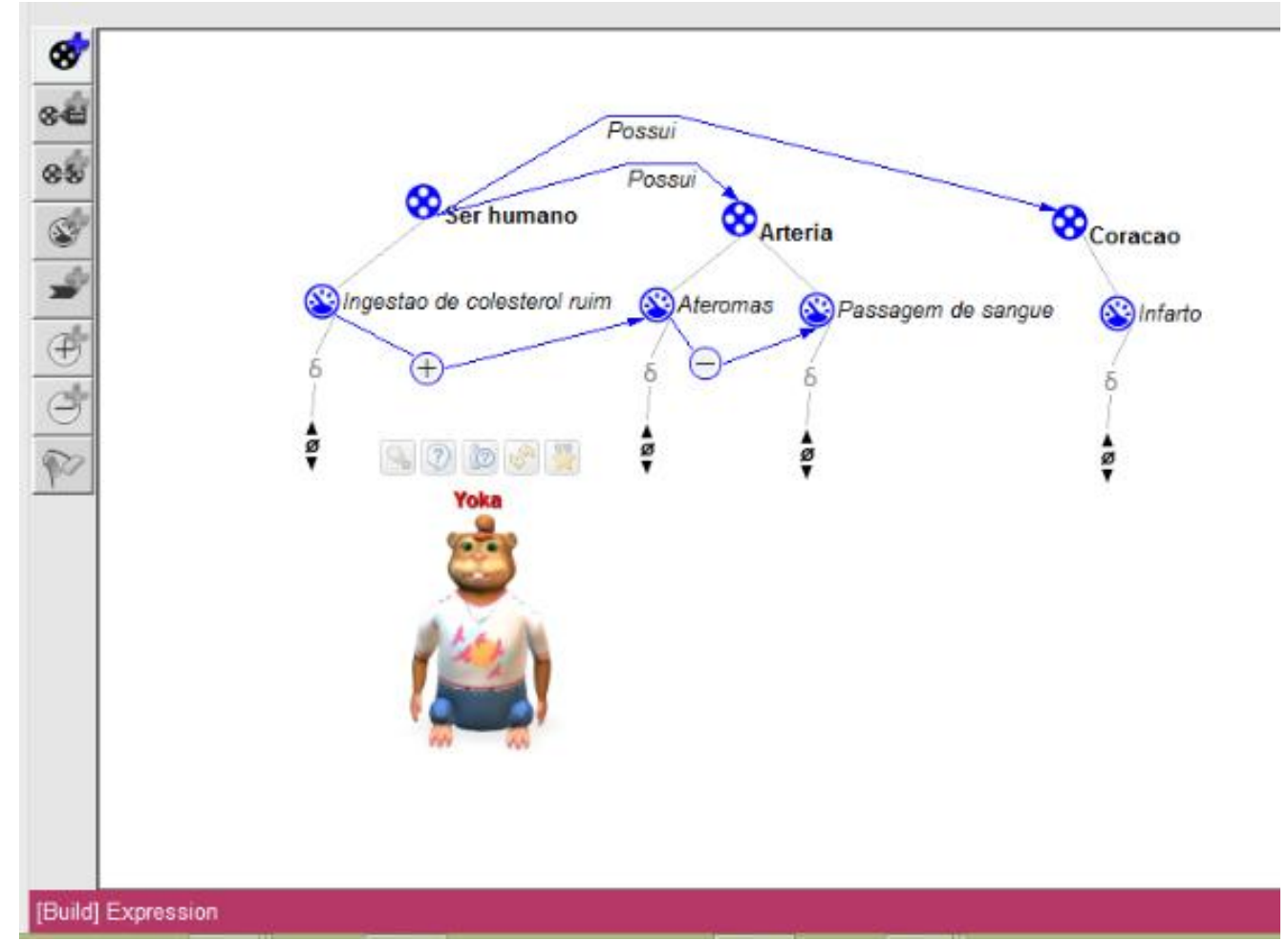

Fig. 3 - O agente aprendiz virtual (Yoka) observando o modelo sendo construído pelo aluno.

Fonte: print screen da aplicação no sistema operacional Windows 8 


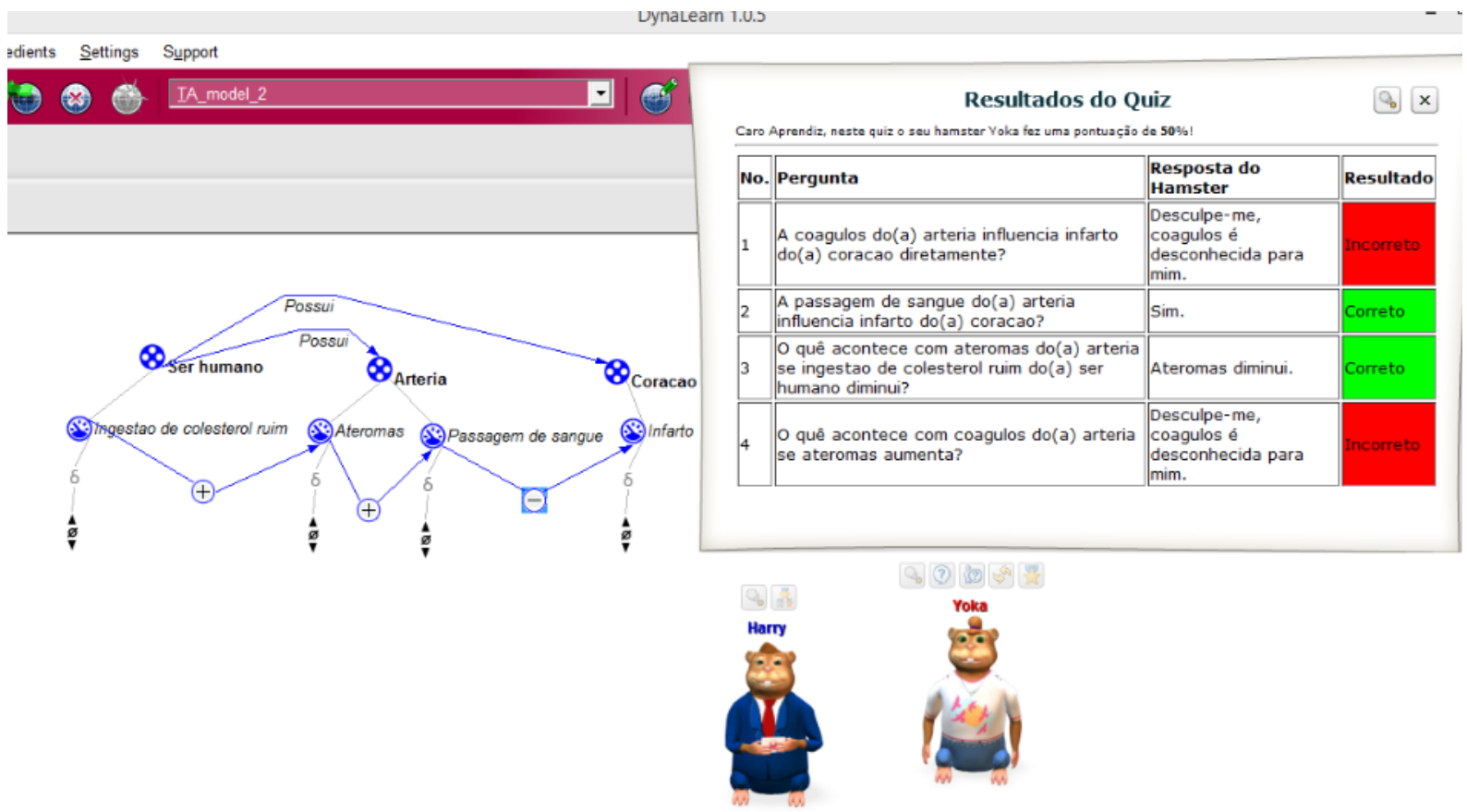

Fig. 4 - O relatório de desempenho, mostrando os erros e acertos sendo apresentado após consulta ao Quizmaster (Harry) pelo aluno.

Fonte: print screen da aplicação no sistema operacional Windows 8

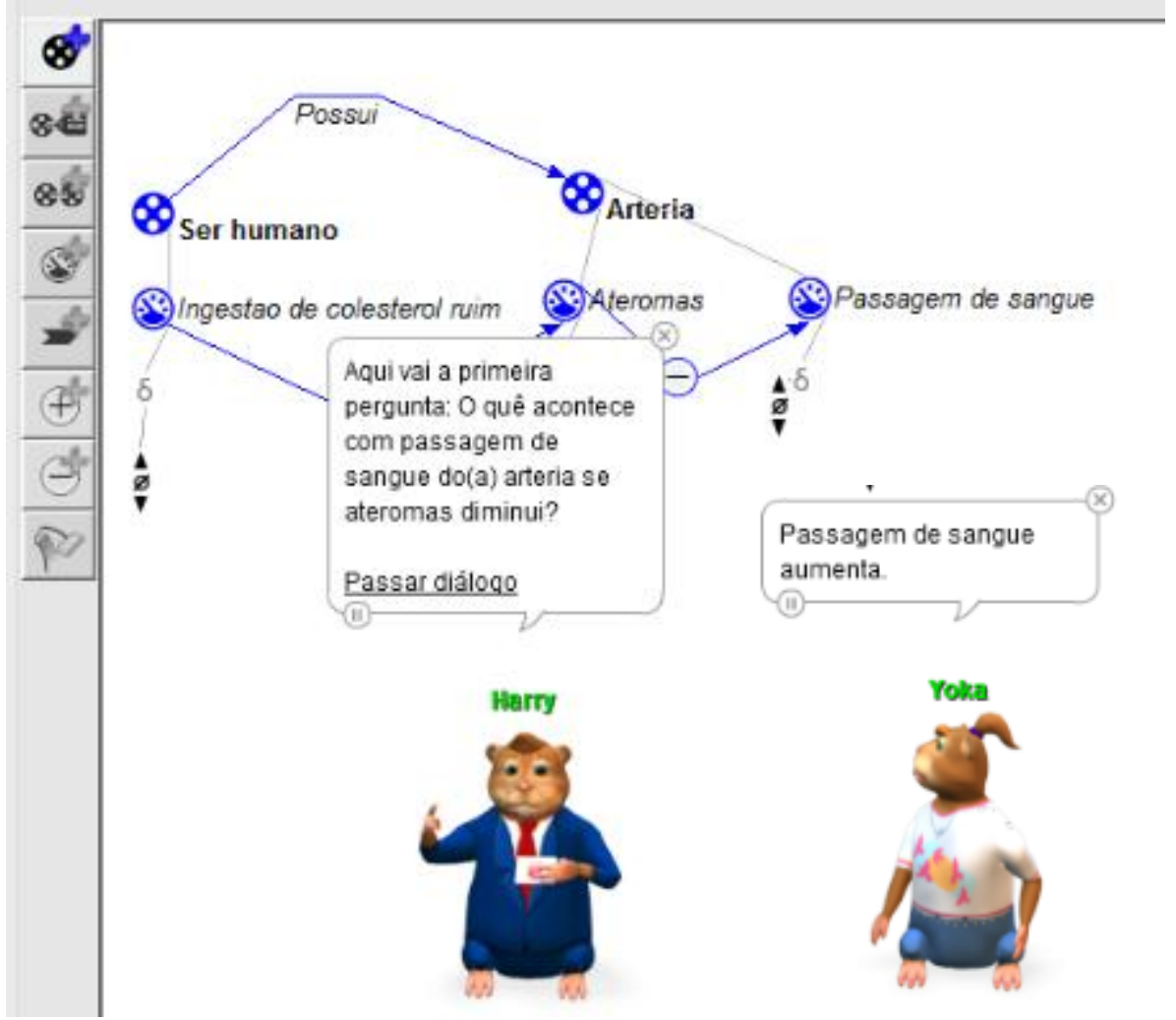

Fig. 5 - O Quizmaster fazendo uma pergunta ao agente aprendiz virtual, que a responde.

Fonte: print screen da aplicação no sistema operacional Windows 8 
O agente aprendiz virtual foi desenvolvido, com base em pesquisas, a partir da idéia de que ensinar aos outros é uma forma prazerosa de aprender (LEELAWONG \& BISWAS, 2008). Os criadores dessa tecnologia desenvolveram agentes educadores e ensináveis que utilizam representação visual. Os alunos consultam seus Pets para monitorar a aprendizagem e o comportamento deles na resolução de problemas. Isso motiva os alunos a aprender mais, para que eles possam ensinar seu Pet, de modo que este tenha melhor desempenho.

O que caracteriza o TA em DynaLearn é a interação do aluno com agentes virtuais que se assemelham a pequenos hamsters de estimação. O professor prepara um modelo, que será a referência a ser comparada com o trabalho do aluno. Esse modelo referência é uploaded no TA, e não será visto por ninguém.

Quando o aluno abre o TA para iniciar seu trabalho, DynaLearn solicita que um agente aprendiz virtual seja adotado como animal de estimação (Pet). O aluno pode escolher entre duas opções e também dar um nome ao Pet. A partir daí, o Pet lança uma fala, solicitando que o aluno o ajude a construir o modelo, adicionando novos conteúdos. Segundo especialistas essa dinâmica gera responsabilidade no aluno a ter que ensinar o seu Pet, já que ele será submetido a um quiz, junto ao Quizmaster, o Harry. Estudos mostram que alunos se esforçam mais para aprender quando têm que ensinar alguém (mesmo sendo uma animação) (LEELAWONG \& BISWAS, 2008; CHIN et al., 2013). Outra vantagem do Pet seria o fato de os erros cometidos por este, que na verdade serão os erros do aluno modelador, amenizam a "culpa" que poderia pesar sobre o aluno caso as perguntas do quiz fossem feitas diretamente ao estudante.

No presente trabalho, a proposta é usar o raciocínio qualitativo e modelagem qualitativa para facilitar o aprendizado de conceitos ( SALLES et al., 2005) e desenvolver o raciocínio lógico (ALVES, 2015), utilizando modelos LS2 de DynaLearn, e o TA, de modo a verificar o potencial do TA para motivar os alunos a se engajarem em atividades de modelagem e, assim, aprender conceitos complexos. 


\section{METODOLOGIA}

A proposta de intervenção pedagógica foi aplicada em uma sequência de cinco atividades com os alunos de uma turma de alunos do $8^{\circ}$ ano do Ensino Fundamental de uma escola pública do DF, divididos em dois grupos (com exceção da atividade 4, na qual a classe inteira participou em um único momento), sendo que, em cada atividade, equipes de dois ou três alunos trabalhavam no mesmo computador, totalizando 10h30min de interação com os alunos. Em duas atividades (atividade 1 e atividade 4), não foi utilizado o TA; nas três outras (atividades 2,3 e 5), foram realizados trabalhos de modelagem com TA.

A metodologia adotada neste trabalho é a do estudo de caso, uma estratégia indicada quando se analisam fenômenos contemporâneos e quando comportamentos e eventos importantes são de difícil controle por parte do pesquisador (YIN, 2001). De acordo com Gil (2002, p. 141), "nos estudos de caso os dados podem ser obtidos mediante análise de documentos, entrevistas, depoimentos pessoais, observação espontânea, observação participante e análise de artefatos físicos". Além do estudo de caso, que é uma abordagem qualitativa, a pesquisa incluiu uma parte experimental, caracterizando a pesquisa também como quantitativa.

De acordo com Triviños (1990), uma pesquisa pode ser qualitativa e quantitativa, observando-se a natureza do trabalho a ser feito, e a seleção adequada de instrumentos para a coleta de dados.

Para Moreira (2003, p. 7),

A pesquisa quantitativa procura estudar os fenômenos de interesse da pesquisa em educação geralmente através de estudos experimentais ou correlacionais caracterizados primordialmente por medições objetivas e análises quantitativas. De um modo geral, esse tipo de enfoque se baseia no modelo de pesquisa, dito científico.

Apesar de a metodologia quantitativa ser comum em pesquisas realizadas em áreas das ciências naturais, Moreira (2003) observa que tanto este tipo de abordagem quanto a abordagem qualitativa têm sido predominantes nas pesquisas em educação e ensino. Para Falcão e Régnier (2000, p. 232),

Em termos gerais, propomos que a ideia de quantificação abrange um conjunto de procedimentos, técnicas e algorítimos destinados a auxiliar o pesquisador a extrair de seus dados subsídios para responder à(s) pergunta(s) que o mesmo estabeleceu como objetivo(s) de trabalho. 
Segundo Moreira (2003), “a pesquisa qualitativa é um termo que tem sido usado alternativamente para designar várias abordagens à pesquisa em ensino, tais como pesquisa etnográfica, participativa observacional, estudo de caso, fenomenológica construtivista, interpretativa, antropológica cognitiva".

Na seção 3.1 serão descritas preparação e a implementação das atividades e dos materiais didáticos. Os instrumentos utilizados na coleta de dados foram a observação direta da professora e dos alunos, entrevistas semiestruturadas, questionários, análise de modelos produzidos pelos alunos, análise dos relatórios gerados pelo quiz, por testes estatísticos e serão melhor descritos na seção 3.2. Na seção 3.3 serão apresentadas as atividades realizadas durante a aplicação da proposição de intervenção pedagógica.

\subsection{Implementação de material didático e dos conteúdos}

Professora e pesquisadores, após longas conversas, definiram os conteúdos a serem trabalhados, a fim de contemplar o planejamento curricular da escola e da professora.

O conteúdo curricular abordado consiste dos seguintes tópicos: discussão entre madeireiros e ambientalistas e biodiversidade, doenças do sistema circulatório humano, aparelho reprodutor masculino, aparelho reprodutor feminino e gravidez.

Alguns modelos foram produzidos pelos pesquisadores e apresentados à professora, que selecionou aqueles que julgava serem mais apropriados para seus alunos. Os modelos selecionados são apresentados no Apêndice D.

Selecionados conteúdos e modelos, depois de conversas e discussões, foram preparados os materiais a serem utilizados nas atividades, incluídos slides, modelos, textos e exercícios. Esses materiais foram apresentados também no Apêndice D.

Foram utilizadas diversas imagens, projetadas por um datashow para representar a estrutura e o comportamento de sistemas, assim como conceitos importantes. Para a elaboração dos os slides apresentados utilizamos o programa Power Point da Microsoft.

\section{2 - Instrumentos utilizados na coleta de dados}

Foi realizada a observação da professora de ciências da turma pesquisada e dos alunos. Para Marconi e Lakatos (2003, p.190), "a observação é uma técnica de coleta de dados para 
conseguir informações e utiliza os sentidos na obtenção de determinados aspectos da realidade". A primeira foi observada durante a descrição do próprio perfil, do perfil da turma de uma forma geral e dos alunos, na escolha, elaboração e preparação dos modelos, textos e slides, foi observada também durante a realização das atividades e entrevistas. Já os estudantes foram observados durante a realização dos testes, leitura e análise dos textos, nas atividades de modelagem e interação com os agentes virtuais e quiz.

Outro instrumento de coleta de dados foi o questionário, que, segundo Marconi e Lakatos (2003, p. 201), "é um instrumento de coleta de dados, constituído por uma série ordenada de perguntas, que devem ser respondidas por escrito e sem a presença do entrevistador." Existem desvantagens no uso deste instrumento de coleta de dados como a impossibilidade de ajudar o informante em questões mal compreendidas e a leitura de determinada questão poder influenciar a resposta de outra(s), porém, as vantagens se sobrepõem, como a obtenção de respostas rápidas e precisas, pouco risco de distorção, pela não influência do pesquisador, pouca pressão sobre os respondentes em relação ao tempo para responder e ao ambiente para tal. E o melhor: por meio deste instrumento, obtêm-se respostas que seriam inacessíveis por outros meios (MARCONI \& LAKATOS, 2003).

Os questionários abordaram questões sobre o uso do programa DynaLearn e da modelagem qualitativa, do Pet e do Quizmaster. Tivemos o cuidado de aplicá-los sem a presença do pesquisador, para evitar possíveis interferências do pesquisador nas respostas. $\mathrm{O}$ intervalo entre a aplicação das atividades de modelagem e os questionários não foi mais do que 12 horas. Estes encontram-se no Apêndice A e os resultados obtidos com tais instrumentos serão apresentados na seção 4.

Foi aplicado um único questionário com dezoito questões à professora ao término das atividades realizadas a fim de se verificar a avaliação das atividades realizadas, em relação aos itens mencionados no parágrafo anterior, na visão da docente. Aos alunos foram aplicados quatro questionários, que serão descritos em seguida.

O primeiro questionário sobre o projeto DynaLearn foi composto por catorze questões, sendo dez com cinco opções de respostas e quatro abertas, que versavam sobre a opinião dos alunos em relação as atitudes e motivações despertadas com as atividades realizadas com o uso do software DynaLearn.

O segundo questionário sobre o projeto DynaLearn foi composto por vinte e duas questões com cinco opções de respostas. Com tal questionário os alunos puderam opinar sobre o uso do software na modelagem conceitual em seus diversos aspectos. 
O questionário sobre o Pet foi aplicado com o objetivo de compreender melhor a opinião dos alunos em relação às atividades didáticas realizadas com o agente aprendiz virtual, ou seja, houve a pretensão em coletar informações sobre a opinião dos alunos em relação a função do Pet, às falas deste, à experiência em sentir estar ensinando-o de verdade, à motivação gerada nos alunos pelo ensino ao animal de estimação virtual em relação ao entendimento dos conceitos e à experiência em aprender conceitos ao ensinar ao mesmo.

Para este questionário, foram cinco pares de perguntas, sendo que cada par tratava de uma mesma categoria, porém de formas antagônicas, ou seja, se a primeira tratasse sobre o questionamento positivo de determinada afirmação, a segunda trataria sobre a negação. As categorias foram: função do Pet; falas do Pet; experiência em sentir estar ensinando ao Pet de verdade; motivação gerada nos alunos pelo ensino ao Pet em relação ao entendimento dos conceitos; experiência em aprender conceitos ao ensinar ao Pet. Cada uma delas, individualmente, apresentava cinco opções de respostas. Além desses cinco pares, o questionário continha duas questões abertas.

O questionário a respeito da experiência dos estudantes em relação ao Quizmaster, continha sete pares de perguntas, sendo que cada par tratava de um mesmo questionamento, porém de formas antagônicas e uma questão (a número cinco) que tratava singularmente sobre o fato de os alunos terem ou não se sentido como em um quiz e cada uma delas, individualmente, apresentava cinco opções de respostas. Além desses sete pares, o questionário continha duas questões abertas.

Houve uma conversa inicial com a professora, antes da execução do projeto, sobre quais são e como têm sido utilizados os principais tipos de instrumentos de ensino e aprendizagem, nas aulas de Ciências. Após isso, foram realizadas duas entrevistas, a primeira, com duração de 25 minutos, após a atividade 2 e a segunda, com duração de 35 minutos, ao término da atividade 5. Ambas do tipo semiestruturada, ou seja, na qual há uma "série de perguntas abertas, feitas verbalmente em uma ordem prevista, mas na qual o entrevistador pode acrescentar perguntas de esclarecimento" (LAVILLLE \& DIONNE, 2008, p.188). A entrevista permite ao entrevistador grande flexibilidade no diálogo estabelecido (MARCONI \& LAKATOS, 2003, p. 198). Segundo Gil (1999, p. 118), essa estratégia de coleta de dados "possibilita captar a expressão corporal do entrevistado, bem como a tonalidade de voz e ênfase nas respostas". Para Marconi \& Lakatos (2003, p. 198) a entrevista "dá oportunidade para a obtenção de dados que não se encontram em fontes documentais e que sejam relevantes e significativos". Os roteiros das entrevistas se encontram no Apêndice B. Ambas foram gravadas e posteriormente transcritas. Antes de cada uma delas, houve o esclarecimento à 
entrevistada sobre a importância da sinceridade e clareza nas respostas e que a mesma poderia interromper o entrevistador a qualquer momento para tirar dúvidas. A primeira entrevista foi composta por 30 questões que abordavam sobre os aspectos gerais a respeito do software DynaLearn, o Quizmaster e o Pet. As perguntas foram pré elaboradas, porém, outras surgiram e foram feitas durante a conversa. A segunda e última entrevista foi composta por 36 questões que tratavam sobre a atividade que foi feita, a experiência com a modelagem, modelos e simulações, os usos da modelagem na educação, o DynaLearn, os agentes virtuais e quatro questões abertas. Os resultados das entrevistas serão apresentados e discutidos na seção 4.

Nas atividades 2, 3 e 5, os alunos interagiram com o TA e participaram de pelo menos um quiz. Foi pedido para eles que registrassem cada consulta ao quiz. Com base nesses registros, os dados foram tabulados em gráficos que representam o número de "rodadas" que cada grupo precisou para completar seu modelo. Os resultados serão apresentados na forma de gráficos na seção 4 .

Também foram utilizados, na coleta de dados, pré-testes e pós-testes que foram aplicados nas atividades 1, 2, 3 e 5. Esse tipo de instrumento é muito utilizado nas pesquisas de ensino. Segundo Moreira (2003, p.10 apud Campbell e Stanley, 1979, p.14):

\footnotetext{
Neste delineamento, aplica-se um pré-teste 01 a um grupo, submete-se esse grupo a um tratamento $\mathrm{X}$ e aplica-se, então, um pós-teste 02.01 e 02 significam que o mesmo grupo é observado antes e depois do tratamento que pode ser, por exemplo, um novo método de ensino ou um recurso didático alternativo. Diferenças entre 02 e 01 (que podem ser simples testes de conhecimento) evidenciariam a eficácia (ou ineficácia) do tratamento X.
}

Cada um dos testes continha um texto para consulta e dez questões objetivas, com afirmações para serem julgadas em verdadeiras ou falsas pelos alunos. As questões traziam frases que exigiam raciocínio qualitativo do tipo condicional, como nos seguintes exemplos: "Se A aumentar/diminuir, Então B irá aumentar/diminuir" ou "A aumentou/diminuiu Porque B aumentou/diminuiu" ou ainda "X aumentará/diminuirá Se Y aumentar/ diminuir". Os pré e pós testes utilizados podem ser encontrados no Apêndice $\mathrm{C}$.

Os testes foram corrigidos e comparados. As atividades seguiram 0 procedimento: começar com o pré-teste (que continha um pequeno texto e as perguntas tipo SE/ ENTÃO), ensinar a modelar, fazer um modelo sobre o tema do pré-teste e fazer o pósteste sobre o mesmo tema.

Para conferir maior credibilidade aos resultados obtidos nos testes estatísticos, foram utilizados, na comparação dos pré-testes e pós-testes, cálculos estatísticos paramétricos e não paramétricos (SPIEGEL, 1994), mais especificamente pelo teste $t$ de Student e teste de 
Wilcoxon, respectivamente, utilizando-se o programa Action, disponibilizado para download gratuito no endereço eletrônico http://www.portalaction.com.br/. Foi estabelecido o nível de significância de $5 \%(0,05)$ para as análises e a rejeição ou aceitação da hipótese nula foi dada pelo valor de $p$ em função de um valor $t$ (no teste $t$ de Student) ou $v$ (no teste de Wilcoxon) calculado, que representa a probabilidade de tal. Para valores de $p$ maiores que 0,05 , as diferenças são tidas como não significativas (os resultados das amostras comparadas não podem ser distinguidos do ponto de vista da análise estatística). Valores de $p$ menores que 0,05 indicam que as diferenças são significativas (mostram que, estatisticamente, a hipótese nula pode ser rejeitada). Probabilidades menores que 0,01 são tidas como altamente significativas, ou seja, supondo-se que o mesmo experimento seja realizado 100 vezes, estatisticamente, existe o risco de que 1 deles não seja verdadeiro.

Nas análises foi considerado o mesmo grupo de alunos, que foi submetido a duas análises, sendo uma antes outra após o tratamento, caracterizando-se assim como um grupo pareado, o que justificou o uso dos testes de $t$ de Student pareado e Wilcoxon pareado (SPIEGEL, 1994). Estas análises serão melhor apresentadas e discutidas na seção 4.

\section{3 - ATIVIDADES REALIZADAS}

A seguir será apresentado um quadro resumo com as atividades realizadas e em seguida essas atividades serão detalhadas.

Quadro 01 - Resumo das atividades realizadas

\begin{tabular}{|c|c|c|c|c|c|}
\hline $\mathbf{N A}$ & D & $\mathbf{N}$ & Uso do TA & CONTEÚDO & RESUMO \\
\hline 1 & $2 \mathrm{~h} 30 \mathrm{~min}$ & 31 & Não & $\begin{array}{l}\text { Madeireiros } \mathrm{x} \\
\text { Ambientalistas }\end{array}$ & $\begin{array}{l}\text { Pré-teste/Treino (modelagem)/ } \\
\text { Modelagem/Pós-teste }\end{array}$ \\
\hline 2 & $2 \mathrm{~h} 30 \mathrm{~min}$ & 33 & Sim & Aterosclerose & $\begin{array}{l}\text { Pré-teste/Treino (TA)/ Modelagem com apoio } \\
\text { do TA/Pós-teste }\end{array}$ \\
\hline 3 & $2 \mathrm{~h} 30 \mathrm{~min}$ & 30 & Sim & $\begin{array}{l}\text { Aparelho } \\
\text { Reprodutor } \\
\text { Masculino }\end{array}$ & $\begin{array}{l}\text { Pré-teste (com leitura de texto)/ } \\
\text { Modelagem com apoio do TA/Pós-teste }\end{array}$ \\
\hline 4 & 1h30min & 34 & Não & $\begin{array}{l}\text { Aparelho } \\
\text { Reprodutor } \\
\text { Feminino }\end{array}$ & $\begin{array}{l}\text { Aula expositiva/Exploração de modelos } \\
\text { qualitativos via projeções por datashow }\end{array}$ \\
\hline 5 & $1 \mathrm{~h} 30 \mathrm{~min}$ & 25 & Sim & Placenta & $\begin{array}{l}\text { Pré-teste (com leitura de texto)/ } \\
\text { Modelagem com apoio do TA } \\
\text { Pós-teste (com leitura de texto) }\end{array}$ \\
\hline
\end{tabular}


A parte experimental teve por objetivo verificar se as hipóteses que estavam sendo testadas seriam ou não aceitas. Para tal, partiu-se do pressuposto abaixo:

\section{Pressuposto:}

Modelagem qualitativa contribui para a compreensão da estrutura e do funcionamento de sistemas, como mostram vários estudos anteriores.

Levantou se a hipótese que foi testada por cálculos estatísticos nas atividades desenvolvidas:

\section{Hipótese:}

A construção de modelos qualitativos, apoiada pela leitura de texto e pelo uso dos agentes aprendizes virtuais, contribui mais para a compreensão do sistema em estudo, que a construção de modelos apoiada apenas pela leitura de textos.

Hipótese nula: não há diferença significativa, em testes sobre a compreensão do fenômeno estudado, entre o desempenho de alunos que constroem modelos com o apoio de textos e do TA e o de alunos que utilizam apenas a leitura de textos;

Hipótese alternativa: há diferença significativa entre o desempenho de alunos que constroem modelos com o apoio de textos e do TA e o daqueles que o fazem apenas com o apoio de textos.

Após a elaboração das hipóteses, partiu se para a realização das atividades de modelagem, que serão detalhadas a seguir. Pré-testes e Pós-testes foram aplicados no início e ao final das atividades 1,2,3, e 5, e, a seguir, analisados estatisticamente. As análises dos resultados obtidos em cada atividade serão apresentadas na seção 4.

\section{Primeira atividade: Treinamento em modelagem}

A Atividade 1 teve duração de 5 horas (sendo 2h30min para cada grupo). Nesse dia, abordou-se o uso de modelos e textos que tratavam sobre a discussão entre ambientalistas e madeireiros, sobre a exploração da floresta e a conservação da biodiversidade. A atividade teve início com um pré-teste sobre este tema. Depois de fazer o pré-teste, foi apresentado um texto e um modelo pronto e bem simples sobre o bloom de algas, para que os alunos aprendessem a manipular o DynaLearn. Foram feitas simulações e foi apresentada com um datashow a construção do modelo, para que todos acompanhassem o processo ao mesmo 
tempo e o repetissem em seus computadores (treinamento). Após essa pequena apresentação, os alunos tiveram um tempo para construir modelos qualitativos no DynaLearn com apoio de textos sobre a discussão entre madeireiros e ambientalistas. Após a construção dos modelos, fizeram um pós-teste no mesmo nível de dificuldade que o pré-teste. Note-se que, nesta atividade o TA não foi utilizado, para que pudesse comparar os resultados obtidos com outros, em que as atividades realizadas tivessem o apoio do TA

\section{Segunda atividade: Modelagem com apoio de TA}

A Atividade 2 teve a mesma duração que a primeira. Novamente foi realizado um préteste sobre a aterosclerose, doença que afeta o sistema circulatório humano. Em seguida, os alunos foram apresentados ao TA. Para esse fim, foram utilizados modelos já conhecidos, sobre a discussão entre madeireiros e ambientalistas, para demonstrar aos alunos como utilizar o apoio do TA (treinamento). Em seguida, foi apresentado aos alunos um texto sobre a aterosclerose, doença que afeta o sistema circulatório humano, e foi solicitado aos alunos que construíssem um modelo sobre esse tema, desta vez com o apoio do TA. Ao final da atividade, os alunos foram submetidos a um pós-teste, visando saber se o uso do TA facilitaria a compreensão dos sistemas modelados.

Depois de realizada esta Atividade 2, a pedido dos alunos e da professora, foram realizadas mais três atividades, com o uso do TA, as quais serviram também para novas rodadas de coleta de dados. Estas atividades serão descritas abaixo.

\section{Terceira atividade: Modelagem com apoio de TA}

Na Atividade 3, adotou-se o mesmo procedimento que nas duas atividades anteriores, exceto pela parte do treinamento, assumido-se que os alunos já estavam familiarizados com as atividades de modelagem e com a manipulação do TA. Ainda assim, o professor que aplicou essas atividades oferecia explicações sempre que os alunos assim o desejassem. Também observou-se melhor adaptação junto à professora dos alunos, que conversou e negociou com estes, em relação aos conteúdos, modelos e tempo de aula. Desse modo, e seguindo o mesmo procedimento, nesta Atividade 3 os modelos e textos utilizados tratavam do aparelho reprodutor masculino. 


\section{Quarta atividade: Aula Expositiva (sem o TA)}

Na Atividade 4, a professora de Ciências da turma, de posse de modelos conceituais que ela mesma ajudou a construir, ministrou aula sobre o aparelho reprodutor feminino, utilizando a linguagem da modelagem qualitativa, enquanto os modelos eram projetados por um datashow. Não foram realizados pré e pós-testes, ou qualquer outro tipo de avaliação.

\section{Quinta atividade: Modelagem com apoio de TA}

$\mathrm{Na}$ Atividade 5, foram adotados os mesmos procedimentos que nas atividades 1, 2 e 3. Foi utilizado um texto um pouco menor (sobre algumas das funções da placenta) e modelos relativamente mais simples, devido ao tempo disponível. As atividades de modelagem foram divididas em duas etapas. Na primeira, os alunos trabalharam com um modelo pequeno, que tratava a dinâmica das trocas de nutrientes entre o corpo materno e o embrião, via placenta. Na segunda etapa, foi solicitado aos alunos que, com base nos conhecimentos já adquiridos no modelo anterior (que, na verdade, era uma parte de um modelo um pouco maior - o mesmo trabalhado nesta etapa), os alunos modelassem também as trocas de excretas e gases entre o corpo materno e o embrião, via placenta.

A hipótese submetida à análise estatística era a de que os resultados obtidos no pré e no pós-testes das atividades 1, 2, 3 e 5, mostrassem diferenças significativas quando o tratamento era a modelagem, em contraposição à leitura (Atividade 1), e que os resultados obtidos com a modelagem com apoio do TA (Atividades 2,3,5) fossem significantemente diferentes daqueles obtidos com leitura e modelagem sem TA. Posteriormente, a análise considerou os resultados nos pós-testes da atividade 1 em relação às atividades 2,3 e 5. Caso as diferenças fossem significativas, seria possível rejeitar a hipótese nula e aceitar a hipótese alternativa, segundo a qual o tratamento (uso do TA) provocou essas diferenças estatisticamente significantes. 


\section{RESULTADOS E DISCUSSÃO}

Esta seção apresenta os resultados obtidos com os instrumentos utilizados na coleta de dados: cinco questionários (um questionário aplicado à professora e os demais aos alunos), duas entrevistas semiestruturadas (aplicadas à professora), relatórios gerados pelo quiz (sobre o desempenho dos alunos durante a modelagem) e os testes (pré-testes e pós testes analisados estatisticamente).

\subsection{Resultados obtidos com os questionários}

No presente trabalho foram aplicados questionários sobre atitudes e motivação para desenvolver as atividades propostas (para a professora e para os alunos), sobre modelagem e sobre os agentes virtuais (para os alunos). Os questionários utilizados estão no Apêndice A.

\subsubsection{Questionário sobre atitudes e motivação para desenvolver as atividades propostas (visão da professora)}

O questionário aplicado à professora tratou basicamente de quatro categorias: Atividades realizadas, Modelagem, Software, Sistemas. A professora considerou que o curso e a atividade de aprendizagem realizada, de modo geral, foi muito boa, conforme a opção marcada por ela no questionário. Indagada sobre a opinião geral sobre a modelagem que utilizamos para desenvolver a sequência didática, a mesma marcou a opção fácil. Para a pergunta sobre como a professora avaliava a experiência de trabalhar com o software DynaLearn, ela optou pela alternativa muito interessante. "Como você avalia a sua compreensão de sistemas utilizando a modelagem" teve como resposta a opção fácil entendimento.

Sobre a importância de construir modelos específicos em diferentes níveis de complexidade no DynaLearn, a docente marcou a opção muito importante. O nível de utilização $L S 2$ com o TA foi o que ela considerou que mais contribuiu para a compreensão dos conceitos representados nos modelos, quando questionada sobre a preferência de trabalhar com os níveis LS1, LS2 sem o TA ou o LS2 com o TA.

A professora marcou a resposta concordo totalmente seis vezes, quando apresentada às seguintes afirmações: A modelagem com o software permitiu compreender melhor a complexidade dos sistemas estudados. O programa abriu novas maneiras de pensar sobre os sistemas em estudo. As características do DynaLearn me motivaram a tentar construir um 
modelo. DynaLearn proporcionou uma maneira confortável de aprendizagem. A modelagem a fez pensar sobre os sistemas de uma forma diferente. A abordagem da modelagem é interessante.

Sobre a atividade de identificar e extrair as informações relevantes essenciais do texto e a respeito da tarefa de mapeamento de conceitos, a professora assinalou a opção muito fácil para ambas. Descrever a estrutura do sistema em um modelo causal básico e compreender a diferenciação entre influências positivas e negativas foi fácil, conforme marcação da professora. Em relação à qualidade dos materiais didáticos escritos, a marcação foi fácil entendimento. Enfim, a respeito da compreensão do funcionamento de sistemas por meio dos modelos, a opção marcada foi muito fácil.

As atividades foram planejadas em consonância com a professora. A docente opinou em todas as etapas do planejamento, e pôde configurar as aulas conforme suas escolhas e necessidades educacionais, já que a mesma é quem melhor conhecia as características dos alunos. O mesmo ocorreu em relação aos materiais didáticos produzidos. Foi apresentado sugestões de slides e modelos para ela, mas a opinião da mesma sempre foi a de maior peso, a fim de que fosse proposto a professora, um material didático diferente dos tradicionais, capaz de oportunizar a interação do aluno com uma ferramenta dinâmica capaz de melhorar o raciocínio lógico dos alunos assim como o entendimento sobre o funcionamento de sistemas. A modelagem foi vista como importante e interessante e permite a melhora na interpretação e compreensão de informações relevantes de um texto, mapeamento de conceitos assim como o entendimento e compreensão do funcionamento de sistemas e seus "ingredientes" (entidades, variáveis, influências).

Todo o conhecimento adquirido sobre sistemas com a prática da modelagem foram possíveis graças ao uso do software DynaLearn, tido como uma ferramenta poderosa na busca dos objetivos propostos. Este programa ofereceu uma maneira prazerosa e motivadora de aprendizagem. Apesar da boa aceitação do programa, é sabido que, na atual organização da escola pública brasileira, as salas de aula são superlotadas e dificilmente possuem laboratórios e computadores disponíveis para uso pelos alunos e quando estão, problemas de logística de uso de softwares educacionais como o DynaLearn surgem, como o uso de sistema operacional incompatível.

Segundo a professora, as atividades desenvolvidas poderiam facilmente ser replicadas e reaplicadas, abordando conteúdos diversos. O ensino sobre a compreensão da complexidade dos sistemas estudados foi realizada de maneira fácil, prazerosa e mostrou resultados em relação à motivação dos alunos e aprendizagem. A professora e alunos tiveram acesso a um 
ambiente que favoreceu o desenvolvimento da criatividade. Algo notório, já que isso é negligenciado nos materiais didáticos tradicionais. As atividades de modelagem proporcionaram a possibilidade de identificação e extração de informações relevantes essenciais do texto, facilitando o ensino, pela docente, de conceitos e aos alunos, o entendimento. Na visão da professora, o entendimento das influências positivas e negativas, seriam de difícil explicação e, consequentemente, de difícil entendimento pelos alunos. O uso do DynaLearn, não só possibilitou a exploração destes conceitos, como também facilitou a explicação dos mesmos . Trabalhar com os agentes aprendizes virtuais contribuiu mais para a compreensão de conceitos representados nos modelos do que sem eles. Ao término da primeira atividade que realizamos (sem o uso dos agentes aprendizes virtuais) a professora já se mostrava entusiasmada com as possibilidades de ensino com a modelagem. Porém, com o uso dos agentes aprendizes virtuais nas atividades posteriores, a professora percebeu que os ganhos da modelagem evidenciados na primeira atividade se potencializaram com o uso dos agentes.

\subsubsection{Avaliação do software DynaLearn pelos alunos}

Os resultados obtidos com o questionário que versava sobre as atitudes e motivações despertadas pelo uso do DynaLearn serão apresentados em seguida, por uma tabela que mostra o quantitativo de cada resposta em valores absoluto e relativo e por descrições das observações mais notáveis em relação às respostas obtidas. Algumas das respostas das questões abertas serão inseridas no decorrer do texto para corroborar os resultados obtidos com as respostas objetivas

Quadro 2 - Respostas dos alunos ao questionário de avaliação do software $(\mathrm{n}=31)$

\begin{tabular}{|c|c|c|c|c|c|}
\hline \multicolumn{6}{|c|}{ 1) Qual é a sua opinião geral sobre o curso e a atividade de aprendizagem que fizemos juntos? } \\
\hline $\begin{array}{l}\text { Opinião dos } \\
\text { alunos }\end{array}$ & Muito ruim & Ruim & Neutro & Bom & Muito Bom \\
\hline $\begin{array}{l}\text { Respostas } \\
\text { (núm. e \%) }\end{array}$ & $\begin{array}{c}0 \\
(0,00 \%)\end{array}$ & $\begin{array}{c}0 \\
(0,00 \%)\end{array}$ & $\begin{array}{c}0 \\
(0,00 \%)\end{array}$ & $\begin{array}{c}15 \\
(48,39 \%)\end{array}$ & $\begin{array}{c}16 \\
(51,61 \%)\end{array}$ \\
\hline \multicolumn{6}{|c|}{ 2) Qual é sua opinião geral sobre a modelagem que utilizou para desenvolver esta atividade educacional? } \\
\hline $\begin{array}{l}\text { Opinião dos } \\
\text { alunos }\end{array}$ & Muito difícil & Difícil & Neutro & Fácil & Muito fácil \\
\hline $\begin{array}{l}\text { Respostas } \\
\text { (núm. e \%) }\end{array}$ & $\begin{array}{c}0 \\
(0,00 \%)\end{array}$ & $\begin{array}{c}8 \\
(25,81 \%)\end{array}$ & $\begin{array}{c}19 \\
(61,29 \%)\end{array}$ & $\begin{array}{c}4 \\
(12,90 \%)\end{array}$ & $\begin{array}{c}0 \\
(0,00 \%)\end{array}$ \\
\hline \multicolumn{6}{|c|}{ 3) Como você avalia a experiência de trabalhar com o software DynaLearn? } \\
\hline
\end{tabular}




\begin{tabular}{|c|c|c|c|c|c|}
\hline \multicolumn{1}{|c|}{$\begin{array}{c}\text { Opinião dos } \\
\text { alunos }\end{array}$} & Muito chato & Chato & Neutro & Interessante & Muito interessante \\
\hline $\begin{array}{c}\text { Respostas } \\
\text { (núm. e \%) }\end{array}$ & $\begin{array}{c}0 \\
(0,00 \%)\end{array}$ & $\begin{array}{c}0 \\
(0,00 \%)\end{array}$ & $\begin{array}{c}2 \\
(6,45 \%)\end{array}$ & $\begin{array}{c}17 \\
(54,84 \%)\end{array}$ & 12 \\
\hline
\end{tabular}

4) Como você avalia sua compreensão dos problemas abordados nos modelos depois de explorar o tema no DynaLearn?

\begin{tabular}{|c|c|c|c|c|c|}
\hline $\begin{array}{c}\text { Opinião dos } \\
\text { alunos }\end{array}$ & $\begin{array}{c}\text { Muito } \\
\text { confuso }\end{array}$ & Confuso & Neutro & Entendível & Fácil entendimento \\
\hline $\begin{array}{c}\text { Respostas } \\
\text { (núm. e \%) }\end{array}$ & $\begin{array}{c}0 \\
(0,00 \%)\end{array}$ & $\begin{array}{c}9 \\
(29,03 \%)\end{array}$ & $\begin{array}{c}7 \\
(22,58 \%)\end{array}$ & $\begin{array}{c}10 \\
(32,26 \%)\end{array}$ & $\begin{array}{c}5 \\
(16,13 \%)\end{array}$ \\
\hline
\end{tabular}

5) Como você avalia a importância de construir modelos específicos no DynaLearn para o seu entendimento dos problemas?

\begin{tabular}{|c|c|c|c|c|c|}
\hline $\begin{array}{c}\text { Opinião dos } \\
\text { alunos }\end{array}$ & $\begin{array}{c}\text { Pouquíssimo } \\
\text { importante }\end{array}$ & $\begin{array}{c}\text { Pouco } \\
\text { importante }\end{array}$ & Neutro & Importante & Muito importante \\
\hline $\begin{array}{c}\text { Respostas } \\
\text { (núm. e } \%)\end{array}$ & $\begin{array}{c}0 \\
(0,00 \%)\end{array}$ & $\begin{array}{c}1 \\
(3,23 \%)\end{array}$ & $\begin{array}{c}5 \\
(16,13 \%)\end{array}$ & $\begin{array}{c}18 \\
(58,06 \%)\end{array}$ & $\begin{array}{c}7 \\
(22,58 \%)\end{array}$ \\
\hline
\end{tabular}

6) A modelagem com o software me permitiu compreender melhor a complexidade dos sistemas estudados.

\begin{tabular}{|c|c|c|c|c|c|}
\hline $\begin{array}{c}\text { Opinião dos } \\
\text { alunos }\end{array}$ & $\begin{array}{c}\text { Discordo } \\
\text { totalmente }\end{array}$ & Discordo & Neutro & Concordo & Concordo totalmente \\
\hline $\begin{array}{c}\text { Respostas } \\
\text { (núm. e \%) }\end{array}$ & $\begin{array}{c}0 \\
(0,00 \%)\end{array}$ & $\begin{array}{c}0 \\
(0,00 \%)\end{array}$ & $\begin{array}{c}3 \\
(9,68 \%)\end{array}$ & $\begin{array}{c}16 \\
(51,61 \%)\end{array}$ & $\begin{array}{c}12 \\
(38,71 \%)\end{array}$ \\
\hline
\end{tabular}

7) A modelagem com o software abriu novas maneiras de pensar sobre os sistemas.

\begin{tabular}{|c|c|c|c|c|c|}
\hline $\begin{array}{c}\text { Opinião dos } \\
\text { alunos }\end{array}$ & $\begin{array}{c}\text { Discordo } \\
\text { totalmente }\end{array}$ & Discordo & Neutro & Concordo & Concordo totalmente \\
\hline $\begin{array}{c}\text { Respostas } \\
\text { (núm. e \%) }\end{array}$ & $\begin{array}{c}0 \\
(0,00 \%)\end{array}$ & $\begin{array}{c}0 \\
(0,00 \%)\end{array}$ & $\begin{array}{c}4 \\
(12,90)\end{array}$ & $\begin{array}{c}18 \\
(58,06 \%)\end{array}$ & $\begin{array}{c}9 \\
(29,03 \%)\end{array}$ \\
\hline
\end{tabular}

\begin{tabular}{|c|c|c|c|c|c|}
\hline \multicolumn{6}{|c|}{8 O) O software e suas características me motivaram a tentar construir um modelo. } \\
\hline $\begin{array}{c}\text { Opinião dos } \\
\text { alunos }\end{array}$ & $\begin{array}{c}\text { Discordo } \\
\text { totalmente }\end{array}$ & Discordo & Neutro & Concordo & Concordo totalmente \\
\hline $\begin{array}{c}\text { Respostas } \\
\text { (núm. e \%) }\end{array}$ & 0 & 1 & 7 & 18 & 5 \\
$(0,00 \%)$ & $(3,23 \%)$ & $(22,58 \%)$ & $(58,06 \%)$ & $(16,13 \%)$ \\
\hline
\end{tabular}

9) A utilização do software me proporciona uma maneira muito confortável de aprendizagem.

\begin{tabular}{|c|c|c|c|c|c|}
\hline $\begin{array}{c}\text { Opinião dos } \\
\text { alunos }\end{array}$ & $\begin{array}{c}\text { Discordo } \\
\text { totalmente }\end{array}$ & Discordo & Neutro & Concordo & Concordo totalmente \\
\hline $\begin{array}{c}\text { Respostas } \\
\text { (núm. e \%) }\end{array}$ & $\begin{array}{c}0 \\
(0,00 \%)\end{array}$ & $\begin{array}{c}1 \\
(3,23 \%)\end{array}$ & $\begin{array}{c}7 \\
(22,58 \%)\end{array}$ & $\begin{array}{c}15 \\
(48,39 \%)\end{array}$ & $\begin{array}{c}8 \\
(25,81 \%)\end{array}$ \\
\hline \multicolumn{6}{|c|}{ 10) A modelagem com o software também pode ser usada em outras disciplinas. } \\
\hline $\begin{array}{c}\text { Opinião dos } \\
\text { alunos }\end{array}$ & $\begin{array}{c}\text { Discordo } \\
\text { totalmente }\end{array}$ & Discordo & Neutro & Concordo & Concordo totalmente \\
\hline $\begin{array}{c}\text { Respostas } \\
\text { (núm. e } \%)\end{array}$ & $\begin{array}{c}1 \\
(3,23 \%)\end{array}$ & $\begin{array}{c}0 \\
(0,00 \%)\end{array}$ & $\begin{array}{c}7 \\
(22,58 \%)\end{array}$ & $\begin{array}{c}15 \\
(48,39 \%)\end{array}$ & $\begin{array}{c}8 \\
(25,81 \%)\end{array}$ \\
\hline
\end{tabular}

Todos os alunos que participaram da pesquisa avaliaram de forma positiva as atividades de preparação e execução de modelagem e aprendizagem realizadas. As amostras de comentários em seguida confirmam esses resultados: 
"Gostei de poder criar modelos e poder facilitar a aprendizagem."

"Gostei da praticidade e o desenvolvimento."

A modelagem utilizada para desenvolver a atividade educacional foi tida como neutra para $61 \%$ dos alunos. Esses resultados foram duvidosos. Há várias indicações para julgar que os alunos gostaram da atividade de modelagem, mas muitos acharam-nas complexas e apontaram dificuldades.

\footnotetext{
"Gostei muito, muito legal de se aprender."

"É um pouco complicado!"

"Não gostei de ter que colocar o + e o -."
}

A experiência de trabalhar com o software foi tida como interessante para a quase totalidade dos alunos (94\%), com exceção de duas respostas neutras.

"Gostei da forma divertida do programa"

$48 \%$ dos alunos optaram ter entendido a compreensão dos problemas abordados nos modelos depois de explorar o tema no DynaLearn.

"Gostei de poder criar modelos. Isso facilitou a aprendizagem."

A maioria dos alunos (81\%) considerou importante a construção de modelos específicos no DynaLearn para o entendimento dos problemas.

"Gostei de ter a chance de criar modelos."

Para a grande maioria dos alunos, nas questões 6 e 7, respectivamente $90 \%$ e $87 \%$, a modelagem com o software permitiu uma compreensão melhor da complexidade dos sistemas estudados e abriu novas maneiras de pensar sobre os sistemas.

"Eu gostei de aprender uma coisa nova. Nunca tinha visto algo parecido".

Sobre o fato de o DynaLearn e suas características terem motivado os alunos a tentar construir um modelo, a utilização do software proporcionar uma maneira confortável de aprendizagem e a modelagem com este programa também poder ser usada em outra 
disciplina, mais de dois terços dos alunos (74\%), em cada uma dessas questões, assinalaram que concordam ou concordam totalmente.

"Gostei muito da experiência. Foi simplesmente incrível."

Para o questionário que tratava sobre a modelagem conceitual no DynaLearn, 33 alunos responderam a 21 perguntas, exceto a primeira pergunta, que teve uma abstenção, totalizando, portanto, 32 respondentes. Os resultados obtidos com as respostas serão apresentados seguindo a mesma lógica do questionário anterior.

Quadro 03 - Respostas dos alunos ao questionário de avaliação da modelagem conceitual (n= 32 e 33)

\begin{tabular}{|c|c|c|c|c|c|c|}
\hline $\begin{array}{l}\text { Opções de } \\
\text { respostas }\end{array}$ & 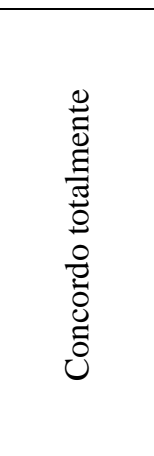 & 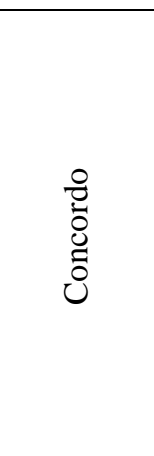 & 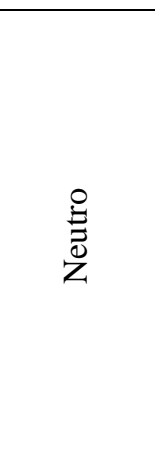 & 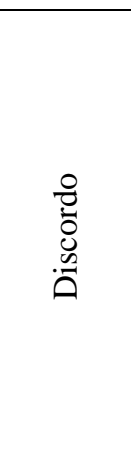 & 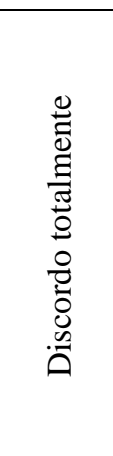 & 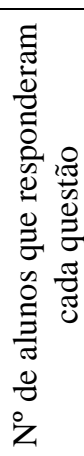 \\
\hline $\begin{array}{l}\text { 1) Modelagem conceitual foi uma } \\
\text { abordagem totalmente nova para o } \\
\text { meu aprendizado }\end{array}$ & $\begin{array}{c}13 \\
(40,63 \%)\end{array}$ & $\begin{array}{c}12 \\
(37,50 \%)\end{array}$ & $\begin{array}{c}6 \\
(18,75 \%)\end{array}$ & $\begin{array}{c}1 \\
(3,13 \%)\end{array}$ & $\begin{array}{c}0 \\
(0,0 \%)\end{array}$ & 32 \\
\hline $\begin{array}{l}\text { 2) A modelagem me fez pensar sobre } \\
\text { os sistemas de uma forma } \\
\text { diferente }\end{array}$ & $\begin{array}{c}12 \\
(36,36 \%)\end{array}$ & $\begin{array}{c}19 \\
(57,58 \%)\end{array}$ & $\begin{array}{c}1 \\
(3,03 \%)\end{array}$ & $\begin{array}{c}1 \\
(3,03 \%)\end{array}$ & $\begin{array}{c}0 \\
(0,0 \%)\end{array}$ & 33 \\
\hline $\begin{array}{l}\text { 3) A modelagem me deu uma nova } \\
\text { visão sobre os fenômenos } \\
\text { abordados nos modelos }\end{array}$ & $\begin{array}{c}8 \\
(24,24 \%)\end{array}$ & $\begin{array}{c}17 \\
(51,52 \%)\end{array}$ & $\begin{array}{c}7 \\
(21,21 \%)\end{array}$ & $\begin{array}{c}1 \\
(3,03 \%)\end{array}$ & $\begin{array}{c}0 \\
(0,0 \%)\end{array}$ & 33 \\
\hline $\begin{array}{l}\text { 4) Ser capaz de simular os modelos } \\
\text { me ajudou a desenvolver minha } \\
\text { compreensão do potencial } \\
\text { comportamento dos sistemas }\end{array}$ & $\begin{array}{c}10 \\
(30,30 \%)\end{array}$ & $\begin{array}{c}17 \\
(51,52 \%)\end{array}$ & $\begin{array}{c}6 \\
(18,18 \%)\end{array}$ & $\begin{array}{c}0 \\
(0,0 \%)\end{array}$ & $\begin{array}{c}0 \\
(0,0 \%)\end{array}$ & 33 \\
\hline $\begin{array}{l}\text { 5) Modelagem foi uma tarefa } \\
\text { motivadora }\end{array}$ & $\begin{array}{c}12 \\
(36,36 \%)\end{array}$ & $\begin{array}{c}16 \\
(48,48 \%) \\
\end{array}$ & $\begin{array}{c}5 \\
(15,15 \%) \\
\end{array}$ & $\begin{array}{c}0 \\
(0,0 \%)\end{array}$ & $\begin{array}{c}0 \\
(0,0 \%) \\
\end{array}$ & 33 \\
\hline $\begin{array}{l}\text { 6) A construção de modelos } \\
\text { conceituais me fez pensar mais } \\
\text { claramente sobre as causas e } \\
\text { efeitos das mudanças em sistemas } \\
\text { ambientais } \\
\end{array}$ & $\begin{array}{c}8 \\
(24,24 \%)\end{array}$ & $\begin{array}{c}15 \\
(45,45 \%)\end{array}$ & $\begin{array}{c}10 \\
(30,30 \%)\end{array}$ & $\begin{array}{c}0 \\
(0,0 \%)\end{array}$ & $\begin{array}{c}0 \\
(0,0 \%)\end{array}$ & 33 \\
\hline $\begin{array}{l}\text { 7) O processo de modelagem me } \\
\text { motivou a aprender mais sobre os } \\
\text { fenômenos }\end{array}$ & $\begin{array}{c}7 \\
(21,21 \%)\end{array}$ & $\begin{array}{c}19 \\
(57,58 \%)\end{array}$ & $\begin{array}{c}7 \\
(21,21 \%)\end{array}$ & $\begin{array}{c}0 \\
(0,0 \%)\end{array}$ & $\begin{array}{c}0 \\
(0,0 \%)\end{array}$ & 33 \\
\hline $\begin{array}{l}\text { 8) Eu posso ver como o uso de } \\
\text { modelos poderia me ajudar a } \\
\text { aprender sobre outros temas }\end{array}$ & $\begin{array}{c}9 \\
(27,27 \%)\end{array}$ & $\begin{array}{c}18 \\
(54,55 \%)\end{array}$ & $\begin{array}{c}6 \\
(18,18 \%)\end{array}$ & $\begin{array}{c}0 \\
(0,0 \%)\end{array}$ & $\begin{array}{c}0 \\
(0,0 \%)\end{array}$ & 33 \\
\hline $\begin{array}{l}\text { 9) Achei interessante a abordagem } \\
\text { da modelagem }\end{array}$ & $\begin{array}{c}11 \\
(33,33 \%)\end{array}$ & $\begin{array}{c}16 \\
(48,48 \%)\end{array}$ & $\begin{array}{c}6 \\
(18,18 \%)\end{array}$ & $\begin{array}{c}0 \\
(0,0 \%)\end{array}$ & $\begin{array}{c}0 \\
(0,0 \%)\end{array}$ & 33 \\
\hline 10)Eu entendi a modelagem & 7 & 13 & 12 & 0 & 1 & 33 \\
\hline
\end{tabular}




\begin{tabular}{|c|c|c|c|c|c|c|}
\hline & $(21,21 \%)$ & $(39,39 \%)$ & $(36,36 \%)$ & $(0,0 \%)$ & $(3,03 \%)$ & \\
\hline $\begin{array}{c}\text { 11)Eu entendi claramente o objetivo } \\
\text { das tarefas de modelagem }\end{array}$ & $\begin{array}{c}6 \\
(18,18 \%)\end{array}$ & $\begin{array}{c}9 \\
(27,27 \%) \\
\end{array}$ & $\begin{array}{c}16 \\
(48,48 \%)\end{array}$ & $\begin{array}{c}1 \\
(3,03 \%)\end{array}$ & $\begin{array}{c}1 \\
(3,03 \%)\end{array}$ & 33 \\
\hline $\begin{array}{l}\text { 12) Trabalhar nas tarefas de } \\
\text { modelagem me ajudou a produzir } \\
\text { as minhas respostas por escrito }\end{array}$ & $\begin{array}{c}5 \\
(15,15 \%)\end{array}$ & $\begin{array}{c}12 \\
(36,36 \%)\end{array}$ & $\begin{array}{c}15 \\
(45,45 \%)\end{array}$ & $\begin{array}{c}0 \\
(0,0 \%)\end{array}$ & $\begin{array}{c}1 \\
(3,03 \%)\end{array}$ & 33 \\
\hline Complete as frases abaixo: & 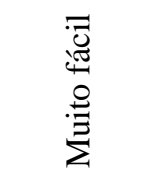 & 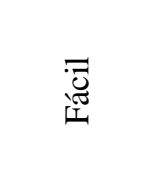 & 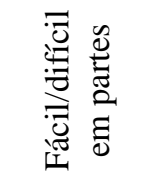 & $\overline{\overline{0}}$ & 龸: 氖 & \\
\hline $\begin{array}{l}\text { 13)Em geral eu achei a modelagem } \\
\text { conceitual... }\end{array}$ & $\begin{array}{c}2 \\
(6,06 \%)\end{array}$ & $\begin{array}{c}14 \\
(42,42 \%)\end{array}$ & $\begin{array}{c}16 \\
(48,48 \%)\end{array}$ & $\begin{array}{c}1 \\
(3,03 \%)\end{array}$ & $\begin{array}{c}0 \\
(0,0 \%)\end{array}$ & 33 \\
\hline $\begin{array}{l}\text { 14) Achei identificar e extrair as } \\
\text { informações relevantes e } \\
\text { essenciais dos textos... }\end{array}$ & $\begin{array}{c}1 \\
(3,03 \%)\end{array}$ & $\begin{array}{c}11 \\
(33,33 \%)\end{array}$ & $\begin{array}{c}17 \\
(51,52 \%)\end{array}$ & $\begin{array}{c}4 \\
(12,12 \%)\end{array}$ & $\begin{array}{c}0 \\
(0,0 \%)\end{array}$ & 33 \\
\hline $\begin{array}{l}\text { 15) Achei a tarefa de identificação de } \\
\text { conceitos... }\end{array}$ & $\begin{array}{c}1 \\
(3,03 \%) \\
\end{array}$ & $\begin{array}{c}13 \\
(39,39 \%) \\
\end{array}$ & $\begin{array}{c}15 \\
(45,45 \%) \\
\end{array}$ & $\begin{array}{c}4 \\
(12,12 \%) \\
\end{array}$ & $\begin{array}{c}0 \\
(0,0 \%)\end{array}$ & 33 \\
\hline $\begin{array}{l}\text { 16) Achei a identificação e descrição } \\
\text { das influencias positivas e } \\
\text { negativas... }\end{array}$ & $\begin{array}{c}4 \\
(12,12 \%)\end{array}$ & $\begin{array}{c}9 \\
(27,27 \%)\end{array}$ & $\begin{array}{c}14 \\
(42,42 \%)\end{array}$ & $\begin{array}{c}6 \\
(18,18 \%)\end{array}$ & $\begin{array}{c}0 \\
(0,0 \%)\end{array}$ & 33 \\
\hline $\begin{array}{l}\text { 17) Descrever a estrutura do sistema } \\
\text { em um modelo causal básico foi... }\end{array}$ & $\begin{array}{c}3 \\
(9,09 \%) \\
\end{array}$ & $\begin{array}{c}11 \\
(33,33 \%)\end{array}$ & $\begin{array}{c}18 \\
(54,55 \%)\end{array}$ & $\begin{array}{c}1 \\
(3,03 \%)\end{array}$ & $\begin{array}{c}0 \\
(0,0 \%)\end{array}$ & 33 \\
\hline 18) Trabalhar com simulações foi... & $\begin{array}{c}3 \\
(9,09 \%)\end{array}$ & $\begin{array}{c}13 \\
(39,39 \%)\end{array}$ & $\begin{array}{c}14 \\
(42,42 \%)\end{array}$ & $\begin{array}{c}3 \\
(9,09 \%)\end{array}$ & $\begin{array}{c}0 \\
(0,0 \%)\end{array}$ & 33 \\
\hline $\begin{array}{c}\text { 19) Achei a diferenciação entre } \\
\text { entidades e quantidades... }\end{array}$ & $\begin{array}{c}5 \\
(15,15 \%) \\
\end{array}$ & $\begin{array}{c}13 \\
(39,39 \%) \\
\end{array}$ & $\begin{array}{c}12 \\
(36,36 \%) \\
\end{array}$ & $\begin{array}{c}3 \\
(9,09 \%) \\
\end{array}$ & $\begin{array}{c}0 \\
(0,0 \%) \\
\end{array}$ & 33 \\
\hline $\begin{array}{c}\text { 20) Compreender a forma como as } \\
\text { derivadas mostram o } \\
\text { comportamento das quantidades } \\
\text { (crescendo, estável, decrescendo) } \\
\text { foi... }\end{array}$ & $\begin{array}{c}3 \\
(9,09 \%)\end{array}$ & $\begin{array}{c}11 \\
(33,33 \%)\end{array}$ & $\begin{array}{c}17 \\
(51,52 \%)\end{array}$ & $\begin{array}{c}2 \\
(6,06 \%)\end{array}$ & $\begin{array}{c}0 \\
(0,0 \%)\end{array}$ & 33 \\
\hline $\begin{array}{l}\text { 21)Compreender as razões para uma } \\
\text { quantidade estar crescendo, } \\
\text { estável ou decrescendo nas } \\
\text { simulações foi... }\end{array}$ & $\begin{array}{c}2 \\
(6,06 \%)\end{array}$ & $\begin{array}{c}6 \\
(18,18 \%)\end{array}$ & $\begin{array}{c}22 \\
(66,67 \%)\end{array}$ & $\begin{array}{c}3 \\
(9,09 \%)\end{array}$ & $\begin{array}{c}0 \\
(0,0 \%)\end{array}$ & 33 \\
\hline $\begin{array}{l}\text { 22)Em geral, achei que entender } \\
\text { como funciona o software foi... }\end{array}$ & $\begin{array}{c}4 \\
(12,12 \%) \\
\end{array}$ & $\begin{array}{c}15 \\
(45,45 \%)\end{array}$ & $\begin{array}{c}14 \\
(42,42 \%)\end{array}$ & $\begin{array}{c}0 \\
(0,0 \%)\end{array}$ & $\begin{array}{c}0 \\
(0,0 \%)\end{array}$ & 33 \\
\hline
\end{tabular}

Ao serem perguntados sobre o fato de a modelagem conceitual ter sido uma abordagem totalmente nova para o aprendizado, $78 \%$ dos alunos concordaram. Estes resultados mostram que a modelagem conceitual foi algo novo para a aprendizagem dos alunos.

À questão sobre se a modelagem fez os alunos pensarem sobre os sistemas de uma forma diferente, $94 \%$ das opiniões foram positivas. Os resultados desta questão mostram que quase a totalidade dos alunos julgou que a modelagem os fez pensar sobre os sistemas de uma forma diferente.

A modelagem deu uma nova visão sobre os fenômenos abordados nos modelos para $76 \%$ dos alunos. Os resultados desta questão mostram que mais de dois terços dos alunos julgou que a modelagem deu uma nova visão sobre os fenômenos abordados nos modelos. 
A pergunta "Ser capaz de simular os modelos me ajudou a desenvolver minha compreensão do potencial comportamento dos sistemas", mostrou que $82 \%$ concordam com esta afirmação. Os resultados desta questão mostram que a grande maioria dos alunos considerou que as simulações com modelos ajudam a desenvolver a compreensão do potencial comportamento dos sistemas.

A modelagem foi uma tarefa motivadora para $85 \%$ dos alunos. Os resultados desta questão mostram que a grande maioria dos alunos considerou que a modelagem foi uma tarefa motivadora.

A construção de modelos conceituais fez $70 \%$ dos alunos pensarem mais claramente sobre as causas e efeitos das mudanças em sistemas ambientais. Os resultados desta questão mostram que a grande maioria dos alunos considerou que a construção de modelos conceituais faz pensar mais claramente sobre as causas e efeitos das mudanças em sistemas ambientais.

Grande parte dos alunos (79\%) consideraram que o processo de modelagem os motivou a aprender mais sobre os fenômenos. Os resultados desta questão mostram que a grande maioria dos alunos considerou o processo de modelagem os motivou a aprender mais sobre os fenômenos.

A grande maioria dos alunos $(82 \%)$ assinalou que podem ver como o uso de modelos poderia os ajudar a aprender sobre outros temas. Os resultados desta questão mostram que a grande maioria dos alunos considerou que a modelagem pode ser útil na aprendizagem de outros temas, além dos que foram tratados.

Ao serem perguntados se seria interessante a abordagem da modelagem, $82 \%$ concordaram. Os resultados desta questão mostram que a grande maioria dos alunos considerou que a modelagem uma abordagem interessante.

"Eu entendi a modelagem”, foi o que assinalou $61 \%$ dos alunos. Os resultados desta questão mostram que a grande maioria dos alunos considerou que a modelagem uma abordagem interessante.

45\% dos alunos concordaram e 49\% marcaram "neutro" quando perguntados sobre o entendimento claro dos objetivos das tarefas de modelagem. Os resultados desta questão mostram que grande parte dos alunos entenderam claramente os objetivos das tarefas de modelagem, porém, a maioria, demonstrou que esteve, talvez, confuso em relação aos objetivos propostos nas tarefas de modelagem.

Trabalhar nas tarefas de modelagem ajudou a produzir as respostas por escrito para $52 \%$ dos alunos e $45 \%$ responderam neutro. Os resultados desta questão mostram que a maior 
parte dos alunos sentiram melhora na hora de construir respostas por escrito, por conta das atividades de modelagem e outra grande parte pode ter estado confusa durante tais atividades.

Quando perguntados sobre a modelagem conceitual, dos 33 alunos, 48\% acharam fácil, mas difícil em algumas partes e $42 \%$ achou fácil. Esses resultados nos levam a concluir que, apesar de quase a metade ter considerado a modelagem conceitual fácil, a maioria se sentiu confuso e optaram por uma resposta intermediária.

Em relação à identificação e extração das informações relevantes e essenciais dos textos, $36 \%$ acharam fácil e 52\% deram uma resposta intermediária. Esses resultados mostram que mais da metade dos alunos se sentiram confusos ou com dificuldades em relação às atividades de identificação e extração das informações relevantes e essenciais dos textos.

Quando indagados sobre a tarefa de identificação de conceitos, 43\% dos alunos acharam fácil e $45 \%$ optaram pela resposta intermediária. Aqui foram evidenciados resultados semelhantes aos observados na questão anterior.

Questionados sobre a identificação e descrição das influências positivas e negativas, $39 \%$ dos alunos consideraram fácil e $42 \%$ fácil, mas difícil em partes. Mais uma vez, apesar de um grande número de alunos ter achado fácil a identificação e descrição das influências positivas e negativas, a resposta intermediária se sobressaiu, evidenciando incertezas e resultados menos claros para uma outra grande parte dos alunos em relação a essa questão.

Sobre a descrição da estrutura do sistema em um modelo causal básico, $42 \%$ consideraram fácil e $55 \%$ que foi fácil, mas difícil em partes. Aqui nota-se que houve resultados semelhantes aos observados na questão anterior, em relação a descrição da estrutura do sistema em um modelo causal básico.

Tratando-se das perguntas sobre o julgamento do trabalho com simulações, $48 \%$ dos alunos acharam fácil e $42 \%$ fácil, mas difícil em partes. Mais uma vez, os resultados foram semelhantes ao da questão anterior, em relação ao julgamento do trabalho com simulações.

$65 \%$ dos alunos acharam fácil, quando indagados sobre a diferenciação entre entidades e quantidades nas atividades de modelagem. Conclui-se, após a análise desta questão, que a maioria dos alunos achou fácil a diferenciação entre entidades e quantidades nas atividades de modelagem.

Compreender a forma como as derivadas mostram o comportamento das quantidades (crescendo, estável, decrescendo) foi fácil para $42 \%$ dos alunos, porém, fácil, mas difícil em partes para $52 \%$ deles. Esses resultados mostram que o comportamento das derivas foi fácil para uma boa parte, porém, uma outra grande parte achou fácil, porém, difícil em algumas partes. 
$24 \%$ dos alunos acharam fácil e $67 \%$ deram uma resposta intermediária quando perguntados como foi compreender as razões para uma quantidade estar crescendo, estável ou decrescendo nas simulações. Esses dados mostram que a grande maioria não se sentiu confiante para dizer que entenderam facilmente o comportamento das variáveis nas simulações.

Por último, quando perguntados sobre o entendimento de como o software funciona, $58 \%$ responderam que foi fácil. Os dados do questionário nos permitem concluir que a maioria entendeu como o software funciona.

\subsubsection{Questionário sobre o Pet}

Perguntas 1 e 2:

Possíveis respostas:

\{concordo totalmente, concordo, neutro, discordo, discordo totalmente\}

Afirmativa: A função do meu Pet ficou clara para mim

Negativa: Achei confusa a função do meu Pet

Quadro 04 - Respostas dos alunos ao questionário sobre o Pet- perguntas 1 e $2(n=31)$

\begin{tabular}{|l|l|l|}
\hline & $\begin{array}{l}\text { Valores absolutos } \\
\text { Valores relativos }(\%)\end{array}$ & Conclusão \\
\hline $\begin{array}{l}\text { Questionamento } \\
\text { afirmativo }\end{array}$ & $\begin{array}{l}{[12: 7: 8: 3: 1]} \\
(39: 23: 26: 10: 3) \%\end{array}$ & $\begin{array}{l}(12+7: 8: 3+1) \text { A maioria (19 ou 61\%) concordou } \\
\text { que a função do Pet ficou clara }\end{array}$ \\
\hline $\begin{array}{l}\text { Questionamento } \\
\text { negativo }\end{array}$ & $\begin{array}{l}(2: 4: 3: 11: 11] \\
(6: 13: 10: 35: 35) \%\end{array}$ & $\begin{array}{l}(2: 4: 3: 11+11) \text { A maioria (22 ou 71\%) } \\
\text { discordou que a função do Pet ficou confusa }\end{array}$ \\
\hline
\end{tabular}

No quadro acima, a indicação de 'valores absolutos' e 'valores relativos' deve ser lida como segue: em relação à pergunta 1, questionamento afirmativo, 12 alunos (ou 39\%) responderam 'concordo totalmente'; 7 alunos (ou 23\%) responderam 'concordo'; 8 alunos (ou $26 \%$ ) responderam 'neutro'; 3 alunos (ou 10\%) responderam 'discordo'; 1 aluno (ou 3\%) respondeu 'discordo totalmente'. 
Com base nos resultados das respostas às questões formuladas como afirmativa e negativa, pode se concluir que a função dos Pets ficou clara para a maioria dos alunos. A fala de um dos alunos, transcrita abaixo, confirma isso:

\section{"Ele está perfeito, eu gostei muito de ensiná-lo, eu também aprendi muito com ele."}

Perguntas 3 e 4:

Possíveis respostas:

\{concordo totalmente, concordo, neutro, discordo, discordo totalmente

Afirmativa: As falas do meu Pet foram divertidas

Negativa: As falas do meu Pet foram chatas

Quadro 05 - Respostas dos alunos ao questionário sobre o Pet- perguntas 3 e 4 (n= 31)

\begin{tabular}{|l|l|l|}
\hline & $\begin{array}{l}\text { Valores absolutos } \\
\text { Valores relativos }(\%)\end{array}$ & Conclusão \\
\hline $\begin{array}{l}\text { Questionamento } \\
\text { afirmativo }\end{array}$ & $\begin{array}{l}{[8: 6: 12: 2: 3]} \\
(26: 19: 39: 6: 10) \%\end{array}$ & $\begin{array}{l}(8+6: 12: 2+3) \text { A maioria }(14 \text { ou } 45 \%) \text { concordou } \\
\text { que as falas do } \text { Pet foram divertidas }\end{array}$ \\
\hline $\begin{array}{l}\text { Questionamento } \\
\text { negativo }\end{array}$ & $\begin{array}{l}{[1: 1: 10: 9: 10]} \\
(3: 3: 32: 29: 32)\end{array}$ & $\begin{array}{l}(1: 1: 10: 9+10) \text { A maioria (19 ou } 61 \%) \text { discordou } \\
\text { que as falas do } \text { Pet foram chatas }\end{array}$ \\
\hline
\end{tabular}

Com base nos resultados das respostas às questões formuladas como afirmativa e negativa, podemos concluir que a fala dos Pets foi divertida para a maioria dos alunos.

Apesar desses resultados, os alunos comentaram sobre as dificuldades em compreender com clareza as falas do Pet, que possui uma fala "robotizada". Isso se confirma com a análise de algumas das respostas das questões abertas:

\section{"O Pet poderia falar mais claro."}

"Melhorar a fala."

Perguntas 5 e 6 :

Possíveis respostas:

\{concordo totalmente, concordo, neutro, discordo, discordo totalmente 
Afirmativa: Eu realmente senti que estava ensinando o Pet

Negativa: Eu não senti que estava ensinando o Pet

Quadro 06 - Respostas dos alunos ao questionário sobre o Pet- perguntas 5 e $6(n=31)$

\begin{tabular}{|l|l|l|}
\hline & $\begin{array}{l}\text { Valores absolutos } \\
\text { Valores relativos }(\%)\end{array}$ & Conclusão \\
\hline $\begin{array}{l}\text { Questionamento } \\
\text { afirmativo }\end{array}$ & $\begin{array}{l}{[11: 11: 5: 4: 0]} \\
(35: 35: 16: 13: 0) \%\end{array}$ & $\begin{array}{l}(11+11: 5: 4: 0) \text { A maioria }(22 \text { ou } 71 \%) \\
\text { concordou que se sentiram ensinando o Pet de } \\
\text { verdade }\end{array}$ \\
\hline $\begin{array}{l}\text { Questionamento } \\
\text { negativo }\end{array}$ & $\begin{array}{l}(1: 2: 7: 9: 12] \\
(3: 6: 23: 29: 39)\end{array}$ & $\begin{array}{l}(1: 2: 9+12) \text { A maioria (21 ou } 68 \%) \text { discordou } \\
\text { não ter sentido que estavam ensinando o Pet }\end{array}$ \\
\hline
\end{tabular}

Com base nos resultados das respostas às questões formuladas como afirmativa e negativa, podemos concluir que a maioria dos alunos se sentiu ensinando o Pet de verdade.

Perguntas 7 e 8:

Possíveis respostas:

\{concordo totalmente, concordo, neutro, discordo, discordo totalmente\}

Afirmativa: Ensinar o Pet me motivou a entender os conceitos corretamente

Negativa: Não estava motivado a entender os conceitos enquanto ensinava o Pet

Quadro 07 - Respostas dos alunos ao questionário sobre o Pet- perguntas 7 e $8(n=31)$

\begin{tabular}{|c|c|c|}
\hline & $\begin{array}{c}\text { Valores absolutos } \\
\text { Valores relativos }(\%)\end{array}$ & Conclusão \\
\hline $\begin{array}{c}\text { Questionamento } \\
\text { afirmativo }\end{array}$ & $\begin{array}{c}{[9: 13: 6: 3: 0]} \\
(29: 42: 19: 10: 0) \%\end{array}$ & $\begin{array}{c}(9+13: 6: 3: 0) \text { A maioria (22 ou 71 \%) } \\
\text { concordou que se sentiu motivado pelo Pet a } \\
\text { entender os conceitos corretamente }\end{array}$ \\
\hline $\begin{array}{c}\text { Questionamento } \\
\text { negativo }\end{array}$ & $\begin{array}{c}(1: 4: 3: 10: 13] \\
(3: 13: 10: 32: 42)\end{array}$ & $\begin{array}{c}(1: 4: 3: 10+13) \text { A maioria (23 ou 74\%) } \\
\text { discordou que o ensinar ao Pet não foi motivador } \\
\text { no entendimento dos conceitos }\end{array}$ \\
\hline
\end{tabular}


Com base nos resultados das respostas às questões formuladas como afirmativa e negativa, pode-se concluir que a maioria dos alunos se sentiu motivado pelo Pet a entender os conceitos corretamente.

Perguntas 9 e 10 :

Possíveis respostas:

\{concordo totalmente, concordo, neutro, discordo, discordo totalmente

Afirmativa: Eu também aprendi enquanto estava ensinando o meu Pet

Negativa: Ensinar o Pet não me fez aprender

Quadro 08 - Respostas dos alunos ao questionário sobre o Pet- perguntas 9 e 10 (n= 30 e 31)

\begin{tabular}{|l|l|l|}
\hline & $\begin{array}{l}\text { Valores absolutos } \\
\text { Valores relativos }(\%)\end{array}$ & Conclusão \\
\hline $\begin{array}{l}\text { Questionamento } \\
\text { afirmativo }\end{array}$ & $\begin{array}{l}{[12: 13: 3: 2: 0]} \\
(40: 43: 10: 7: 0) \%\end{array}$ & $\begin{array}{l}(12+13: 3: 2: 0) \text { A maioria (25 ou 83 \%) } \\
\text { concordou que aprendeu enquanto estava } \\
\text { ensinando o Pet. }\end{array}$ \\
\hline $\begin{array}{l}\text { Questionamento } \\
\text { negativo }\end{array}$ & $\begin{array}{l}(2: 2: 2: 11: 14] \\
(6: 6: 6: 35: 45)\end{array}$ & $\begin{array}{l}\text { discordou que o ensinar ao Pet não os fizeram } \\
\text { aprender. }\end{array}$ \\
\hline
\end{tabular}

Com base nos resultados das respostas às questões formuladas como afirmativa e negativa, pode-se concluir que a maioria dos alunos aprendeu enquanto estavam ensinando o Pet.

\subsubsection{Questionário sobre o Quizmaster}

Em relação ao questionário sobre o Quizmaster, a maioria das perguntas teve 32 alunos respondentes, sendo que nas de números 6 e 13, 31 responderam e nas de número 10 , 12 e 14 , tivemos 33 respondentes.

Perguntas 1 e 2:

Possíveis respostas:

\{concordo totalmente, concordo, neutro, discordo, discordo totalmente $\}$ 
Afirmativa: A função do Quizmaster ficou clara para mim

Negativa: A função do Quizmaster ficou confusa para mim

Quadro 09 - Respostas dos alunos ao questionário sobre o Quizmaster- perguntas 1 e 2 (n= 32)

\begin{tabular}{|l|l|l|}
\hline & $\begin{array}{l}\text { Valores absolutos } \\
\text { Valores relativos }(\%)\end{array}$ & Conclusão \\
\hline $\begin{array}{l}\text { Questionamento } \\
\text { afirmativo }\end{array}$ & $\begin{array}{l}{[11: 14: 7: 0: 0]} \\
(34: 44: 22: 0: 0) \%\end{array}$ & $\begin{array}{l}(11+14: 7: 0: 0) \text { A maioria (25 ou } 78 \%) \\
\text { concordou que a função do Quizmaster ficou clara. }\end{array}$ \\
\hline $\begin{array}{l}\text { Questionamento } \\
\text { negativo }\end{array}$ & $\begin{array}{l}{[1: 1: 7: 18: 5]} \\
(3: 3: 22: 56: 16)\end{array}$ & $\begin{array}{l}(1: 1: 7: 18+5) \text { A maioria (23 ou 72\%) discordou } \\
\text { que a função do Quizmaster ficou confusa. }\end{array}$ \\
\hline
\end{tabular}

Com base nos resultados das respostas às questões formuladas como afirmativa e negativa, pode-se concluir que a maioria dos alunos achou a função do Quizmaster clara, como ilustra a resposta de um dos alunos.

\section{"A explicação e as perguntas do Quizmaster foram simples e claras. Deu para entender."}

Perguntas 3 e 4:

Possíveis respostas:

\{concordo totalmente, concordo, neutro, discordo, discordo totalmente\}

Afirmativa: As falas do Quizmaster foram divertidas

Negativa: As falas do Quizmaster foram chatas

Quadro 10 - Respostas dos alunos ao questionário sobre o Quizmaster- perguntas 3 e 4 (n= 32)

\begin{tabular}{|l|l|l|}
\hline & $\begin{array}{l}\text { Valores absolutos } \\
\text { Valores relativos }(\%)\end{array}$ & Conclusão \\
\hline $\begin{array}{l}\text { Questionamento } \\
\text { afirmativo }\end{array}$ & $\begin{array}{l}(7: 11: 8: 3: 3] \\
(22: 34: 25: 9: 9) \%\end{array}$ & $\begin{array}{l}\text { concordou que as falas do Quizmaster foram } \\
\text { divertidas. }\end{array}$ \\
\hline $\begin{array}{l}\text { Questionamento } \\
\text { negativo }\end{array}$ & $\begin{array}{l}(0: 2: 8: 15: 7] \\
(0: 6: 25: 47: 22)\end{array}$ & $\begin{array}{l}(0: 2: 8: 15+7) \text { A maioria (22 ou 69\%) discordou } \\
\text { que as falas do Quizmaster foram chatas. }\end{array}$ \\
\hline
\end{tabular}

Com base nos resultados das respostas às questões formuladas como afirmativa e negativa, pode-se concluir que a maioria dos alunos achou as falas do Quizmaster divertidas, 
porém, alguns alunos indicaram dificuldades para entender com clareza as falas deste agente virtual, o que pode ser evidenciado na transcrição das falas dos alunos abaixo:

\section{"Acho que já esta bom assim. Só devia melhorar na fala do Quizmaster." "... deixar um pouco mais claro as respostas que os agentes virtuais dão."}

\section{Pergunta 5:}

Possíveis respostas:

\{concordo totalmente, concordo, neutro, discordo, discordo totalmente

Afirmativa: Eu realmente me senti fazendo parte de um quiz.

Quadro 11 - Respostas dos alunos ao questionário sobre o Quizmaster-pergunta 5 (n=32)

\begin{tabular}{|l|l|l|}
\hline & $\begin{array}{l}\text { Valores absolutos } \\
\text { Valores relativos }(\%)\end{array}$ & Conclusão \\
\hline $\begin{array}{l}\text { Questionamento } \\
\text { afirmativo }\end{array}$ & $\begin{array}{l}{[5: 13: 9: 3: 2]} \\
(16: 41: 28: 9: 6) \%\end{array}$ & $\begin{array}{l}(5+13: 9: 3: 2) \text { A maioria (18 ou } 56 \%) \text { se sentiu } \\
\text { fazendo parte de um quiz. }\end{array}$ \\
\hline
\end{tabular}

Com base nos resultados das respostas à questão formulada como afirmativa, podemos concluir que a maioria dos alunos se sentiu fazendo parte de um quiz.

Perguntas 6 e 7 :

Possíveis respostas:

\{concordo totalmente, concordo, neutro, discordo, discordo totalmente

Afirmativa: Eu tive a preocupação de me sair bem no quiz

Negativa: Eu não me preocupei em me sair bem no quiz

Quadro 12 - Respostas dos alunos ao questionário sobre o Quizmaster- pergunta 6 e 7 (n= 31)

\begin{tabular}{|l|l|l|}
\hline & $\begin{array}{l}\text { Valores absolutos } \\
\text { Valores relativos }(\%)\end{array}$ & Conclusão \\
\hline $\begin{array}{l}\text { Questionamento } \\
\text { afirmativo }\end{array}$ & $\begin{array}{l}(9: 13: 7: 2: 0] \\
(29: 42: 23: 6: 0) \%\end{array}$ & $\begin{array}{l}(9+13: 7: 2: 0) \text { A maioria (22 ou } 71 \%) \\
\text { concordou que teve preocupação em se sair bem } \\
\text { no quiz. }\end{array}$ \\
\hline $\begin{array}{l}\text { Questionamento } \\
\text { negativo }\end{array}$ & $\begin{array}{l}(2: 2: 4: 14: 10] \\
(6: 6: 13: 44: 31)\end{array}$ & $\begin{array}{l}\text { discordou que não se preocupou em se sair bem } \\
\text { no quiz. }\end{array}$ \\
\hline
\end{tabular}


Com base nos resultados das respostas às questões formuladas como afirmativa e negativa, pode-se concluir que a maioria dos alunos teve preocupação em se sair bem no quiz.

Perguntas 8 e 9:

Possíveis respostas:

\{concordo totalmente, concordo, neutro, discordo, discordo totalmente $\}$

Afirmativa: Eu entendi o que o Quizmaster estava falando

Negativa: O que o Quizmaster falava era confuso para mim

Quadro 13 - Respostas dos alunos ao questionário sobre o Quizmaster-pergunta 8 e $9(n=32)$

\begin{tabular}{|l|l|l|}
\hline & $\begin{array}{l}\text { Valores absolutos } \\
\text { Valores relativos }(\%)\end{array}$ & \begin{tabular}{l} 
Conclusão \\
\hline $\begin{array}{l}\text { Questionamento } \\
\text { afirmativo }\end{array}$
\end{tabular} \\
$\begin{array}{l}\text { Q } 3: 6: 13: 4: 6] \\
\text { Questionamento } \\
\text { negativo }\end{array}$ & $\begin{array}{l}(3: 3: 13: 13: 19) \\
\text { resposta neutra quando perguntados se entenderam } \\
\text { o que o Quizmaster estavam falando. }\end{array}$ \\
\hline
\end{tabular}

Com base nos resultados das respostas às questões formuladas como afirmativa e negativa, pode-se concluir que a opinião dos alunos em relação às falas do Quizmaster foram pouco claras.

Perguntas 10 e 11:

Possíveis respostas:

\{concordo totalmente, concordo, neutro, discordo, discordo totalmente

Afirmativa: Responder uma pergunta corretamente me motivou

Negativa: Não me senti motivado quando obtive respostas corretas 
Quadro 14 - Respostas dos alunos ao questionário sobre o Quizmaster- pergunta 10 e 11 (n= 32)

\begin{tabular}{|l|l|l|}
\hline & $\begin{array}{l}\text { Valores absolutos } \\
\text { Valores relativos (\%) }\end{array}$ & Conclusão \\
\hline $\begin{array}{l}\text { Questionamento } \\
\text { afirmativo }\end{array}$ & $\begin{array}{l}{[14: 14: 2: 2: 0]} \\
(44: 44: 6: 6: 0) \%\end{array}$ & $\begin{array}{l}(14+14: 2: 2: 0) \text { A maioria (28 ou } 88 \%) \\
\text { concordou que responder uma pergunta } \\
\text { corretamente os motivou. }\end{array}$ \\
\hline $\begin{array}{l}\text { Questionamento } \\
\text { negativo }\end{array}$ & $\begin{array}{l}\text { (24) A maioria (24 ou 73\%) discordou que não se } \\
(9: 6: 12: 36: 36) \%\end{array}$ & \begin{tabular}{l} 
sentiu motivado quando obteve respostas corretas. \\
\hline
\end{tabular}
\end{tabular}

Com base nos resultados das respostas às questões formuladas como afirmativa e negativa, pode-se concluir que a maioria dos alunos se sentiu motivado ao responder corretamente a perguntas do quiz.

Perguntas 12 e 13:

Possíveis respostas:

\{concordo totalmente, concordo, neutro, discordo, discordo totalmente

Afirmativa: O quiz ajudou a entender melhor o modelo

Negativa: Mesmo com o quiz, não consegui entender direito o modelo

Quadro 15 - Respostas dos alunos ao questionário sobre o Quizmaster- pergunta 12 e 13 (n= 31)

\begin{tabular}{|l|l|l|}
\hline & $\begin{array}{l}\text { Valores absolutos } \\
\text { Valores relativos }(\%)\end{array}$ & Conclusão \\
\hline $\begin{array}{l}\text { Questionamento } \\
\text { afirmativo }\end{array}$ & $\begin{array}{l}{[12: 8: 10: 1: 0]} \\
(39: 26: 32: 3: 0) \%\end{array}$ & $\begin{array}{l}(12+8: 10: 1: 0) \text { A maioria }(20 \text { ou } 65 \%) \\
\text { concordou que o quiz ajudou a entender melhor o } \\
\text { modelo. }\end{array}$ \\
\hline $\begin{array}{l}\text { Questionamento } \\
\text { negativo }\end{array}$ & $\begin{array}{l}(2: 1: 10: 8: 12] \\
(6: 3: 30: 24: 36)\end{array}$ & $\begin{array}{l}\text { discordou que não conseguiu entender direito o } \\
\text { modelo com o quiz. }\end{array}$ \\
\hline
\end{tabular}

Com base nos resultados das respostas às questões formuladas como afirmativa e negativa, pode-se concluir que a maioria dos alunos conseguiu entender melhor os modelos por causa do quiz. 
Perguntas 14 e 15:

Possíveis respostas:

\{concordo totalmente, concordo, neutro, discordo, discordo totalmente $\}$

Afirmativa: O quiz ajudou a corrigir meus erros iniciais

Negativa: Não consegui corrigir meus erros com a ajuda do quiz

Quadro 16 - Respostas dos alunos ao questionário sobre o Quizmaster- pergunta 14 e 15 (n= 33)

\begin{tabular}{|l|l|l|}
\hline & $\begin{array}{l}\text { Valores absolutos } \\
\text { Valores relativos }(\%)\end{array}$ & Conclusão \\
\hline $\begin{array}{l}\text { Questionamento } \\
\text { afirmativo }\end{array}$ & $\begin{array}{l}{[15: 14: 4: 0: 0]} \\
(45: 42: 12: 0: 0) \%\end{array}$ & $\begin{array}{l}(15+14: 4: 0: 0) \text { A maioria }(29 \text { ou } 88 \%) \\
\text { concordou que o quiz ajudou a corrigir os erros } \\
\text { iniciais. }\end{array}$ \\
\hline $\begin{array}{l}\text { Questionamento } \\
\text { negativo }\end{array}$ & $\begin{array}{l}(1: 0: 5: 15: 11] \\
(1: 0: 16: 47: 34)\end{array}$ & $\begin{array}{l}\text { discordou que não conseguiu corrigir os erros com } \\
\text { a ajuda do quiz. }\end{array}$ \\
\hline
\end{tabular}

Com base nos resultados das respostas às questões formuladas como afirmativa e negativa, pode-se concluir que a maioria dos alunos conseguiu corrigir os erros iniciais com a ajuda do quiz.

\subsection{Resultados obtidos com as entrevistas}

A professora também foi entrevistada sobre aspectos gerais da atividade e sobre suas opiniões a respeito de diversos assuntos. O roteiro para as entrevistas está no Apêndice B. Nesta seção, é apresentado um resumo das entrevistas. Abaixo da descrição das questões e comentários haverá transcrição de trechos literais da entrevista (para reforçar e subsidiar os comentários), para a maioria das questões. Algumas questões dispensam comentários, visto que o depoimento da professora (que será apresentado sempre com fontes menores), por si só, será suficiente para demonstrar sua opinião.

As entrevista abordaram temas sobre a opinião geral da docente sobre as ativiades realizadas, sobre o software DynaLearn, sobre a capacidade do software DynaLearn e dos agentes virtuais contribuírem no ensino e compreensão de funcionamento de sistemas, sobre a capacidade de motivação dos agentes virtuais e seu potencial pedagógico. 


\section{$1^{\text {a }}$ entrevista concedida pela professora de Ciências da turma}

Sobre a opinião geral sobre o curso e a atividade de aprendizagem que foi realizada a professora considerou " que foi um sucesso!".

A professora gostou da modelagem que utilizamos com os alunos para desenvolver a atividade educacional e afirmou ser algo novo para ela.

Eu gostei muito de conhecer.

Achei uma novidade que veio para ficar.

Sobre a experiência de trabalhar com o software DynaLearn, como a professora avaliou a compreensão dos alunos em relação aos problemas abordados nos modelos depois de explorar o tema no DynaLearn e se o programa ajudou no processo de aprendizagem e como ele poderia ser usado em outras séries. A professora classificou como positiva, a experiência. Espera poder trabalhar mais vezes com programas desta categoria. Destacou os problemas de interpretação e leitura característicos dos alunos atuais. Segundo ela, o programa ajudou no entendimento de conceitos abstratos e poderia ser usado em outros níveis escolares.

uma geração que não lê. Então, se eles não leem, obviamente eles tem problema de interpretação textual.

O programa ajudou na interpretação do texto. Ele traz informações suplementares para que o aluno entenda o que é tão abstrato para ele num texto.

Acho que este sistema de modelagem pode se adaptar a qualquer nível escolar.

A experiência de trabalhar foi muito positiva e minha esperança é que a gente consiga implementar programas como esse no dia a dia, na sala de aula.

Quanto a dosagem dos textos, a professora achou os complexos, mas elogiou o desempenho dos alunos. Se sentiu surpreendida.

Aprovei e selecionei os textos, eles foram interessantes, mas percebi, após a experiência que fizemos, que eles estavam acima do nível dos alunos. Apesar de tudo, acho que a maioria conseguiu compreender boa parte dos textos.

Mesmo eu achando complexo inicialmente, mesmo com as dificuldades deles, eles acompanharam. 
Sobre a importância de construir modelos específicos no DynaLearn, com os alunos, para o entendimento dos problemas abordados, a professora deixou claro que a construção de modelos específicos no software é fundamental.

a especificidade dos conteúdos é importante para a idade e para o nível dos alunos.

"Você realmente acha que o texto da aterosclerose foi complexo?" Foi uma das peguntas que não estavam programadas e que surgiu durante o diálogo com a docente.

Segundo ela, o texto da atividade 2 foi complexo, mas destacou o bom desempenho dos alunos na atividade e pôs em questão o fato de alguns grupos não terem tido tempo para concluirem seus modelos, já que havia um cronograma e o horário disponível e condições não nos permitiram ir mais além.

Acho que foi complexo, mas é importante desafiar eles, pois assim eles conseguem chegar mais longe.

O tempo para mim foi a principal causa da não conclusão de alguns trabalhos. Todos iam conseguir, tenho certeza. Teve grupo que concluiu o relatório em $100 \%$ depois de 2 ou 3 tentativas, enquanto outros grupos demoram mais.

$\mathrm{Na}$ visão da professora, a modelagem com o software permitiu que os alunos compreendessem melhor a complexidade dos sistemas estudados (tema de um dos questionamentos), para ela, a possibilidade de se trabalhar com outros sistemas (tema de um outro questionamento) existe e é bem abrangente. O software e suas características motivaram os alunos a tentar construir um modelo (também foi tema de uma das questões da entrevista), porém, a mesma observou que existem barreiras em relação aos recursos disponíveis para a utilização do software em sala de aula. Ela destacou que houve interação e participação de todos os alunos que compunham cada grupo.

Eu ainda não achei como transpor a barreira da falta de computadores e da falta de sistema que seja acessível às nossas pesquisas, mas minha mente se abriu a novas possibilidades.

Eu conversei com eles (alunos) que qualquer conteúdo pode ser abordado na modelagem.

Se fosse só a leitura e uma interpretação simples de texto, provavelmente alguns se destacariam, dariam as respostas e outra parte do grupo ficaria acomodada. Com esse formato, não. Todos queriam participar, todos do grupo. 
Foi perguntado se a utilização do software proporcionou uma maneira muito “confortável” de aprendizagem aos alunos.

A docente disse, na sua visão, que o programa é desafiador e oportuniza uma maneira diferente de aprender. Apesar de os alunos terem se sentido motivados e interessados nas atividades de aprendizagem com o programa, a professora notou algumas dificuldades destes em entender algumas funções do programa e características da modelagem, mas que este problema seria resolvido se as atividades de modelagem e uso do software fizesse parte da rotina dos estudantes. Ressaltou ainda que, apesar dos pontos negativos, as atividades, de longe, são mais cômodas que as atividades rotineiras e tradicionais a que os alunos estão acostumados.

A aula com o programa é diferente do que a gente tá acostumado a fazer. O dia a dia dos alunos é praticamente caderno e livro... O software trouxe muito interesse para eles, mas eu não acho um programa cômodo. Acho um programa desafiador.

Perguntada sobre o que gostou, ela levantou aspectos positivos, como a inserção da tecnologia na sala de aula, o aprender ensinando, a colaboração e a característica do programa em considerar as diversas personalidades de cada aluno: os mais tímidos ou não, os mais rápididos, os mais lentos, todos se beneficiaram, pois a dinâmica dos agentes aprendizes virtuais permitiu isso.

Gostei da inserção da tecnologia na sala de aula. Embora a gente tenha percebido que tem gente que não tinha noções básicas, eles aprendem rápido. O TA facilita eles a interpretarem, a captarem um conteúdo através do ensinamento e isso é inovador e muito importante. Também desenvolve a iniciativa de ajudar ao outro. Alguns terminam primeiro e se interessam em ajudar os outros. Esse programa incentiva a todos: os mais tímidos ensinam ao Pet, os mais desinibidos também assim como os mais rápidos ou os que tem um tempo mais lento. Todos tem a capacidade de aprender ensinando.

Perguntada sobre alguma idéia para melhorar o software, a professora destacou que o programa vem em inglês e que a fala dos agentes virtuais é mais próxima da robótica do que de seres humanos. Mas frisou que talvez fosse essa uma oportunidade para se desenvolver projetos interdisciplinares com a inclusão da disciplina de inglês.

Acho que o idioma é um ponto a ser melhorado. Os meninos se demoram por causa dos termos em inglês. Talvez seria interessante o uso do TA numa aula de interdisciplinaridade com aulas de inglês. 
Questionada sobre a diferença no uso ou não dos agentes aprendizes virtuais, a professora relatou que com os agentes aprendizes virtuais, as possibilidades de interação aumentaram. Foi mais didático.

\footnotetext{
Na minha opinião com o agente aprendiz virtual é melhor porque o nível aumenta. A possibilidade deles ensinarem, deles perceberem onde erraram, lendo, vendo a descrição... Você errou aqui e ter a capacidade de pensar. Se ele está dizendo isso, tenho que corrigir ali, isso envolve muitas aprendizagens. Eu acho melhor.
}

Ainda, sobre o uso do TA, segundo a professora, seria possível utilizar os relatórios gerados como um instrumento de avaliação.

Tinhamos a pretenção de utilizar, junto à professora, os modelos e relatórios gerados pelo quiz como instrumento de avaliação. Foi constatado que seria possível e interessante, mas a docente, por problemas pessoais e por inviabilidade no calendário escolar, não pôde dar continuidade ao projeto, justamente quando seria explorada esta questão. Talvez, em trabalhos posteriores, essa análise possa ser feita, pois a pesquisa mostrou que há indícios de possibilidade para isso.

Acho que o modelo pode ser uma avaliação e o relatório a gente pode avaliar a partir do número de tentativas, ou seja, a quantidade de vezes que eles precisaram para tentar chegar a um resultado de $100 \%$ ou próximo disso.

Quando perguntada se o TA poderia ser utilizado como facilitador de práticas de avaliação formativa, devido a, atualmente, estarem comentando sobre a implantação e incentivo à avaliação formativa no sistema educacional do Distrito Federal, a professora analisou que essa tecnologia se configura com características interessantes para isso, porém, enfatiza os diversos problemas que temos para implantar o uso de uma ferramenta como essa em sala de aula.

O programa oferece a possibilidade do aluno aprender por várias tentativas, o que é uma das propriedades da avaliação formativa, mas não vejo como a gente pode implantar isso num sistema educacional em que a gente tem restrição de tecnologia, de software, de hardware, de profissionais bem treinados e de tempo. Isso seria, inclusive, um modelo ideal para a escola integral.

Perguntada se a função do Quizmaster ficou clara para ela e para os alunos, e se as falas dele foram divertidas ou chatas, a professora respondeu que a função foi clara, mas fez críticas, mais uma vez, ao fato de a voz dos agentes ser muito robótica e sugeriu que isso possa ser melhorado no programa. Inclusive, ao responder sobre se o que o Quizmaster falava era claro para ela e para os alunos, ela comentou sobre a dificuldade de alguns entenderem 
de imediato o que os agentes estavam dizendo. Ainda sobre o Quiz, foi importante quando afirmou que as respostas corretas motivaram os alunos (abordado em uma outra questão) e que o quiz facilitou o entendimento dos modelos pelos alunos ( tema de uma das perguntas).

Pelo que eu observei, todos entenderam cada personagem e a função de cada um.

Alguns acharam ele ( $o$ Harry) grosseiro, mas eu achei, de verdade, bem tranquilo. $\mathrm{O}$ único fator que a gente pode criticar, como já disse anteriormente, é a voz robótica. Muito robótica. Existem vozes robóticas hoje em dia bem mais claras. Sei que isso está em evolução e que poderá ser melhorado com o tempo.

Os acertos sempre motivam.

Perguntada se os alunos se sentiram fazendo parte de um quiz e se tiveram a preocupação de se sair bem neste, a professora respondeu de forma positiva.

Eu acho que sim. Eles entraram na brincadeira, entraram na onda, adoraram.

Questionada se o quiz proporcionaria aos alunos a possibilidade de corrigir os erros de modelagem. Sobre o que mais o Quizmaster poderia fazer nas atividades. Na primeira, a professora concordou e, na segunda, disse que o Quizmaster, para ela, é um exemplo de tecnologia moderna e que ele executa seu papel perfeitamente. Ela não apontou mais críticas ou análises, ao ser questionada, se o que o Quizmaster poderia fazer algo de maneira diferente.

Com certeza. A função dele é a de mostrar o erro e o aluno sentir o interesse em corrigir.

Eu gostei. Acho ele divertido.

As respostas foram positivas para as questões "A função do Pet ficou clara?", "As falas do Pet foram divertidas?", "O Pet proporcionou ao aluno sentir que estava ensinando ao Pet?" e "O ensino do Pet facilitou a aprendizagem e o ensino de conceitos?". "O ensino do Pet motivou os alunos a entenderem os conceitos corretamente?", " facilitou a aprendizagem de conceitos corretamente?".

A função do Pet ficou clara para mim e principalmente para os alunos.

Todo mundo observou isso: foi muito interessante ensinar. 
Eles pensam "Ah, eu primeiro tenho que entender o texto para depois ensinar". Eles tinham essa dificuldade. Mas com a tentativa e erro eles acabavam aprendendo naturalmente.

A última questão deste tópico objetivava investigar, na visão da professora, o que mais o Quizmaster deveria fazer no tipo de atividade que realizamos.

De acordo com a professora, não há críticas neste aspecto. Inclusive, a mesma cita o poder de empolgação que o programa desperta nos alunos. Esse aspecto foi interessante, assim como o fato de o programa conseguir prender a atenção dos alunos. Em função do tempo necessário para executar uma atividade pedagógica, alguns alunos ficaram vários minutos lendo e relendo o texto, interagindo com o programa em busca de soluções para os problemas colocados pela modelagem e pelo TA, sem sair do foco ou desviar dos objetivos propostos. O TA realmente conseguiu empolgar, emocionar e chamar a atenção e despertar o interesse dos estudantes e da professora, tornando a atividade de aprendizagem prazerosa.

$\mathrm{Eu}$ gostei muito. O feedback da maioria foi excelente. Eu vi que todos se empolgaram. Nenhum queria sair.

\section{$2^{\text {a }}$ entrevista concedida pela professora de ciências da turma}

A seguir será apresentado o resultado e comentários obtidos na entrevista dada pela professora ao final da aplicação de todas as etapas do projeto, em dezembro de 2014.

Questionada sobre a identificação, descrição e compreensão das influências positivas e negativas, a docente afirma que foi a parte mais difícil para os alunos compreenderem. $\mathrm{O}$ raciocínio lógico não é trabalhado de forma direta e sistemática nas aulas do Ensino Fundamental e, por isso, os alunos não têm o costume de trabalhar atividades que envolvam este tipo de habilidade. As atividades que foram realizadas contribuíram, mesmo que de forma um pouco tímida, para o desenvolvimento do raciocínio lógico dos alunos em relação à observação de fenômenos que envolvem sistemas.

Em relação às influências negativas e positivas alguns tinham certa dificuldade. Pra eles, acho que foi o nível mais complexo deles entenderem. Para eles foi bastante desafiador, mas eu considero uma experiência excelente, porque eles começaram do zero e acredito que a maioria conseguiu aprender essas influências.

Foi indagado à professora sobre como foi trabalhar com simulações e se simular os modelos ajudou a desenvolver a compreensão do potencial comportamento dos sistemas. 
A professora respondeu:

Sim, com certeza. A simulação é uma das portas que eles tiveram para sair do abstrato, dos conceitos abstratos, e praticar, fazendo com que aquela aprendizagem fosse um pouco mais completa.

"Quais são as principais dificuldades que você apontaria para levar a modelagem para a sala de aula? E as possíveis soluções para essas dificuldades?" - foram questionamentos que fizeram a professora dar "aquela respirada", de quem é compromissada com a educação, mas vê que os problemas existem, mas não são simples de serem resolvidos. Ela fez críticas às estruturas das escolas e ao cronograma imposto pelo calendário escolar.

\begin{abstract}
As escolas não tem estrutura física e tecnológica pra comportar um projeto como esse... Falando em deficiências tecnológicas, acredito que nós solucionaríamos se a gente pudesse aumentar o número de computadores, ter espaços maiores para esses computadores e que os sistemas utilizados nesses computadores sejam compatíveis com o que nós trabalhamos. Acredito que o Windows, hoje, é o sistema mais adaptável para qualquer forma de atividade que a gente tenha.
\end{abstract}

Falando também de outra dificuldade, acredito que é a temporal. A gente tem cronogramas muito apertados, a gente sempre tem cobranças e tudo isso envolve tempo e aprendizagem; nem sempre ele pode ser cumprido no tempo determinado. Então, acredito que se a gente conseguisse ter uma educação integral eficiente de qualidade onde a gente pudesse ter mais tempo de qualidade trabalhando com eles, um projeto desses seria $100 \%$ de eficaz.

Perguntamos como a professora avaliou a importância de construir modelos específicos em diferentes níveis de complexidade no DynaLearn.

Segundo ela, isso é importante, pois desafios devem ser sempre gerados, para que os alunos se sintam motivados e possam passar de um nível de complexidade a outro, no DynaLearn, simultaneamente à evolução na aprendizagem.

Acredito que é importante, porque a gente começa num nível menor, onde eles possam compreender o sistema e depois evoluir num mesmo sistema, mas com a gente desafiando eles a desenvolverem modelos mais complexos, num segundo, terceiro e quarto nível.

Pelo depoimento da professora, inferimos que o nível LS2 com o TA foi o que mais contribuiu para a compreensão dos conceitos representados nos modelos que trabalhamos (tema abordado em um dos questionamentos). E que a modelagem com o software pode ser usada em outros tópicos de aprendizagem, inclusive em atividades interdisciplinares ou com projetos (tema também abordado na entrevista).

Esse é um sistema que é muito amplo e a gente pode utilizar para trabalhar qualquer projeto. 


\section{Questões abertas para a professora de Ciências da turma}

Questionada sobre o que gostou, a professora disse que da influência que os agentes aprendizes virtuais foram capazes de causar no desempenho dos alunos, principalmente em relação à motivação e aprendizagem.

O que eu mais gostei foi o uso da ferramenta. Como ele é dinâmico, como ele é interativo, como ele influencia na motivação e principalmente nos resultados. Especialmente nos resultados positivos que os alunos tiveram.

Perguntada sobre o que não gostou, a educadora apontou a pressão que os alunos sofreram, em alguns momentos, por conta do pouco tempo que nos foi disponibilizado (considerando a real necessidade do projeto e ritmo a que os alunos estavam acostumados). Algo não corriqueiro ocorreu: quando, em geral, o professor pede aos alunos que concluam logo suas atividades porque o tempo da aula acabou, rotineiramente os alunos pedem para que o professor finalize logo a aula. Muitas vezes, assim que o sinal da escola "bate", os alunos literalmente saem correndo, sem ao menos esperar que o professor conclua um eventual raciocínio relativo ao conteúdo da aula. No trabalho aqui descrito, os alunos que apresentaram um ritmo mais lento quiseram ficar realizando as atividades de modelagem além do tempo previsto.

Eles queriam terminar e não demonstraram estar preocupados em passar uma, duas ou três horas em frente ao computador. No decorrer de cada nova atividade realizada com o TA, fomos dando mais tempo para eles terem contato com o programa. Cada vez mais eles se mostravam entrosados com o software, o que fazia com que o tempo disponível ser, a cada nova atividade, mais efetivo, mais bem aproveitado. Somando a conquista de maior experiência à maior disponibilidade de tempo, os resultados apresentados pelos alunos foram sucessivamente melhorando. Eles mostraram muita vontade, e isso foi atribuído ao TA. Traçaram objetivos e queriam concluí-los. Quem mais se beneficiou com isso foram os próprios alunos, que ganharam muito em aprendizagem.

\footnotetext{
Eu não gostei da pressão que os alunos foram submetidos, muitas vezes, para concluírem as atividades no tempo programado, mas fico feliz, porque mesmo assim, muitos trouxeram resultados positivos.
}

A questão 4 teve como objetivo abrir espaço para que a professora pudesse tecer comentários diversos, que são apresentados abaixo: 
Fico muito feliz de ter participado de um projeto como esse e dos meus alunos terem tido a oportunidade de, na vida deles, eu não sei se isso vai se repetir, infelizmente, mas fico feliz de parte deles terem tido a oportunidade de participar de um projeto tão rico. Espero que um projeto como esse possa ser ampliado para toda a rede pública e, para onde eles forem, em qualquer colégio que eles estejam, que eles possam trabalhar e nós professores possamos começar trabalhar um pouco mais com tecnologia.

Segundo a mesma, o uso de modelos a influenciou a pensar de uma forma diferente sobre modelos e que isso é algo novo, que não está implícito nos livro didáticos e que ajuda na interpretação de textos.

O uso de modelos trouxe uma amplitude maior para o que a gente pode apresentar para os alunos.

"Esse tipo de abordagem foi interessante para sua formação?", foi questionado e a professora assim respondeu:

Com certeza. Quando a gente usa um sistema desse, a gente consegue ampliar os horizontes e não trazer apenas conceitos, mas trazer relações, trazer interações entre os temas que a gente estuda. Faz muito a gente pensar mais à frente o que aconteceria com algumas situações, com alterações, com simulações... Então, um sistema como este faz a gente pensar além. Além do que uma simples interpretação textual.

De acordo com relatos da professora, a sequência didática realizada, proporcionou o acesso a uma metodologia que propõe um pensamento mais elaborado para o aluno.

Indagada sobre o que ela achava que poderia ser feito para aproveitarmos mais os conceitos propostos. A resposta foi:

Acho que o que foi feito foi o máximo, foi feito com grande qualidade, mas se a gente pudesse contar com ainda mais recursos tecnológicos, com um número maior de computadores e com um pouco mais de tempo... Acho que seria mais eficaz.

\subsection{Resultados obtidos com o quiz}

Durante a construção dos modelos nas atividades 2,3,5 (esta em duas partes, I e II), os alunos podiam interromper suas atividades e chamar o Quizmaster, que fazia uma série de perguntas para o agente aprendiz virtual. As respostas corrigidas eram apresentadas em uma tabela, e os alunos podiam então corrigir seus erros e continuar a modelar até que o modelo ficasse completo e correto. Os gráficos abaixo representam o número de "rodadas" que cada 
grupo precisou para atingir seu desempenho máximo (em $\%$ de acertos) nos quizes. Por exemplo, o gráfico referente à Atividade 2 mostra que na primeira rodada (Quiz 1) o grupo de alunos 1 acertou 50\% das perguntas, e o grupo 2,60\%. Este grupo atingiu a nota máxima na segunda rodada, enquanto o grupo 1 parou na quinta rodada, com $85 \%$ de acertos. Os modelos são apresentados no Apêndice D.

Atividade 2 - Modelo da aterosclerose:

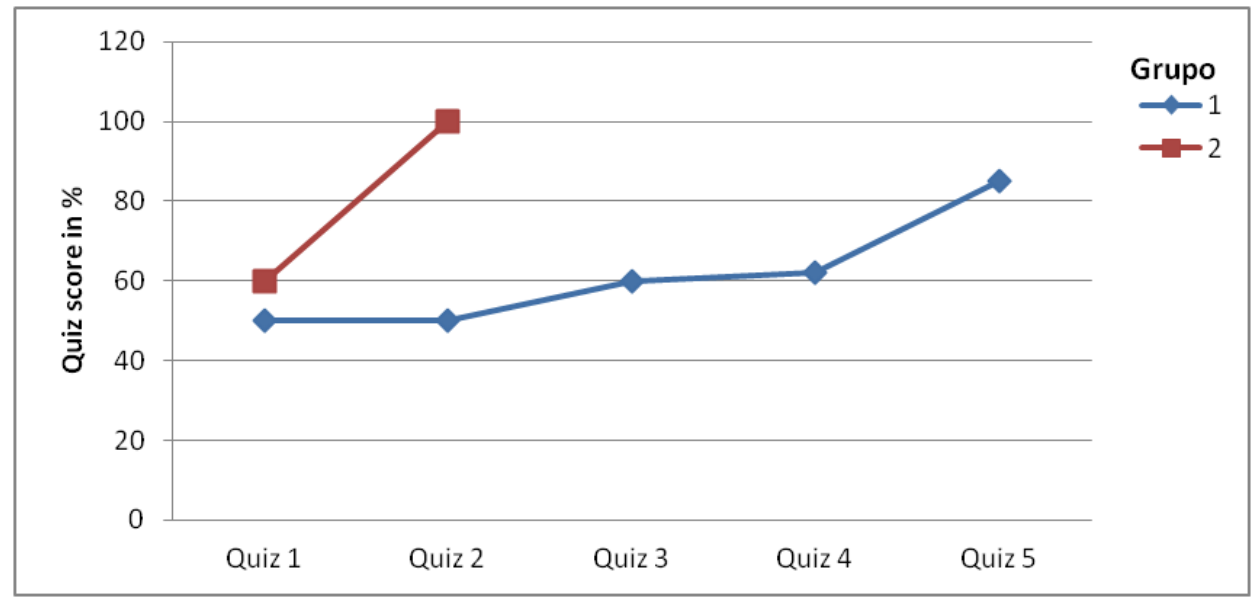

Gráfico 1- Número de "rodadas" que os grupos 1 e 2 precisaram para atingir seu desempenho máximo (em \% de acertos) nos quizes da atividade 2.

Fonte: próprio autor

O grupo 1 precisou de cinco rodadas para atingir o seu máximo, que foi $85 \%$. Já o grupo 2 precisou de duas rodadas para atingir $100 \%$ do quiz.

Nessa atividade, os alunos tiveram muita dificuldade para trabalhar com comandos básicos de computação, como o uso da tecla "print" (que capta a imagem do computador) e dos comandos de cópia e colagem de imagens em editores de texto ou em pastas. Esse fator foi o principal responsável pelo número reduzido de registros de imagens referentes às interações dos alunos com o seu Pet e com o quiz. Apesar disso, observou-se que todos os alunos consultaram o Quizmaster algumas vezes, interagiram com o agente aprendiz virtual e receberam feedbacks, porém, poucos atingiram os $100 \%$ de desempenho. 
Atividade 3 - Modelo do aparelho reprodutor masculino:

Os alunos que participaram desta atividade foram divididos em 14 grupos. Devido à limitação de espaço nos gráficos, os resultados abaixo foram divididos em três gráficos.

Grupos 1 a 4:

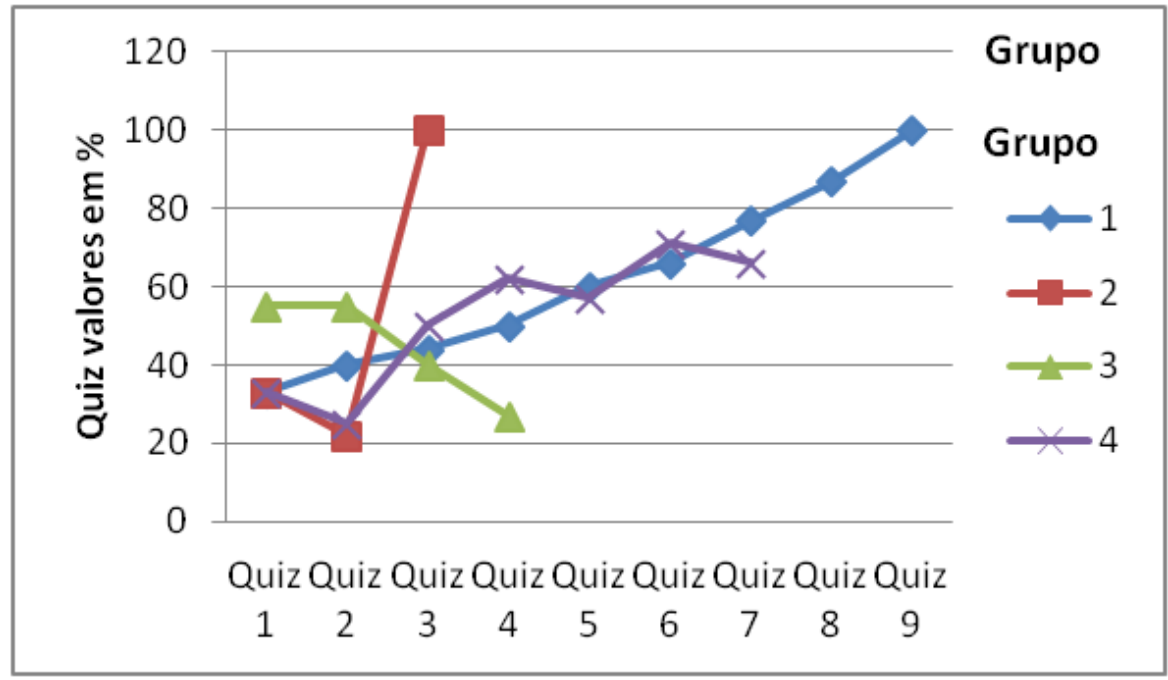

Gráfico 2- Número de "rodadas" que os grupos 1, 2, 3 e 4 precisaram para atingir seu desempenho máximo (em \% de acertos) nos quizes da atividade 3.

Fonte: próprio autor

O grupo 1 precisou de nove rodadas para atingir $100 \%$ do quiz. O grupo 2, três rodadas. $\mathrm{O}$ grupo 3, curiosamente, atingiu, na primeira rodada 55\%, mas teve seu desempenho reduzido, após quatro rodadas, para pouco mais que 27\%. O grupo 4 teve resultados oscilantes, mas após sete rodadas atingiu seu desempenho máximo (66\%).

Grupos 5 a 9: 


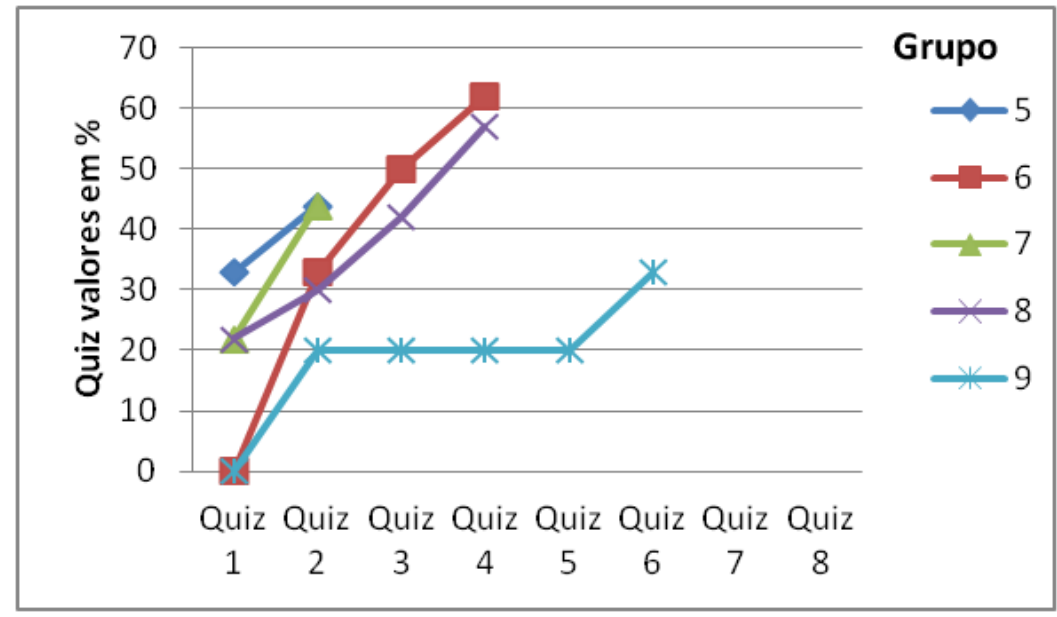

Gráfico 3- Número de "rodadas" que os grupos 5, 6, 7,8 e 9 precisaram para atingir seu desempenho máximo (em \% de acertos) nos quizes da atividade 3.

Fonte: próprio autor

O grupo 5 precisou de duas rodadas para atingir seu desempenho máximo (44\%). O grupo 6, após quatro rodadas, atingiu 62\% de desempenho. O grupo 7, após duas rodadas, atingiu o mesmo valor de desempenho máximo que o grupo 5 . O grupo 8 atingiu $57 \%$ de desempenho, após quatro rodadas. O grupo 9, após seis rodadas, atingiu 33\% de desempenho.

Grupos 10 a 14:

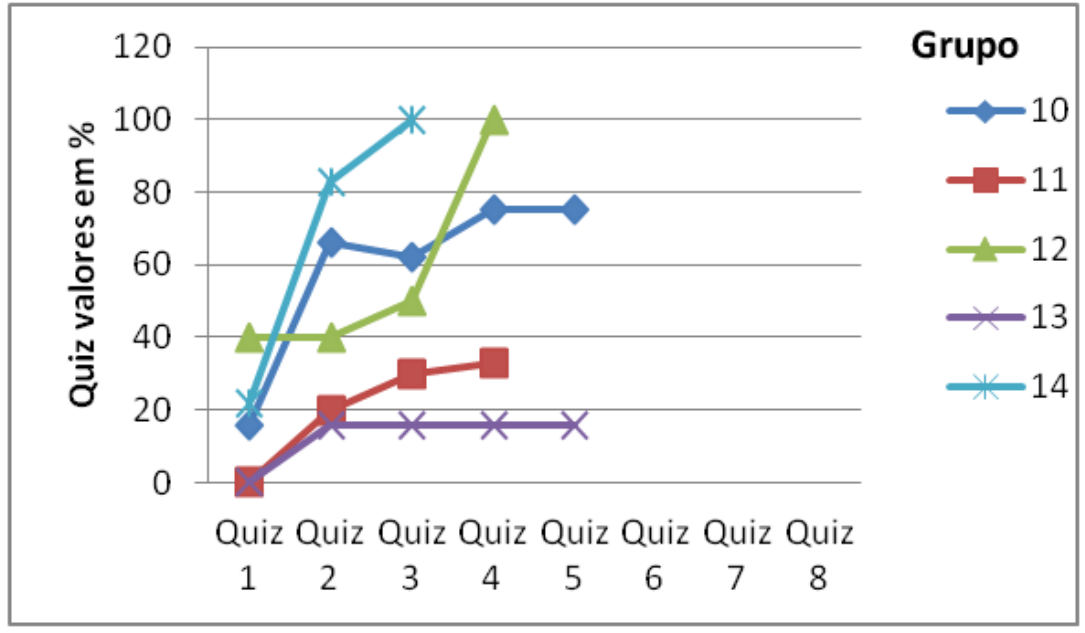

Gráfico 4 - Número de "rodadas" que os grupos 10, 11, 12, 13 e 14 precisaram para atingir seu desempenho máximo (em \% de acertos) nos quizes da atividade 3 .

Fonte: próprio autor 
O grupo 10 precisou de cinco rodadas para atingir seu desempenho máximo (75\%). O grupo 11 atingiu o desempenho máximo de 33\%, após 4 rodadas. $\mathrm{O}$ grupo 12 precisou de quatro rodadas para atingir $100 \%$ de desempenho no quiz. O grupo 13 , na segunda rodada atingiu $16 \%$, e permaneceu neste até a quinta e última rodada. O grupo 14 precisou de 3 rodadas para atingir o percentual máximo de desempenho (100\%).

Nesta atividade, os alunos apresentaram menores dificuldades nos registros e arquivamento das imagens, o que resultou no melhor desempenho de quase todos os grupos. Observou-se que alguns alunos consultaram o Quizmaster, algumas vezes, por impulso, com o objetivo de apenas ver seu agente aprendiz virtual se sair bem no quiz. O objetivo de aprendizagem e entendimento do funcionamento dos sistemas, as vezes, foi negligenciado, talvez por conta do ritmo lento dos alunos ou da voz robótica e pouco entendível dos agentes, que chegou a irritar a alguns alunos. Mas a maioria dos alunos "entrou" na "brincadeira" e tirou bastante proveito dos recursos do programa para adquirir novos conhecimentos.

Atividade 5 - Modelo da placenta

Parte I:

Grupos 1 a 5

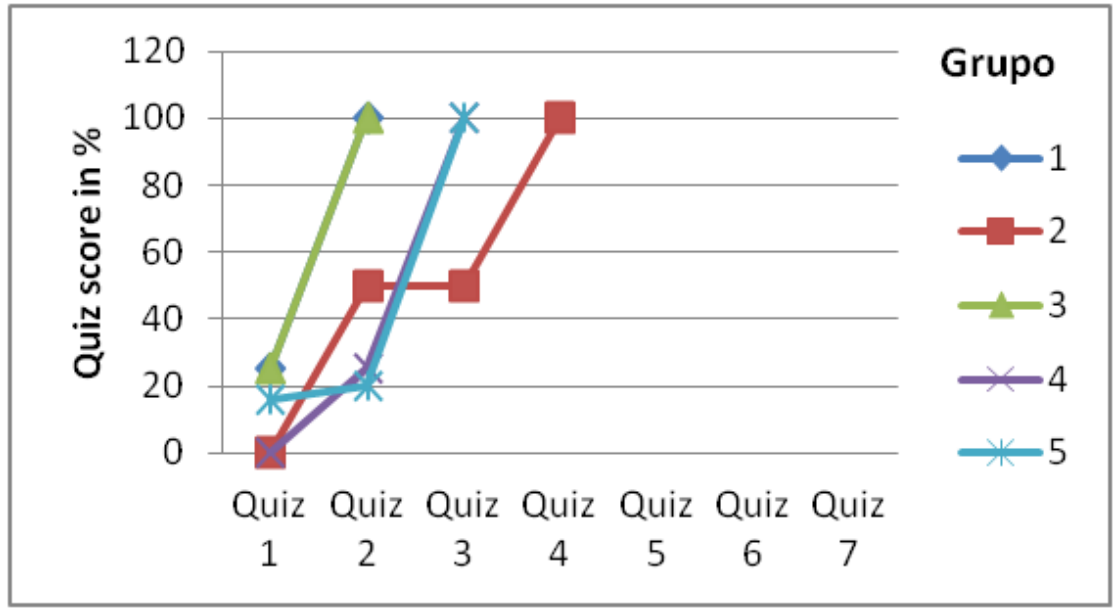

Gráfico 5- Número de "rodadas" que os grupos 1, 2, 3,4 e 5 precisaram para atingir seu desempenho máximo (em \% de acertos) nos quizes da atividade 5 .

Fonte: próprio autor 
O grupo 1 e o grupo 3 tiveram o mesmo comportamento e a após duas rodadas atingiram os $100 \%$ no quiz. O grupo 2 precisou de quatro rodadas para atingir os $100 \%$. O grupo 4 e o 5 precisaram de três rodadas para atingir os $100 \%$.

Grupos 6 a 10

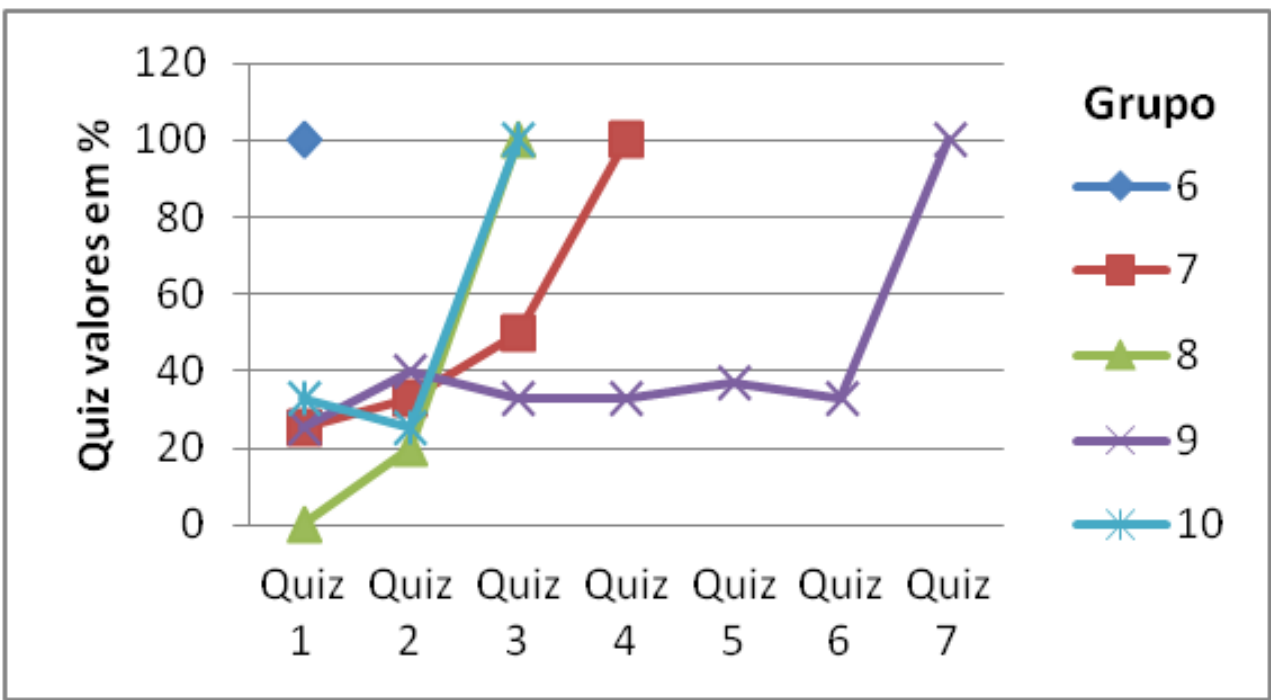

Gráfico 6- Número de "rodadas" que os grupos 6, 7, 8, 9 e 10 precisaram para atingir seu desempenho máximo (em \% de acertos) nos quizes da atividade 5.

Fonte: próprio autor

O grupo 6 atingiu 100\% na primeira rodada. Atingiram o 100\% de desempenho, o grupo 7 após 4 rodadas, o grupo 8 e o 10 após 3 rodadas. $\mathrm{O}$ grupo 9 precisou de 7 rodadas para atingir os $100 \%$.

Parte II:

Grupos 1 a 5 


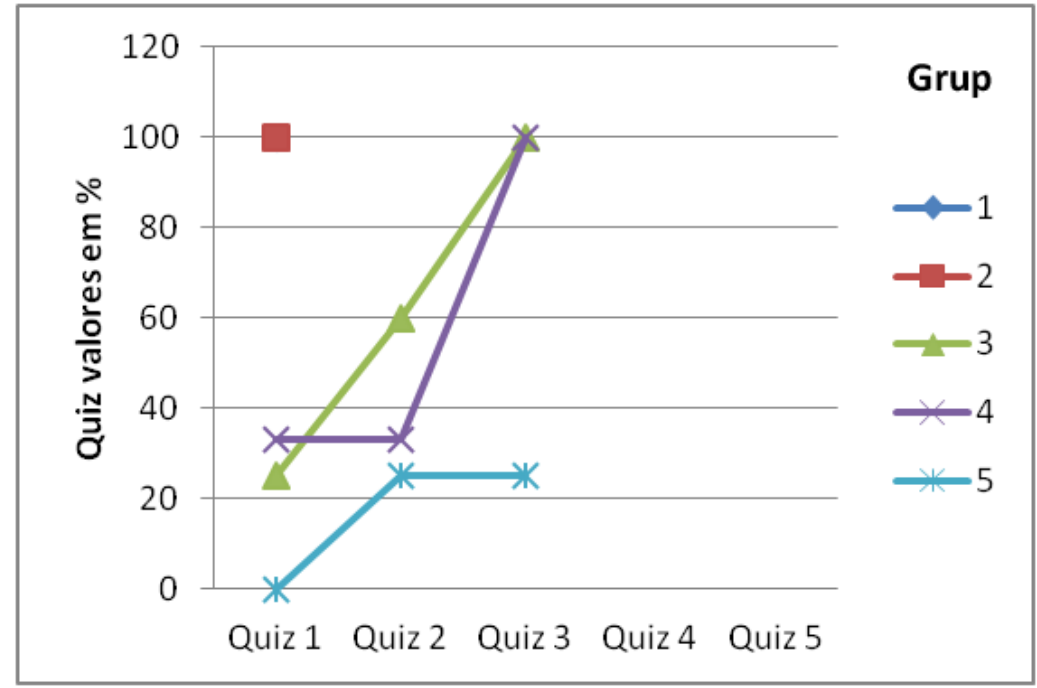

Gráfico 7 - Número de "rodadas" que os grupos 1, 2, 3, 4 e 5 precisaram para atingir seu desempenho máximo (em \% de acertos) nos quizes da atividade 5 (parte II).

Fonte: próprio autor

O grupo 1 e o grupo 2 atingiram os $100 \%$ na primeira rodada. Os grupos 3 e 4 atingiram os $100 \%$ após 3 rodadas. O grupo 5 interrompeu sua atividade depois de 3 rodadas, e atingiu apenas $20 \%$.

Grupos 6 a 10

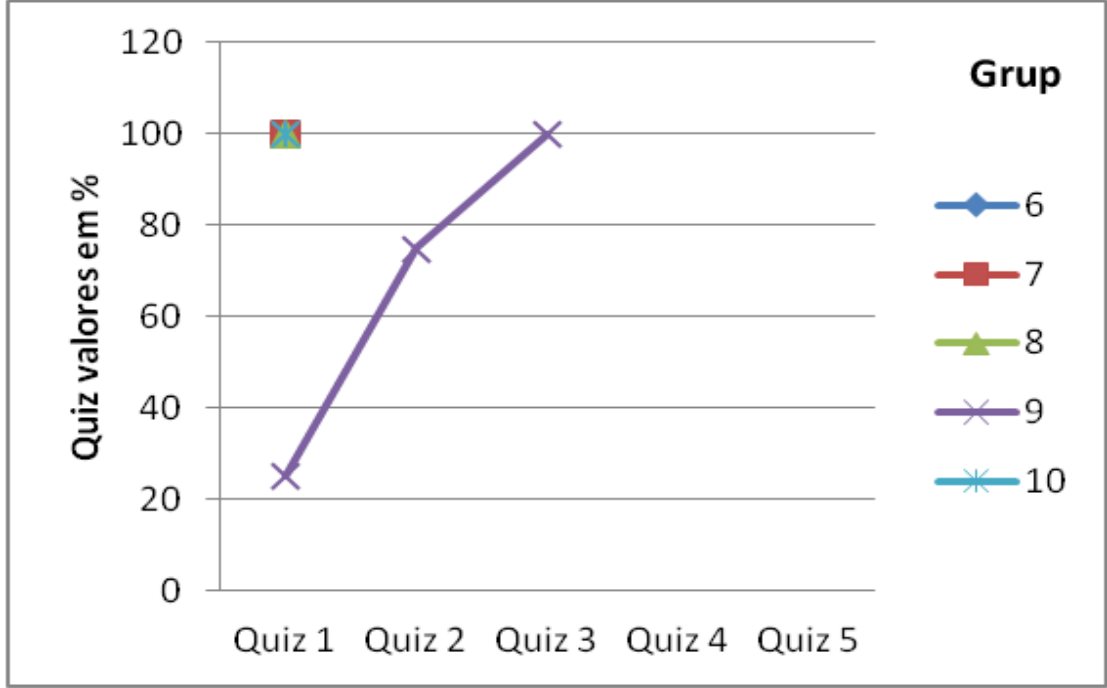

Gráfico 8- Número de "rodadas" que os grupos 6, 7, 8, 9 e 10 precisaram para atingir seu desempenho máximo (em \% de acertos) nos quizes da atividade 5 (parte II).

Fonte: próprio autor 
Os grupos 6,7, 8 e 10 atingiram os $100 \%$ na primeira rodada. Já o grupo 9 precisou de 3 rodadas para atingir os $100 \%$.

Nesta atividade, foi usado um modelo com cadeias causais menos complexas, porém com mais associações entre entidades e variáveis. O modelo completo foi dividido em dois modelos parciais, sendo o primeiro com metade das entidades e variáveis e o segundo, o modelo completo. Porém, os alunos só tiveram acesso a este modelo após conseguirem atingir os $100 \%$ no modelo parcial.

Foi interessante observar o comportamento dos alunos nesta etapa. Mostraram-se bastante motivados e interessados. Ao atingirem os $100 \%$ de desempenho no primeiro modelo, sentiram-se motivados e confiantes para iniciarem a modelagem do modelo completo. Todos os grupos atingiram os $100 \%$ de desempenho na primeira parte do modelo. Trabalhando com o modelo completo, praticamente todos os grupos atingiram os $100 \%$ de desempenho, ora na primeira rodada, ora de maneira progressiva, pois apenas um grupo não atingiu os $100 \%$ de desempenho nesta etapa.

Os resultados mostram que houve uma melhora sucessiva no número de grupos que concluíram os modelos a cada nova atividade realizada e também no número de modelos completos, produzidos por cada grupo.

Fica evidente que os alunos melhoraram o desempenho e a aprendizagem a cada nova atividade com o uso do TA. Essa observação confirma que, quanto maior a experiência dos alunos com a modelagem apoiada pelo TA, melhores são os desempenhos apresentados no quiz e, consequentemente, maior a aprendizagem sobre o funcionamento de sistemas (ver os resultados dos testes abaixo).

Os alunos montavam seus modelos e, com o intuito de verificar se seu raciocínio estava correto, consultavam o agente aprendiz virtual. Desta forma, o aluno poderia refletir sobre seu raciocínio e sobre o comportamento das variáveis adicionadas ao modelo. É uma maneira de fazer um autoteste. Caso o aluno não soubesse o significado de suas próprias ações de modelagem, recebia um "feedback" da máquina a este respeito. Ao consultarem o quiz, os alunos puderam identificar acertos e erros. Os acertos claramente os motivavam. Poderia ter ocorrido que se desmotivassem com os erros, mas esse efeito negativo foi amenizado pelo fato de os alunos atribuírem os erros ao seu agente aprendiz virtual e não a si próprios. A partir dos erros, os alunos conversavam entre si, pesquisavam nos textos, reliam, pensavam refletiam e assim retornavam aos seus modelos, 'ensinando' novamente novos conteúdos ao agente aprendiz virtual e consequentemente consultavam novamente o quiz. 


\subsection{Análises estatísticas dos estudos comparativos}

Análises estatísticas em relação aos testes foram feitas utilizando-se o teste $t$ de Student (cálculo de $t$ ) e o teste não paramétrico de Wilcoxon (cálculo de $v$ ), e os resultados foram resumidos e apresentados nas Tabelas 01 e 02 . Abaixo de cada tabela serão feitas algumas análises.

\section{Análise dos resultados dos pré-testes x pós-testes}

A hipótese, na Atividade 1, era a de que haveria diferença significativa, causada pela atividade de modelagem (além da leitura de texto). Caso a modelagem não fizesse efeito, não haveria diferença significativa entre os resultados dos dois testes, e as hipótese nula seria aceita.

Nas atividades 2, 3 e 5, a hipótese era a de que o tratamento representado pelo uso do TA (além da leitura e da própria atividade de modelagem) deveria ter algum efeito nos resultados medidos pelos testes. Caso a modelagem com o TA não fizesse efeito, não haveria diferença significativa entre os resultados obtidos nos pre e pós-testes, em cada atividade.

A Tabela a seguir mostra os resultados obtidos nessas comparações.

Tabela 01 : Resultados dos testes estatísticos aplicados à amostra de alunos em relação ao pré teste x pós-teste dentro de cada uma das Atividades 1( sem uso do TA), 2, 3 e 5 (com uso do TA).

\begin{tabular}{|c|c|c|c|c|}
\hline \multirow{2}{*}{ Atividade } & \multicolumn{2}{|c|}{ Valores de $t$ e $v$, e de $p$} & \multirow{2}{*}{ Significância } & \multirow{2}{*}{ Efeitos da modelagem } \\
\hline & t de Student & Wilcoxon & & \\
\hline 1 & $\begin{array}{l}\mathrm{t}=2,97 \\
\mathrm{p}<0,01\end{array}$ & $\begin{array}{l}\mathrm{v}=43,5 \\
\mathrm{p}<0,01\end{array}$ & $S$ & $\begin{array}{c}\text { A modelagem fez } \\
\text { diferença. }\end{array}$ \\
\hline 2 & $\begin{array}{l}t=2,15 \\
p<0,05\end{array}$ & $\begin{array}{l}\mathrm{v}=72,5 \\
\mathrm{p}<0,05\end{array}$ & S & \multirow{3}{*}{$\begin{array}{l}\text { A modelagem com } \\
\text { TA fez diferença. }\end{array}$} \\
\hline 3 & $\begin{array}{l}\mathrm{t}=3,65 \\
\mathrm{p}<0,01\end{array}$ & $\begin{array}{l}\mathrm{v}=30 \\
\mathrm{p}<0,01\end{array}$ & $\mathrm{~S}$ & \\
\hline 5 & $\begin{array}{l}t=4,08 \\
p<0,001\end{array}$ & $\begin{array}{c}v=3 \\
p<0,01\end{array}$ & AS & \\
\hline
\end{tabular}

* $\mathrm{S}=$ Significativo/ AS = Altamente significativo 
A análise estatística dos resultados obtidos em todos os testes nos permitiu rejeitar $\mathrm{H} 0$ e aceitar H1, ou seja, concluir que há diferenças significativas entre os resultados obtidos entre os respectivos pré-teste e pós-teste.

A análise da Atividade 1 mostrou que o uso da modelagem qualitativa resultou em diferenças significativas na melhora o desempenho dos alunos em relação à leitura de textos.

A análise das Atividades 2, 3 e 5, mostrou que o uso da modelagem qualitativa com o apoio do TA também tem efeito positivo significativo em relação ao desempenho dos alunos em relação à leitura de textos.

\section{Análise comparada dos resultados dos pós-testes de diferentes atividades}

Nesta seção, o objetivo é verificar se confirma-se que hipótese de que o uso do TA produz resultados significantemente melhores que o uso de modelos sem o TA. Para isso, comparam-se os resultados dos pós-testes das atividades 1,2,3,5. Conforme explicado anteriormente, o tratamento adotado na Atividade 1 foi a combinação de [leitura + modelagem], e nas demais Atividades $(2,3,5)$, o tratamento adotado incluiu o apoio do agente aprendiz [leitura + modelagem + TA] . Para essa comparação, parte-se do pressuposto de que as condições iniciais nas quatro atividades analisadas não eram significativamente diferentes ${ }^{2}$.

Na Tabela 02, são apresentadas as análises estatísticas das comparações entre pósteste da Atividade 1 x pós-teste da Atividade 2; pós-teste da Atividade 1 x pós-teste da Atividade 3; e pós-teste da Atividade 1 x pós-teste da Atividade 5.

Tabela 02 : Resultados dos testes estatísticos aplicados à amostra de alunos em comparações entre o pós-teste da Atividade 1 x pós-teste das Atividades 2, 3 e 5.

\begin{tabular}{|c|c|c|c|c|}
\hline \multirow{2}{*}{ Atividade } & \multicolumn{2}{|c|}{ Valores de $t$ e $v$, e de $p$} & \multirow{2}{*}{ Significância } & \multirow{2}{*}{$\begin{array}{c}\text { Efeitos da } \\
\text { modelagem }\end{array}$} \\
\hline & $\mathrm{t}$ de Student & Wilcoxon & & \\
\hline 2 & $\begin{aligned} t & =5,88 \\
P & <0,001\end{aligned}$ & $\begin{array}{c}\mathrm{v}=9,5 \\
\mathrm{p}<0,001\end{array}$ & AS & \multirow{3}{*}{$\begin{array}{l}\text { O trabalho com o TA, } \\
\text { além da leitura e da } \\
\text { modelagem, fez uma } \\
\text { diferença significativa. }\end{array}$} \\
\hline 3 & $\begin{array}{c}t=6,73 \\
p<0,001\end{array}$ & $\begin{array}{c}\mathrm{v}=8 \\
\mathrm{p}<0,001\end{array}$ & $\mathrm{AS}$ & \\
\hline 5 & $\begin{array}{c}\mathrm{t}=8,59 \\
\mathrm{p}<0,001\end{array}$ & $\begin{array}{c}\mathrm{v}=210 \\
\mathrm{p}<0,001\end{array}$ & AS & \\
\hline
\end{tabular}

$* \mathrm{~S}=$ Significativo/ AS $=$ Altamente significativo

\footnotetext{
${ }^{2}$ Com efeito, foram feitas análises estatísticas comparando os resultados do pré-teste da Atividade 1 x pré-teste da Atividade 2; do pré-teste da Atividade 1 x pré-teste da Atividade 3; e do pré-teste da Atividade 1 x pré-teste da Atividade 5. Em todos os casos, não se registraram diferenças significativas.
} 
Os dados obtidos nas análises estatísticas acima nos permitem rejeitar $\mathrm{H} 0$ e aceitar $\mathrm{H} 1$, ou seja, as diferenças são altamente significativas. Portanto, podemos concluir que, de acordo com os testes realizados, a aplicação do TA produziu resultados significativamente melhores que a modelagem sem o apoio do TA realizada na Atividade 1.

Reunidos os resultados mostrados nas Tabelas 01 e 02 , concluímos que os resultados obtidos a partir dos experimentos realizados nas Atividades 1,2,3 e 5 indicam que a atividade de modelagem produz resultados significantes sobre a atividade isolada de leitura compreensão dos sistemas estudados (Atividade 1). Além disso, as demais atividades mostraram que o uso do TA produziu resultados significantes melhores do que aqueles obtidos com a modelagem, sem o Agente Aprendiz.

\section{5- CONSIDERAÇÕES FINAIS}

Neste trabalho, foram obtidas evidências que sustentam a hipótese de que o uso de modelos qualitativos, apoiados por agentes aprendizes virtuais, contribui para motivar os alunos a continuar as tarefas de modelagem. Os alunos sentiram que realmente estavam ensinando seus Pets. Estes agentes foram ensinados pelos alunos e aplicaram os conhecimentos 'adquiridos' ao se submeterem ao quiz. Desta forma, os agentes aprendizes virtuais foram capazes de despertar nos estudantes a responsabilidade pela aprendizagem destes agentes e pelo desempenho dos mesmos no quiz. Os alunos demonstraram aumento no interesse e capacidade em relação à extração de informações relevantes de textos com intervenções mínimas da professora ou do pesquisador, a partir dos feedbacks recebidos do software (obtidos principalmente pela interação dos estudantes com o seu agente aprendiz virtual).

O software educacional utilizado neste trabalho foi bem aceito pela professora e alunos pesquisados, como bancada exclusiva para os trabalhos de modelagem apoiada pelo uso de agentes virtuais nas atividades exigidas. Nas atividades de modelagem com uso dos agentes aprendizes virtuais, os alunos tiveram acesso a um registro do desempenho de seus Pets nos quizes, em forma de relatório. Pelas respostas corretas, mostradas por este relatório, os alunos sentiram-se motivados a continuar trabalhando. A partir das respostas erradas, puderam se preparar melhor, retornando à leitura dos textos base, para 'ensinar' melhor o agente aprendiz virtual, antes de submeterem seus Pets a novas rodadas de perguntas. Essa é a 
aplicação do princípio da representação compartilhada (LEELAWONG \& BISWAS, 2008), já que os estudantes tiveram uma visão panorâmica das atividades desenvolvidas no ambiente virtual. Puderam ver como seus agentes virtuais descobrem as respostas e como organizam seu conhecimento, por meio dos modelos qualitativos produzidos. Dessa forma, puderam 'visualizar' o raciocínio envolvido nas atividades de modelagem.

Este trabalho apresenta também uma análise do uso de modelos formais como material didático, em uma sequência de ações pedagógicas desenvolvidas com uma turma de $8^{\circ}$ ano do Ensino Fundamental. Foram realizados experimentos controlados com o objetivo de testar hipóteses sobre os efeitos da modelagem apoiada por agentes aprendizes virtuais na contribuição da compreensão dos sistemas em estudo. As respostas obtidas nos testes e os depoimentos dos alunos permitem concluir que os modelos utilizados traduziram os fenômenos modelados de maneira simples, o que facilitou a compreensão e aumentou a motivação dos alunos. A atividade 1 oferece suporte para a hipótese de que a prática da modelagem produz resultados melhores do que a leitura de textos no aprendizagem de conceitos. Além disso, as atividades 2, 3 e 5 indicam que a modelagem apoiada por agentes aprendizes virtuais produziu melhores resultados na compreensão sobre sistemas do que se os alunos estivessem modelando sem o apoio destes agentes. Essa foi também a percepção da professora que acompanhou os trabalhos na escola.

O uso de DynaLearn teve grande aceitação por parte da professora que conduziu a turma e dos alunos. Em depoimento, a professora considerou que o curso e a atividade desenvolvidas foram muito boas, a tarefa de modelagem era fácil para seus alunos, que a experiência de trabalhar com o software foi muito interessante e que a estrutura e o funcionamento dos sistemas, com o apoio de modelos e modelagem, foram de fácil entendimento.

Os alunos também avaliaram de forma positiva a preparação e a execução de atividades de modelagem realizadas e a aprendizagem mediada por modelos qualitativos e por agentes aprendizes virtuais. Apesar de consideram de nível intermediário o grau de dificuldade para lidar com modelos qualitativos, mais de $90 \%$ deles considerou interessante ou muito interessante a experiência que tiveram com o DynaLearn, e concorda que essas atividades abriram novas maneiras de pensar sobre sistemas complexos.

Tanto professora como estudantes consideraram que modelagem e uso de agentes aprendizes virtuais poderiam ser aplicados a outras disciplinas. Essa abordagem foi considerada inovadora, interessante, estimulante para o pensamento causal e motivadora para aprender mais sobre os fenômenos estudados. 
O objetivo principal deste trabalho foi alcançado: foi formulado e apresentado (em anexo) uma proposta de intervenção pedagógica no ensino de Ciências para alunos do $8^{\circ}$ ano do Ensino Fundamental, baseada em material didático construído a partir de modelos qualitativos apoiados por agentes aprendizes virtuais. Os materiais didáticos necessários para a elaboração da proposta foram elaborados e implementados. Foi verificado os efeitos da modelagem qualitativa apoiada por agentes aprendizes virtuais sobre a compreensão da estrutura e da dinâmica de sistemas biológicos e sobre a motivação de alunos. Foram coletadas as opiniões da professora de Ciências da turma e dos alunos sobre diversos aspectos do uso dos modelos qualitativos apoiados por agentes aprendizes virtuais.

Salienta-se que os bons resultados apresentados pela pesquisa não devem ser atribuídos tão somente a introdução de uma nova ferramenta pedagógica ou abordagem nas aulas de Ciências. O empenho dos pesquisadores e da professora no preparo dos materiais, do ambiente e das estratégias a serem utilizadas, assim como dos modelos e na própria preparação em relação aos conhecimentos necessários para uma pesquisa desta natureza foram fatores muito relevantes para o sucesso da pesquisa e criação da proposta de intervenção didática que será apresentada em documento separado.

Apesar dos resultados gerais terem sido positivos, diversas limitações para o uso dos agentes aprendizes virtuais foram verificadas nas condições da presente pesquisa. Primeiramente, foi observado que o uso de recursos baseados em tecnologia inteligente era algo distante da realidade dos alunos da escola pesquisada. A modelagem qualitativa e o DynaLearn eram totalmente desconhecidas de todos. A pouca familiaridade dos alunos em relação aos conhecimentos básicos de computação foi verificada em diversas atividades, tais como no registro e na organização das imagens que representavam as interações e desempenho dos alunos com os agentes virtuais. Com efeito, o laboratório de informática da escola era equipado com computadores com um sistema operacional livre (o Linux educacional). O uso de software livre reduz os custos do laboratório, pois não são exigidas taxas de licença para uso e manutenção. Mas, por outro lado, os diversos softwares livres não são compatíveis com vários recursos com os quais a maioria dos usuários de computador está acostumada a usar (o sistema operacional mais difundido e com maior compatibilidade em relação aos diversos softwares de uso rotineiro no nosso país, inclusive com o DynaLearn, é o Windows da Microsoft).

O número de alunos por turma (40 matriculados em média) fica bem acima do ideal para o desenvolvimento de trabalhos didáticos, considerando-se a estrutura e calendário sobrecarregado de uma escola pública. O sistema de tradução do TA no DynaLearn é falho 
para a língua portuguesa, o que causou estranhamento nos alunos, particularmente no início das atividades. O currículo da disciplina de ciências é muito extenso. Conseguir encaixar as aulas com o uso da modelagem qualitativa e os agentes aprendizes virtuais, mesmo abordando o conteúdo curricular planejado pela professora, não foi tarefa fácil. A escola conta com um calendário estreito para dar conta de tantos compromissos, dentre os quais, passeios, eventos, torneios esportivos, reuniões, além dos recessos e feriados.

Seria interessante que os trabalhos pudessem ser feitos de forma a permitir maior tempo de exposição e contato dos alunos com as práticas de modelagem apoiadas por agentes aprendizes virtuais. Deste modo, trabalhos que visem dar apoio ao crescimento das habilidades e práticas de aprendizagem independente, em que os alunos criem seus próprios modelos apoiados por agentes virtuais, poderão ser explorados futuramente. Práticas como essa poderão confirmar os resultados obtidos no presente estudo, e ampliar as possibilidades da modelagem qualitativas, pouco exploradas aqui, como, por exemplo, a capacidade de levar os alunos a criarem seus próprios modelos.

O uso do agente aprendiz no DynaLearn, atualmente, só é possível no nível LS2, o que traz uma série de limitações de recursos de modelagem. Permite a visualização de apenas um estado, ou seja, não possibilita a visualização de sequência de estados, o que tornaria a análise da dinâmica de sistemas mais interessante e produtiva. Não permite o trabalho com noção de magnitude, ou seja, a diferenciação entre os limites das quantidades (pequeno, médio, grande, por exemplo). Não permite o uso do conhecimento condicional (em que alguns fatos modelados só são aceitos sobre certas condições). Mostra somente mecanismos de retroalimentação reforçadora (em que uma entidade A influencia positivamente ou negativamente uma entidade $\mathrm{B}$, e este efeito afeta a entidade A novamente, ampliando o efeito da influência de origem). A retroalimentação balanceadora, em que o efeito propagado por uma entidade origem retorna para a mesma, com uma influência oposta ao que foi propagado, não pode ser explorado neste nível (por exemplo, uma influência positiva propagada por uma variável A para a variável B pode retornar para a mesma, propagada por B, como uma influência negativa, o que levaria o sistema ao equilíbrio).

No presente trabalho, não foi explorado o papel do "professor", o Mr. Davis, pois esta funcionalidade não era relevante para a pesquisa aqui desenvolvia, mas poderá vir a ser tema de pesquisas realizadas em trabalhos futuros. Também seria interessante a exploração do potencial da modelagem apoiada por agentes virtuais como instrumento de avaliação.

Trabalhos futuros dos desenvolvedores do DynaLearn poderiam incluir os agentes aprendizes virtuais em níveis mais avançados. O ideal seria a disponibilização desta 
tecnologia em todos os níveis, ou pelo menos no nível LS4, para a realização de trabalhos de modelagem mais aprofundados e que possam chegar mais próximos da realidade dos sistemas modelados, com a exploração de mais de um estado, da noção de magnitude, do conhecimento condicional e dos mecanismos de retroalimentação balanceadores.

Os alunos se sentiram mais motivados para o estudo dos conceitos de ciências, e a professora considerou muito produtivo o uso de agentes aprendizes virtuais para seu trabalho docente. As contribuições decorrentes das atividades e experiências aqui descritas foram reunidas na formulação de uma proposta de intervenção pedagógica, objetivo principal do presente trabalho, apresentada como material suplementar desta Dissertação: Proposta Metodológica para a Utilização de Agentes Aprendizes Virtuais como Ferramenta de Ensino. 


\section{REFERÊNCIAS BIBLIOGRÁFICAS}

\section{ALVES, F. B. RACIOCÍNIO QUALITATIVO COMO FERRAMENTA PARA O DESENVOLVIMENTO DE RACIOCÍNIO HIPOTÉTICO DEDUTIVO EM ALUNOS}

SURDOS. 2015. Dissertação (Mestrado) (em elaboração) - Curso de Programa de Pós Graduação em Ensino de Ciências, Universidade de Brasília, Brasília-DF, 2015.

BASTOS, R.C.G.. INTRODUÇÃO À DINÂMICA DE SISTEMAS: proposta de disciplina a distância para curso de licenciatura em biologia, com uso de modelos qualitativos. 2014. $119 \mathrm{f}$. Dissertação (Mestrado) - Curso de Programa de Pós Graduação em Ensino de Ciências, Universidade de Brasília, Brasília-DF, 2014.

BOSSEL, H. (1986) Ecological systems analysis: An introduction to modelling and simulation. Kassel, Germany, German Foundation for International Development, DSE; Food and Agriculture Development Centre, ZEL.

BREDEWEG, B.; LIEM, J.; BEEK, W.; LINNEBANK, F.; GRACIA, J.; LOZANO, E.; WIßNER, M.; BÜHLING, R.; SALLES, P.; NOBLE, R.; ZITEK, A.; BORISOVA, P.; MIODUSER, D. (2013). DynaLearn - An Intelligent Learning Environment for Learning Conceptual Knowledge. AI Magazine, 34 (4): 46-65.

CHIN, D.B.; DOHMEN, I.M.; SCHWARTZ, D.L. Young Children Can Learn Scientific Reasoning with Teachable Agents. IEEE Transactions On Learning Technologies, USA, v. 6, n. 03, p.248257, jul. 2013. Trimestral.

DORNAS, W.C.; OLIVEIRA, T.T.; AUGUSTO, L.E.F.; NAGEM, T.J. Aterosclerose Experimental em Coelhos. Arquivos Brasileiros de Cardiologia, Minas Gerais, n. 95, p.272-278, 2010.

FALCÃO, J.T.R.; RÉGNIER, Jean Claude. Sobre os métodos quantitativos na pesquisa em ciências humanas: riscos e benefícios para o pesquisador. Revista Brasileira de Estudos Pedagógicos, Brasília, v. 81, n. 198, p.229-243, maio 2000.

FELTRINI, G.M. Aplicação de Modelos Qualitativos à Educação Científica de Surdos. 2009. 221 f. Dissertação (Mestrado) - Curso de Programa de Pós Graduação em Ensino de Ciências, Universidade de Brasília, Brasília-DF, 2009.

FORBUS, K. (1984) Qualitative Process Theory. Artificial Intelligence 24: 85-168.

GIL, A. C. Como elaborar projetos de pesquisa. 4. ed. São Paulo: Atlas, 2002.

GIL, A.C. Métodos e técnicas de pesquisa social. São Paulo: Atlas, 1999.

JOHNSON, W.L.; RICKEL, W.J.; LESTER, J.C. Animated Pedagogical Agents: Face-to-Face Interaction in Interactive Learning Environments. International Journal Of Artificial Intelligence In Education, v. 11, n. 1, p.47-78, 2000.

LAVILLLE, C., DIONNE, J. A construção do saber: manual de metodologia da pesquisa em ciências humanas. Tradução Heloisa Monteiro e Francisco Settineri.-Porto Alegre: Artmed; Belo Horizonte: Editora UFMQ 1999. Reimpressão 2008. 
LEELAWONG, K.; BISWAS, G. Designing Learning by Teaching Agents: The Betty's Brain System. International Journal of Artificial Intelligence in Education, USA, v. 18, n. 3, p.181-208, out. 2008.

MARCONI, M. de A.; LAKATOS, E. M. Fundamentos de metodologia científica. 5. ed. São Paulo: Atlas, 2003.

MEHLMANN, G., HÄRING, M., BÜHLING, R., WIßNER, M., and ANDRÉ, E. (2010). Multiple Agent Roles in an Adaptive Virtual Classroom Environment. Allbeck, J., Badler, N., Bickmore, T., Pelachaud, C., and Safonova A. (eds.). In: Lecture Notes in Computer Science, Volume 6356, 2010, DOI: 10.1007/978-3-642-15892-6. Intelligent Virtual Agents, 10th International Conference, IVA 2010, pp. 250-256, Philadelphia, PA, USA, September 20-22, 2010. Proceedings.

MIODUSER, D.; ZUZOVSKY, R.; SALLES, P.; SOUZA, A.; PORTELLA, A.; BRAGA, E.; WILHELMS, L.; RESENDE M,P..; Morison, G.; SILVA, P.A.C..; SÁ, I.G.; PIRES, L.; SIMÕ̃ES, A.; NOBLE, R., COWX, I., BORISOVA, P., LIEM, J., UZUNOV, Y., ZUREL, D., LEIBA, M., BENAYAHU, H., NACHMIAS, R., RAM J., ZITEK, A., POPPE, M. \& STELZHAMMER, M. (2012). Final report on DynaLearn evaluation studies. DynaLearn, EC FP7 STREP project 231526, Deliverable D7.4.

MOREIRA, M. A. Pesquisa em Ensino: Aspectos Metodológicos. Adaptado do capítulo 2 do livro "Pesquisa em ensino: o Vê epistemológico de Gowin", de M. A. Moreira. São Paulo: Pedagógica e Universitária Ltda, 1990. Texto de Apoio n. 19 do Programa Internacional de Doutorado em Ensino de Ciências da Universidade de Burgos, Espanha, em convênio com a UFRGS, 2003.

NÓVOA, A. Os Professores na Virada do Milênio: do excesso dos discursos à pobreza das práticas. Revista Educação e Pesquisa, São Paulo, v.25, n.1, p.11-19,1999.

\section{RESENDE, M.M.P. AVALIAÇÃO DO USO DE MODELOS QUALITATIVOS COMO} INSTRUMENTO DIDÁTICO NO ENSINO DE CIÊNCIAS PARA ESTUDANTES SURDOS E OUVINTES. 2010. 162 f. Dissertação (Mestrado) - Curso de Programa de Pós Graduação em Ensino de Ciências, Universidade de Brasília, Brasília-DF, 2010.

SPIEGEL, M.. Estatística. 3. ed. São Paulo: Makron Books, 1994. 660 p. Tradução de Pedro Cosentino.

SALLES, H.; SALLES, P.; BREDEWEG, B. Qualitative reasoning in the education of deaf students: scientific education and acquisition of Portuguese as a second language. In: Forbus, K. \& de Kleer, J. (eds.) Proceedings of the 18th International Workshop on Qualitative Reasoning $(Q R$ ' 04$)$, pages 97-104, Evanston, Illinois, August, 2-4, 2004.

SALLES, P.; LIMA-SALLES, H.; BREDEWEG, B. (2005) The Use of Qualitative Reasoning Models of Interactions Between Populations to Support Causal Reasoning of Deaf Students. In Looi, C.-K.; McCalla, G.; Bredeweg, B. \& Breuker, J. (eds.) Artificial Intelligence and Education: Supporting learning through Intelligent and Socially Informed Technology. Amsterdam, IOS Press / Omasha, pp. 579-586, 2005.

SALLES, H. (Org.). Bilinguismo e surdez. Questões linguísticas e educacionais. Goiânia: Cânone Editorial, 2007.

SALLES, P. and BREDEWEG, B. 2006. Modelos conceituais baseados em Raciocínio Qualitativo. Proceedings of the Workshop Informática e Aprendizagem em Organizações, G.M. da Nóbrega (ed.), pages 1-11, Brasília, Brazil, 9 November, 2006. 
TRIVIÑOS, A. N. S. Introdução à pesquisa em ciências sociais: a pesquisa qualitativa em educação. São Paulo: Atlas S.A, 1990.

VALENTE, J.A.: O uso inteligente do computador na educação, in Pátio, Ano 1, n. ${ }^{\circ}$, Ed. Artes Médicas Sul, pp. 19-21, 1997.

WIßNER, M.; HÄRING, M.; BÜHLING, R.; BEEK, W.; LINNEBANK, F.; LIEM, J.; BREDEWEG, B. \& ANDRÉ, E. Basic Help and Teachable Agent. DynaLearn, EC FP7 STREP project 231526, Deliverable D5.3, 2010.

YIN, R.K.. ESTUDO DE CASO: PLANEJAMENTO E MÉTODOS. 2. ed. Porto Alegre: Bookman, 2001. 207 p. Tradução de Daniel Grassi.

ZHAO, G.; AILIYA; SHEN, Zhiqi. Learning by Teaching: Designing Teachable Agents with Intrinsic Motivation. Educational Technology \& Society, v. 15, n. 4, p.62-74, out. 2012. 


\section{APÊNDICE A - Questionários:}

a) Questionário de atitudes/motivação (aplicado à professora A)

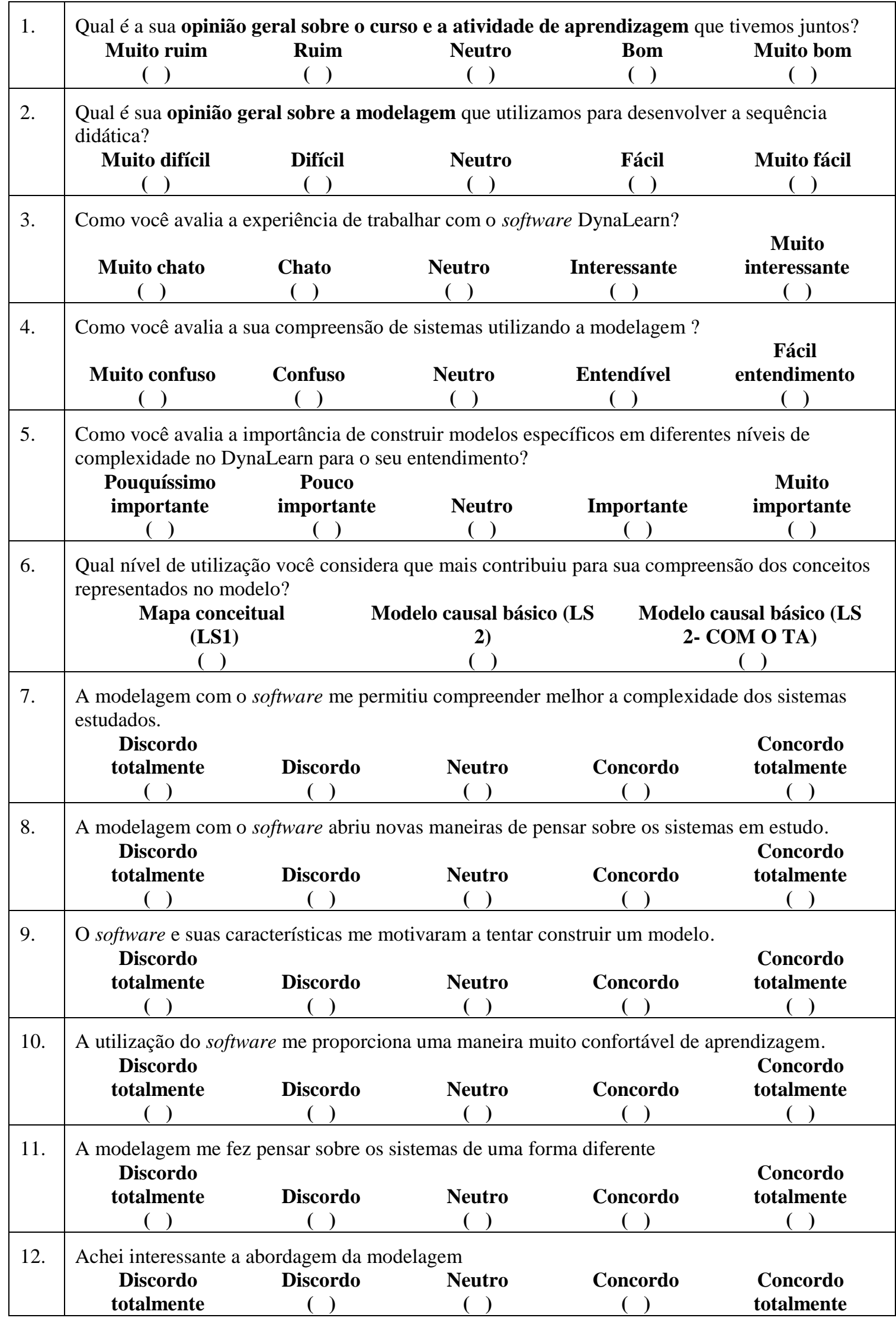




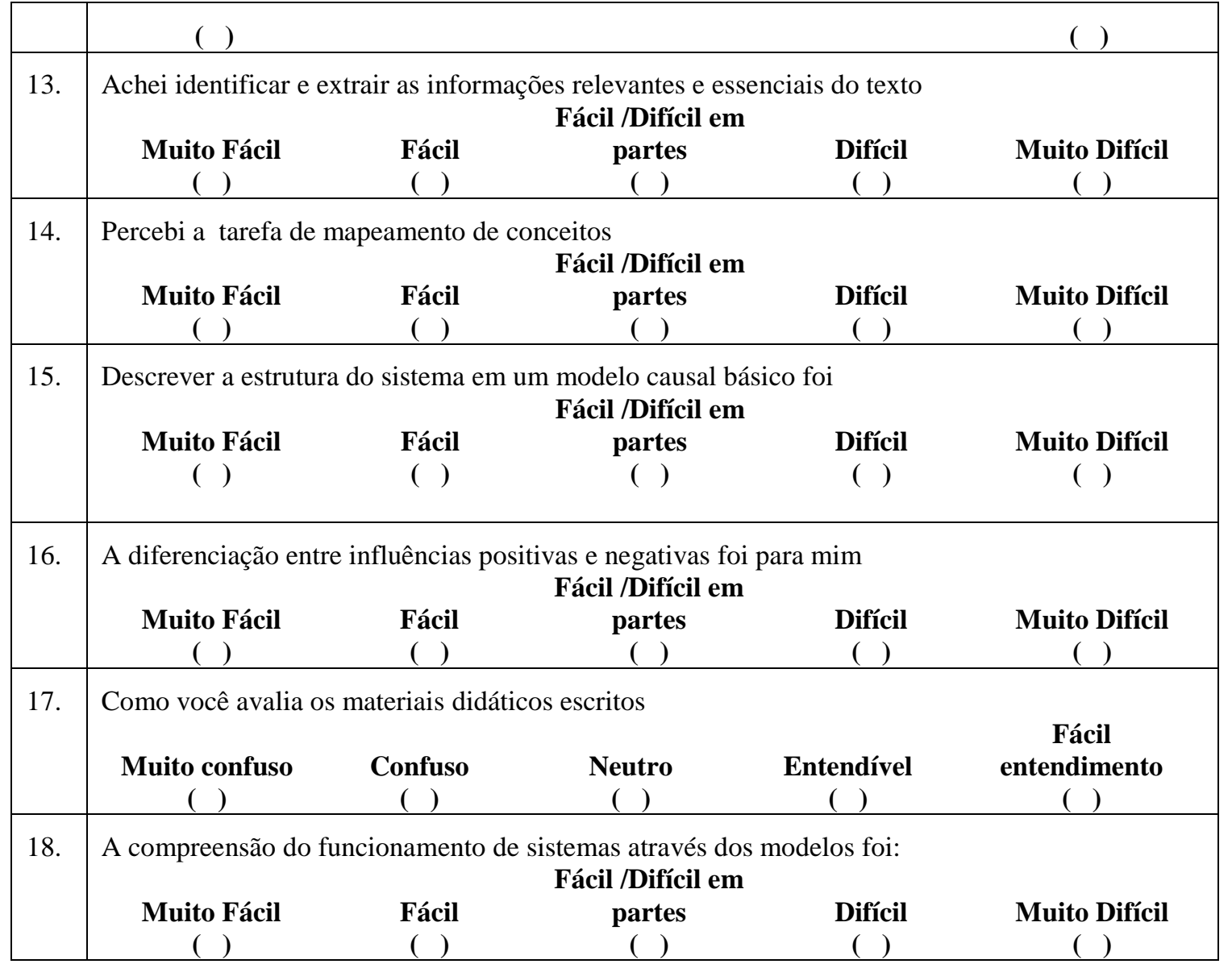

\section{b) Questionário de atitudes/motivação (aplicado aos alunos)}

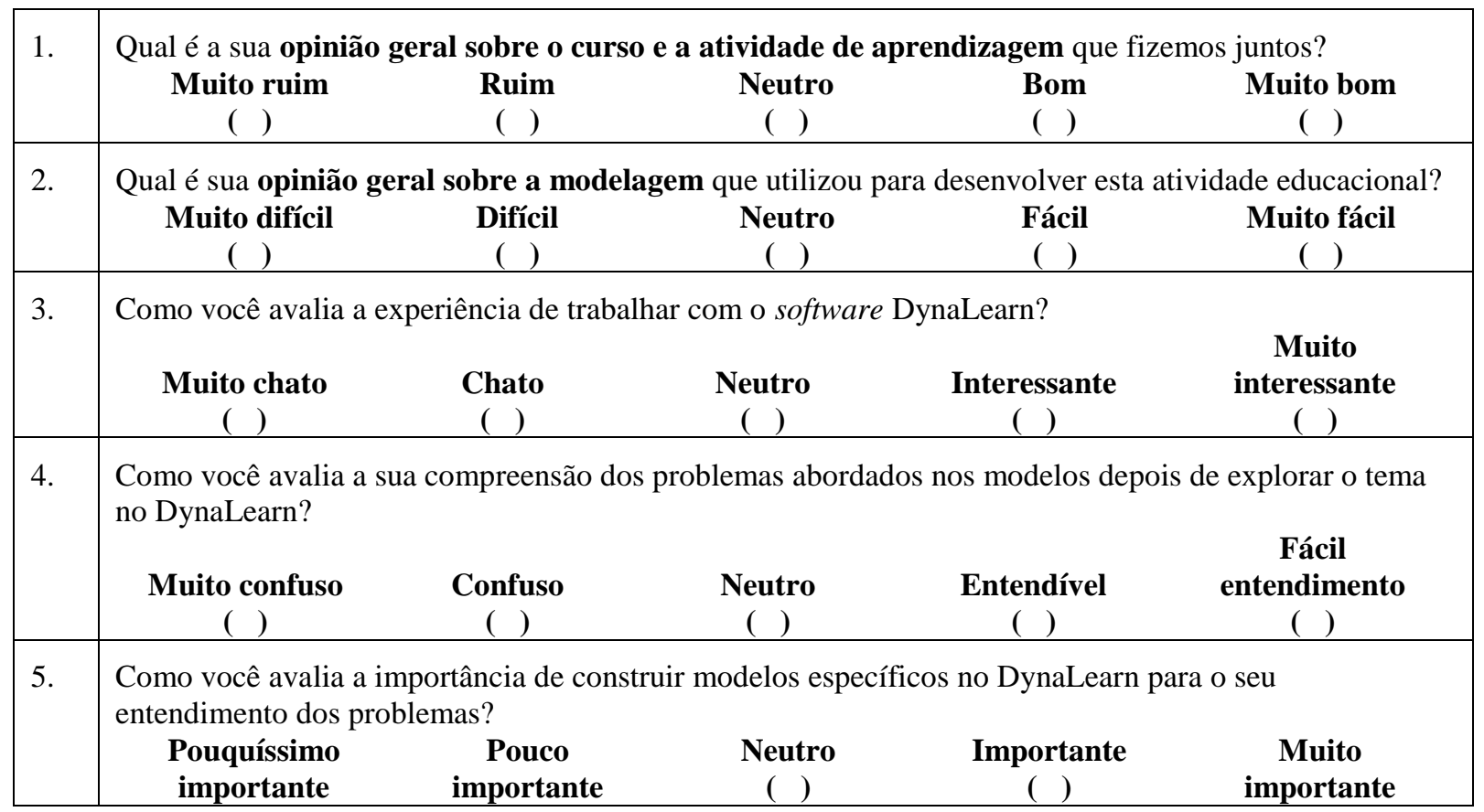




\begin{tabular}{|c|c|c|c|}
\hline & $($ ) & & $($ ) \\
\hline 6. & $\begin{array}{l}\text { A modelagem com o software me permiti } \\
\text { Discordo } \\
\text { totalmente } \\
(()\end{array}$ & $\begin{array}{l}\text { preender melhor a complexidade } \\
\text { Neutro } \\
(\quad)\end{array}$ & $\begin{array}{l}\text { temas estudados. } \\
\text { Concordo } \\
\text { totalmente } \\
(\quad)\end{array}$ \\
\hline 7. & $\begin{array}{l}\text { A modelagem com o software abriu nova } \\
\text { Discordo } \\
\text { totalmente } \\
(()\end{array}$ & $\begin{array}{l}\text { eiras de pensar sobre os sistemas. } \\
\text { Neutro } \\
(\text { Concordo }\end{array}$ & $\begin{array}{c}\text { Concordo } \\
\text { totalmente } \\
(\text { ( ) }\end{array}$ \\
\hline 8. & $\begin{array}{l}\text { O software e suas características me moti } \\
\text { Discordo } \\
\text { totalmente } \\
(()\end{array}$ & $\begin{array}{l}\text { a tentar construir um modelo. } \\
\text { Neutro } \\
(()\end{array}$ & $\begin{array}{c}\text { Concordo } \\
\text { totalmente } \\
(\quad)\end{array}$ \\
\hline 9. & $\begin{array}{l}\text { A utilização do software me proporciona } \\
\text { Discordo } \\
\text { totalmente } \\
(\quad)\end{array}$ & $\begin{array}{l}\text { aneira muito confortável de apre } \\
\text { Neutro } \\
\left(\begin{array}{c}\text { Concordo } \\
(\end{array}\right)\end{array}$ & $\begin{array}{l}\text { em. } \\
\text { Concordo } \\
\text { totalmente } \\
(())\end{array}$ \\
\hline 10. & $\begin{array}{l}\text { A modelagem com o software também po } \\
\text { Discordo } \\
\text { totalmente } \\
(()\end{array}$ & $\begin{array}{l}\text { usada em outras disciplinas. } \\
\text { Neutro } \\
(\quad) \\
\end{array}$ & $\begin{array}{c}\text { Concordo } \\
\text { totalmente } \\
(\quad)\end{array}$ \\
\hline 11. & O que você gostou? & & \\
\hline 12. & O que você não gostou? & & \\
\hline 13. & Alguma idéia para melhorar o software? & & \\
\hline 14. & Outros comentários? & & \\
\hline
\end{tabular}


c) Questionário modelagem

\section{Seção 1}

\begin{tabular}{|c|c|c|c|c|c|}
\hline Julgue as afirmações a seguir: & 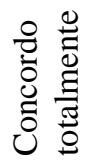 & 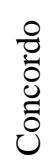 & $\begin{array}{l}\stackrel{\Xi}{\Xi} \\
0 \\
Z\end{array}$ & 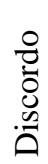 & 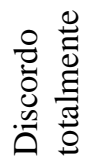 \\
\hline \multicolumn{6}{|l|}{$\begin{array}{l}\text { 1) Modelagem conceitual foi uma abordagem totalmente nova para } \\
\text { o meu aprendizado }\end{array}$} \\
\hline \multicolumn{6}{|l|}{$\begin{array}{l}\text { 2) A modelagem me fez pensar sobre os sistemas de uma forma } \\
\text { diferente }\end{array}$} \\
\hline \multicolumn{6}{|l|}{$\begin{array}{l}\text { 3) A modelagem me deu uma nova visão sobre os fenômenos } \\
\text { abordados nos modelos }\end{array}$} \\
\hline \multicolumn{6}{|l|}{$\begin{array}{l}\text { 4) Ser capaz de simular os modelos me ajudou a desenvolver minha } \\
\text { compreensão do potencial comportamento dos sistemas }\end{array}$} \\
\hline \multicolumn{6}{|l|}{ 5) Modelagem foi uma tarefa motivadora } \\
\hline \multicolumn{6}{|l|}{$\begin{array}{l}\text { 6) A construção de modelos conceituais me fez pensar mais } \\
\text { claramente sobre as causas e efeitos das mudanças em sistemas } \\
\text { ambientais }\end{array}$} \\
\hline \multicolumn{6}{|l|}{$\begin{array}{l}\text { 7) O processo de modelagem me motivou a aprender mais sobre os } \\
\text { fenômenos }\end{array}$} \\
\hline \multicolumn{6}{|l|}{$\begin{array}{l}\text { 8) Eu posso ver como o uso de modelos poderia me ajudar a } \\
\text { aprender sobre outros temas }\end{array}$} \\
\hline \multicolumn{6}{|l|}{ 9) Achei interessante a abordagem da modelagem } \\
\hline \multicolumn{6}{|l|}{ 10)Eu entendi a modelagem } \\
\hline \multicolumn{6}{|l|}{ 11)Eu entendi claramente o objetivo das tarefas de modelagem } \\
\hline $\begin{array}{l}\text { 12) Trabalhar nas tarefas de modelagem me ajudou a produzir as } \\
\text { minhas respostas por escrito }\end{array}$ & & & & & \\
\hline
\end{tabular}

\section{Seção 2}

\begin{tabular}{|c|c|c|c|c|c|}
\hline Complete as frases abaixo: & 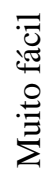 & 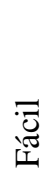 & 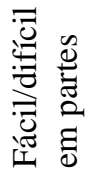 & 突 & 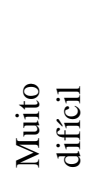 \\
\hline \multicolumn{6}{|l|}{ 13)Em geral eu achei a modelagem conceitual... } \\
\hline \multicolumn{6}{|l|}{$\begin{array}{l}\text { 14) Achei identificar e extrair as informações relevantes e essenciais } \\
\text { dos textos... }\end{array}$} \\
\hline \multicolumn{6}{|l|}{ 15)Achei a tarefa de identificação de conceitos... } \\
\hline \multicolumn{6}{|l|}{$\begin{array}{l}\text { 16) Achei a identificação e descrição das influencias positivas e } \\
\text { negativas... }\end{array}$} \\
\hline \multicolumn{6}{|l|}{$\begin{array}{l}\text { 17)Descrever a estrutura do sistema em um modelo causal básico } \\
\text { foi... }\end{array}$} \\
\hline \multicolumn{6}{|l|}{ 18)Trabalhar com simulações foi... } \\
\hline \multicolumn{6}{|l|}{ 19)Achei a diferenciação entre entidades e quantidades... } \\
\hline $\begin{array}{l}\text { 20) Compreender a forma como as derivadas mostram o } \\
\text { comportamento das quantidades (crescendo, estável, decrescendo) } \\
\text { foi... }\end{array}$ & & & & & \\
\hline
\end{tabular}


21)Compreender as razões para uma quantidade estar crescendo, estável ou decrescendo nas simulações foi...

22)Em geral, achei que entender como funciona o software foi...

\section{d) Questionário sobre os agentes virtuais.}

\section{Seção 1 - Agente virtual: Quizmaster}

\begin{tabular}{|c|c|c|c|c|c|}
\hline Julgue as seguintes afirmações. & 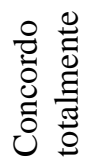 & 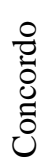 & $\begin{array}{l}\stackrel{0}{\Xi} \\
0 \\
\text { Z }\end{array}$ & $\begin{array}{l}\stackrel{0}{0} \\
0 \\
0 \\
0 \\
0\end{array}$ & 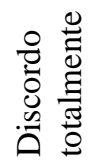 \\
\hline \multicolumn{6}{|l|}{ 1) A função do Quizmaster ficou clara para mim } \\
\hline \multicolumn{6}{|l|}{ 2) A função do Quizmaster ficou confusa para mim } \\
\hline \multicolumn{6}{|l|}{ 3) As falas do Quizmaster foram divertidas } \\
\hline \multicolumn{6}{|l|}{ 4) As falas do Quizmater foram chatas } \\
\hline \multicolumn{6}{|l|}{ 5) Eu realmente me senti fazendo parte de um quiz } \\
\hline \multicolumn{6}{|l|}{ 6) Eu tive a preocupação de me sair bem no quiz } \\
\hline \multicolumn{6}{|l|}{ 7) Eu não me preocupei em me sair bem no quiz } \\
\hline \multicolumn{6}{|l|}{ 8) O que o Quizmaster falava era confuso para mim } \\
\hline \multicolumn{6}{|l|}{ 9) Eu entendi o que o Quizmaster estava falando } \\
\hline \multicolumn{6}{|l|}{ 10)Não me senti motivado quando obtive respostas corretas } \\
\hline \multicolumn{6}{|l|}{ 11)Responder uma pergunta corretamente me motivou } \\
\hline \multicolumn{6}{|l|}{ 12)Mesmo com o quiz, não consegui entender direito o modelo } \\
\hline \multicolumn{6}{|l|}{ 13) $\mathrm{O}$ quiz ajudou a entender melhor o modelo } \\
\hline \multicolumn{6}{|l|}{ 14)O quiz ajudou a corrigir meus erros iniciais } \\
\hline 15)Não consegui corrigir meus erros com a ajuda do qu & & & & & \\
\hline
\end{tabular}

16) O que mais você acha que o Quizmaster deveria fazer nesse tipo de atividade? 
17) Você acha que o Quizmaster poderia fazer algo de maneira diferente? O quê e de que maneira?

\section{Seção 2 - Agente aprendiz virtual: Pet}

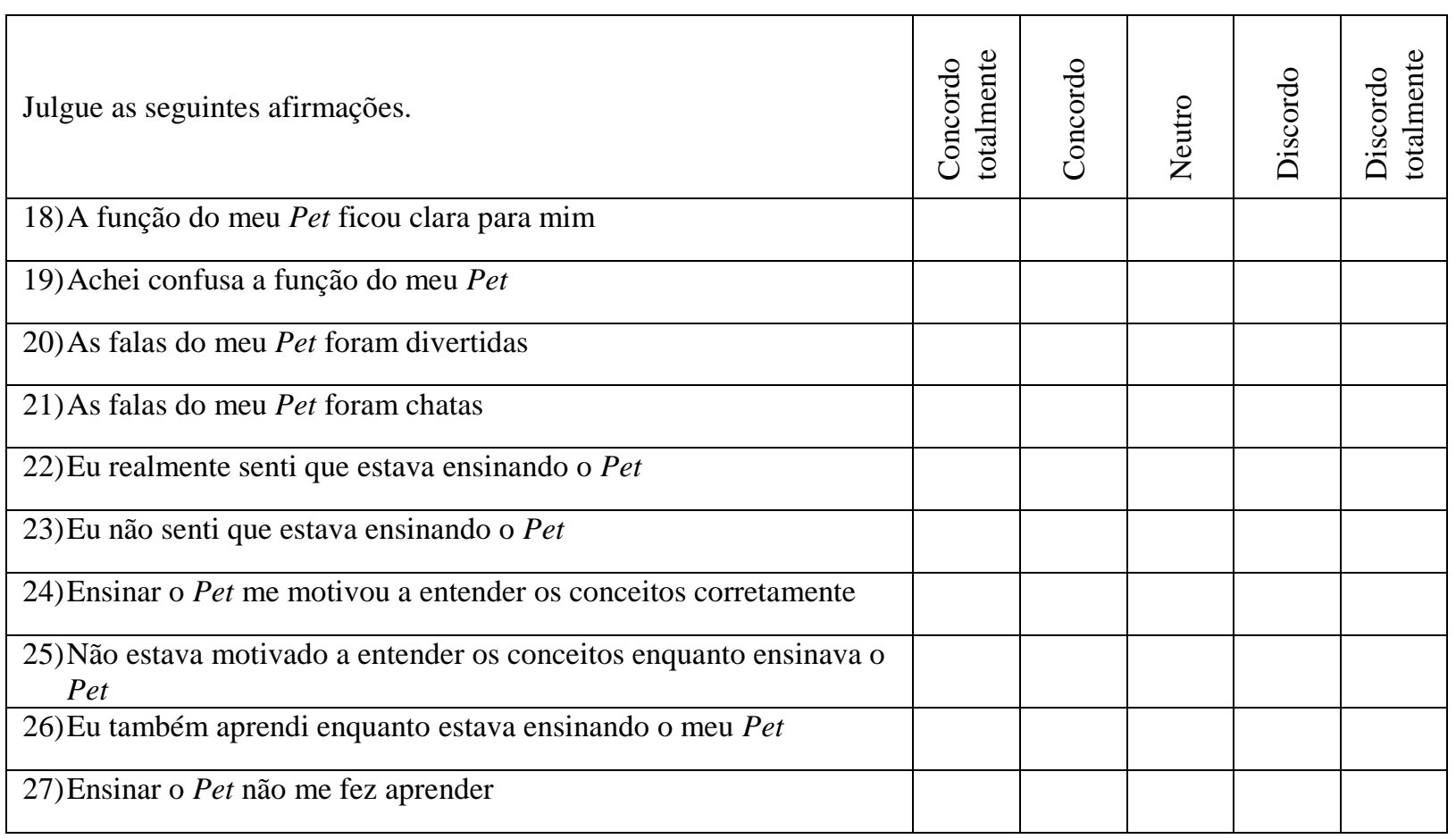

28) O que mais você acha que o Pet deveria fazer nesse tipo de atividade? 
29) Você acha que o Pet poderia fazer algo de maneira diferente? O quê e de que maneira?

\section{APÊNDICE B - Roteiro para as entrevistas com a professora:}

\section{a) Primeira entrevista:}

Parte I - DynaLearn

1. Qual é a sua opinião geral sobre o curso e a atividade de aprendizagem que fizemos juntos?

2. Qual é sua opinião geral sobre a modelagem que utilizamos com os alunos para desenvolver esta atividade educacional?

3. Como você avalia a experiência de trabalhar com o software DynaLearn?

4. Como você avalia a compreensão, pelos alunos, dos problemas abordados nos modelos depois de explorar o tema no DynaLearn?

5. O programa ajudou?

6. Como você avalia a importância de construir modelos específicos no DynaLearn, com os alunos, para o entendimento dos problemas abordados?

7. A modelagem com o software permitiu que os alunos compreendessem melhor a complexidade dos sistemas estudados? Na sua visão.

8. O software e suas características motivaram os alunos a tentar construir um modelo?

9. A utilização do software proporciona uma maneira muito "confortável" de aprendizagem aos alunos?

10. Qual a sua opinião sobre o assunto e a calibragem dos textos e conteúdos abordados na nossa pesquisa?

11. Qual a sua opinião sobre a metodologia de ensino adotada pelos pesquisadores?

12. A pesquisa poderia ser reelaborada e reaplicada? Quais as possibilidades? Como seria?

13. O que você gostou?

14. Alguma idéia para melhorar o software? 
Parte II - Quizmaster

1. A função do Quizmaster ficou clara para você e para os alunos?

2. As falas do Quizmaster foram divertidas ou chatas?

3. Os alunos se sentiram fazendo parte de um quiz ?

4. Os alunos tiveram a preocupação de se sair bem no quiz ou não?

5. O que o Quizmaster falava era claro para você e para os alunos?

6. As respostas corretas motivaram os alunos?

7. O quiz facilitou o entendimento do modelo pelos alunos?

8. O quiz proporciona aos alunos a possibilidade de corrigir os erros de modelagem?

9. O que mais você acha que o Quizmaster deveria fazer nesse tipo de atividade?

10. Você acha que o Quizmaster poderia fazer algo de maneira diferente? O quê e de que maneira?

Parte III - Pet

1) A função do Pet ficou clara?

2) As falas do Pet foram divertidas?

3) O Pet proporcionou ao aluno sentir que estava ensinando ao Pet?

4) O ensino do Pet motivou os alunos a entenderem os conceitos corretamente?

5) O ensino do Pet facilita a aprendizagem e o ensino de conceitos?

6) O que mais você acha que o Quizmaster deveria fazer nesse tipo de atividade?

\section{b) Segunda entrevista:}

\section{QUESTÕES SOBRE AS ATIVIDADES QUE FIZEMOS}

1) Você acredita que o TA pode ser um instrumento (ou ferramenta) viável de ensinoaprendizagem de conceitos de ciências?

2) Você acha que ele serve para ensinar? 
3) Você acredita que conseguimos representar parte da dinâmica e da estrutura dos sistemas que envolvem a aterosclerose, o aparelho reprodutor masculino e feminino (humanos) por modelagem qualitativa com uso do TA?

4) As atividades que fizemos juntos foi capaz de despertar o interesse e aumentar a motivação dos alunos em aprender os conteúdos trabalhados?

5) Qual sua avaliação dos materiais didáticos que produzimos a partir da modelagem qualitativa em LS2 com o uso do TA?

6) Seria possível o desenvolvimento de outros materiais didáticos para o ensino de conceitos de ciências seguindo-se a mesma abordagem que fizemos?

\section{EXPERIÊNCIA COM MODELAGEM}

1) A modelagem foi uma tarefa motivadora?

2) Você compreendeu claramente o objetivo das tarefas de modelagem?

3) O que você achou da modelagem conceitual? Modelos conceituais poderiam ajudar a aprender sobre outros temas?

\section{MODELOS E SIMULAÇÕES}

1) $\mathrm{O}$ que você achou da identificação e descrição das entidades, configurações e das quantidades em sistemas?

2) $O$ que você achou da identificação, descrição e compreensão das influências positivas e negativas?

3) O que você achou da identificação, descrição e compreensão das derivadas?

4) Como foi trabalhar com simulações? Simular os modelos ajuda a desenvolver a compreensão do potencial comportamento dos sistemas? 


\section{USOS NA EDUCAÇÃO}

1) Qual é a sua opinião geral sobre a sequência didática e as atividades de aprendizagem que tivemos juntos?

2) Em sua opinião, que aspectos da aprendizagem dos alunos podem ser desenvolvidos com o uso de modelos e atividades de modelagem?

3) Quais são as principais dificuldades que você apontaria para levar a modelagem para a sala de aula? E as possíveis soluções para essas dificuldades?

\section{DYNALEARN}

1) Como você avalia a experiência de trabalhar com o software DynaLearn?

2) Como você avalia a importância de construir modelos específicos em diferentes níveis de complexidade no DynaLearn?

3) Qual nível (LS1, LS2 ou LS2 com o TA) de utilização você considera que mais contribui para sua compreensão dos conceitos representados nos modelos que trabalhamos?

4) A modelagem com o software também pode ser usada em outros tópicos de aprendizagem? Atividades interdisciplinares? Trabalhar com Projetos?

\section{AGENTES APRENDIZES VIRTUAIS}

1) Qual modo ( LS2 sem x com o TA) de utilização você considera que mais contribui para a compreensão dos conceitos representados nos modelos?

2) Os alunos aprenderam com o TA?

3) Você acha que o TA fez diferença em relação às atividades sem o uso do TA?

4) Você usaria o TA em outras aulas? 
5) Os alunos construíram modelos. Como foi a reação deles durante a construção dos modelos? Descreva.

6) E o interesse?

7) Eles ficaram dispersos ou se concentraram na atividade?

8) Demonstraram motivação para ir até o final?

10) Aponte aspectos positivos e negativos sobre os Pet's. Os Pet's foram convincentes? Eles têm papel pedagógico?

11) Você acha que se não tivéssemos utilizado os Pet's, faria falta à nossas atividades?

12) Você acha que eles deveriam ser diferentes? Como você acha que os alunos se sentiram em relação aos Pet's e ao Harry?

\section{QUESTÕES ABERTAS}

1) O que você gostou?

2) O que você não gostou?

3) Alguma ideia para melhorar o software?

4) Você tem algum outro comentário? 


\section{APÊNDICE C - Testes}

\section{Atividade 1}

\section{a) Pré teste sem o uso do TA: Madeireiros e ambientalistas}

\section{TESTE 1}

Nome:

Leia o texto abaixo:

"Grupo de defesa da natureza quer impedir que uma empresa madeireira retire árvores de uma floresta, para salvar as lagoas onde vive uma espécie rara de anfíbio. Os diretores da empresa dizem que as lagoas e a quantidade de anfíbios não podem ser mais importantes do que a sociedade, os empregos gerados com a venda da madeira e o dinheiro arrecadado com impostos.

O grupo de defesa da natureza argumenta que os anfíbios são parte importante da biodiversidade natural e que se as árvores forem retiradas, as lagoas secam, e sem elas, os anfíbios morrem e os insetos proliferam. Ao se alimentarem, os anfíbios consomem grande quantidade de insetos. Assim, os anfíbios contribuem também para reduzir insetos-praga que transmitem doenças para plantas, diminuindo a quantidade de produtos da floresta. Com as árvores preservadas, a sociedade ganha mais empregos na exploração de produtos florestais e da biodiversidade, e tem melhor qualidade de vida."

Considerando apenas o texto, julgue as afirmações abaixo, colocando $V$ para as que julgar verdadeiras, e $\boldsymbol{F}$ para as que julgar falsas.

1. ( ) SE aumentam as árvores preservadas, ENTÃO diminui a biodiversidade.

2. ( ) A quantidade de empregos aumentou PORQUE aumentou a quantidade de produtos da floresta.

3. ( ) SE diminui a quantidade de anfíbios, ENTÃO diminui a quantidade de insetos-praga.

4. ( ) A quantidade de empregos disponíveis diminui SE aumentar a quantidade de insetos-praga.

5. ( ) A quantidade de produtos da floresta diminuiu PORQUE aumentou a quantidade de anfíbios.

6. ( ) SE aumenta a quantidade de lagoas, ENTÃO aumenta a quantidade de empregos disponíveis.

7. ( ) SE diminui a quantidade de anfíbios, ENTÃO a quantidade de empregos disponíveis aumenta.

8. ( ) A quantidade de insetos aumentou PORQUE a quantidade de anfíbios diminuiu.

9. ( ) A quantidade de produtos da floresta aumenta SE a quantidade de lagoas aumentar.

10. ( ) A quantidade de insetos aumenta PORQUE aumentou a quantidade de árvores preservadas. 


\section{b) Pós teste sem o uso do TA: Madeireiros e ambientalistas}

\section{TESTE 2}

Nome:

Leia o seguinte texto:

"Grupo de defesa da natureza quer impedir que uma empresa madeireira retire árvores de uma floresta, para salvar as lagoas onde vive uma espécie rara de anfíbio. Os diretores da empresa dizem que as lagoas e a quantidade de anfíbios não podem ser mais importantes do que a sociedade, os empregos gerados com a venda da madeira e o dinheiro arrecadado com impostos.

O grupo de defesa da natureza argumenta que os anfíbios são parte importante da biodiversidade natural e que se as árvores forem retiradas, as lagoas secam, e sem elas, os anfíbios morrem e os insetos proliferam. Ao se alimentarem, os anfíbios consomem grande quantidade de insetos. Assim, os anfíbios contribuem também para reduzir insetos-praga que transmitem doenças para plantas, diminuindo a quantidade de produtos da floresta. Com as árvores preservadas, a sociedade ganha mais empregos na exploração de produtos florestais e da biodiversidade, e tem melhor qualidade de vida."

Considerando o texto julgue as afirmações abaixo, colocando $\boldsymbol{V}$ para as que julgar verdadeiras, e $\boldsymbol{F}$ para as que julgar falsas.

1. ( ) A quantidade de lagoas diminuiu PORQUE a quantidade de madeira retirada diminuiu.

2. ( ) A quantidade de insetos aumentou PORQUE diminuiu a quantidade de anfíbios.

3. ( ) Como a quantidade de insetos-praga diminuiu, ENTÃO a quantidade de produtos da floresta aumentou.

4. ( ) Como a quantidade de madeira retirada diminuiu, ENTÃO a quantidade de impostos diminuiu.

5. ( ) A quantidade de insetos-praga diminuiu PORQUE aumentou a quantidade de lagoas.

6. ( ) A quantidade de lagoas e a quantidade de anfíbios variam na mesma direção

7. ( ) A quantidade de empregos aumentou PORQUE a quantidade de produtos da floresta aumentou.

8. ( ) Como a quantidade de anfíbios aumentou, ENTÃO a quantidade de produtos da floresta aumentou.

9. ( ) A quantidade de insetos aumentou PORQUE aumentou a quantidade de insetos-praga.

10. ( ) A quantidade de madeira retirada e a quantidade de produtos da floresta variam na mesma direção. 


\section{c) Pré teste com o uso do TA - Aterosclerose}

\section{TESTE 1}

Nome:

Leia o seguinte texto:

"Aterosclerose é uma doença em que placas de gordura, chamadas ateromas, bloqueiam vasos sanguíneos e podem causar sérios problemas para nossa saúde, como derrame cerebral, infarto no coração e trombose nas pernas.

Quando o ser humano come, em excesso, alimentos ricos em colesterol ruim, formam-se ateromas em artérias do cérebro, do coração e das pernas. Essas placas de gordura reduzem o diâmetro das artérias e prejudicam a passagem de sangue. Em algumas pessoas, essa situação favorece a coagulação do sangue dentro desses vasos, e a formação de coágulos que entopem as artérias.

Artérias entupidas com coágulos podem causar três tipos de acidentes vasculares: no cérebro, aumenta o risco de derrames cerebrais; no coração, aumenta o risco de infarto do miocárdio; e nas pernas, aumenta o risco de trombose, uma doença que pode levar à morte dos tecidos e até à amputação da perna."

Considerando apenas o texto acima, julgue as afirmações abaixo, colocando $\boldsymbol{V}$ nas verdadeiras e $\boldsymbol{F}$ nas falsas.

1. ( ) SE a quantidade de colesterol ruim ingerido diminui, ENTÃO diminui o risco de derrames cerebrais.

2. ( ) SE a quantidade de ateromas na artéria aumenta, ENTÃO a formação de coágulos diminui.

3. ( ) SE a passagem de sangue em uma artéria da perna ficar reduzida, ENTÃO aumenta o risco de infarto do miocárdio.

4. ( ) SE aumenta a quantidade de pessoas com passagem de sangue reduzido nas artérias, ENTÃO aumenta o risco de acidentes vasculares na população.

5. ( ) SE a formação de coágulos diminui, ENTÃO aumenta o risco de trombose nas pernas.

6. ( ) O risco de derrame cerebral pode permanecer estável, SE a passagem de sangue nas artérias for bloqueada.

7. ( ) A quantidade de coágulos em determinada artéria aumentou PORQUE as formação de placas de gordura aumentou.

8. ( ) SE uma pessoa tiver infarto do miocárdio devido a aterosclerose, ENTÃO essa pessoa também terá derrame cerebral.

9. ( ) SE campanhas pela redução do colesterol ruim forem estimuladas, ENTÃO a mortalidade causada por acidentes vasculares pode diminuir.

10. ( ) O risco de trombose foi reduzido PORQUE a população ingeriu menos alimentos com colesterol ruim. 


\section{d) Pós teste com o uso do TA - Aterosclerose}

\section{TESTE 2}

Nome:

Leia o seguinte texto:

"Aterosclerose é uma doença em que placas de gordura, chamadas ateromas, bloqueiam vasos sanguíneos e podem causar sérios problemas para nossa saúde, como derrame cerebral, infarto no coração e trombose nas pernas.

Quando o ser humano come, em excesso, alimentos ricos em colesterol ruim, formam-se ateromas em artérias do cérebro, do coração e das pernas. Essas placas de gordura reduzem o diâmetro das artérias e prejudicam a passagem de sangue. Em algumas pessoas, essa situação favorece a coagulação do sangue dentro desses vasos, e a formação de coágulos que entopem as artérias.

Artérias entupidas com coágulos podem causar três tipos de acidentes vasculares: no cérebro, aumenta o risco de derrames cerebrais; no coração, aumenta o risco de infarto do miocárdio; e nas pernas, aumenta o risco de trombose, uma doença que pode levar à morte dos tecidos e até à amputação da perna.

A educação alimentar e o uso de remédios podem reduzir os riscos de acidentes vasculares. Devemos escolher "alimentos bons", isto é, alimentos pobres em colesterol ruim, que diminuem a formação de ateromas, e o uso de remédios que dissolvem as placas de gordura podem contribuir para reduzir os riscos de derrames cerebrais, infartos e tromboses."

Considerando apenas o texto acima, julgue as afirmações abaixo, colocando $\boldsymbol{V}$ nas verdadeiras $\boldsymbol{e} \boldsymbol{F}$ nas falsas.

1. ( ) SE forem estimuladas as campanhas de educação alimentar, ENTÃO a mortalidade causada por acidentes vasculares pode diminuir.

2. ( ) Coágulos podem ser dissolvidos no interior da artéria SE os remédios mencionados no texto forem utilizados.

3. ( ) SE mais "alimentos bons" forem ingeridos pela população, ENTÃO diminui o risco de infarto do miocárdio.

4. ( ) O risco de formação de ateromas subiu, PORQUE aumentou o consumo de alimentos pobres em colesterol ruim.

5. ( ) O risco de ocorrer trombose na perna ou derrame cerebral diminui, SE aumenta a passagem de sangue pelas artérias.

6. ( ) SE aumentar a ingestão de colesterol ruim, ENTÃO aumenta o risco de entupimento nas artérias cerebrais, mas não nas pernas.

7. ( ) O risco de formação de coágulos no sangue e de ocorrer infarto do miocárdio aumenta SE a quantidade de placas de gordura nas artérias do coração for maior.

8. ( ) SE diminui a ingestão de alimentos pobres em colesterol ruim, ENTÃO aumenta a passagem de sangue nas artérias do corpo.

9. ( ) O risco de trombose nas pernas pode permanecer estável SE a passagem de sangue nas artérias for ampliada com o uso de remédios.

10. ( ) O infarto do miocárdio ocorre SE aumentarem as artérias com passagem de sangue reduzida nas pernas. 


\section{e) Pré teste com o uso do TA - Aparelho reprodutor masculino}

\section{TESTE 1}

Nome:

Data:

Leia o seguinte texto:

\section{$\underline{\text { O aparelho reprodutor masculino }}$}

O aparelho reprodutor masculino é constituído, de uma maneira geral, por testículos, dutos genitais, glândulas acessórias e pênis.

O testículo, órgão protegido por uma bolsa - o escroto, possui em seu interior células intersticiais que são responsáveis pela produção de um hormônio denominado testosterona. Divisões celulares ocorrem nos túbulos seminíferos, por ação da testosterona, favorecendo o desenvolvimento de células responsáveis pela produção dos espermatozoides: as gônias. Estas originam os espermatozoides, que passam por algumas modificações até serem lançados para o meio exterior. Dos túbulos seminíferos, os espermatozoides seguem ao epidídimo, passam pelos ductos deferentes e, antes de chegarem à uretra, recebem secreção líquida da vesícula seminal e da próstata, formando o sêmen, líquido específico eliminado pelo pênis, na ejaculação.

Julgue as afirmações abaixo, colocando $\boldsymbol{V}$ nas verdadeiras e $\boldsymbol{F}$ nas falsas.

1. ( ) SE a quantidade de divisões celulares aumentar, ENTÃO o número de espermatozoides no ducto deferente diminuirá.

2. ( ) Houve diminuição do número de espermatozoides no epidídimo PORQUE a quantidade de gônias aumentou.

3. ( ) O volume de sêmen aumentou PORQUE a quantidade de gônias aumentou.

4. ( ) SE o número de divisões celulares aumentar, ENTÃO o número de gônias aumentará.

5. ( ) SE o número de espermatozoides do ducto deferente aumentar,ENTÃO a quantidade de sêmen irá diminuir.

6. ( ) A quantidade de sêmen diminuiu PORQUE a produção do hormônio testosterona liberado pelas células intersticiais diminuíram.

7. ( ) SE secreção líquida da vesícula seminal diminuir, ENTÃO o volume da ejaculação irá diminuir.

8. ( ) SE a quantidade de sêmen estiver diminuindo, ENTÃO o número de espermatozoides no ducto deferente aumentará.

9. ( ) A quantidade de espermatozoides no epidídimo aumentou PORQUE as divisões celulares aumentaram.

10. ( ) O volume da ejaculação aumentou PORQUE as divisões celulares no testículo diminuíram. 


\section{f) Pós teste com o uso do TA - Aparelho reprodutor masculino.}

\section{TESTE 2}

Nome:

Data:

Leia o seguinte texto:

\section{$\underline{O}$ aparelho reprodutor masculino}

O aparelho reprodutor masculino é constituído, de uma maneira geral, por testículos, dutos genitais, glândulas acessórias e pênis.

O testículo, órgão protegido por uma bolsa - o escroto, possui em seu interior células intersticiais que são responsáveis pela produção de um hormônio denominado testosterona. Divisões celulares ocorrem nos túbulos seminíferos, por ação da testosterona, favorecendo o desenvolvimento de células responsáveis pela produção dos espermatozoides: as gônias. Estas originam os espermatozoides, que passam por algumas modificações até serem lançados para o meio exterior. Dos túbulos seminíferos, os espermatozoides seguem ao epidídimo, passam pelos ductos deferentes e, antes de chegarem à uretra, recebem secreção líquida da vesícula seminal e da próstata, formando o sêmen, líquido específico eliminado pelo pênis, na ejaculação.

Considerando apenas o texto acima, julgue as afirmações abaixo, colocando $\boldsymbol{V}$ nas verdadeiras $\boldsymbol{e} \boldsymbol{F}$ nas falsas.

1. ( ) SE o número de espermatozoides no epidídimo diminuir, ENTÃO o número de espermatozoides no ducto deferente aumentará.

2. ( ) A quantidade de sêmen aumentará SE a quantidade de gônias aumentar.

3. ( ) O volume de ejaculação diminuiu PORQUE a quantidade de testosterona produzida nas células intersticiais aumentou.

4. ( ) SE secreção líquida da próstata diminuir, ENTÃO o volume de sêmen irá aumentar.

5. ( ) SE o número de gônias aumentar, ENTÃO a quantidade de espermatozoides no epidídimo irá aumentar.

6. ( ) SE os espermatozoides do epidídimo diminuírem, ENTÃO o volume da ejaculação diminuirá.

7. ( ) SE a quantidade de testosterona aumentar, ENTÃO a quantidade de divisões celulares aumentará.

8. ( ) O volume da ejaculação aumentou PORQUE a quantidade de gônias aumentou.

9. ( ) Houve aumento na quantidade de gônias PORQUE a quantidade de testosterona produzida no testículo diminuiu.

10. ( ) SE as divisões celulares nos túbulos seminíferos diminuírem, ENTÃO os espermatozoides no ducto deferente aumentarão. 


\section{g) Pré teste com o uso do TA: Placenta}

\section{TESTE 1}

Nome:

Data:

Leia o seguinte texto:

\section{Placenta}

A placenta da grávida tem como principal função realizar trocas entre o corpo materno e o embrião. Estas trocas ocorrem por difusão, sempre de algum dos sistemas da mãe para o sangue do embrião e vice-versa. A difusão que ocorre na placenta permite:

$\checkmark$ Que os nutrientes do sistema digestor da mãe cheguem até o sangue do embrião;

$\checkmark$ Que as excretas, presentes no sangue do embrião, sejam liberadas pelo sistema excretor materno;

$\checkmark$ Que o oxigênio do sistema respiratório da mãe chegue até o sangue do embrião;

$\checkmark$ Que o gás carbônico do sangue do embrião seja liberado pelo sistema respiratório materno.

Julgue as afirmações abaixo, colocando $\boldsymbol{V}$ nas verdadeiras e $\boldsymbol{F}$ nas falsas.

1. ( ) SE difusão de nutrientes da placenta aumentar, ENTÃO nutrientes do sangue do embrião irão aumentar.

2. ( ) SE oxigênio do sistema respiratório aumentar, ENTÃO oxigênio do sangue do embrião irá diminuir.

3. ( ) SE difusão de excretas da placenta diminuir, ENTÃO excretas do sistema excretor irá aumentar.

4. ( ) O gás carbônico do sistema respiratório aumentou, PORQUE a difusão de gás carbônico da placenta diminuiu.

5. ( ) Excretas do sistema excretor diminuiu, PORQUE excretas do sangue do embrião diminuiu.

6. ( ) SE gás carbônico do sangue do embrião diminuir, ENTÃO gás carbônico do sistema respiratório irá aumentar.

7. ( ) Difusão de oxigênio da placenta diminuiu, PORQUE o oxigênio do sistema respiratório diminuiu.

8. ( ) SE excretas do sangue do embrião aumentar, ENTÃO difusão de excretas na placenta irá aumentar.

9. ( ) O oxigênio do sangue do embrião aumentou, PORQUE a difusão de oxigênio da placenta aumentou.

10. ( ) SE nutrientes do sistema digestor diminuir, ENTÃO nutrientes do sangue do embrião irão aumentar. 


\section{h) Pós teste com o uso do TA: Placenta}

\section{TESTE 2}

Nome:

Data:

Leia o seguinte texto:

\section{Placenta}

A placenta da grávida tem como principal função realizar trocas entre o corpo materno e o embrião. Estas trocas ocorrem por difusão, sempre de algum dos sistemas da mãe para o sangue do embrião e vice-versa. A difusão que ocorre na placenta permite:

$\checkmark$ Que os nutrientes do sistema digestor da mãe cheguem até o sangue do embrião;

$\checkmark$ Que as excretas, presentes no sangue do embrião, sejam liberadas pelo sistema excretor materno;

$\checkmark$ Que o oxigênio do sistema respiratório da mãe chegue até o sangue do embrião;

$\checkmark$ Que o gás carbônico do sangue do embrião seja liberado pelo sistema respiratório materno.

Julgue as afirmações abaixo, colocando $\boldsymbol{V}$ nas verdadeiras e $\boldsymbol{F}$ nas falsas.

1. ( ) SE excretas do sangue do embrião diminuir, ENTÃO difusão de excretas na placenta irá aumentar.

2. ( ) A difusão de nutrientes na placenta aumentou, PORQUE nutrientes do sistema digestor aumentou.

3. ( ) SE oxigênio do sistema respiratório diminuir, ENTÃO difusão de oxigênio da placenta irá diminuir.

4. ( ) Nutrientes do sangue do embrião aumentaram, PORQUE nutrientes do sistema digestor aumentou.

5. ( ) SE difusão de excretas da placenta aumentar, ENTÃO excretas do sistema excretor irá aumentar.

6. ( ) SE gás carbônico do sangue do embrião aumentar, ENTÃO gás carbônico do sistema respiratório irá diminuir.

7. ( ) SE gás carbônico do sangue do embrião diminuir, ENTÃO difusão de gás carbônico da placenta irá aumentar.

8. ( ) Excretas do sistema excretor aumentou, PORQUE excretas do sangue do embrião aumentou.

9. ( ) O oxigênio do sangue do embrião aumentou, PORQUE a difusão de oxigênio da placenta diminuiu.

10. ( ) Nutrientes do sangue do embrião aumentaram, PORQUE a difusão de nutrientes da placenta diminuiu. 


\section{APÊNDICE D - Materiais didáticos produzidos}

\section{Materiais didáticos produzidos:}

Foram produzidos os seguintes materiais didáticos para o minicurso proposto:

I. Material para apresentação do DynaLearn e suas principais funcionalidades no LS2;

II. Material para apresentação do TA;

III. Texto e modelo sobre aterosclerose;

IV. Texto e modelo sobre o aparelho reprodutor masculino;

V. Mapas conceituais sobre o aparelho reprodutor masculino;

VI. Texto e modelo conceitual sobre o aparelho reprodutor feminino;

VII. Texto e modelo sobre a placenta.

Alguns desses materiais didáticos serão descritos abaixo.

\section{Material para apresentação do DynaLearn, do LS2 e do TA}

O esquema na figura 1 foi utilizado para apresentar a tela principal do DynaLearn e suas principais funções.

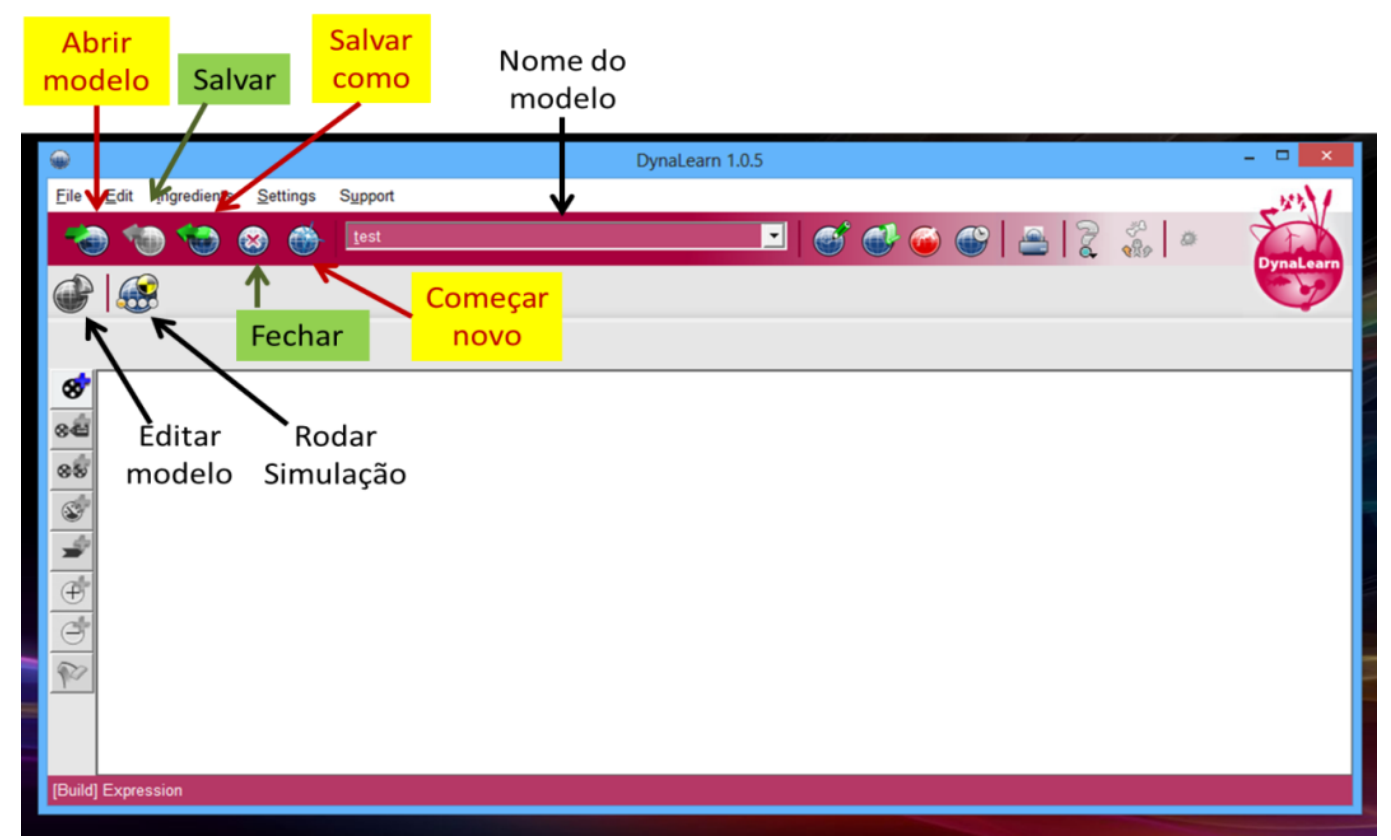

Fig.01 - Software DynaLearn: tela principal e suas principais funções 
O esquema na figura 2 foi usado para apresentar o nível LS2 (modelo causal básico), no DynaLearn e suas principais funções.

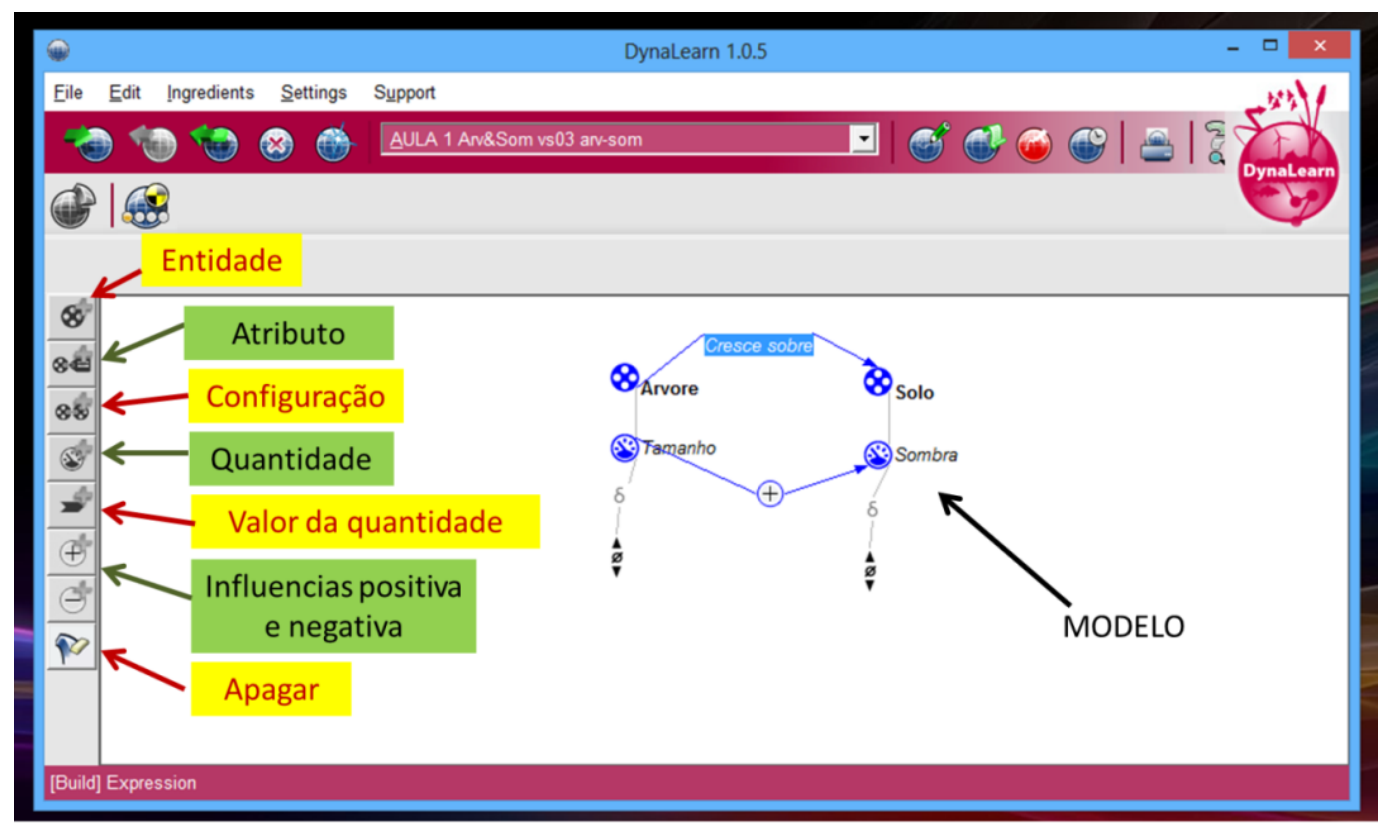

Fig.02 - DynaLearn - Botões para atividades de modelagem em LS2

O esquema abaixo foi utilizado para apresentar os elementos de um modelo em LS2.

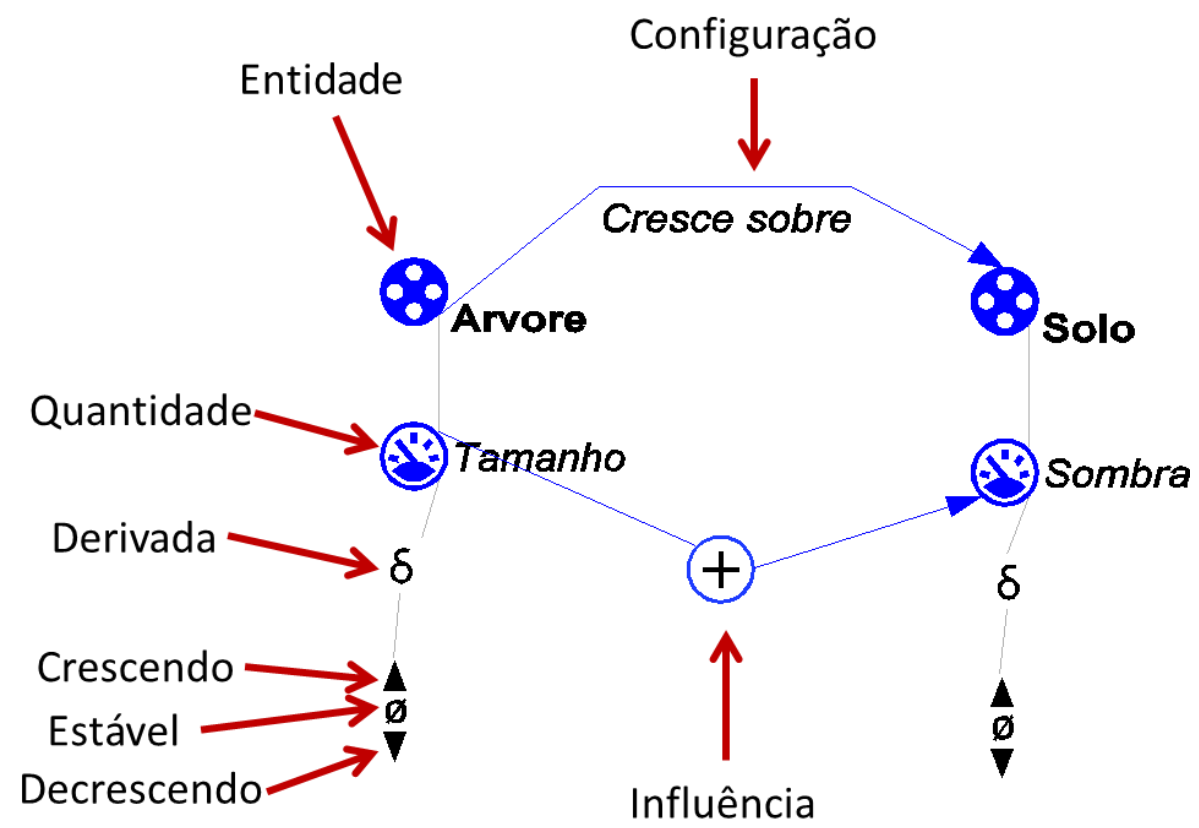

Fig.03 - Software DynaLearn: elementos de um modelo LS2 
O esquema abaixo foi usado para ensinar aos alunos como trabalhar com simulações no LS2.

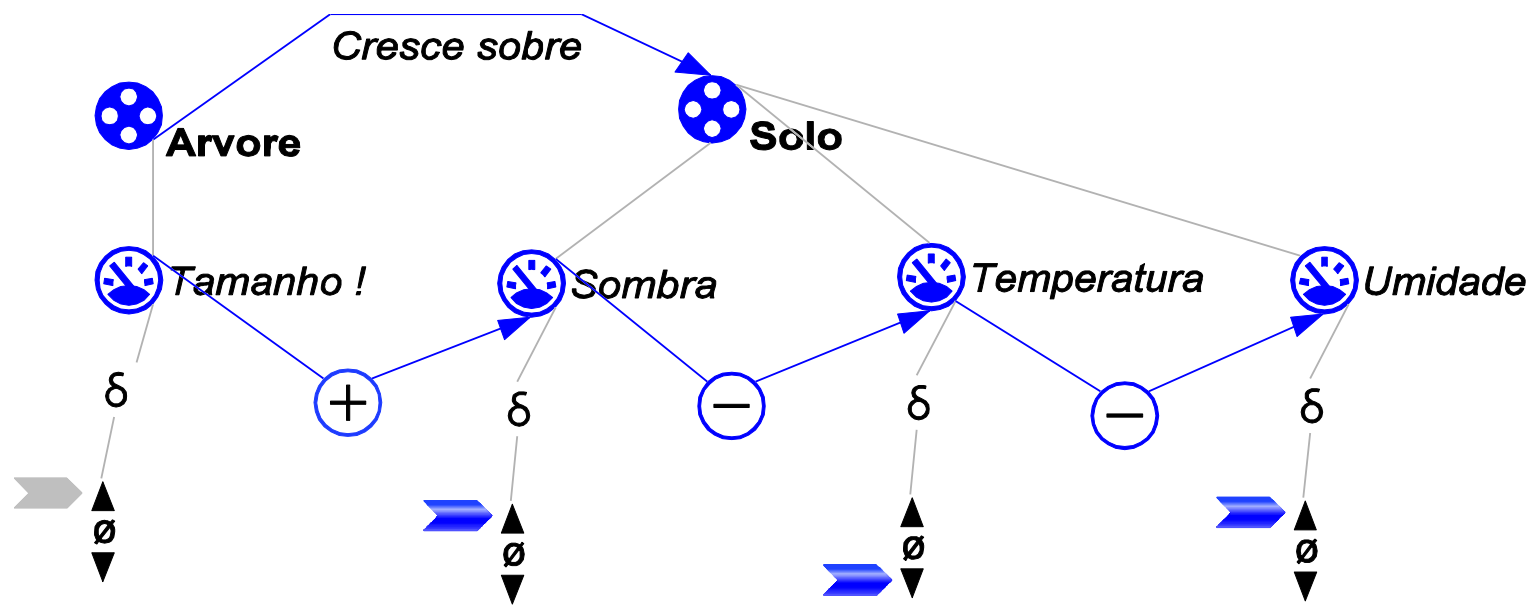

Fig.04 - Simulação com modelo "Árvore e Sombra”

O texto e modelo mostrado no quadro 1 , foram utilizados para ensinar os alunos a identificar entidades, quantidades e influências e a construir modelos representativos a partir de textos.

Quadro 1 - Texto e modelo "Bloom de Algas" completo: entidades, configurações, quantidades e influências

\section{Modelo" Bloom de Algas"}

Uma cidade fica perto do Lago. A cidade produz esgotos, que caem no Lago e causam poluição. A poluição por esgotos favorece o crescimento da população de um tipo de algas, que produzem um veneno (toxina) que fica dissolvido na água do lago. Essas toxinas reduzem o tamanho da população de peixes. O tratamento de esgotos pode resolver esse problema.

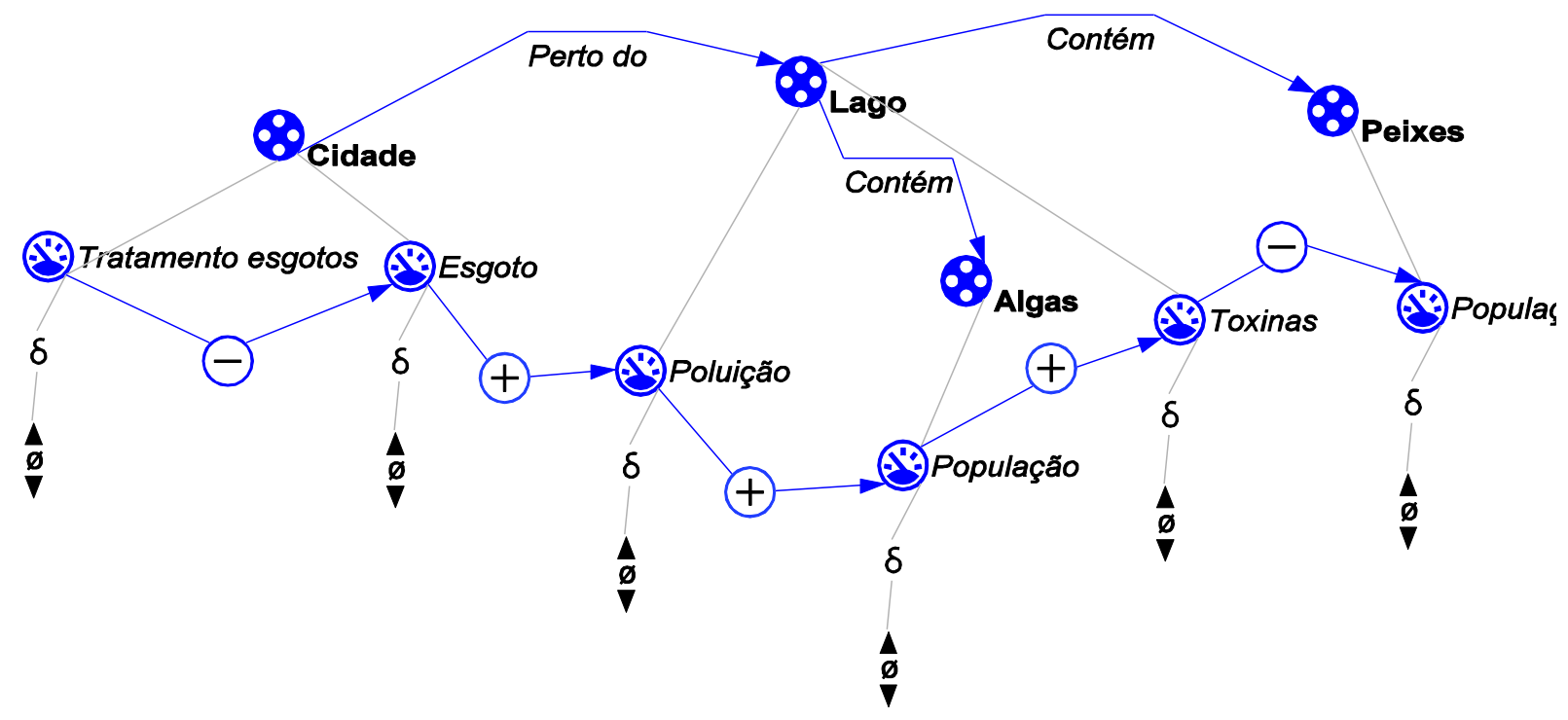




\section{Material para apresentação do TA}

A figura 5 mostra algumas das telas utilizadas para a apresentação do TA aos alunos.

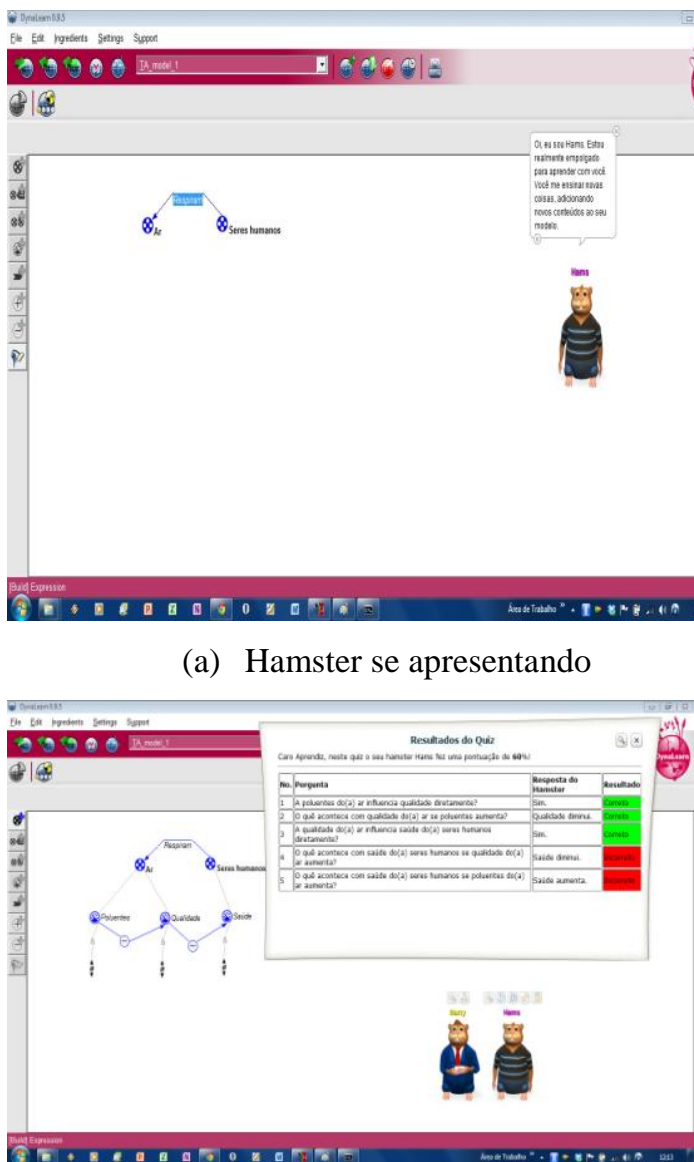

(c) Erro na influência

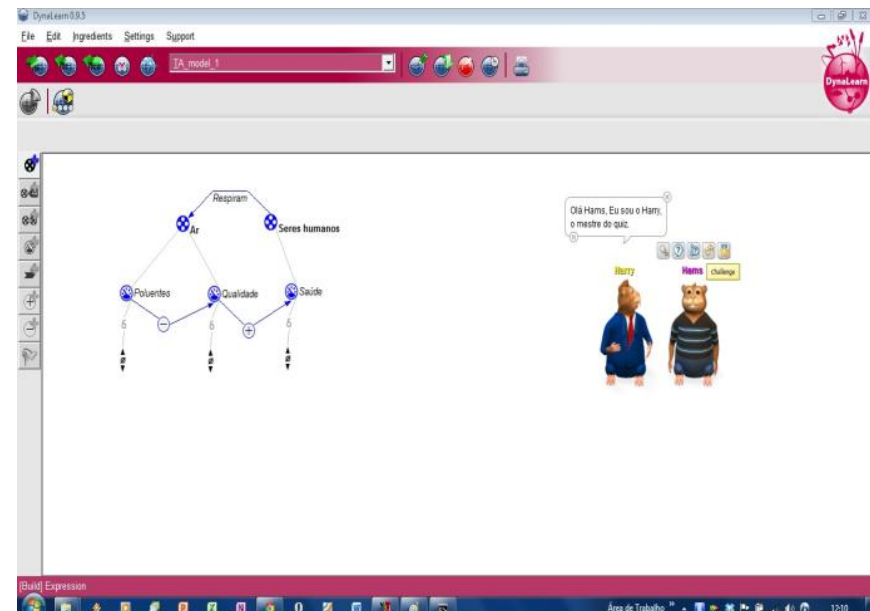

(b) O professor se apresentando

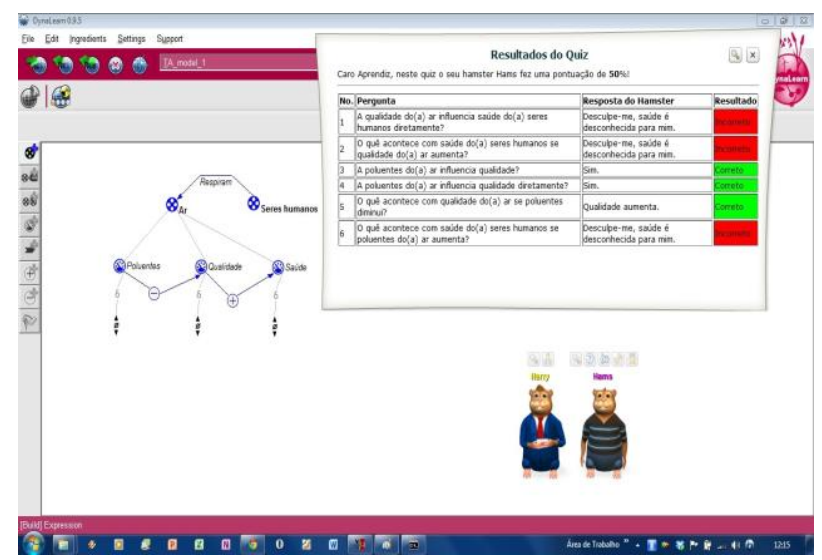

(d) Erro na associação quantidade-entidade

Figura 05 - Apresentando o TA

\section{Modelo da aterosclerose}

\section{a. A estrutura do sistema}

No modelo foi assuida a representação dos principais eventos relacionados à aterosclerose a fim de realizar discussõs sobre as causas, consequências e tratamento (ou prevenção) desta doença, ligada, principalmente, ao sistema circulatório humano.

A estrutura do sistema no modelo é representada pelas entidades "Ser humano", "Artéria", "Coração", "Cérebro" e "Pernas" (veja-se figura 6). 


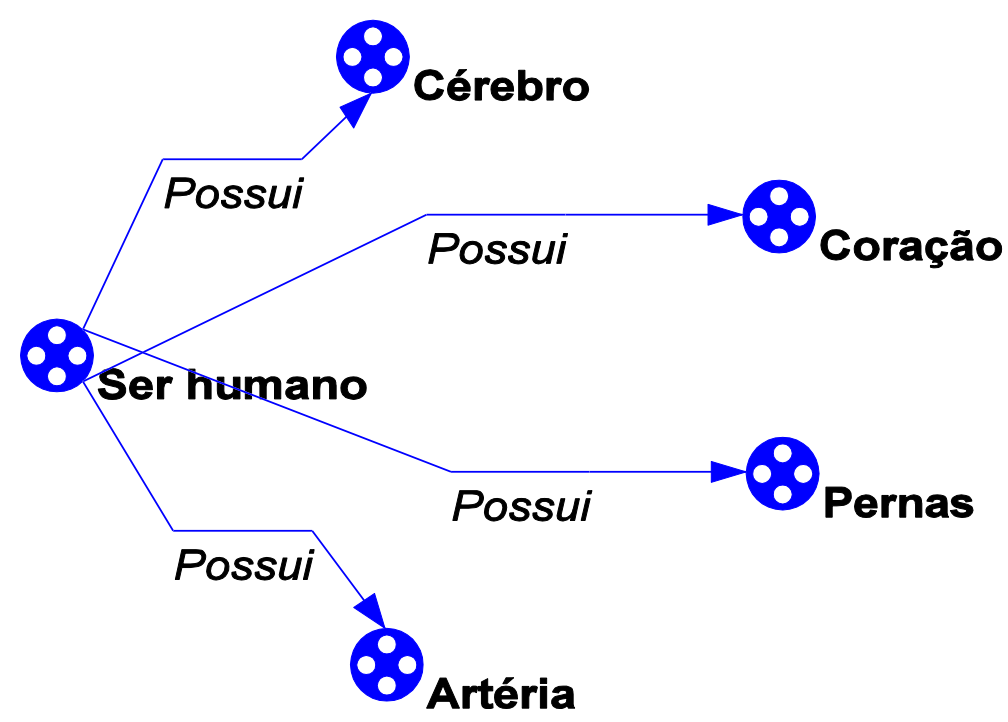

Figura 6. Árvore de entidades

\section{b. Variáveis}

Cada entidade foi associada a variáveis (quantidades), que expressam características interessantes para o problema estudado. As variáveis utilizadas no modelo estão representadas no quadro abaixo.

Quadro 2- Representação das variáveis.

\begin{tabular}{|l|l|l|}
\hline Entidade & Variáveis & Significado \\
\hline \multirow{2}{*}{ Ser humano } & $\begin{array}{l}\text { Alimentos pobres em } \\
\text { colesterol ruim. }\end{array}$ & $\begin{array}{l}\text { Medida da quantidade de ingestão de alimentos com } \\
\text { pouco ou nenhum colesterol ruim. }\end{array}$ \\
\cline { 2 - 3 } & $\begin{array}{l}\text { Ingestão de colesterol } \\
\text { ruim. }\end{array}$ & $\begin{array}{l}\text { Medida da quantidade de ingestão de alimentos com } \\
\text { colesterol ruim. }\end{array}$ \\
\cline { 2 - 3 } & Remédios. & $\begin{array}{l}\text { Medida da quantidade ideal de ingestão de remédios } \\
\text { próprios para o tratamento ou prevenção da } \\
\text { aterosclerose. }\end{array}$ \\
\hline Artéria & Ateromas. & $\begin{array}{l}\text { Medida da quantidade de ateromas formados nas } \\
\text { artérias do cérebro, coração ou pernas. }\end{array}$ \\
\cline { 2 - 3 } & Passagem de sangue. & $\begin{array}{l}\text { Medida da quantidade de passagem de sangue nas } \\
\text { artérias. }\end{array}$ \\
\cline { 2 - 4 } & Coágulos. & $\begin{array}{l}\text { Medida da quantidade de coágulos presentes nas } \\
\text { artérias do cérebro, coração ou pernas. }\end{array}$ \\
\hline Coração & Infarto & $\begin{array}{l}\text { Medida da quantidade de infartos que podem ocorrer } \\
\text { no coração. }\end{array}$ \\
\hline Cérebro & Derrame cerebral & $\begin{array}{l}\text { Medida da quantidade de derrames que podem ocorrer } \\
\text { no cérebro. }\end{array}$ \\
\hline Pernas & Trombose & $\begin{array}{l}\text { Medida da quantidade de tromboses que podem } \\
\text { ocorrer no pernas. }\end{array}$ \\
\hline
\end{tabular}




\section{c. Sub modelos}

Os modelos podem ser fracionados em modelos menores, que representam trechos com cadeias de causalidade. Serão descritos abaixo alguns desses submodelos, e os modelos completos são apresentados a seguir. Foi utilizado abaixo a sigla $S M$ que significa "submodelo".

\section{d. Um exemplo de cadeia de causalidade}

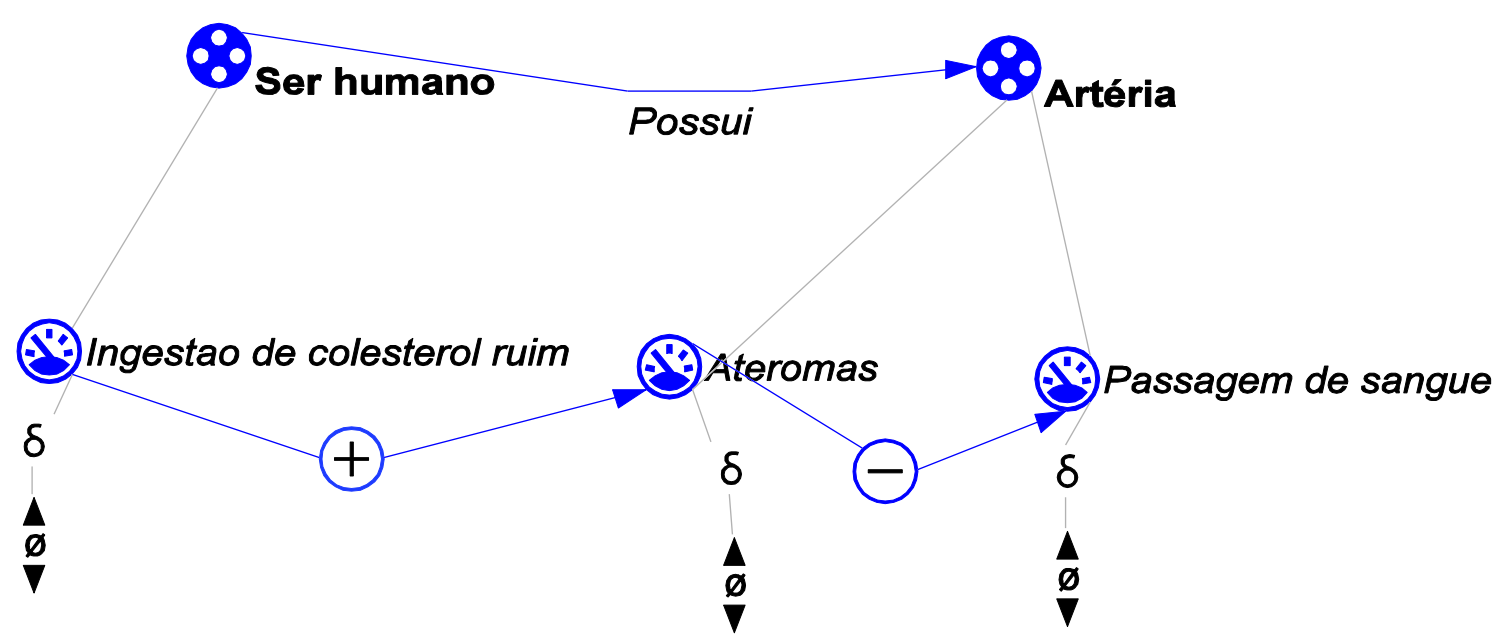

Fig. 07 - SM 01: 'Ingestão de colesterol ruim' influencia 'Ateromas' que influencia 'Passagem de sangue'.

O SM 01 demonstra a cadeia de causalidade entre as variáveis 'Ingestão de colesterol ruim', a formação de 'Ateromas' e a 'Passagem de sangue' nas artérias. Conforme a figura acima, a seta “+” direcionada da 'Ingestão de colesterol ruim' para 'Ateromas', representa que quanto maior for a ingestão de colesterol ruim, mais ateromas serão formados nas artérias humanas e quanto menor a ingestão deste colesterol, menos ateromas serão formados.

A seta “_" direcionada de 'Ateromas' para a 'Passagem de sangue' representa que quanto maior for a formação de ateromas nas artérias, menor será o potencial de passagem de sangue nestes vasos sanguíneos, pois estes terão seu calibre reduzido. Esta seta negativa, significa ainda, que a diminuição na formação de ateromas nas artérias, aumentará o potencial de passagem de sangue nestas. Considerando duas entidades " $\mathrm{A}$ " $\mathrm{e}$ " $\mathrm{B}$ " em que há uma seta direcionada da primeira para a segunda, poderemos observar o seguinte: o sinal "+ “ representa variação igual, ou seja, se uma variável aumenta a outra tembém aumenta. Se uma diminui a outra também. O sinal “_“ representa variação oposta, ou seja, se uma variável aumenta a outra irá diminuir. Se uma diminui a outra irá aumentar. 


\section{e. Representando problemas e propondo soluções por modelagem}

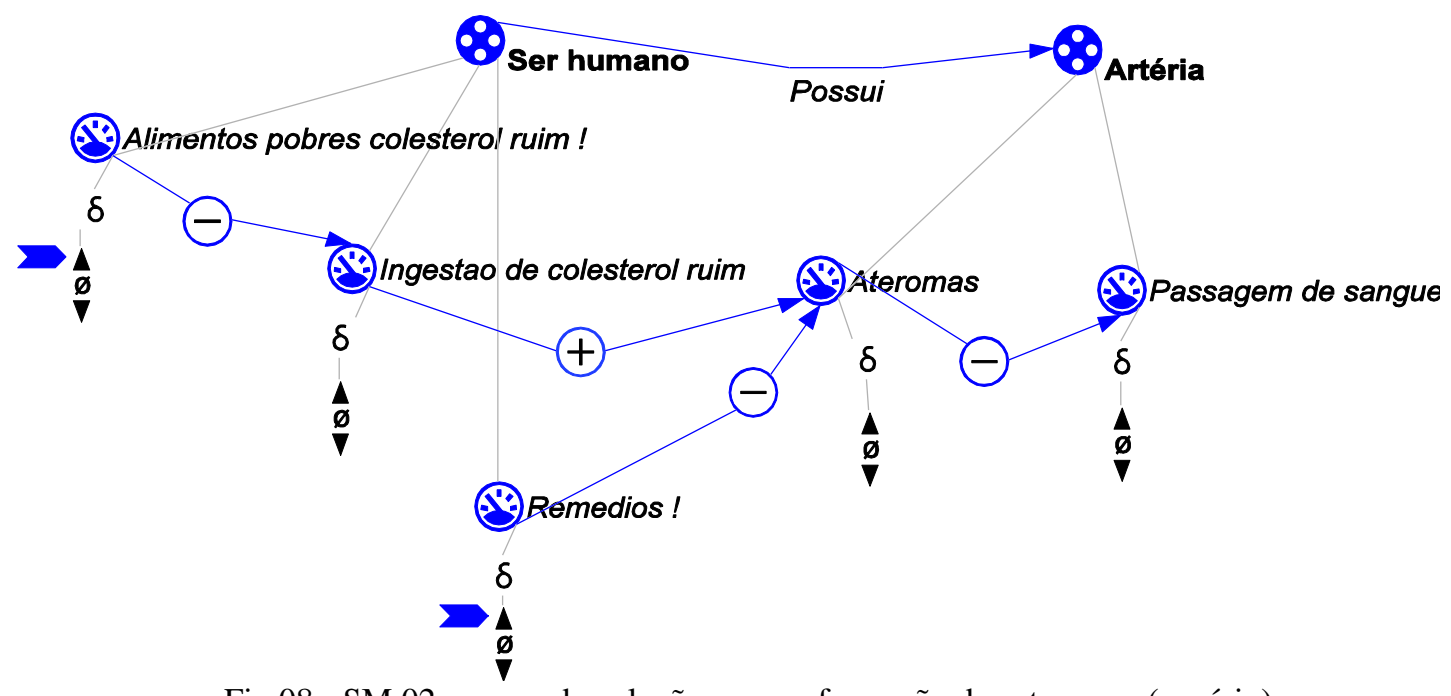

Fig.08 - SM 02: propondo soluções para a formação dos ateromas (cenário)

A figura acima representa a mesma cadeia de causalidade mostrada na figura anterior, porém, neste caso, foi modelado uma proposta de solução para a formação dos ateromas que reduzem a passagem de sangue nas artérias do corpo humano, pela adição das variáveis "Alimentos pobres em colesterol ruim" e "Remédios". A primeira sugere mudança nos hábitos alimentares ao propor que o aumento da ingestão de alimentos pobres em colesterol ruim, diminuem a ingestão de alimentos com o colesterol ruim. A segunda propõe que remédios podem agir diretamente sobre a formação dos ateromas, diminuindo estes.

\section{f. Fazendo simulações com o LS2}

A figura abaixo mostra como ocorre uma simulação em LS2 para o sub modelo 01, para um cenário em que a derivada da variável 'Ingestão de colesterol ruim' esteja marcada como aumentando.

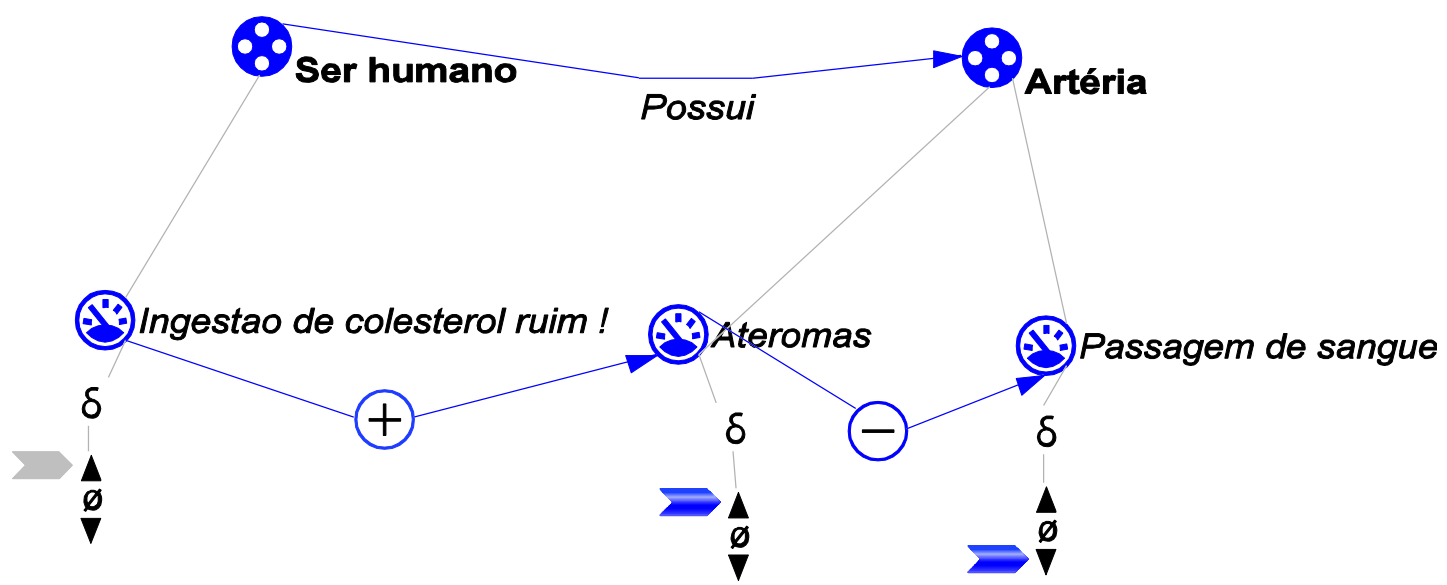

Fig. 9 - Simulação em LS2 sem o TA

O aluno pode marcar a derivada aumentando, da variável 'Ingestão de colesterol ruim' e 'solicitar' ao programa que rode a simulação (o valor inicial da simulação -cenário - está assinalado na 
cor cinza). O resultado será apresentado na cor azul, que no caso será aumentando para a variável 'Ateromas' e diminuído para a variável 'Passagem de sangue'.

A figura abaixo representa o resultado da simulação referente ao cenário do SM 02 mostrado na figura 8.

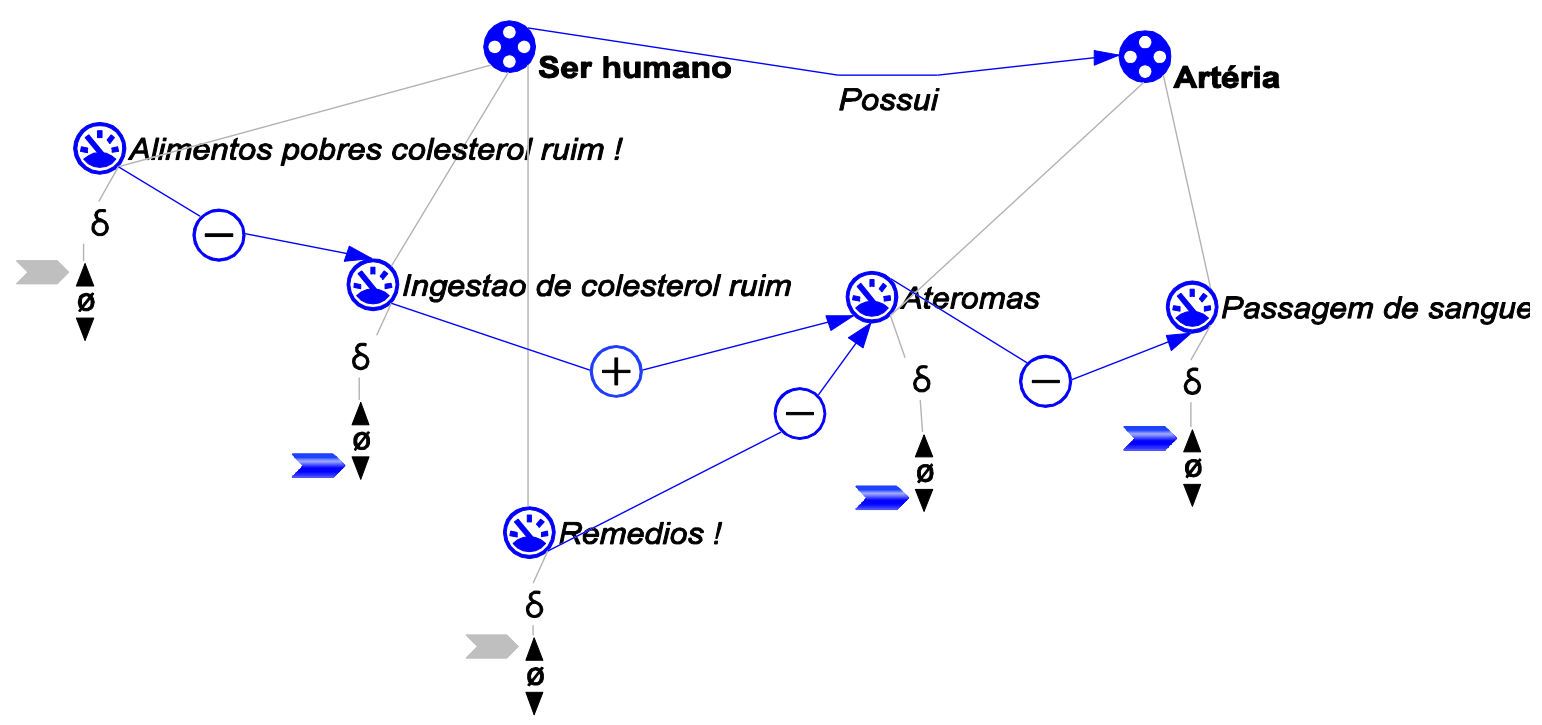

Fig. 10 - Propondo soluções para a formação dos ateromas (simulação)

A ingestão de alimentos pobres em colesterol ruim causa um efeito negativo na ingestão de colesterol ruim, que diminui o que por sua vez diminui a formação das placas de ateromas nas artérias humanas, favorecendo o aumento na passagem de sangue pelas artérias. Os remédios agem diretamente nos ateromas, diminuindo a formação destes.

\section{g. Simulação em LS2 com o TA}

A mesma simulação representada na figura 09 e já descrita pode ser feita com o uso do TA. Para isso, basta consultar o mestre do quiz, o Harry. Ele fará questionamentos sobre as influências positivas ou negativas entre as variáveis do modelo. Veja-se o exemplo abaixo: 

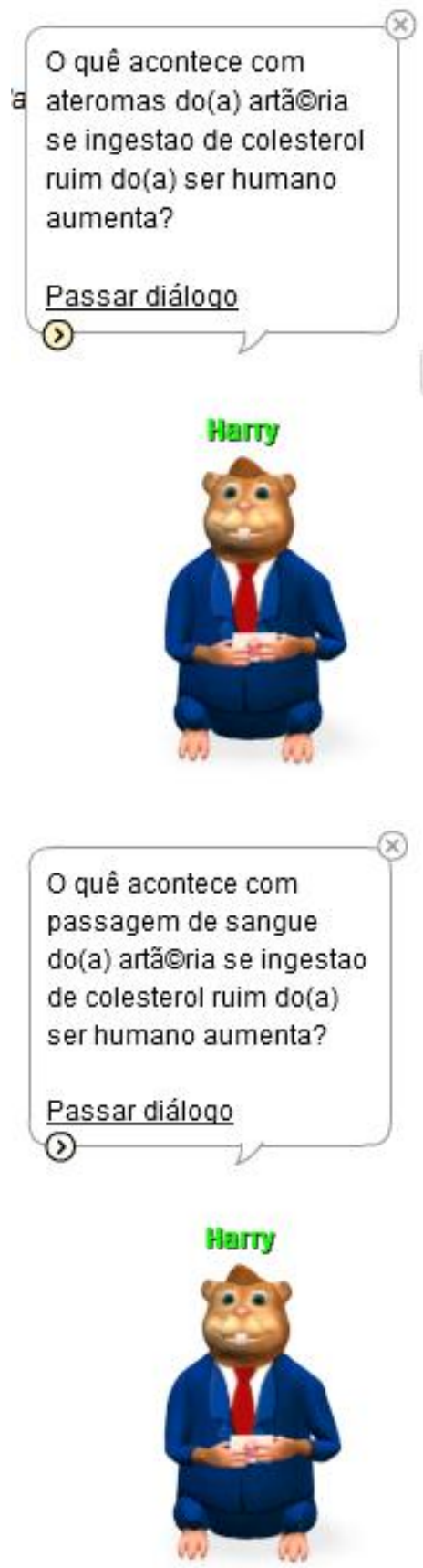

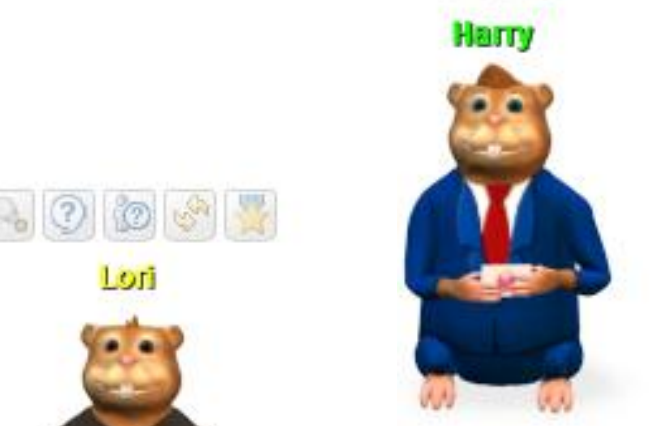

Ateromas aumenta.

(2)

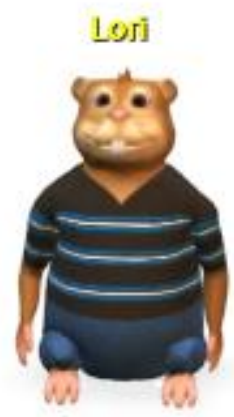

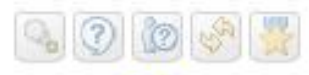

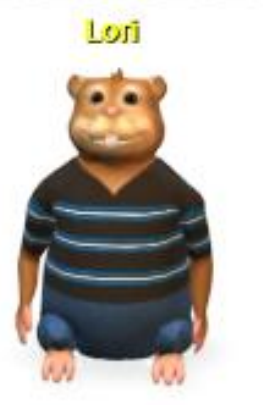

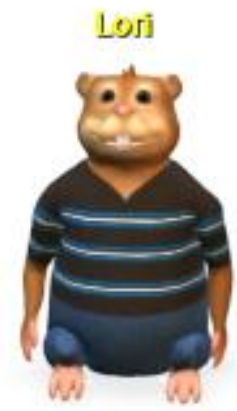

Fig. 11 - Diálogo entre agentes durante simulação em LS2 com o TA

Pela análise e observação do diálogo ocorrido entre o mestre do quiz e o agente aprendiz virtual, as simulações são feitas. Ressalta-se que as perguntas de simulações feitas no modo TA são feitas de modo aleatório, a critério do próprio programa, a fim de evitar que os alunos apenas decorem respostas. Essa aleatoriedade induz o aluno a ter que raciocinar sobre a dinâmica entre o mestre do quiz e o Pet aprendiz, de modo que o aluno possa fazer previsões e análises sobre o sistema modelado. 


\section{Modelo do aparelho reprodutor masculino}

\section{a. A estrutura do sistema}

A figura abaixo mostra a árvore de entidades que representa a estrutura do sistema reprodutor masculino.

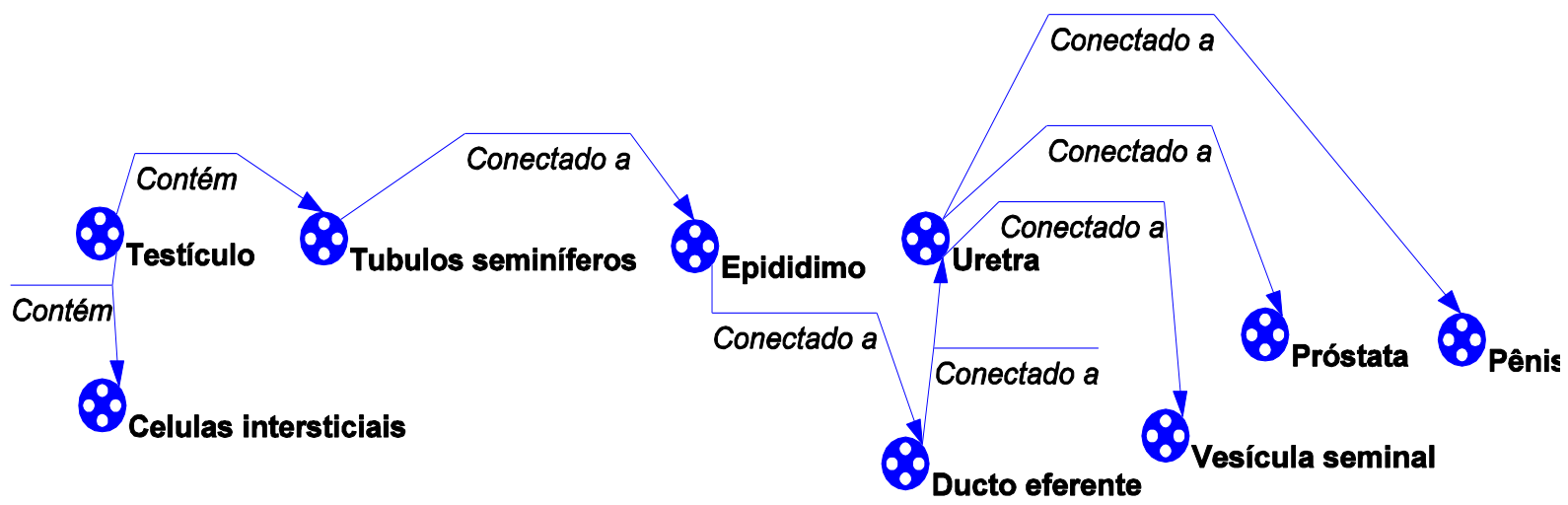

Fig. 12. Árvore de entidades

Neste modelo foi assumida a representação dos principais eventos relacionados ao funcionamento do sistema reprodutor masculino a fim de realizar discussõs sobre o assunto. Para tal foram usadas nove entidades que representam a estrutura do sistema - 'Testículo', 'Células Intersticiais', 'Túbulos seminíferos', 'Epidídimo', 'Ducto eferente', 'Uretra', 'Vesícula seminal', 'Próstata' e 'Pênis'.

\section{b. Variáveis}

Cada entidade foi associada a variáveis, que expressam características interessantes para o problema estudado. As variáveis utilizadas no modelo estão representadas no quadro abaixo: 
Quadro 2- Representação das quantidades.

\begin{tabular}{|c|c|c|}
\hline Entidade & Quantidade & Significado \\
\hline Testículo & ------ & ------ \\
\hline $\begin{array}{l}\text { Células } \\
\text { Intersticiais }\end{array}$ & Testosterona & $\begin{array}{l}\text { Medida da quantidade de testosterona } \\
\text { produzida nas células intersticiais dos } \\
\text { testículos. }\end{array}$ \\
\hline \multirow[t]{2}{*}{$\begin{array}{l}\text { Túbulos } \\
\text { seminíferos }\end{array}$} & Divisões celulares & $\begin{array}{l}\text { Medida da quantidade de divisões } \\
\text { celulares que ocorrem nos túbulos } \\
\text { seminíferos. }\end{array}$ \\
\hline & Gônias & $\begin{array}{l}\text { Medida da quantidade de gônias que } \\
\text { se formam nos túbulos seminíferos. }\end{array}$ \\
\hline Epidídimo & Espermatozoides & $\begin{array}{l}\text { Medida da quantidade de } \\
\text { espermatozoides presentes no } \\
\text { epidídimo. }\end{array}$ \\
\hline Ducto eferente & Espermatozoides & $\begin{array}{l}\text { Medida da quantidade de } \\
\text { espermatozoides presentes no ducto } \\
\text { eferente. }\end{array}$ \\
\hline Uretra & Sêmen & $\begin{array}{l}\text { Medida da quantidade de sêmen } \\
\text { presentes na uretra. }\end{array}$ \\
\hline Vesícula seminal & Secreção líquida & $\begin{array}{l}\text { Medida da quantidade de secreção } \\
\text { líquida produzida pela vesícula } \\
\text { seminal. }\end{array}$ \\
\hline Próstata & Secreção líquida & $\begin{array}{l}\text { Medida da quantidade de secreção } \\
\text { líquida produzida pela próstata. }\end{array}$ \\
\hline Pênis & Ejaculação & $\begin{array}{l}\text { Medida da quantidade de ejaculação } \\
\text { realizada pelo pênis. }\end{array}$ \\
\hline
\end{tabular}

\section{c. Sub modelos}

A figura abaixo mostra o SM que representa a formação do sêmen na uretra do aparelho reprodutor masculino humano. 


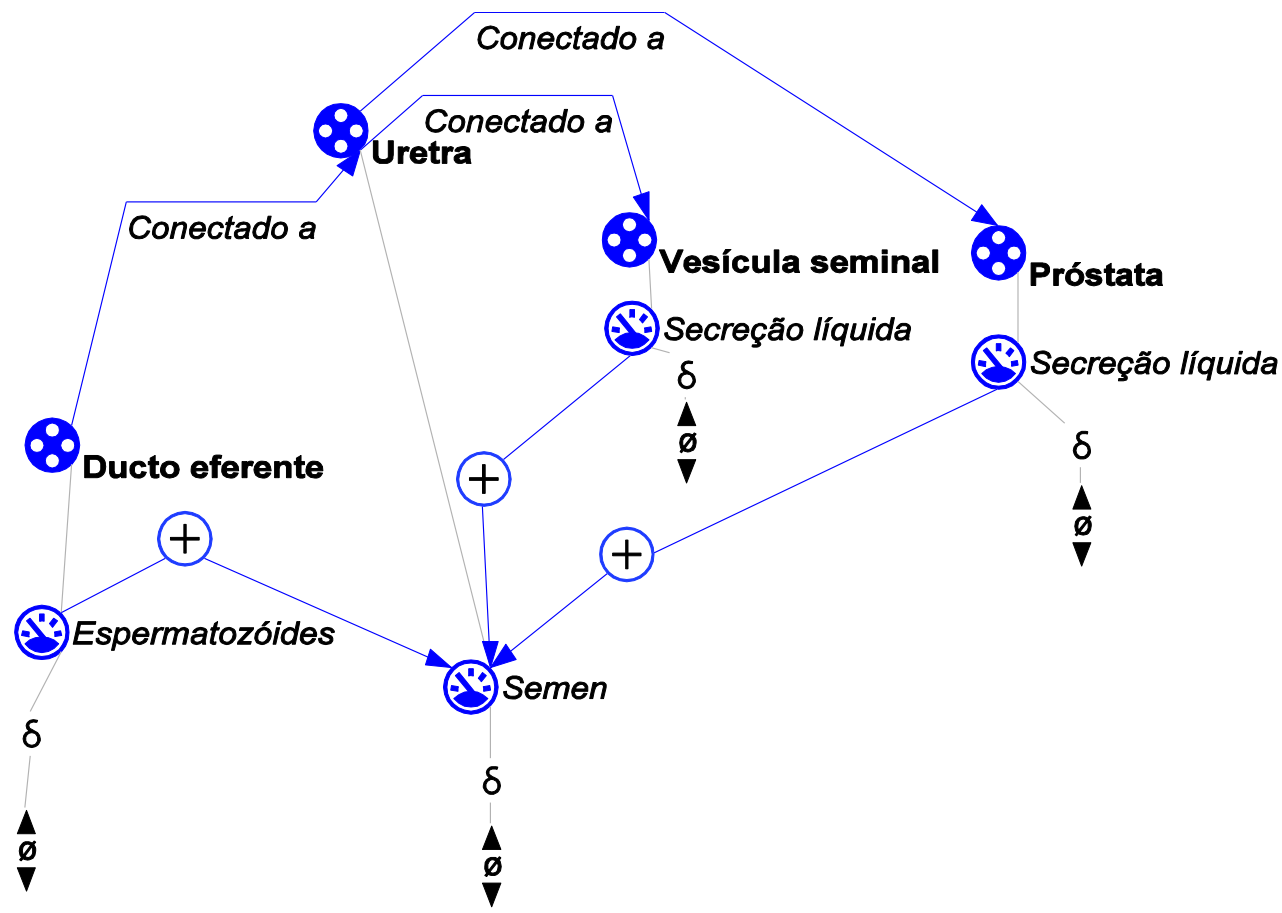

Fig. 13 - SM - Formação do sêmen

Conforme a figura 13, a seta “+” direcionada das variáveis 'Espermtozoides' para 'Semen', representa que quanto maior for a quantidade de espermatozoides nos ductos eferentes do aparelho reprodutor masculino, maior será a quantidade de sêmen na uretra. Da mesma forma, quanto menor a quantidade do primeiro, menor será a do segundo. Comportamento semelhante é notado em relação às variáveis 'Secreção líquida' da vesícula e 'Secreção líquida' da próstata em relação à variável 'Semen'.

\section{d. Representando a vasectomia e propondo discussões}

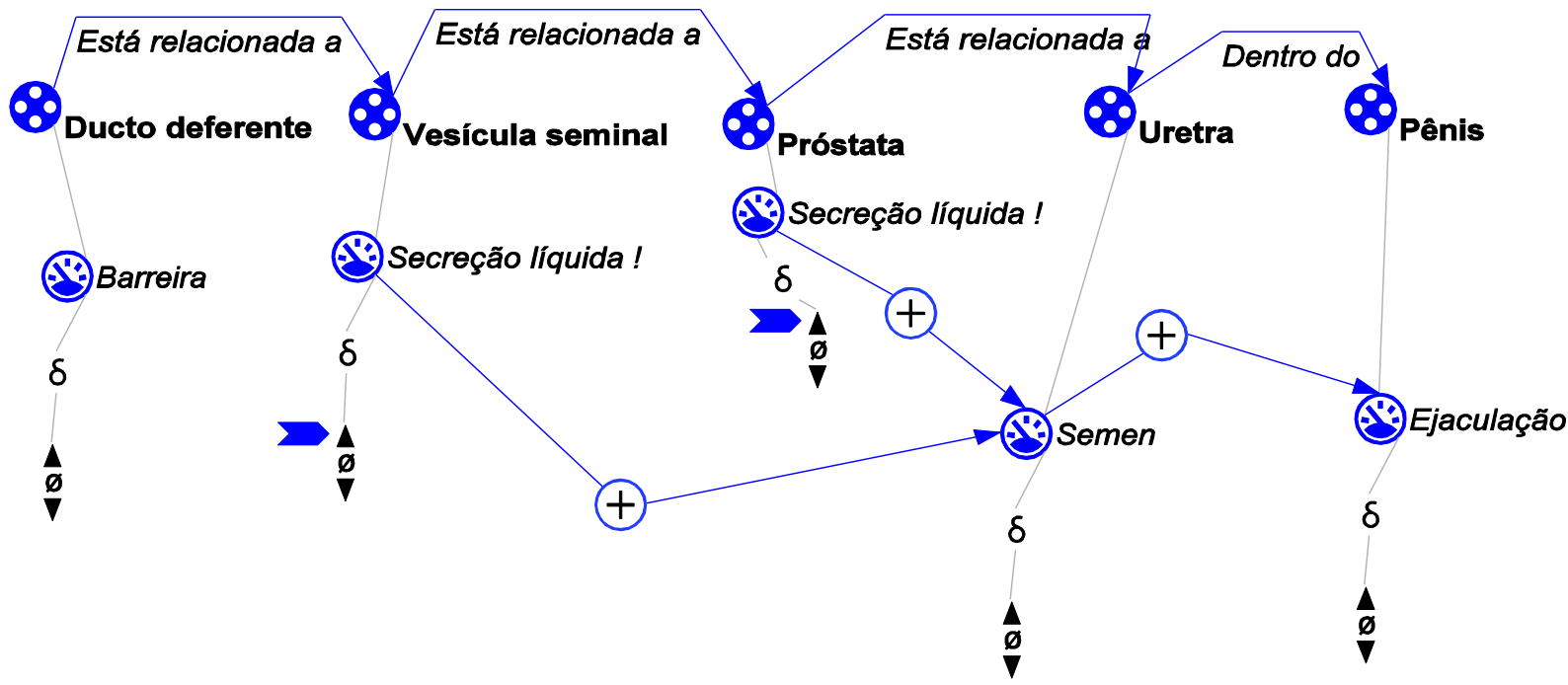

Fig.14 - SM -Formação do sêmen sem espermatozoides (cenário) 
A Figura 14 representa a mesma cadeia de causalidade mostrada na figura anterior, porém, neste cenário, foi modelada uma situação para ser discutida, sobre a presença de uma barreira nos ductos deferentes, ou seja, a vasectomia, em que os espermatozoides se tornam ausentes neste tubo. Neste caso, observa-se a formação do sêmen pelos líquidos das vesículas seminais e próstata, mas sem espermatozoides. O resultado da simulação proposta nesta figura está representada na Figura 15.

\section{e. Fazendo simulações com o LS2}

A figura abaixo mostra como ocorre uma simulação em LS2 para um cenário referente ao SM representado na Figura 14.

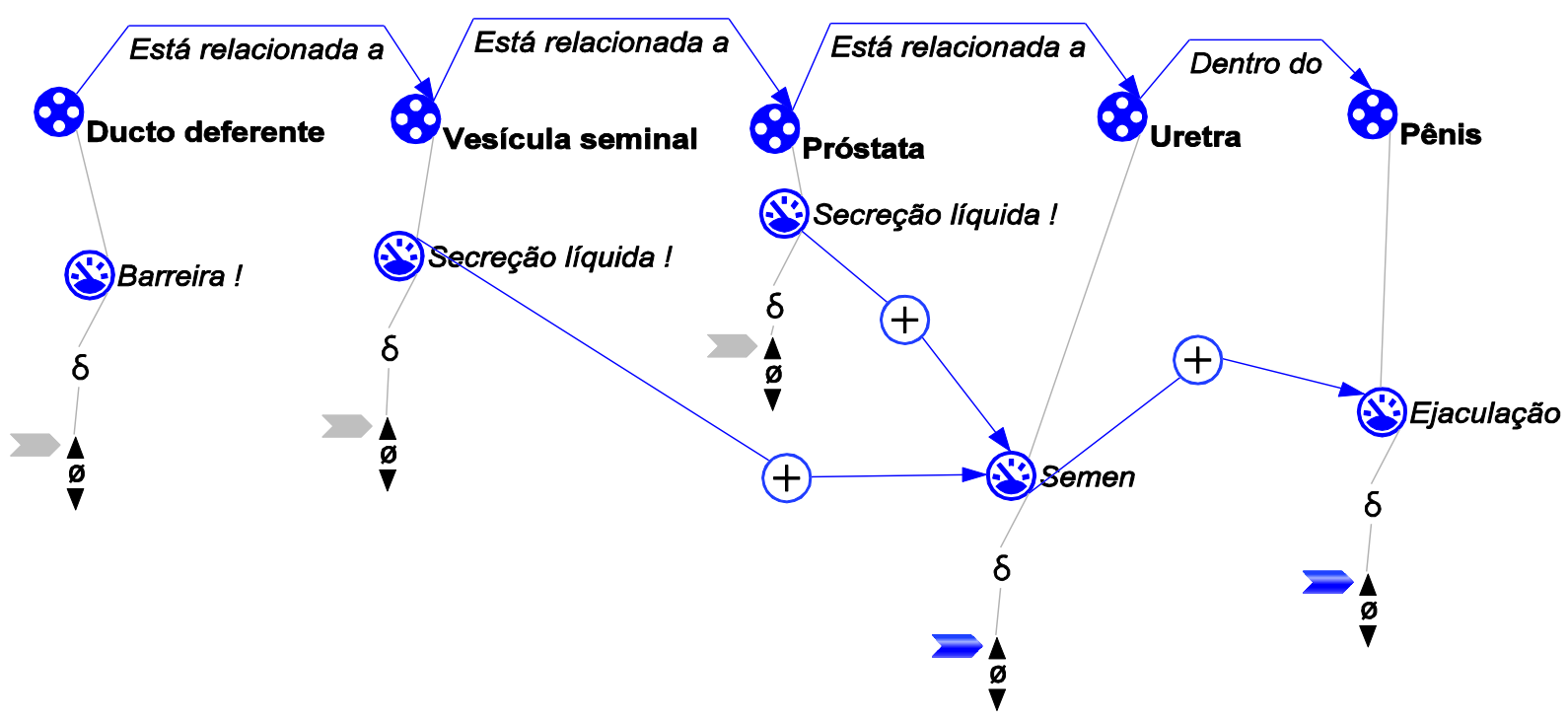

Fig. 15 - SM - Formação do sêmen sem espermatozoides (simulação)

O aluno pode marcar a derivada aumentando, da variável 'Barreira' e 'Secreção líquida' e rodar a simulação no programa. O resultado será aumentando para todas as variáveis do cenário.

A figura abaixo representa a simulação para um cenário de um SM em que não houve a vasectomia, ou seja, sem a presença da variável 'Barreira'. Neste caso o sêmen produzido terá, na sua constituição, os espermatozoides. 


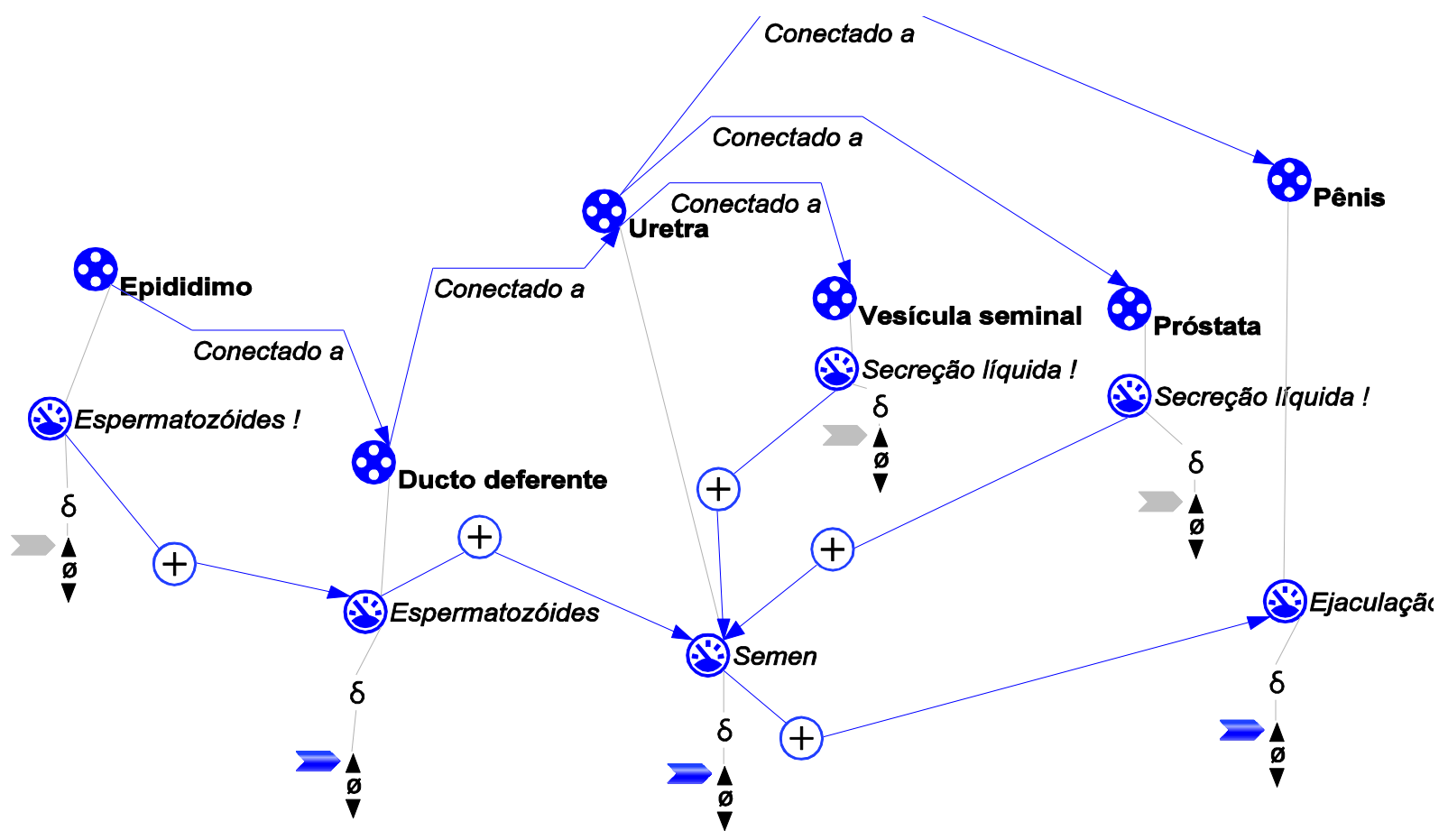

Fig. 16 - SM - Formação do sêmen com espermatozoides

\section{f. Simulação em LS2 com o TA}

As mesmas simulações representadas nas Figuras 15 e 16 podem ser feitas com o uso do TA, como foi explicado no modelo da aterosclerose.

V - Mapas conceituais sobre o aparelho reprodutor masculino.

Atividade baseada na apresentação de slides sobre modelos

VI - Texto e modelo conceitual sobre o aparelho reprodutor feminino.

Atividade baseada na apresentação de slides sobre modelos 
VII - Texto e modelo sobre a placenta.

\section{a. A estrutura do sistema}

No modelo foi assumida a representação dos principais eventos relacionados às funções da placenta do sistema reprodutor feminino humano a fim de realizar discussõs sobre o assunto. Para tal foram usadas sete entidades - 'Mãe', ' Sistema digestor', 'Sistema excretor', 'Sistema respoiratório', 'Placenta', 'Embrião', 'Sangue do embrião' que representam a estrutura do sistema no modelo como mostra a figura abaixo:

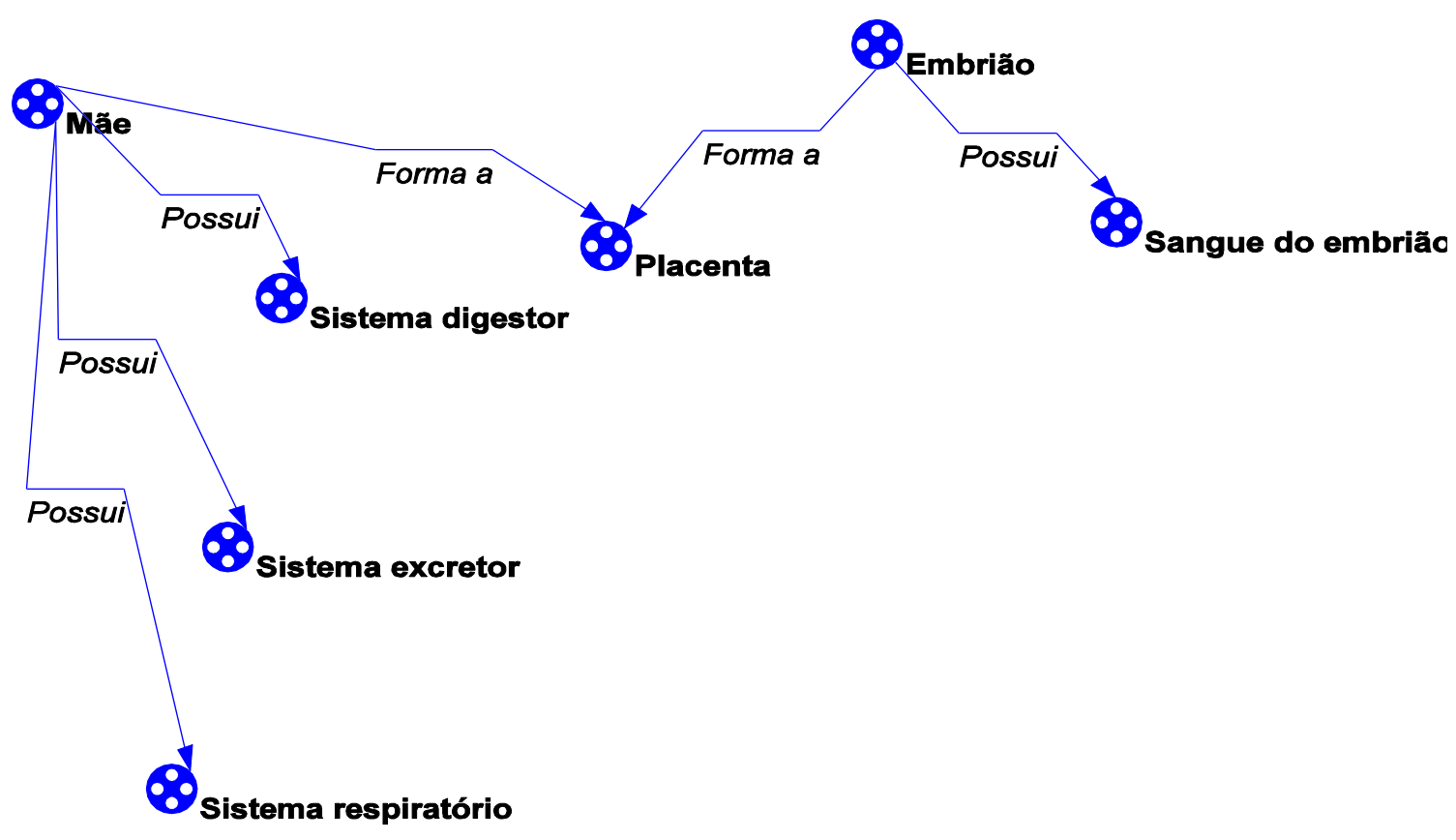

Figura 17. Árvore de entidades 


\section{b. Variáveis}

Quadro 3 - Representação das variáveis.

\begin{tabular}{|c|c|c|}
\hline Entidade & Variável & Significado \\
\hline Mãe & ----- & ------ \\
\hline Sistema digestor & Nutrientes & $\begin{array}{l}\text { Medida da quantidade de nutrientes presentes } \\
\text { no sistema digestor materno. }\end{array}$ \\
\hline Sistema excretor & Excretas & $\begin{array}{l}\text { Medida da quantidade de excretas presentes no } \\
\text { sistema excretor materno. }\end{array}$ \\
\hline \multirow[t]{2}{*}{ Sistema respiratório } & Oxigênio & $\begin{array}{l}\text { Medida da quantidade de oxigênio presente no } \\
\text { sistema respiratório materno. }\end{array}$ \\
\hline & Gás carbônico & $\begin{array}{l}\text { Medida da quantidade de gás carbônico } \\
\text { presente no sistema respiratório materno. }\end{array}$ \\
\hline \multirow[t]{4}{*}{ Placenta } & Difusão de nutrientes & $\begin{array}{l}\text { Medida da quantidade de nutrientes presente } \\
\text { na placenta materna. }\end{array}$ \\
\hline & Difusão de excretas & $\begin{array}{l}\text { Medida da quantidade de excretas presente na } \\
\text { placenta materna. }\end{array}$ \\
\hline & Difusão de oxigênio & $\begin{array}{l}\text { Medida da quantidade de oxigênio presente na } \\
\text { placenta materna. }\end{array}$ \\
\hline & Difusão de gás carbônico & $\begin{array}{l}\text { Medida da quantidade de gás carbônico } \\
\text { presente na placenta materna. }\end{array}$ \\
\hline Embrião & $\begin{array}{ll}------- \\
\end{array}$ & $\begin{array}{ll}------- \\
\end{array}$ \\
\hline \multirow[t]{4}{*}{ Sangue do embrião } & Nutrientes & $\begin{array}{l}\text { Medida da quantidade de nutrientes presentes } \\
\text { no sangue do embrião. }\end{array}$ \\
\hline & Excretas & $\begin{array}{l}\text { Medida da quantidade de excretas presentes no } \\
\text { sangue do embrião. }\end{array}$ \\
\hline & Oxigênio & $\begin{array}{l}\text { Medida da quantidade de oxigênio presente no } \\
\text { sangue do embrião. }\end{array}$ \\
\hline & Gás carbônico & $\begin{array}{l}\text { Medida da quantidade de gás carbônico } \\
\text { presente no sangue do embrião. }\end{array}$ \\
\hline
\end{tabular}




\section{c. Sub modelos}

A figura abaixo representa as trocas gasosas que ocorrem entre o sistema respiratório do corpo materno e o sangue do embrião.

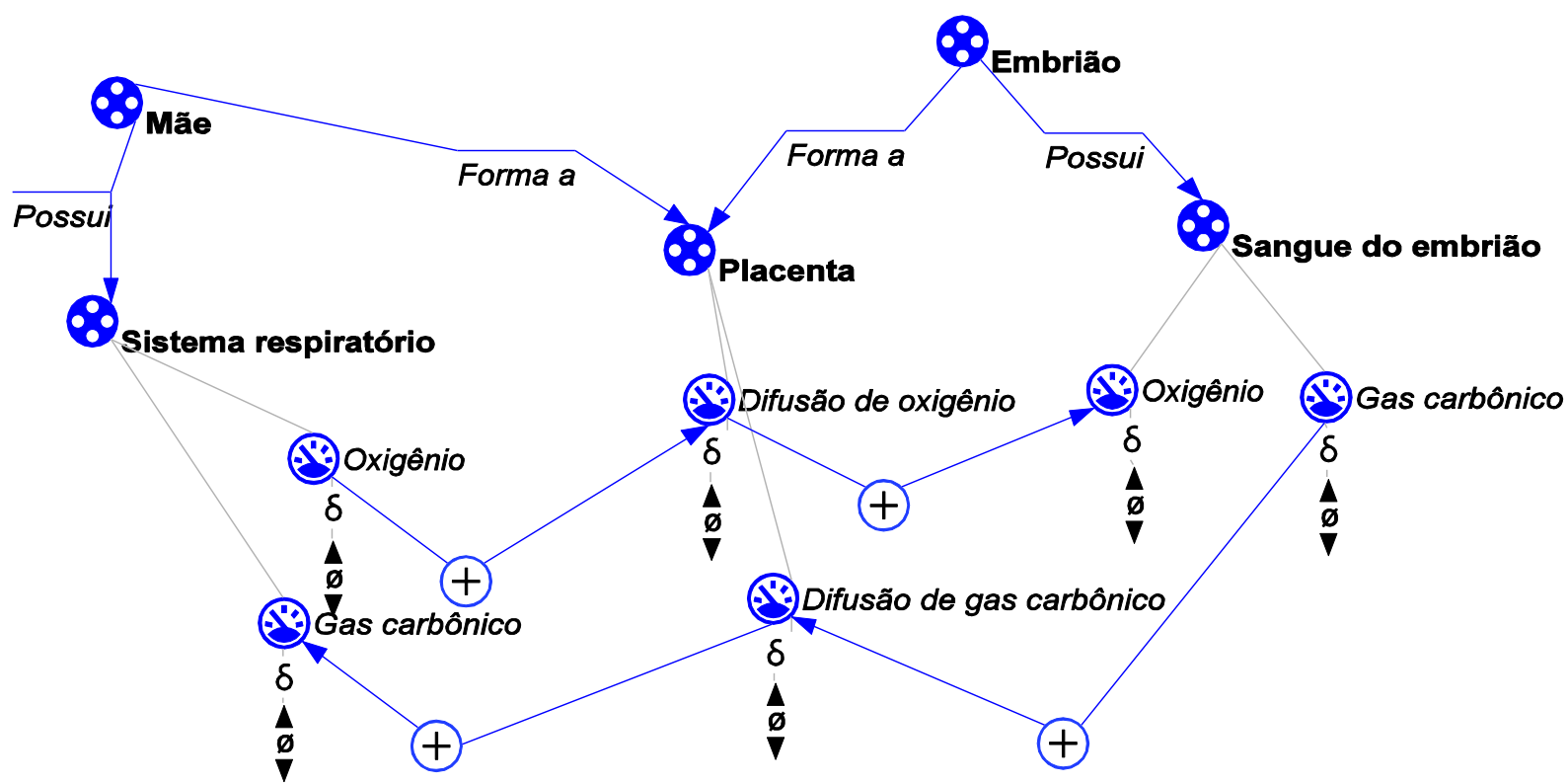

Fig. 18 - SM - Trocas gasosas entre corpo materno e embrião

Conforme a figura, a variável 'Oxigênio' da entidade 'Sistem respiratório' influencia positivamente a variável 'Difusão de oxigênio' da entidade 'Placenta' que por sua vez infuencia, também positivamente, a variável 'Oxigênio' da entidade 'Sangue do embrião'. Comportamento semelhante é observado em relação às variáveis 'Gas carbônico' - 'Difusão de gas carbônico' e 'Gas carbônico'.

\section{e. Fazendo simulações com o LS2}

A figura abaixo demonstra uma simulação em LS2 para um cenário do SM representado na figura anterior. 


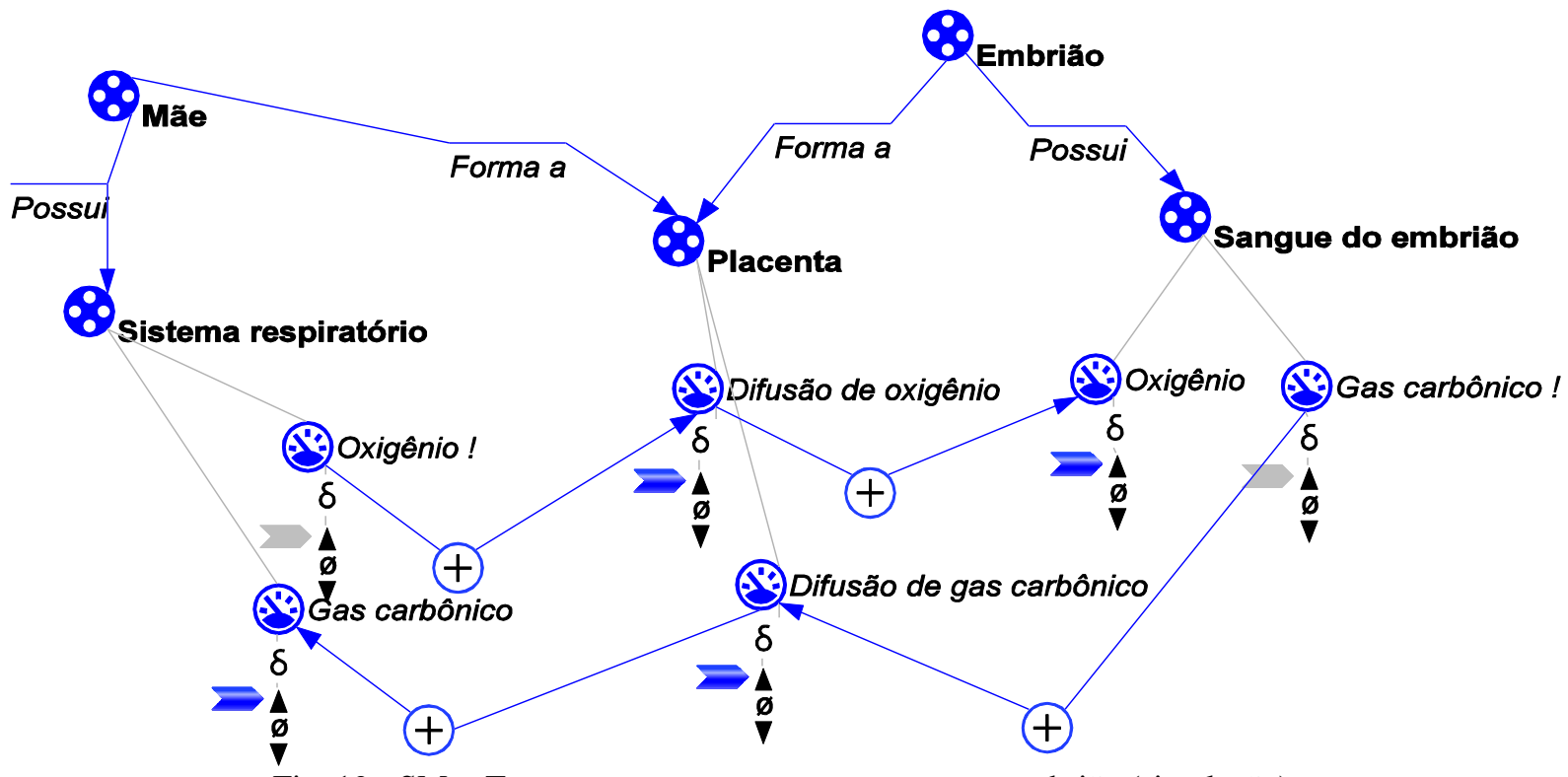

Fig. 19 - SM - Trocas gasosas entre corpo materno e embrião (simulação)

O aluno pode marcar a derivada aumentando, das variáveis 'Oxigênio' da entidade 'Sistema respiratório' e 'Gás carbônico' da entidade 'Sangue do embrião' e rodar a simulação no programa. O resultado (comportamento das variáveis) para o aumento do oxigênio será: 'Difusão de oxigênio' da entidade 'Placenta' aumentando, 'Oxigênio' da entidade 'Sangue do embrião' aumentando. A consequência do aumento do gás carbônico no comportamento das variáveis do cenário será: 'Difusão de gás carbônico' da entidade 'Placenta' aumentando e 'Gás carbônico' da entidade 'Sistema respiratório' aumentando.

\section{f. Simulação em LS2 com o TA}

As mesmas simulações representadas na Figura 19 podem ser feitas com o uso do TA, como foi explicado. 


\section{APÊNDICE}

1 - Cenários e simulações - modelo da aterosclerose.

\section{FIGURAS ATEROSCLEROSE SEM TRATAMENTO}

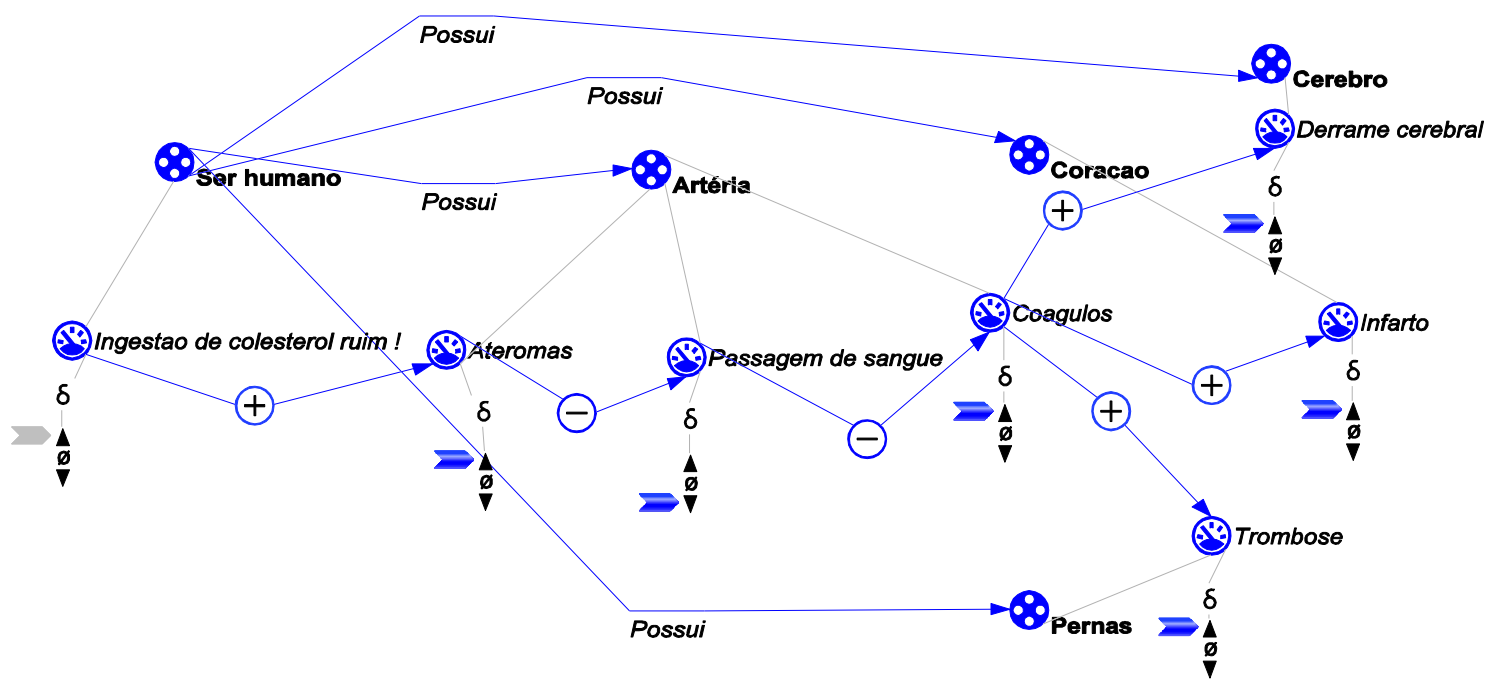

Expressão "sem tratamento" colesterol crescendo

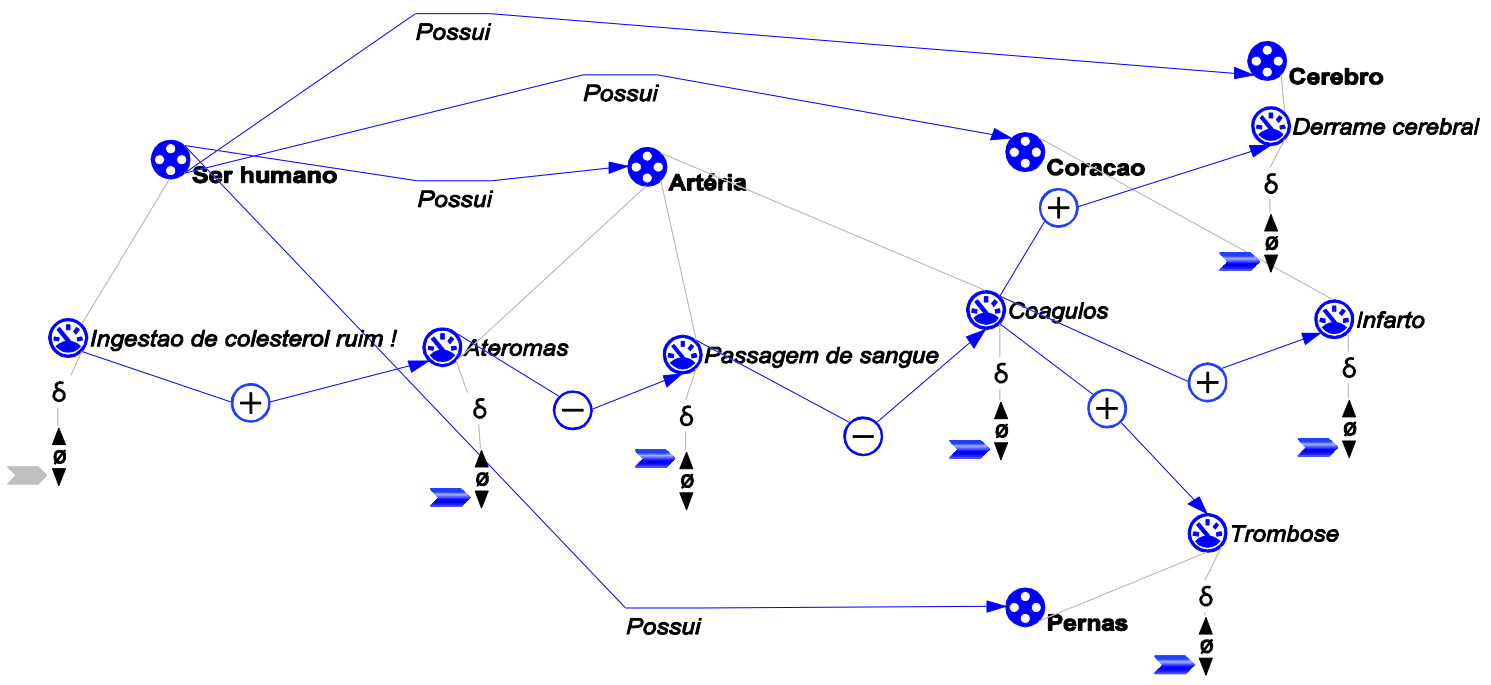

Expressão "sem tratamento" colesterol decrescendo 


\section{FIGURAS ATEROSCLEROSE COM TRATAMENTO}

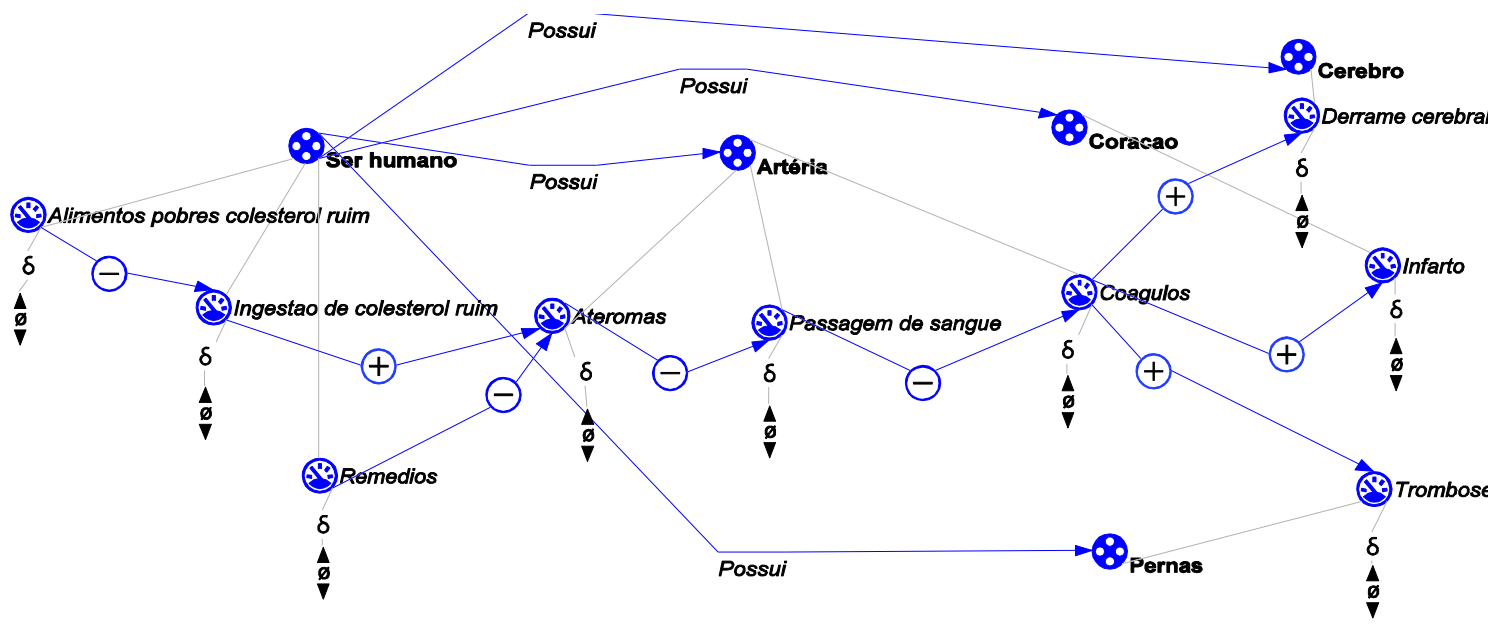

Expressão "com tratamento"

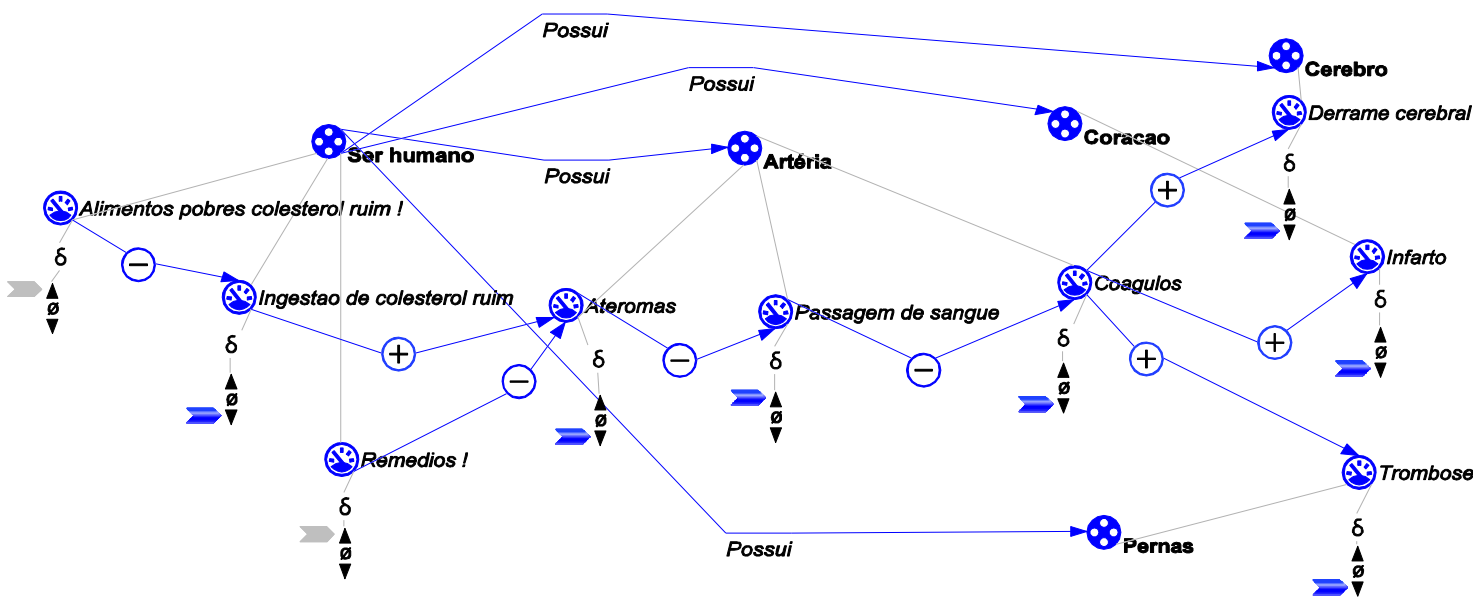

Simulação "com tratamento" baseados em alimentos bons e remédios aumentando

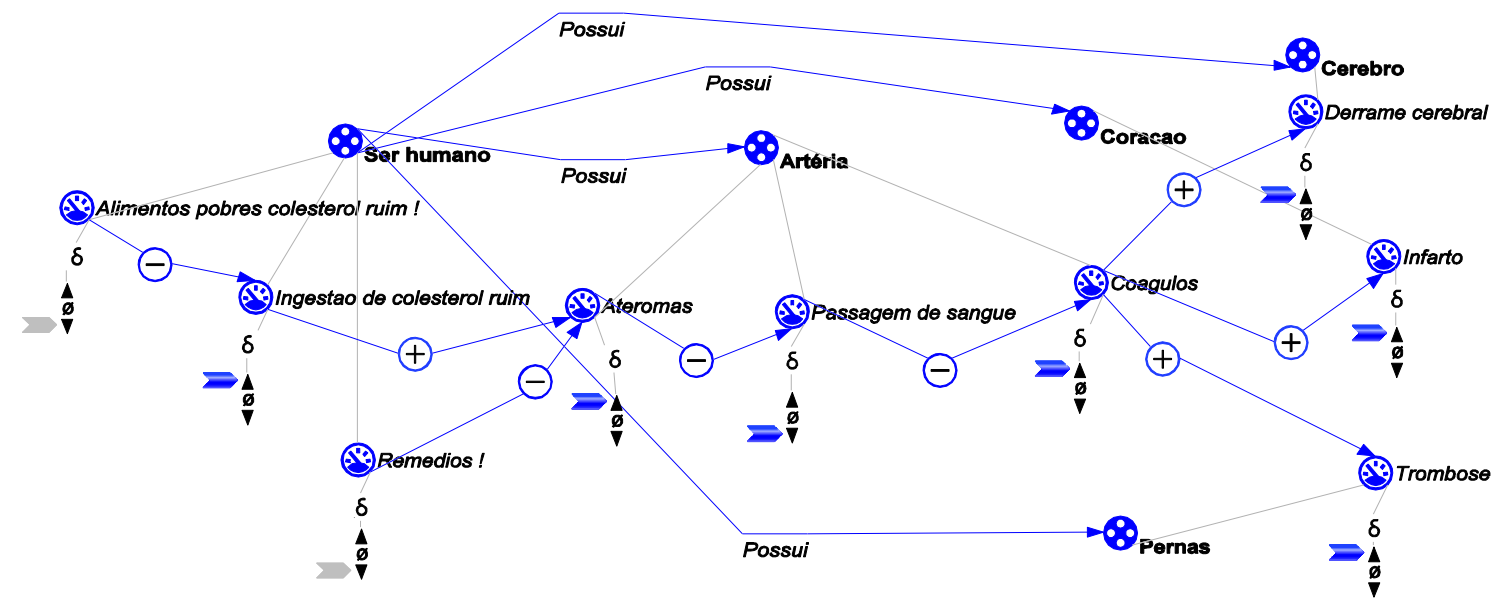

Simulação "com tratamento" baseados em alimentos bons e remédios diminuindo 


\section{2 - Cenários e simulações - modelo do aparelho reprodutor masculino.}

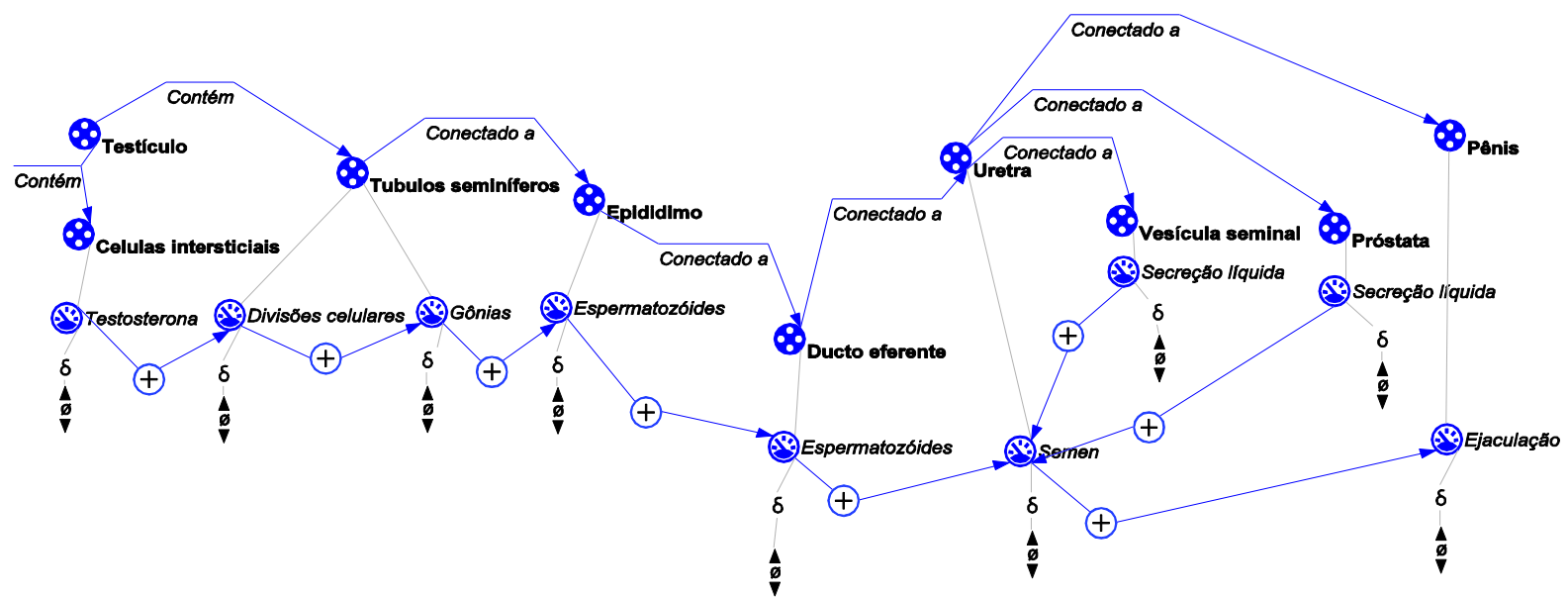

Expressão do modelo Aparelho reprodutor masculino

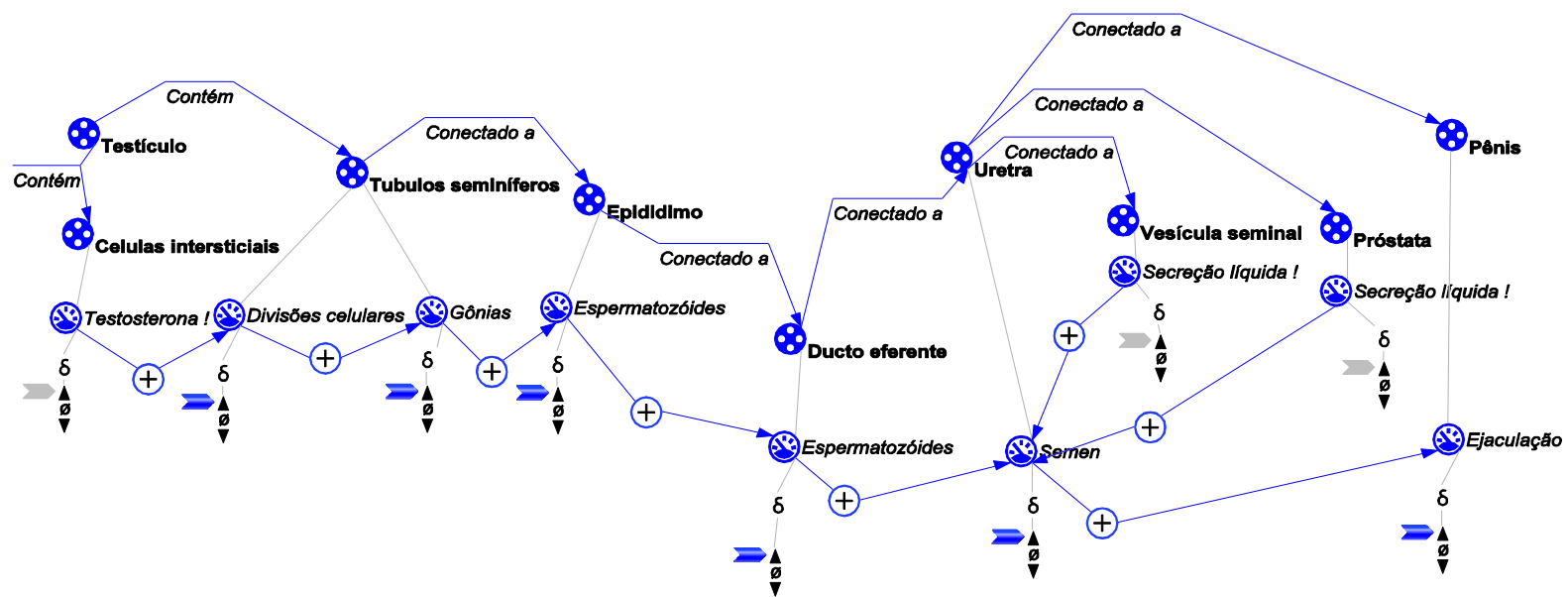

Simulação com produção de testosterona e secreção líquida aumentando

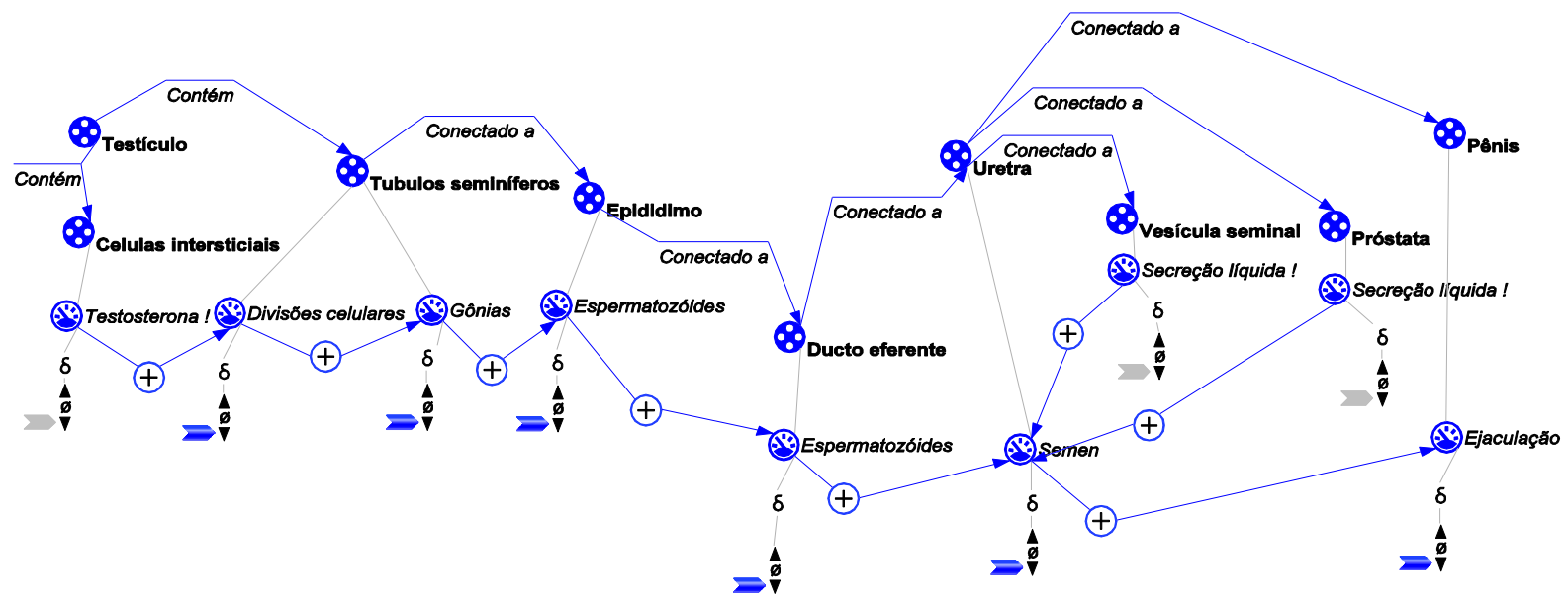

Simulação com produção de testosterona e secreção líquida diminuindo 


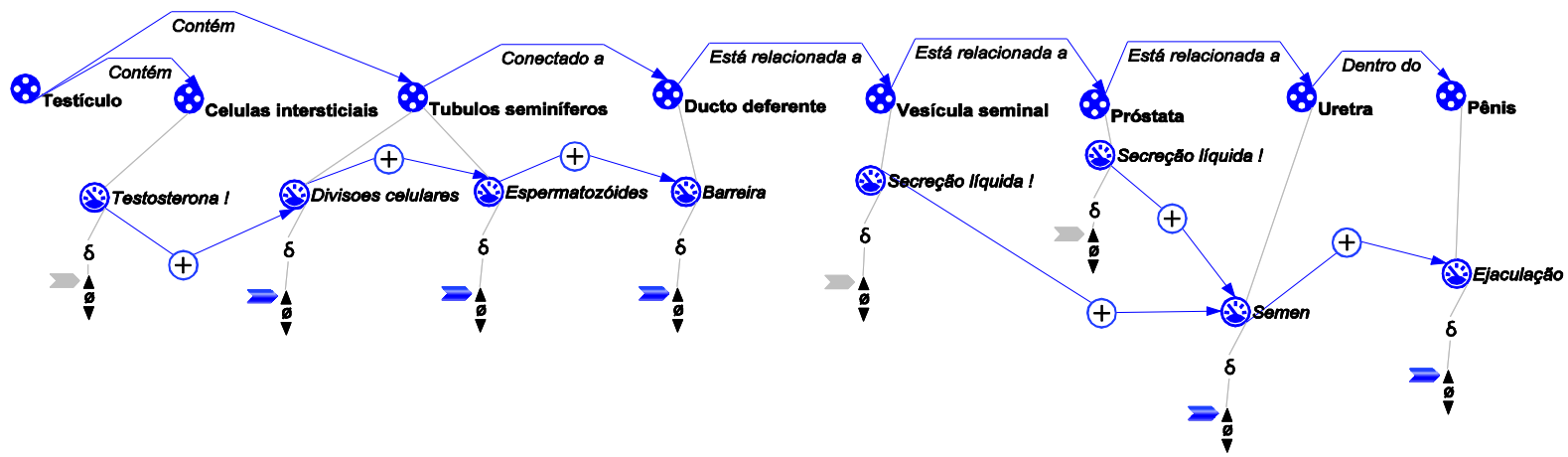

Simulação vasectomia: testosterona e secreções líquidas aumentando

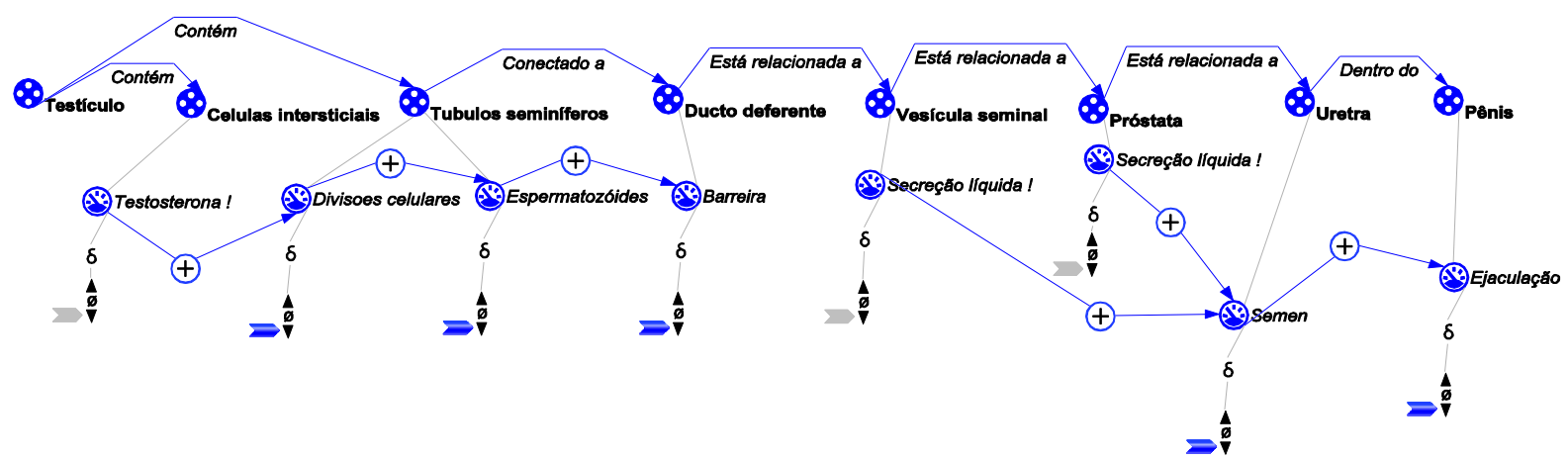

Simulação vasectomia: testosterona e secreções líquidas diminuindo 
3 - Cenários e simulações - modelo da placenta.
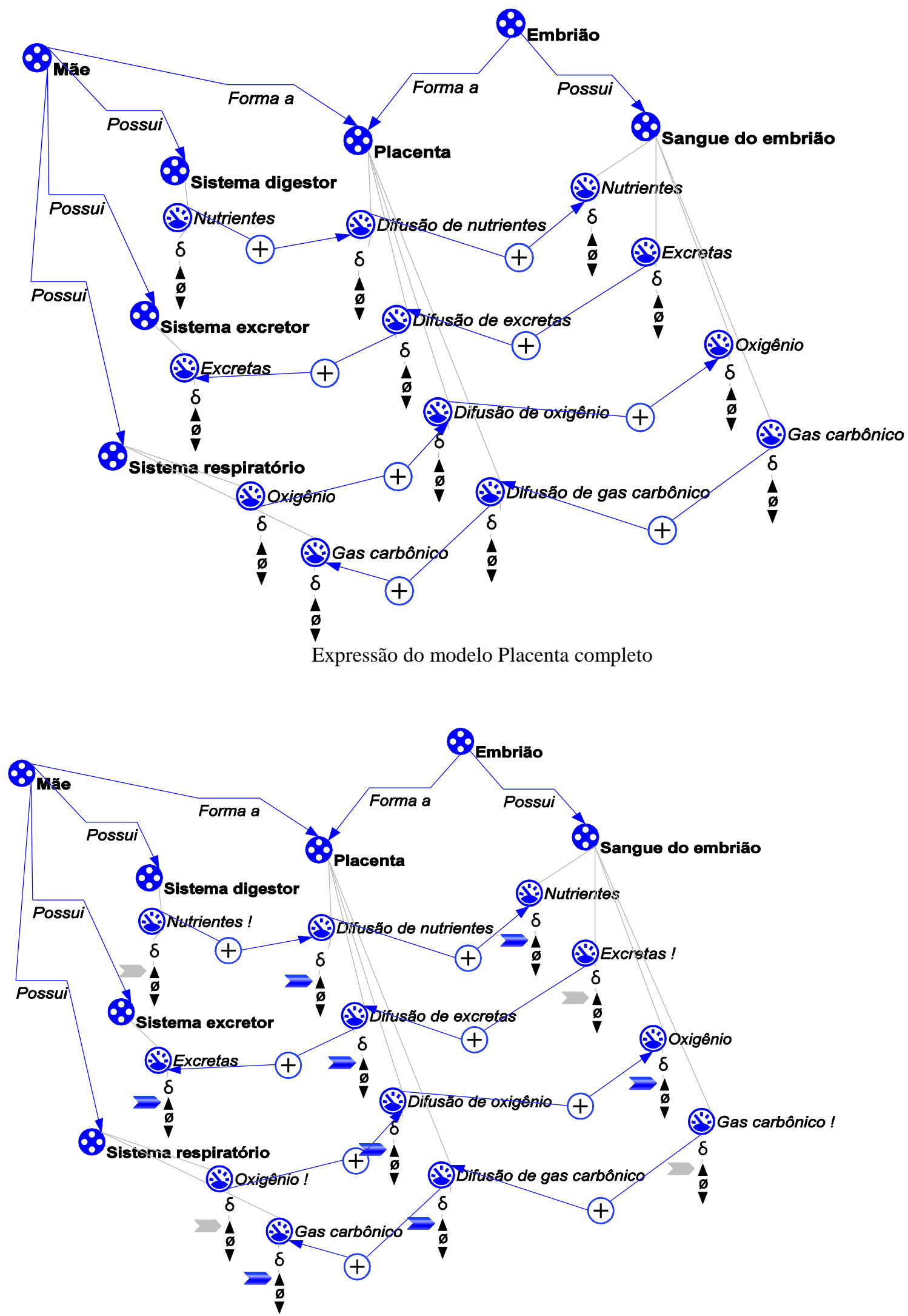

Simulação: Nutrientes e Oxigênio da mãe aumentando. Isso faz com que Excretas e Gás carbônico do sangue do embrião também estejam aumentando. 


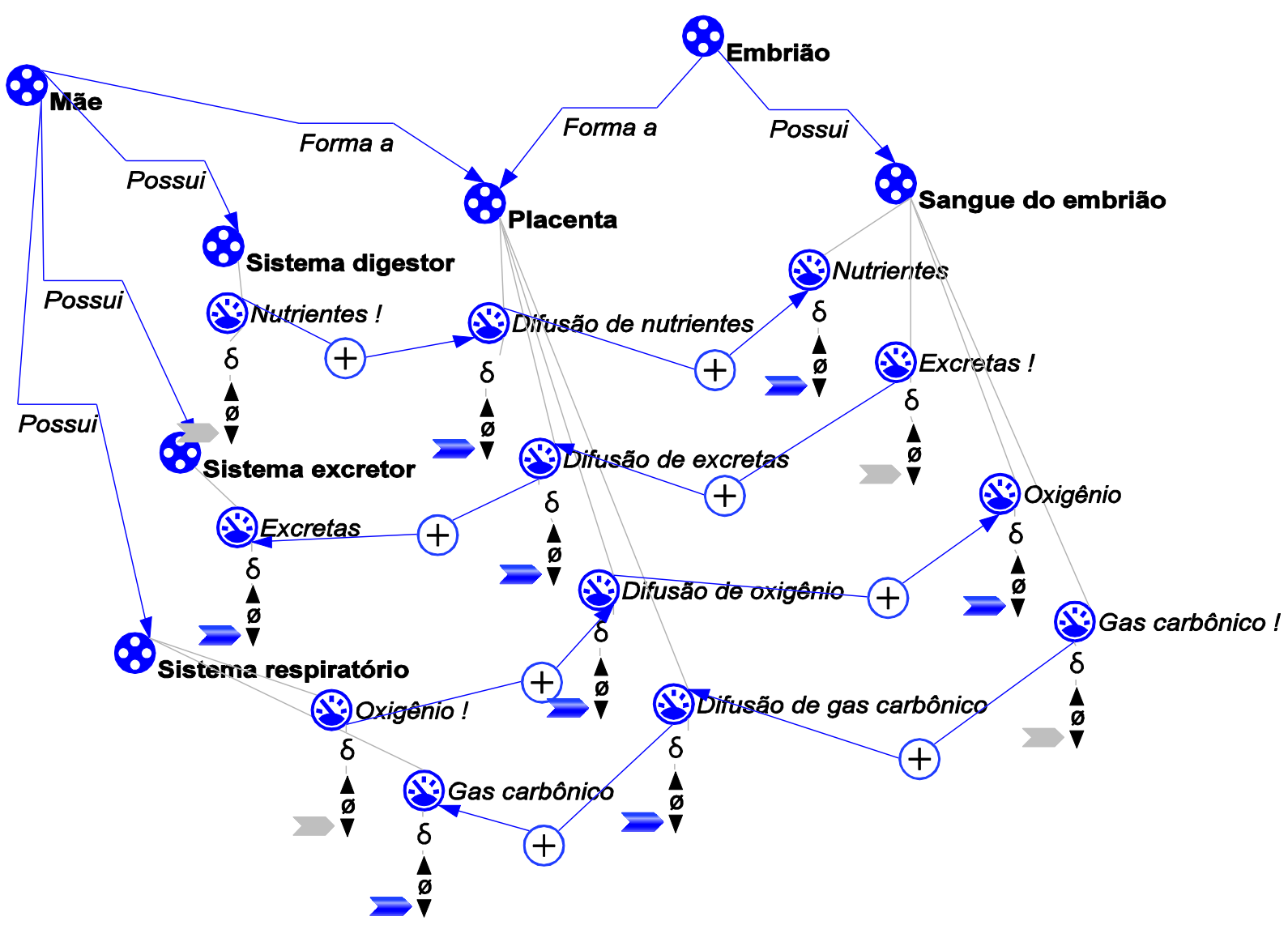

Simulação: Nutrientes e Oxigênio da mãe diminuindo. Excretas e Gás carbônico do sangue do embrião também estejam diminuindo. 
APÊNDICE E - Proposição

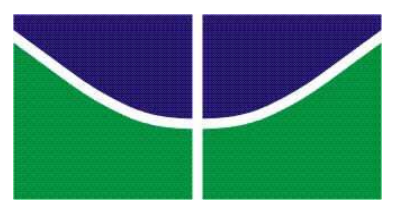

UNIVERSIDADE DE BRASÍLIA

Instituto de Ciências Biológicas

Instituto de Física

Instituto de Química

Faculdade UnB Planaltina

Programa de Pós-Graduação em Ensino de Ciências

Mestrado Profissional em Ensino de Ciências

\title{
Proposta Metodológica para a Utilização de Agentes Aprendizes Virtuais como Ferramenta de Ensino
}

\author{
Tarcisio Ferreira Cavalcante \\ Orientador: Prof. Dr. Paulo Sérgio B. de Almeida Salles
}

Brasília, DF

2015 


\section{SUMÁRIO}

Apresentação.................................................................................... 3

1- Introdução......................................................................................................... 4

2- Modelagem qualitativa fundamentada na Teoria Qualitativa dos Processos ............................................................................................................ 7

3- Atividades Propostas..................................................................................... 16

Referências.................................................................................................. 25

Apêndice I - Texto e modelo 'Boom de Algas'............................................... 26

Apêndice II - Texto e modelo 'Madeireiros x Ambientalistas'.................... 26

Apêndice III - Slides para apresentação do agente aprendiz..................... 27

Apêndice IV - Salvando um modelo no modo Agente Aprendiz................ 34

Apêndice V - Apresentando o modelo da 'Aterosclerose'............................ 36

Apêndice VI - Modelo do aparelho reprodutor masculino........................... 42

Apêndice VII - Texto e modelo sobre a placenta........................................... 47

Apêndice VIII - Outros Modelos, Cenários e Simulações............................. 50 


\section{APRESENTAÇÃO}

O minicurso aqui apresentado propõe uma alternativa para o ensino e aprendizagem sobre $\mathrm{o}$ funcionamento de sistemas em um ambiente virtual de aprendizagem subsidiado por modelagem qualitativa apoiada por agentes aprendizes virtuais a alunos do $8^{\circ}$ ano do Ensino Fundamental. Esta proposição é o cerne de uma pesquisa de mestrado junto ao programa de Pós graduação em Ensino de Ciências - PPGEC/UnB. Na pesquisa foi investigada as potencialidades do uso de modelos qualitativos apoiados por agentes aprendizes virtuais (TA ou teachable agent) no ensino de conceitos relacionados ao funcionamento de sistemas. $\mathrm{O}$ conteúdo curricular abordado consiste na discussão entre madeireiros e ambientalistas e biodiversidade, doenças do sistema circulatório humano, aparelho reprodutor masculino e aparelho reprodutor feminino. Salienta-se que o público alvo, duração das aulas, conteúdos abordados e proposta de atividades a serem realizadas nesta proposta de intervenção pedagógica foram sugeridas com base na experiência do autor e podem ser adaptadas de acordo com necessidades e características diferentes das que aqui foram propostas.

Público alvo da proposta de minicurso: professores do $8^{\circ}$ ano do Ensino Fundamental Duração do minicurso: 12 encontros de 50 minutos cada Conteúdos abordados: discussão entre madeireiros e ambientalistas e biodiversidade, doenças do sistema circulatório humano, aparelho reprodutor masculino e aparelho reprodutor feminino.

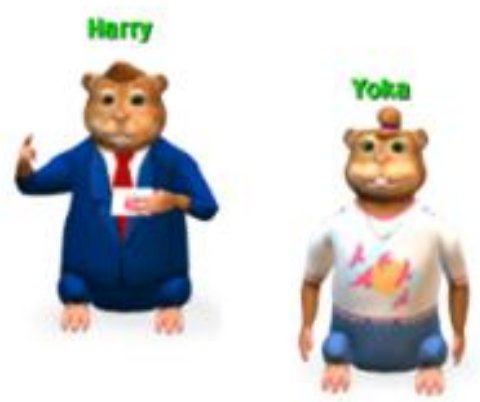

Agentes pedagógicos virtuais 


\section{1 - INTRODUÇÃO}

O agente aprendiz virtual (TA ou teachable agent) que assume a figura de um Pet (animal de estimação), é uma tecnologia desenvolvida para ambientes virtuais de aprendizagem que usa a figura de agentes pedagógicos capazes de realizar tarefas complexas, aumentam a motivação dos alunos para as atividades educacionais, e estão em constante desenvolvimento e aprimoramento de suas interfaces e funcionalidades (JOHNSON et al., 2000; ZHAO; AILIYA; SHEN, 2012; MIODUSER et al., 2012).

Os agentes aprendizes virtuais são apresentados aos estudantes para quem serão "ensinados" conceitos. Portanto, o seu foco é principalmente fazer com que o aluno aprenda ao ensinar o agente aprendiz virtual, um princípio conhecido por aprender ensinando (learning by teaching) (WIßNER et al., 2010; ZHAO et al., 2012).

Nesta tecnologia, existem basicamente três tipos de agentes virtuais que assumem papéis metafóricos: o agente aprendiz - que é o que solicita ser ensinado pelo aluno e sua aprendizagem representa a aprendizagem do aluno. O agente professor (Mr. Davis) - que representa a figura do professor, ou seja, aquele que detém conhecimentos confiáveis e fornece explicações ao aluno e o agente Quizmaster (mestre do quiz) que representa a figura de um animador de platéia, cuja função é fazer perguntas e apontar erros e acertos nas perguntas que o mesmo faz. A presente proposta foca nas contribuições didáticas do agente aprendiz.

O agente aprendiz virtual tem como função principal fazer com que o aluno sinta que esteja 'ensinando-o' novos conhecimentos. Tem a capacidade de aplicar o conhecimento 'aprendido' ao responder perguntas tanto ao aluno quanto ao Quizmaster sobre o conteúdo aprendido. Outra função deste agente virtual é a de estabelecer bom relacionamento com os alunos (por exemplo, o programa permite que o aluno dê um nome ao seu Pet) e incentivá-los a ensinar bem, a fim de estimular o aluno a assumir a responsabilidade de aprendizagem (ZHAO et al., 2012).

O Quizmaster assume papel importante ao analisarmos o agente aprendiz: ele é o responsável por fazer um jogo de perguntas - um quiz interativo - em que o agente aprendiz virtual testa seus conhecimentos (que, na verdade, são os conhecimentos do estudante) e recebe um relatório final (que é um feedback indireto, já que, metaforicamente, quem comete 
os erros é o agente aprendiz virtual) com o seu desempenho a cada nova consulta ao Quizmaster.

As respostas certas e erradas são mostradas a fim da série de perguntas, para que o aluno tenha ciência de seus erros e acertos e possa se preparar melhor (preparar melhor o agente aprendiz virtual) e submeter seu agente aprendiz virtual a novas consultas ao quiz. Esse é o princípio da representação compartilhada, citada no Cérebro de Betty (LEELAWONG \& BISWAS, 2008).

Estudantes que usam o TA podem ver como eles descobrem as respostas e como organizam seu conhecimento, pois o conhecimento é organizado e representado por modelos qualitativos, ao contrário de outros softwares nesta área, nos quais o aluno recebe a resposta certa ou errada, mas ele pode ter "chutado" essa resposta ou ter dado uma resposta "decorada" (DORIS et al., 2013).

O uso de modelagem qualitativa por meio de programas computacionais com base no Raciocínio Qualitativo tem mostrado ser uma abordagem interessante para uso em atividades educacionais (BASTOS, 2014; FELTRINI, 2009; SALLES \& BREDEWEG, 2006).

A Teoria Qualitativa dos Processos (FORBUS, 1984) oferece base conceitual para a elaboração dos modelos a serem utilizados como instrumentos de ensino-aprendizagem, que serão apresentados mais adiante. Propõe-se o uso de um software baseado nesta teoria para ser utilizado na formulação e manipulação dos modelos qualitativos que servirão como instrumento de ensino-aprendizagem. O software denomina-se DynaLearn (www.dynalearn.eu) e tem se mostrado, por meio de pesquisas, com enorme potencial para uso em atividades educacionais (Bredeweg et al. 2013).

\subsection{O objetivo}

$\checkmark \quad$ O objetivo deste trabalho é apresentar uma proposta de minicurso no ensino de Ciências para alunos do $8^{\circ}$ ano do Ensino Fundamental, baseada em material didático construído a partir de modelos qualitativos apoiados por agentes aprendizes virtuais, a serem utilizados por professores do Ensino Fundamental.

A pergunta de pesquisa desta proposta busca responder basicamente a uma questão: 
=> Como professores poderiam comunicar conceitos sobre a dinâmica de sistemas em modelos conceituais qualitativos, apoiados por agentes aprendizes virtuais, de maneira adequada para alunos do $8^{\circ}$ ano do Ensino Fundamental?

\section{2 - Estruturação desta proposta}

Esta proposta de intervenção pedagógica está estruturada em três seções, incluindo esta primeira, que é a introdução. A seção 2 apresenta o Raciocínio Qualitativo e a modelagem qualitativa que são dois conceitos importantes para o entendimento da base conceitual que fundamenta este trabalho, que é a Teoria Qualitativa dos Processos (FORBUS, 1984). Descreve o software utilizado nesta pesquisa, o DynaLearn, particularmente o nível LS2 (modelos causais básicos), e traz informações sobre os agentes aprendizes virtuais.

A metodologia proposta para que professores de ciências ensinem conceitos sobre o funcionamento da dinâmica e estrutura de sistemas a alunos do $8^{\circ}$ ano do Ensino Fundamental é descrita na seção 3. 


\section{2 - MODELAGEM QUALITATIVA FUNDAMENTADA NA TEORIA QUALITATIVA DOS PROCESSOS}

\section{1 - Raciocínio Qualitativo e Modelagem Qualitativa}

O Raciocínio Qualitativo é uma área da Inteligência Artificial adotada em estudos e representações de propriedades contínuas de sistemas físicos, sobre os quais os dados disponíveis são incompletos ou imprecisos, sem o uso de cálculos matemáticos (FORBUS, 1984). Este tipo de raciocíno é muito útil nos casos em que não se exige respostas exatas e baseia-se em observações. É muito usado no estudo da predição do comportamento de sistemas físicos com base na representação da estrutura dos sistemas modelados.

A modelagem qualitativa é fundamentada no Raciocínio Qualitativo. O foco desse tipo de modelagem é desenvolver e implementar técnicas que permitam representar e facilitar a compreensão da estrutura e dinâmica de sistemas (Forbus, 1984).

\section{2 - Teoria Qualitativa dos Processos}

A abordagem que fundamenta este trabalho baseia-se na Teoria Qualitativa dos Processos, frequentemente representada pela sigla TQP (FORBUS, 1984).

De acordo com esta teoria, os sistemas são delimitações de conjuntos constituídos por objetos. Estes objetos se relacionam e são capazes de realizar funções específicas, cujos estados dependem uns dos outros. Possui uma delimitação que define o que faz parte ou não do sistema (SALLES \& BREDEWEG, 2006).

Os objetos de um sistema (representados pelas entidades) têm suas relações estabelecidas por configurações e possuem certas "quantidades" ou "variáveis". As variáveis podem estar diminuindo, estáveis ou aumentando. Esta variação representada por -, 0 ,+ é a derivada (SALLES \& BREDEWEG, 2006).

Como exemplo, o sistema pode ser representado pelo 'ser humano', definido como uma entidade do modelo que pode ter relação com outra entidade, como por exemplo, o 'cérebro' e neste caso, uma configuração ('possui') irá mostrar esta relação: 'ser humano' 
possui 'cérebro'. A entidade 'ser humano' possui algumas propriedades definidas como variáveis, dentre as quais podemos citar a 'ingestão de colesterol ruim' que é representada no modelo exatamente pelo mesmo nome. "Artéria" possui as variáveis Ateromas e Passagem de sangue. Os valores dessas variáveis são representados apenas pelas derivadas. A cadeia causal representada é: se Ingestão aumenta, Ateomas aumentam e Passagem de sangue diminui.

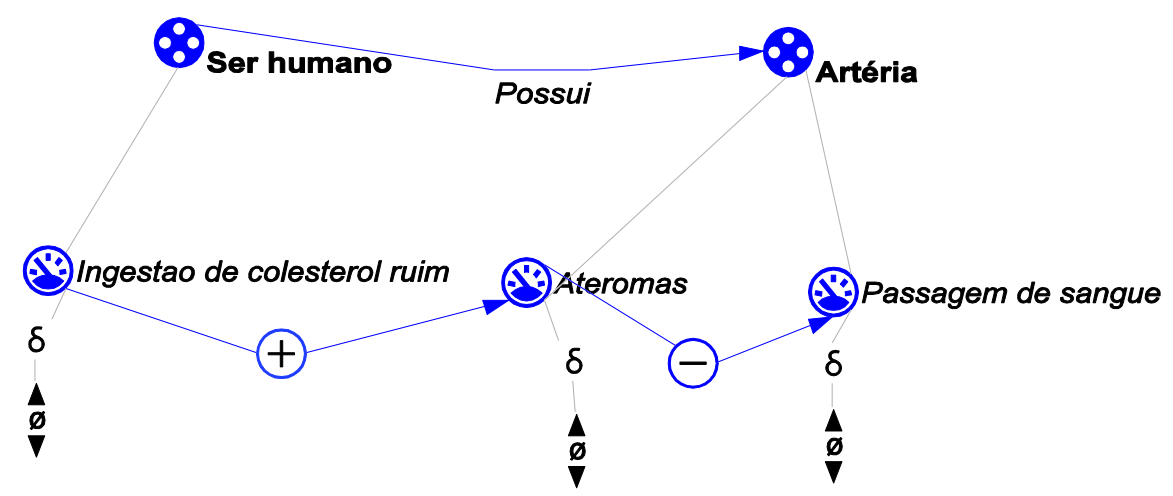

Figura demonstrativa - modelo no qual Ingestão de colesterol ruim influencia Ateromas, que por sua vez influenciam Passagem de sangue.

\section{3 - O DynaLearn}

O simulador utilizado no presente trabalho foi o DynaLearn, na versão 1.0.5 (BREDEWEG et al., 2013). O download deste software para uso acadêmico pode ser feito a partir do sítio http://hcs.science.uva.nl/projects/DynaLearn/software/\#download.

Este programa apresenta um ambiente de aprendizagem inteligente, que permite que os alunos adquiram conhecimentos conceituais por meio da construção de modelos qualitativos e simulação de como os sistemas se comportam. Neste programa, representações diagramáticas devem ser criadas pelos alunos para expressarem suas ideias. O ambiente é equipado com componentes de tecnologia semântica capazes de gerar um feedback baseado no conhecimento, e personagens virtuais aumentam a interação com os alunos, aumentando a motivação destes (BREDEWEG et al., 2013).

Este programa permite que os alunos construam sua interpretação conceitual do comportamento dos sistemas estudados e ao mesmo tempo aprender conceitos de diversas disciplinas. Por meio dos modelos construídos, os alunos podem fazer simulações e elaborar explicações sobre os conteúdos estudados e ainda, guardar seus modelos em um repositório on line e compará-los a outros modelos (BREDEWEG et al., 2013).

O DynaLearn é um software projetado para atender, principalmente, necessidades para uso em atividades educacionais. O comportamento de sistemas de interesse do usuário pode 
ser representado por esquemas visuais, e simulações podem prever mudanças no comportamento do sistema. Por meio de adição, retirada ou mudança de conteúdos do modelo, é possível prever estados futuros do sistema ou alterar as condições do cenário inicial e explorar simulações do tipo "o que aconteceria se...".

$\mathrm{O}$ ambiente inteligente de aprendizagem de DynaLearn permite aos alunos externalizarem suas ideias e abstrações, tornando-as visíveis. Essas abstrações, uma vez visualizadas por expressões diagramáticas, podem ser melhor organizadas, o que permite um melhor entendimento, aprofundamento e reflexão, tanto individual quanto coletiva, em prol da construção de conhecimentos e entendimento de fenômenos abstratos ou de difícil compreensão se apresentados apenas em linguagem verbal ou escrita.

Este software faz parte de uma categoria que, além de gerar feedbacks em relação ao tema que o usuário modela, cria situações de interatividade por meio de sua interface, com ícones autoexplicativos e agentes aprendizes virtuais, que beneficia os alunos modeladores e os incentiva a desenvolver sua autonomia. Desse modo, os alunos vivem situações em que são "autores" da representação que constroem de conceitos científicos e sujeitos ativos no processo de desenvolvimento de conhecimento conceitual.

O DynaLearn tem sido utilizado em cursos de formação de professores e preparação de atividades didáticas com alunos surdos e ouvintes e inclusive em educação a distância (BASTOS, 2014; RESENDE, 2010). O programa é versátil e permite a manipulação e a criação de modelos conceituais, que são aqueles capazes de abordar conteúdos diversos, desde que contemplem a visão sistêmica e contribuam para a compreensão dos conteúdos modelados (SALLES \& BREDEWEG, 2006). Com DynaLearn, é possível capturar imagens das telas em qualquer etapa da modelagem. o que, juntamente com as características já descritas, permite a criação de materiais didáticos inovadores.

Dynalearn oferece a seus usuários 6 níveis de espaços de aprendizagem, crescentes e complementares de complexidade (representados pela sigla LS que em inglês significa Learning Space), projetados para serem usados independentemente, ou como degraus na aprendizagem dos alunos, já que cada um dos primeiros 5 níveis serve de preparação para que o aluno possa utilizar os níveis subsequentes. Desse modo, cada espaço de aprendizagem funciona como uma etapa na sequência da aprendizagem iniciada nos níveis anteriores, com maior aprofundamento na exploração de conteúdos, o que exige maior esforço de modelagem.

O nível de menor complexidade do DynaLearn é o LS1 - ("Mapas conceituais"), que permite a construção de diagramas formando nós (representando conceitos) e ligados entre si por meio de setas (descrevendo a ligação entre dois nós), conhecidos como mapas conceituais. 
Nesse ambiente, há uma grande liberdade na hora da modelagem, o que dá algumas vantagens, como a facilidade de manipulação por usuários com o mínimo de experiência com o software e a linguagem da modelagem. Porém, traz limitações em relação ao aprofundamento dos modelos construídos e dos conteúdos de aprendizagem. Neste espaço de aprendizagem, não existem cadeias de causalidade e não é possível fazer simulações, como ocorre nos outros 5 níveis subsequentes. Mapas conceituais são muito úteis para alunos e professores, para a organização de idéias, planejamento de ações e avalição. Apesar das limitações descritas para o contexto deste trabalho, serve de ancoragem para o uso do nível 2 (LS2).

O LS2 ("Modelo Causal Básico") tem como objetivo fazer com que os alunos adquiram uma compreensão global das relações de causa e efeito que regem o comportamento de um sistema (BREDEWEG et al., 2013). Permite aos alunos aprenderem sobre a distinção entre entidades e variáveis, e que os alunos expressem relações de dependência entre as variáveis que carregam a informação causal (sempre na direção da variável origem para a variável destino). Este nível será melhor detalhado ainda nesta seção.

No nível LS3 de complexidade ("Modelo Causal com Gráfico de Estado"), o usuário pode analisar mais de um estado de comportamento do sistema. Além de permitir a comparação entre estados diferentes, o LS3 introduz as magnitudes das variáveis, com seus respectivos espaços quantitativos. Por exemplo, \{zero, pequeno, médio, grande, máximo $\}$. $\mathrm{O}$ aluno modelador pode estabelecer relações entre as magnitudes, aumentando o nível de profundidade e melhorando compreensão do comportamento do sistema modelado.

O objetivo do LS4 ("Diferenciação Causal") é refinar a noção de causalidade nos alunos modeladores pela diferenciação das influências direta e indireta (BREDEWEG et al., 2013), comentada na seção 2.2. Nesse nível, é possível representar melhor processos com efeitos opostos (por exemplo, encher X esvaziar containers; emitir poluentes X despoluir; natalidade X mortalidade), criar todos os tipos de mecanismos de retroalimentação e considerar, nos modelos, a ação de agentes externos ao sistema.

O objetivo do nível de complexidade LS5 ("Conhecimento Condicional") é que os alunos adquiram uma compreensão mais refinada das condições para que processos comecem ou terminem seus efeitos sobre o comportamento do sistema (BREDEWEG et al., 2013). Em relação ao LS4, a diferença é considerar conhecimento condicional aquele segundo o qual alguns fatos modelados só produzirão efeitos sobre o sistema em determinadas condições. Este nível pode ser considerado uma versão simplificada do LS6. 
O LS6 ("Conhecimentos genéricos e reusáveis") é o nível mais complexo. Os alunos criam cenários (descrevem estados iniciais do sistema) e, em lugar de construir todo o modelo em uma única tela, utilizam fragmentos de modelos, pequenas partes de um modelo que capturam representações de processos ou de situações, e que podem ser reutilizadas (por exemplo, a descrição do processo natalidade pode ser usada na mesma simulação em duas ou mais populações diferentes), e que podem trazer algumas regras para as simulações realizadas a partir de cenários diferentes (BREDEWEG et al., 2013).

\section{4 - Modelos Causais Básicos (LS2)}

Os diagramas de influência permitem a construção de modelos qualitativos que podem ser utilizados para o ensino sobre noções da estrutura e funcionamento de sistemas. A dinâmica de sistemas pode ser representada e trabalhada com os alunos por meio de cadeias de causalidade em que um objeto A influencia um B e este um C, por exemplo. Os diagramas de influência podem ser úteis na representação de conteúdos sobre sistemas dinâmicos pela representação de quais quantidades recebem influência e quais são influenciadas por elas em determinado sistema.

Este nível de aprendizagem costumar ser utilizado por modeladores que desejam aperfeiçoar seus modelos, em busca de representação de diferentes sistemas e de representação das dinâmicas dos sistemas modelados. Este nível de aprendizagem pode ser preferido em relação aos seus níveis subsequentes em atividades que requerem modelos de menor complexidade, e em atividades de introdução de conceitos elementares sobre estrutura e funcionamento de sistemas dinâmicos. Para as atividades propostas no presente trabalho, este nível de complexidade pareceu ser o mais próximo do nível de maturidade dos alunos, jovens de $8^{\circ}$ ano do Ensino Fundamental, e foi suficiente para aplicarmos nossas análises.

Por último, mas não menos importante, este nível é, na versão corrente de DynaLearn, o único que permite o uso de agentes aprendizes virtuais personalizados e ensináveis que auxiliam na construção de modelos e despertam o estímulo e motivação dos alunos durante a modelagem.

O modelo é constituído por entidades interligadas por configurações que representam a estrutura do sistema e por variáveis relacionadas por setas positivas e negativas que representam cadeias de causa e efeito. A cadeia de causalidade é representada por meio de setas, que partem da variável A no sentido da variável $B$. As setas são identificadas pelo sinal 
positivo (+) ou pelo sinal negativo (-). A situação momentânea de um sistema, considerando as variáveis e as cadeias de causalidade agindo entre elas é dito um estado do sistema. A representação de uma situação inicial de um sistema, pronto para rodar uma simulação, denomina-se cenário.

Para que simulações sejam realizadas no LS2, marca-se o valor inicial da(s) derivada(s) de uma ou mais variáveis que iniciam uma cadeia de causalidade. A partir desse cenário, a mudança no sistema se propaga pela alteração dos valores das derivadas das demais quantidades, por meio das influências positiva ou negativa, da variável A para a variável B, de $\mathrm{B}$ para a $\mathrm{C}$, e assim por diante, até que a última influência aja sobre a última variável da cadeia de causalidade.

Se a relação entre as duas quantidades é mediada por uma influência de sinal negativo $(-)$, as duas quantidades variam em direções opostas. Veja-se as figuras abaixo:

\section{Influência negativa:}

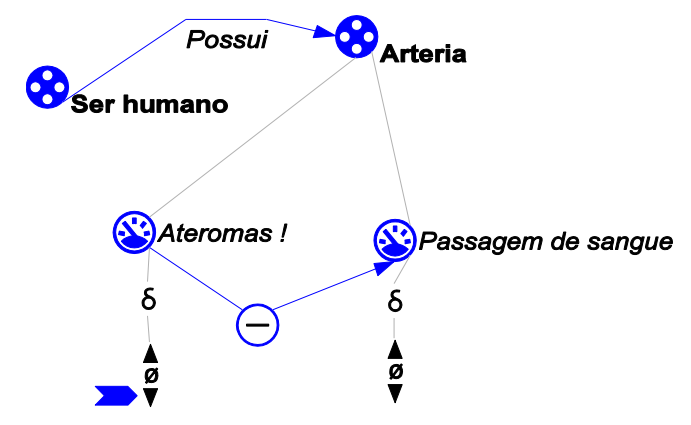

Figura 1a. Cenário LS2, com Ateromas diminuindo

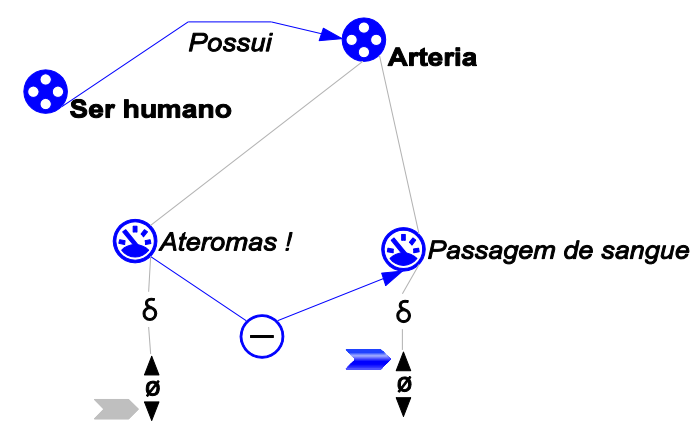

Figura 1b. Simulação LS2 com Ateromas diminuindo e influenciando Passagem de sangue

Se Ateromas estiver diminuindo (Figura 1a), sua influencia negativa sobre Passagem de sangue fará com que esta quantidade aumente (Figura 1b). Se Ateromas estiver aumentando, sua influencia negativa sobre Passagem de sangue fará com que esta quantidade diminua. Ou seja, se a variável A estiver crescendo, a variável B estará diminuindo; se A estiver diminuindo, B aumentará; e se A estiver estável, b também se manterá estável. 
Por outro lado, se a relação entre as duas quantidades é mediada por uma influência de sinal positivo (+), as duas quantidades variam na mesma direção (ambas crescem, permanecem estáveis ou diminuem).

\section{5 - O AGENTE APRENDIZ}

A proposta do programa é que o aluno simule o "ensino" a um Pet que tem a capacidade de "aprender", adicionando conteúdos (representados por elementos de modelagem como entidades, configurações, quantidades e influências) na forma de modelos. Este Pet é capaz de responder a questões do tipo "aumenta" ou "diminui", de acordo com a montagem do modelo pelo aluno. Durante o processo de modelagem, sempre que o aluno julgar necessário, o Pet aprendiz é submetido a um pequeno teste, por meio de questionamentos feitos pelo mestre do quiz (Quizmaster). Os acertos ou erros cometidos pelo Pet aprendiz são demonstrados por meio de um relatório. As figuras 2,3 e 4 mostram algumas situações de modelagem com uso dos agentes aprendizes virtuais.

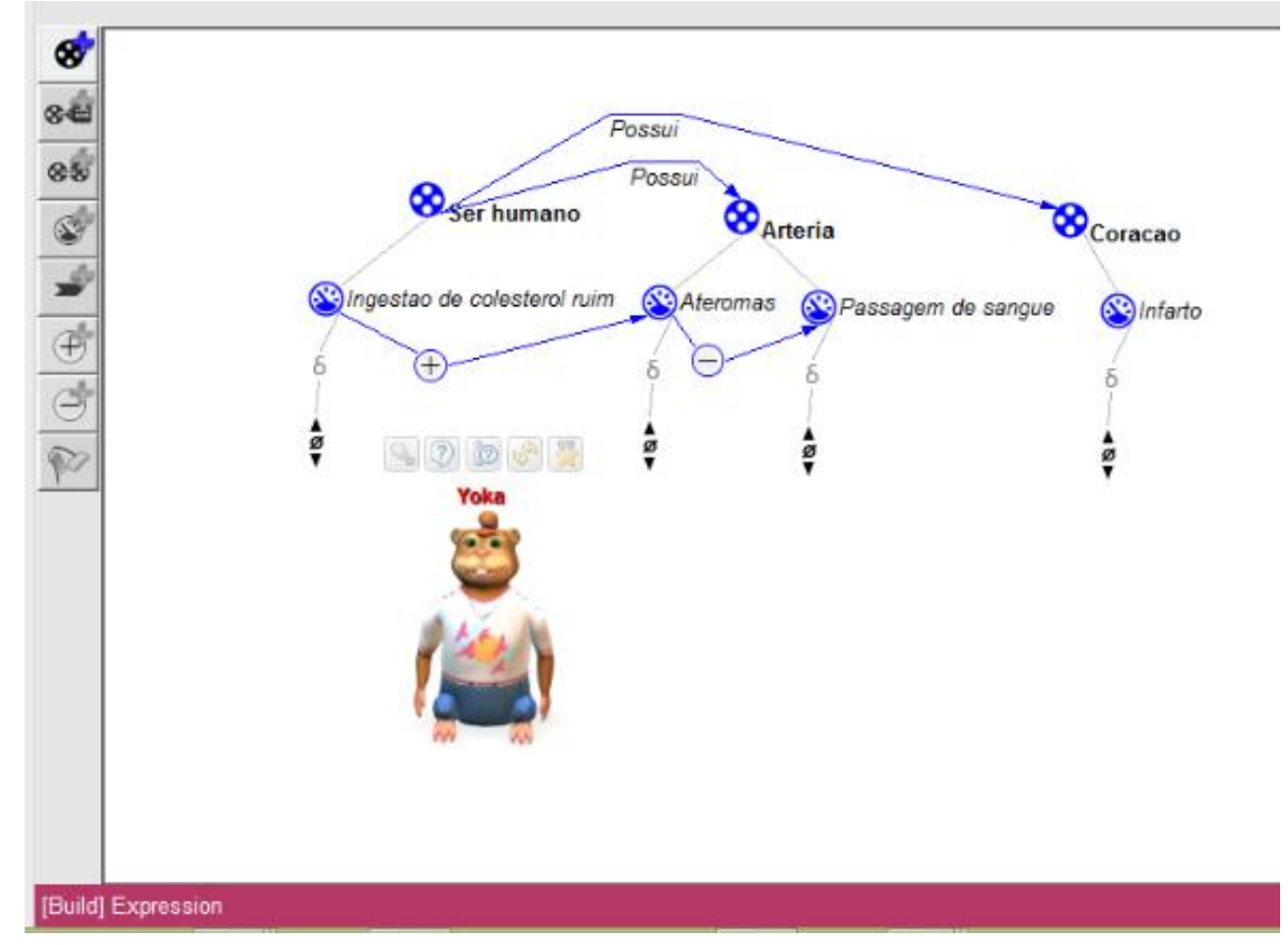

Fig. 2 - O agente aprendiz observando o modelo sendo construído pelo aluno. 


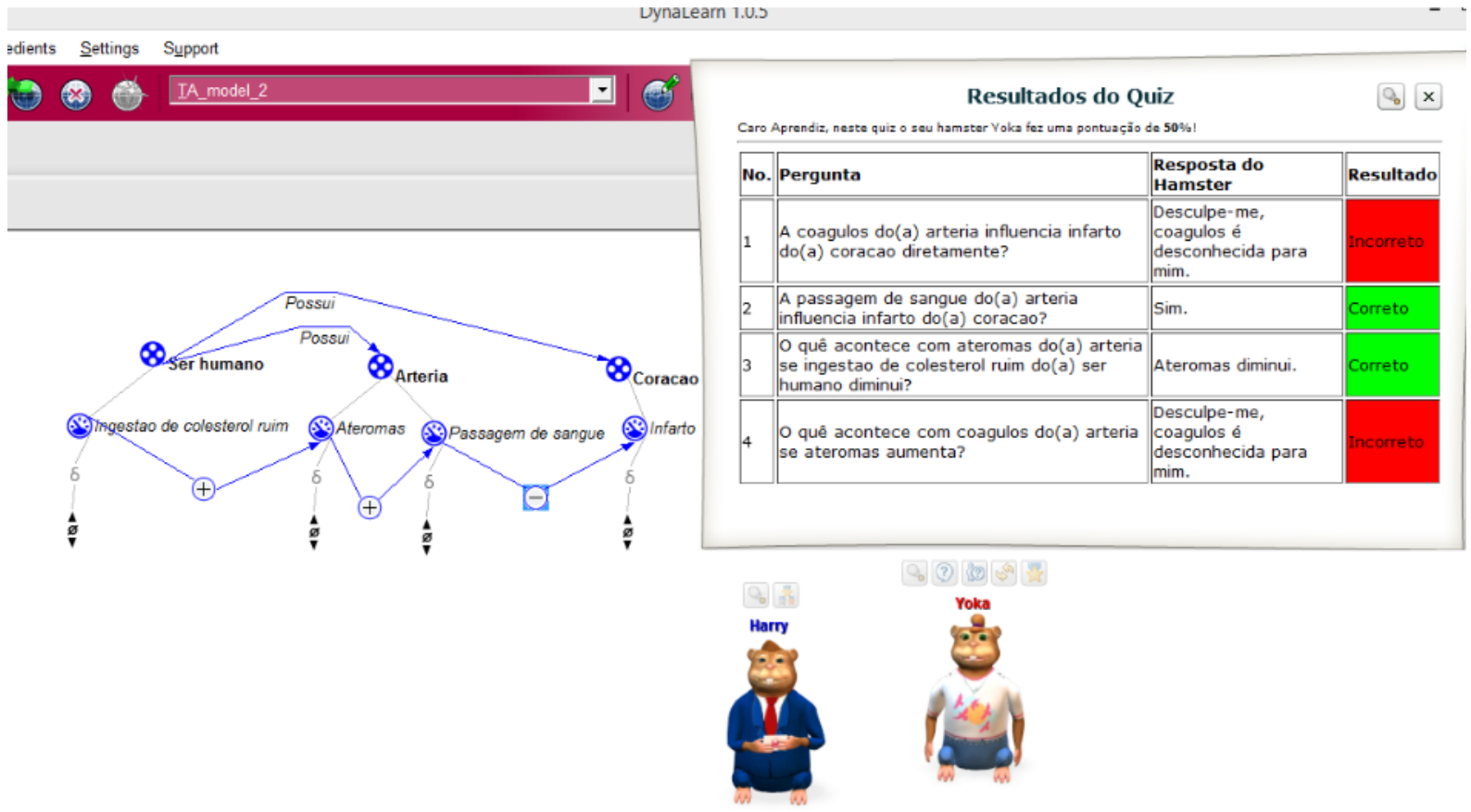

Fig. 3 - O relatório de desempenho, mostrando os erros e acertos sendo apresentado após consulta ao Quizmaster pelo aluno.

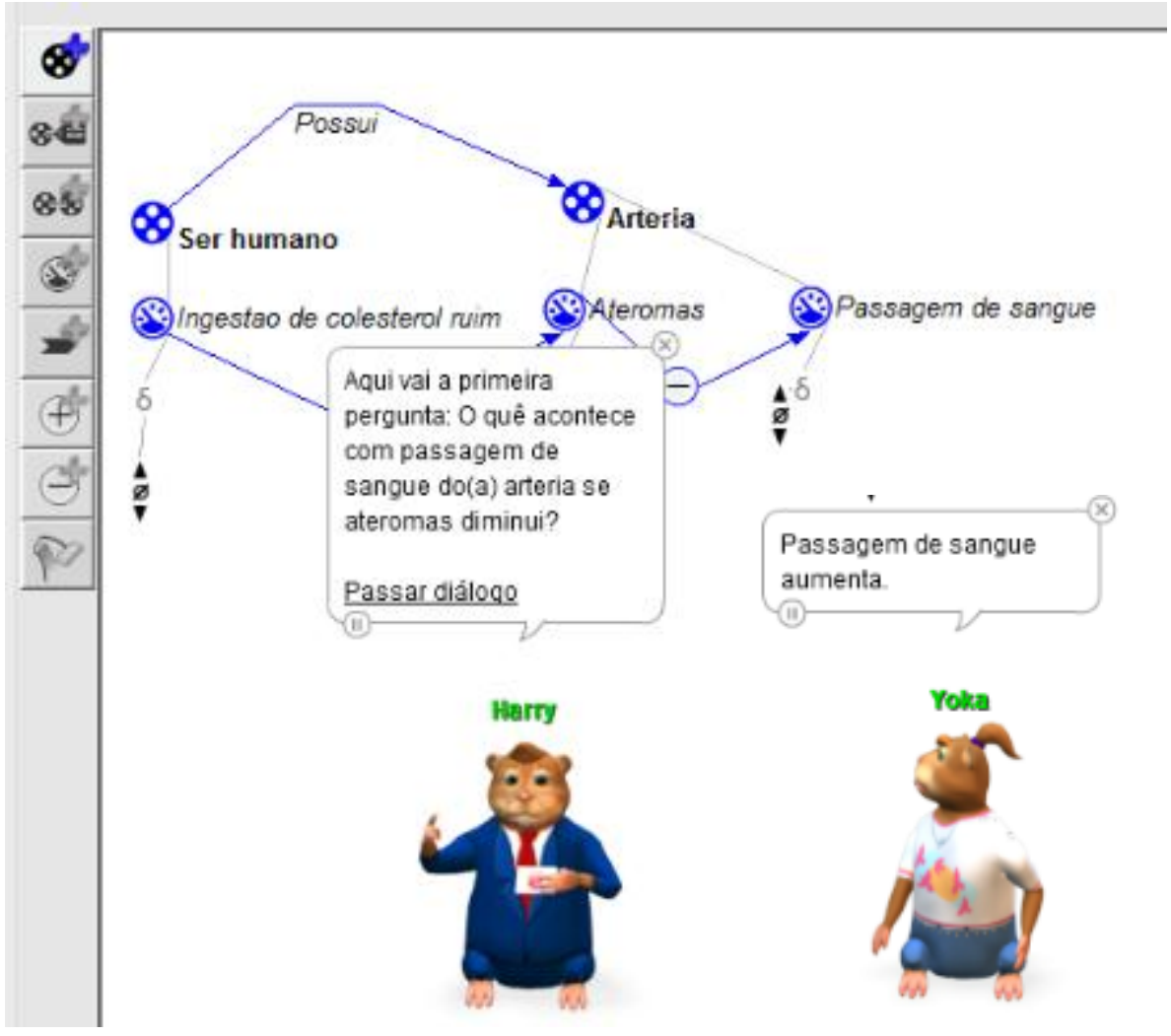

Fig. 4 - O Quizmaster fazendo uma pergunta ao agente virtual, que a responde. 
Os alunos consultam seu Pet para monitorar sua aprendizagem e comportamento de resolução de problemas. Isso motiva os alunos para aprender mais para que eles possam ensinar seu Pet, de modo que este tenha melhor desempenho.

Quando o aluno abre o TA para iniciar seu trabalho, DynaLearn solicita que um agente virtual seja adotado como animal de estimação (Pet). O aluno pode escolher entre duas opções e também dar um nome ao Pet. A partir daí, o Pet lança uma fala, solicitando que o aluno o ajude a construir o modelo, adicionando novos conteúdos. Segundo especialistas essa dinâmica gera responsabilidade no aluno a ter que ensinar o seu Pet, já que ele será submetido a um quiz, junto ao Quizmaster, o Harry. Estudos mostram que alunos se esforçam mais para aprender quando têm que ensinar alguém (mesmo sendo uma animação) (CHIN et al., 2013; LEELAWONG \& BISWAS, 2008). Outra vantagem do Pet seria o fato de os erros cometidos por este, que na verdade serão os erros do aluno modelador, amenizam a "culpa" que poderia pesar sobre o aluno caso as perguntas do quiz fossem feitas diretamente ao estudante. 


\section{3 - ATIVIDADES PROPOSTAS}

A proposta do presente minicurso estão organizadas em 4 atividades, cada uma disposta em momentos e ações a serem realizadas. A natureza das atividades foram divididas em dois grupos: de familiarização com as ferramentas do software ou de atividades práticas.

Para a realização das atividades propostas no minicurso é necessário um Data Show e um notebook contendo o software Dynalearn instalado com o número de máquinas compatível ao número de participantes.

Os modelos a serem utilizados também devem ser previamente construídos pelo professor e salvos no formato TA. Os alunos, ao abrirem os modelos no formato TA, não terão acesso ao modelo original instantaneamente. O acesso ocorrerá gradativamente, conforme as correções feitas nos modelos com base na interação direta com o agente aprendiz e na observação do desempenho deste agente no quiz.

\section{ATIVIDADE 1 - FAMILIARIZAÇÃO COM O LS2 :}

Objetivo: apresentar o software DynaLearn aos alunos e tornar os botões e ícones familiares aos estudantes, ao nível LS2.

Duração: 3 aulas de 50 minutos

\begin{tabular}{|l|l|}
\hline Momento & Ação \\
\hline 1 & Apresentar o DynaLearn \\
\hline 2 & Apresentar os botões e ícones do LS2 \\
\hline 3 & Apresentação dos elementos de um modelo em LS2. \\
\hline 4 & Explicar aos alunos a diferença entre influência positiva e negativa. \\
\hline 5 & $\begin{array}{l}\text { Ensinar aos alunos como trabalhar com simulações no LS2. } \\
\text { Mostrar o modelo "Árvore e Sombra" completo, projetando via Data Show; } \\
\text { Explicar e discutir sobre as possibilidades de simulações e comportamento } \\
\text { das variáveis. }\end{array}$ \\
\hline 6 & $\begin{array}{l}\text { Construir o modelo "Árvore e Sombra", projetando via Data Show a tela do } \\
\text { DynaLearn para que toda a turma acompanhe (1 }{ }^{\mathbf{0}} \text { entidade 'Árvore', } 2^{\circ} \\
\text { entidade 'Solo', } 3^{\circ} \text { Variável 'Tamanho' } 4^{\circ} \text { variável 'Temperatura', } 5^{\circ} \text { variável } \\
\text { 'Umidade', } 6^{\circ} \text { influências entre as variáveis). } \\
\text { Mostrar as simulações no programa. }\end{array}$ \\
\hline
\end{tabular}

Em seguida, sugestões de figuras e esquemas que podem ser utilizados para realização das ações propostas em cada momento na atividade 1 .

1- Apresentar o Dynalearn: 


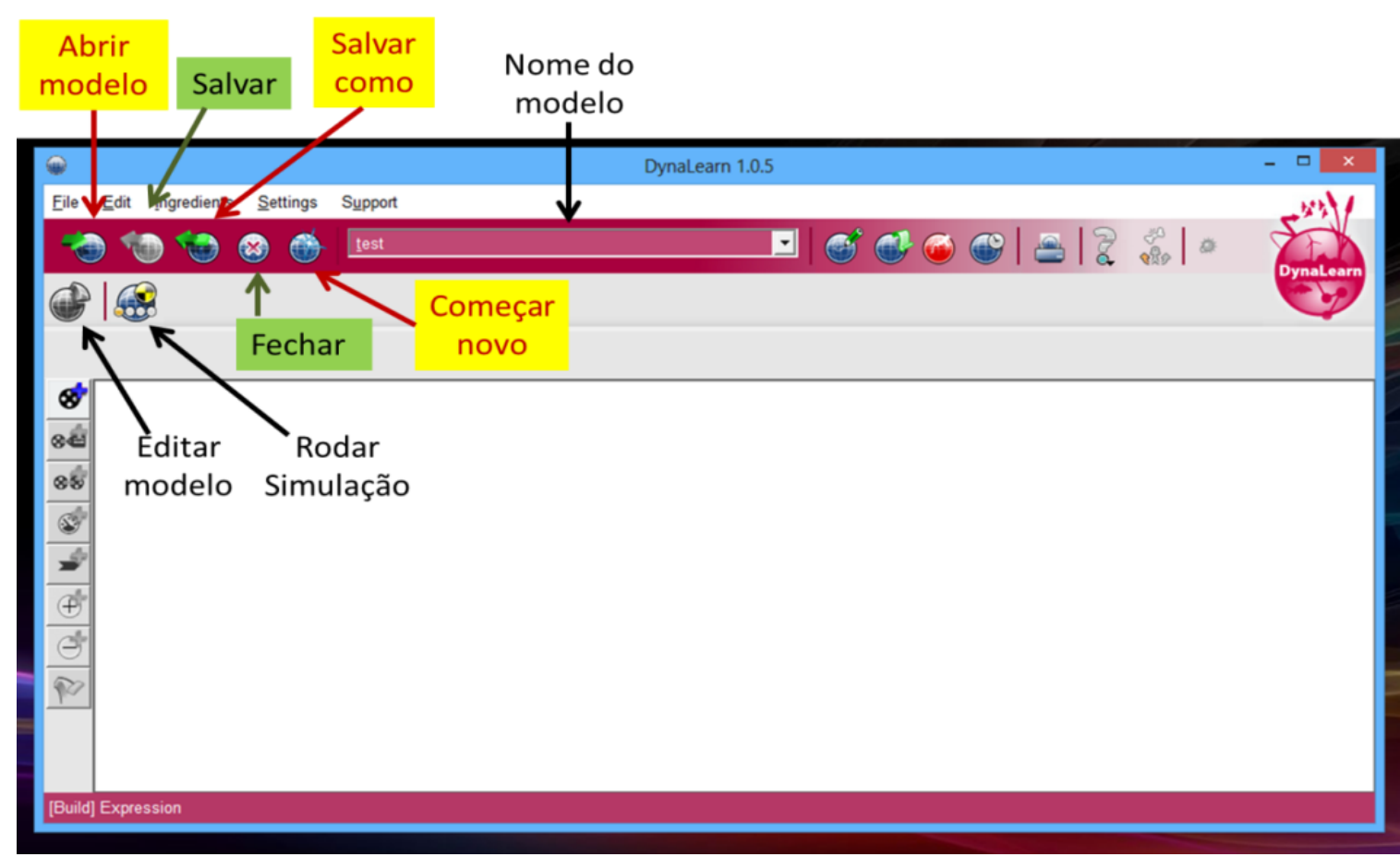

Fig.01 - Software DynaLearn: tela principal e suas principais funções

2- Apresentar os botões e ícones do LS2:

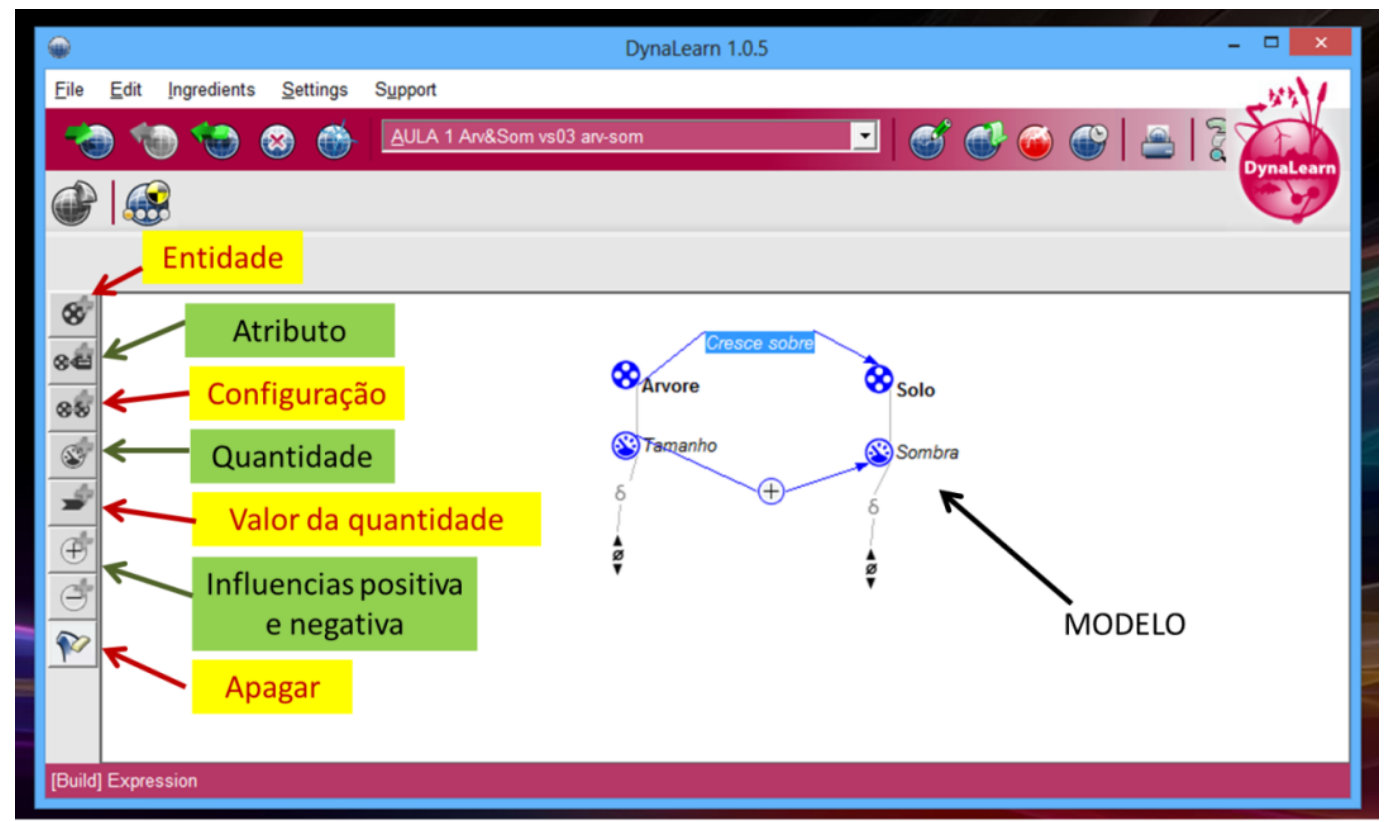

Fig.02 - DynaLearn - Botões para atividades de modelagem em LS2

3- Apresentar os elementos de um modelo em LS2 


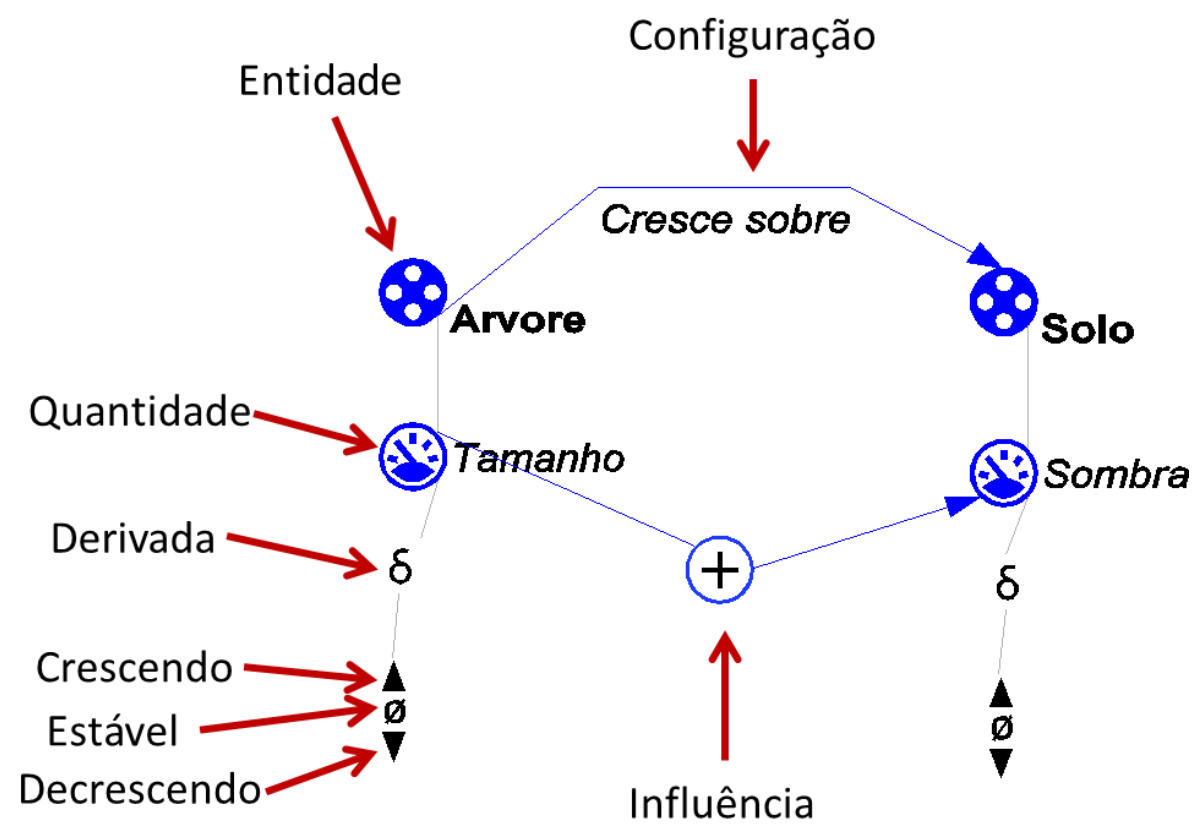

Fig.03 - Software DynaLearn: elementos de um modelo LS2

4 - Explicar a diferença entre influência positiva e negativa:

a) Projetar a imagem abaixo (cenário) e explicar aos alunos o que é a influência positiva.

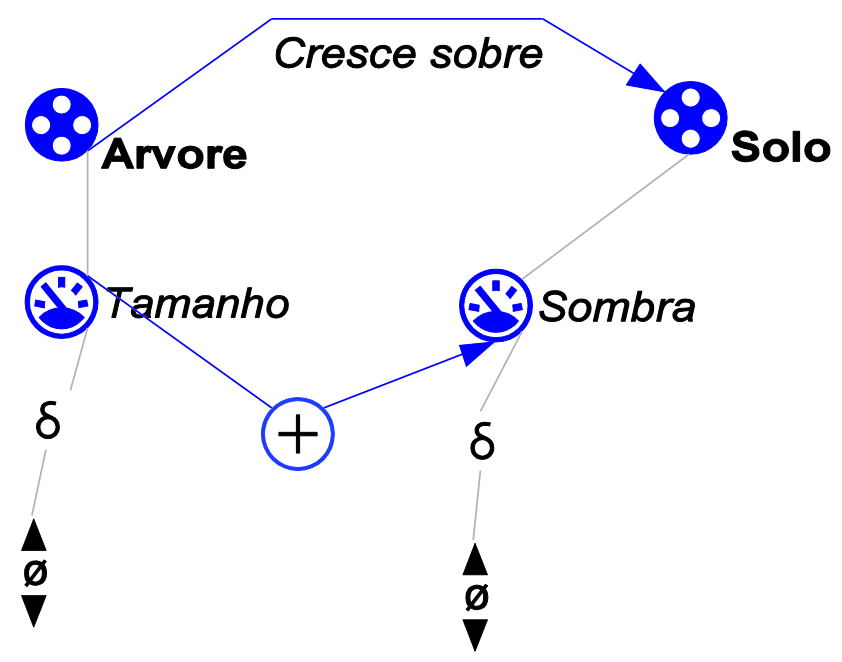

Fig. 4 -Submodelo 1- 'Arvore e Sombra' 


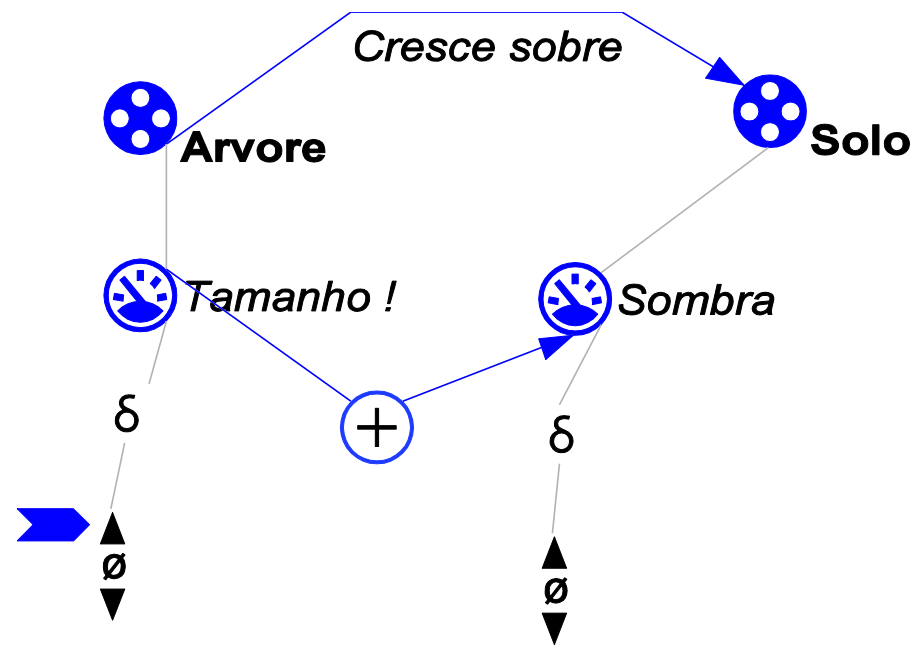

Fig. 5 - Cenário 1-

Perguntar aos alunos o que ocorrerá com a sombra (aumenta ou diminui?). Em seguida mostrar o resultado da simulação.

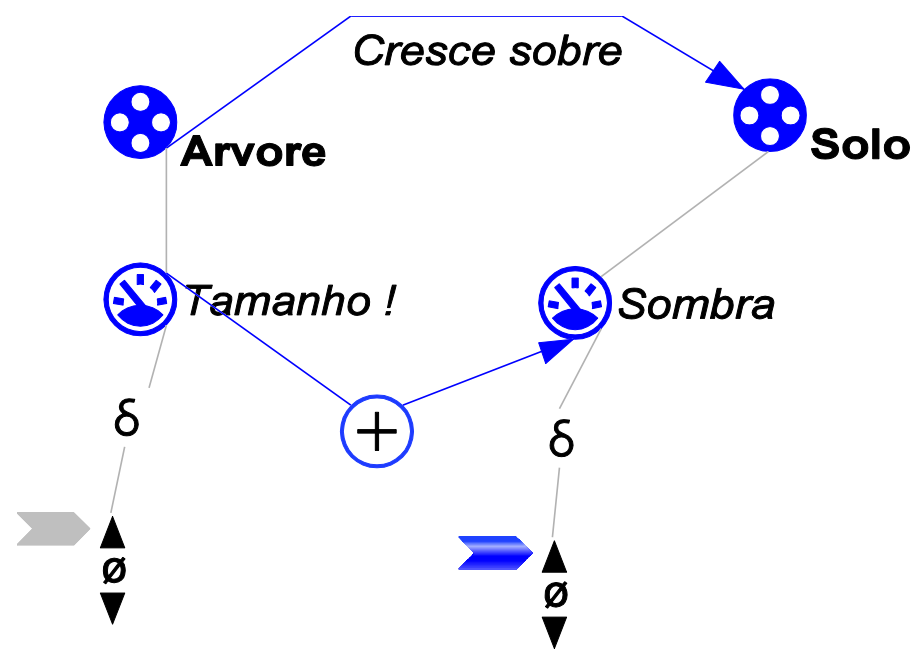

Fig. 6 - Simulação cenário 1

Em seguida marcar a derivada da variável 'Tamanho' diminuindo e perguntar aos alunos o que ocorrerá com a variável 'Sombra' nesta situação.

Explicar a influência negativa:

Projetar a imagem abaixo e perguntar aos alunos o que irá ocorrer. 


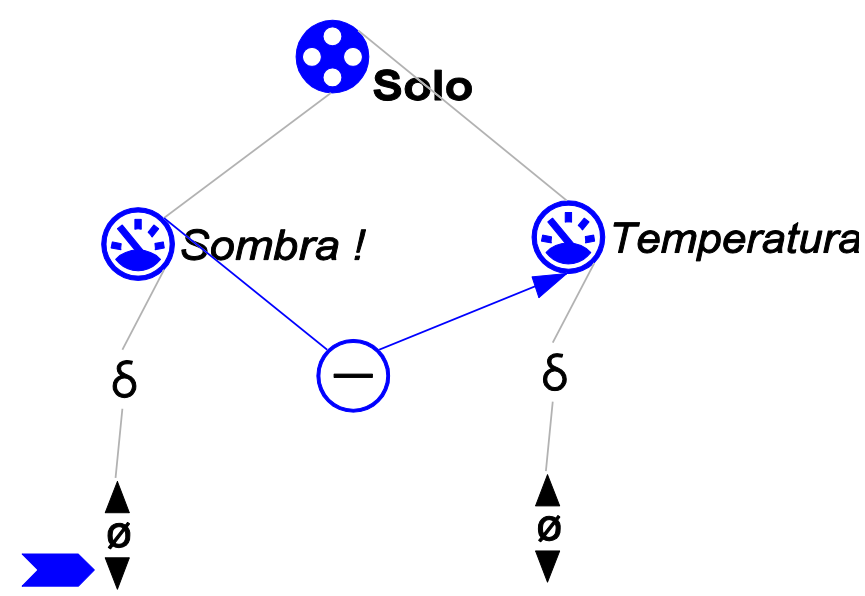

Fig. 7 - Submodelo 2

Perguntar aos alunos o que ocorrerá com a temperatura (aumenta ou diminui?).

Em seguida mostrar o resultado da simulação.

5 - Ensinar aos alunos como trabalhar com simulações no LS2.

Projetar a imagem do modelo 'Arvore e Sombra' completo com a derivada da variável 'Tamanho' aumentando e perguntar aos alunos o que ocorrerá com as demais variáveis, sequencialmente.

Explicar as cadeias causais. Levantar discussões sobre o tamanho da árvore ser capaz de influenciar a umidade do solo por uma cadeia de influências.

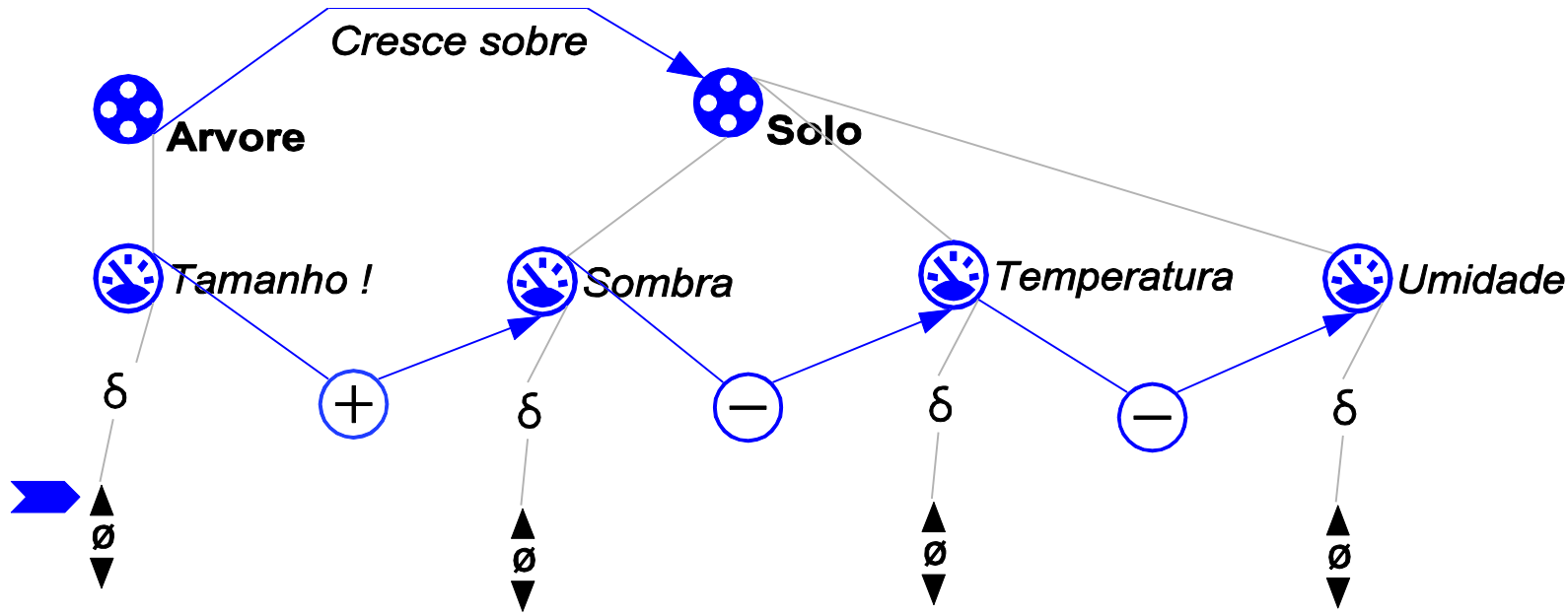

Fig. 8 - Modelo completo 'Arvore e Sombra' - cenário

Mostrar o resultado da simulação. 


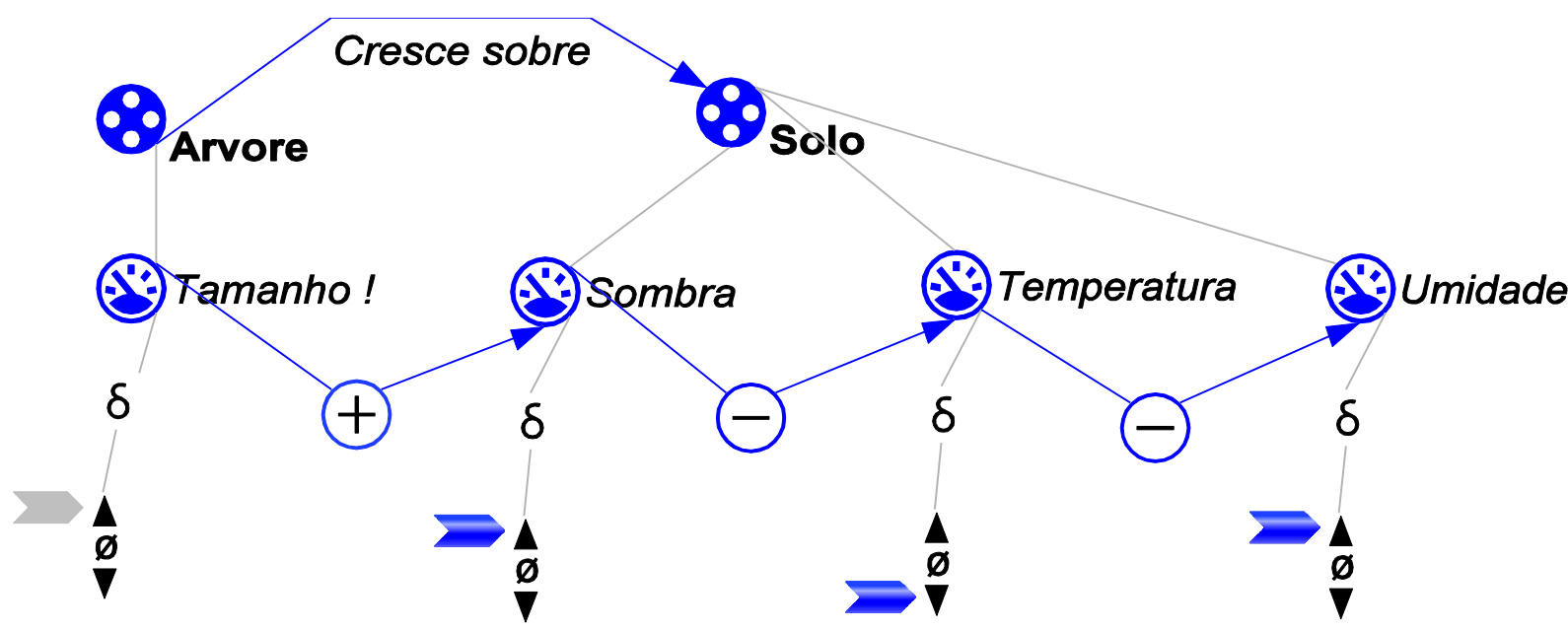

Fig. 9 - Modelo completo 'Arvore e Sombra' - simulação

6 - Ensinando a construção do modelo 'Árvore e Sombra'

Projetar a tela do DynaLearn e construir (e explicar) o modelo 'Árvore e Sombra' passo a passo. Mostrar simulações no programa para os alunos.

\section{ATIVIDADE 2 - PRÁTICA COM O LS2}

Objetivo: praticar com os alunos a modelagem no nível LS2 no software DynaLearn, primeiramente com um modelo mais simples, em seguida, partir para um modelo mais complexo.

Duração: 2 aulas de 50 minutos

\begin{tabular}{|l|l|}
\hline Momento & Ação \\
\hline 1 & $\begin{array}{l}\text { Entregar o texto do 'Bloom de algas' para os alunos (em dupla) e pedir para } \\
\text { que identifiquem no texto as entidades e variáveis e construam o modelo com } \\
\text { as relações causais. } \\
\text { => Este modelo servirá como 'treino', pois trata-se de um modelo simples. }\end{array}$ \\
\hline 2 & $\begin{array}{l}\text { Entregar o texto da discussão entre madeireiros e ambientalistas e pedira às } \\
\text { duplas que construam o modelo no nível LS2. } \\
\text { => Aqui a atividade é voltada para o ensino sobre o funcionamento de } \\
\text { sistemas relacionados ao conteúdo curricular dos alunos. }\end{array}$ \\
\hline
\end{tabular}

1 - Texto e modelo do 'Boom de algas' - Treinamento: 
a) Pedir aos alunos que abram o programa e o modelo.

b) Entregar o tex to impresso e pedir para os alunos que identifiquem as entidades (em negrito) e variáveis (sublinhadas) no texto e construam o modelo 'Bloom de algas'. O texto e modelo encontram-se no Apêndice I.

2 - Entregar o texto e pedir aos alunos que construam o modelo 'Madeireiros x Ambientalista'. O texto e modelo encontram-se no Apêndice II.

\section{ATIVIDADE 3 - FAMILIARIZAÇÃO COM O TA:}

Objetivo: apresentar o agente aprendiz aos alunos e tornar esta tecnologia familiar aos estudantes.

Duração: 1 aula de 50 minutos

\begin{tabular}{|l|l|}
\hline Momento & Ação \\
\hline 1 & Apresentar o agente aprendiz \\
\hline
\end{tabular}

1 - Apresentação do agente aprendiz.

a) Apresentar o agente aprendiz por meio de slides (que se encontram no Apêndice III).

b) Projetar a imagem abaixo para a turma e ensiná-los a abrirem um modelo no modo Agente Aprendiz.

Para abrir um modelo no modo Agente Aprendiz, vá em 'File", em seguida em 'Open 
Teachable Agent model from file', navegue até o local em que o arquivo do modelo foi salvo previamente e abra-o.

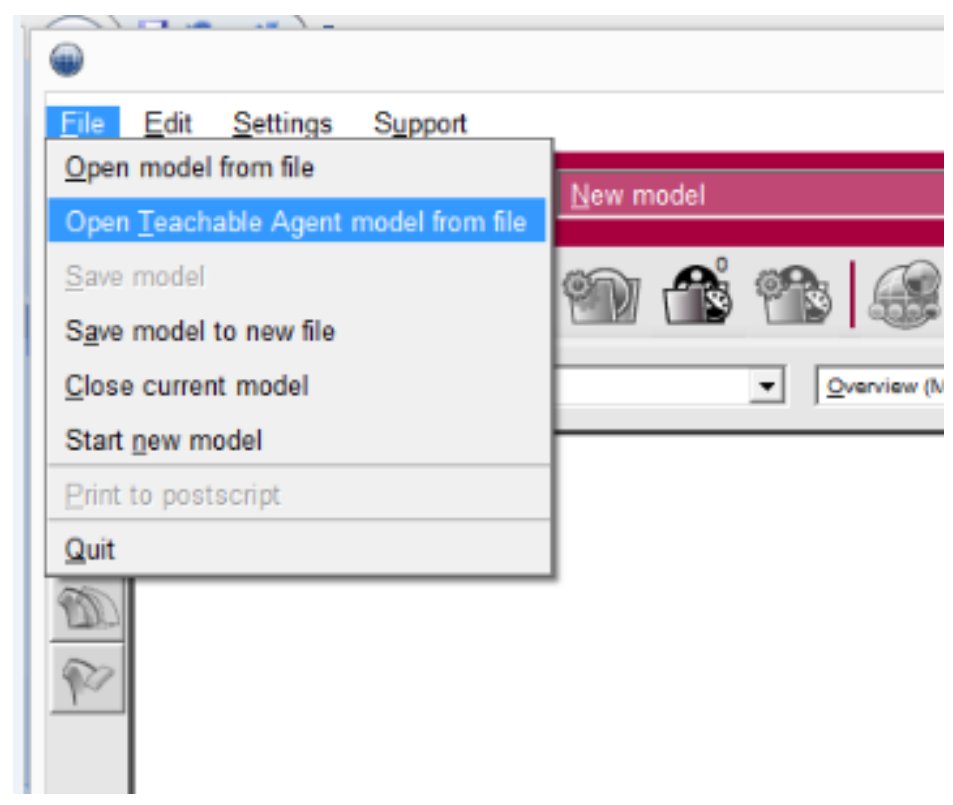

Fig. 10 - Abrindo um modelo no modo Agente Aprendiz

\section{ATIVIDADE 4 - PRÁTICA COM O TA}

Objetivo: praticar com os alunos a modelagem apoiada por agentes aprendizes virtuais no software DynaLearn, primeiramente com um modelo já trabalhado com os alunos, em seguida, partir para um modelo mais complexo, abordando conteúdos inéditos aos alunos.

Duração: 6 aulas de 50 minutos

\begin{tabular}{|c|c|}
\hline Momento & Ação \\
\hline 1 & $\begin{array}{l}\text { Reutilizar o texto da discussão entre madeireiros e ambientalistas e pedir às } \\
\text { duplas que construam o modelo no nível LS } 2 \text { com o apoio do TA. } \\
\text { Deixar claro para os alunos que estes deverão: } \\
\checkmark \quad \text { Interagir com o seu Pet, fazendo-lhes perguntas sobre o modelo, para } \\
\text { verificarem se estão 'pensando' corretamente; } \\
\checkmark \text { Interagir com o Quizmaster, por meio do quiz ao qual o seu Pet é } \\
\text { submetido, a fim de verificar quão próximo o seu modelo se encontra } \\
\text { do modelo de referência (que não é visível ao aluno). } \\
\text { => Este modelo servirá como 'treino', pois trata-se de um modelo já } \\
\text { conhecido pelos alunos, nas atividades práticas com o LS2. }\end{array}$ \\
\hline 2 & $\begin{array}{l}\text { Entregar o texto da 'Aterosclerose' e pedir às duplas que construam o modelo } \\
\text { no nível LS2 com o apoio do TA. }\end{array}$ \\
\hline
\end{tabular}




\begin{tabular}{|c|c|}
\hline & $\begin{array}{l}\text { Deixar claro para os alunos que estes deverão (além do já exposto no } \\
\text { momento anterior): } \\
\checkmark \text { Registrar (por meio da tecla 'Print') o desempenho de seu Pet no quiz, } \\
\text { ou seja, registrar a imagem dos relatórios gerados pelo programa, ao } \\
\text { final da construção do modelo e registrar os modelos produzidos. } \\
\text { (esse registro poderá ser utilizado pelo professor para compreender e } \\
\text { avaliar o processo de aprendizagem dos alunos assim como preparar } \\
\text { novas atividades. O professor saberá quantas vezes cada dupla } \\
\text { consultou o Quizmaster, como ocorreu a evolução nos relatórios } \\
\text { gerados pelo programa a cada nova consulta ao quiz e como se deu a } \\
\text { evolução nos modelos produzidos). }\end{array}$ \\
\hline 3 & $\begin{array}{l}\text { Avaliar e analisar o desempenho dos alunos por meio: } \\
\text { dos modelos produzidos; } \\
\text { das imagens do desempenho no quiz; }\end{array}$ \\
\hline 4 & $\begin{array}{l}\text { Repetir os momentos } 2 \text { e } 3 \text { em relação ao modelo do 'Aparelho Reprodutor } \\
\text { Masculino'. }\end{array}$ \\
\hline 5 & Repetir os momentos 2 e 3 em relação ao modelo da 'Placenta". \\
\hline
\end{tabular}

1 - Construção do modelo 'Madeireiros x Ambientalistas' com apoio do TA:

=> Pedir aos alunos que abram o modelo no modo TA.

Obs: este modelo deverá ser salvo previamente pelo professor, no modo TA (ver Apêndice IV).

2- Construção do modelo 'Aterosclerose' com apoio do TA:

=> O professor deverá construir o modelo (previamente) no modo LS2 sem o agente aprendiz.

Com o modelo pronto, deverá marcar o modelo no modo Agente Aprendiz.

O modelo é apresentado no Apêndice V.

3 - Avaliar e analisar o desempenho dos alunos por meio:

- dos modelos produzidos;

- das imagens do desempenho no quiz;

4- Repetir os procedimentos 2 e 3 em relação aos modelos 'Aparelho Reprodutor Masculino' (apresentado e descrito no Apêndice VI) e 'Placenta'( apresentado e descrito no Apêndice VII). 


\section{REFERÊNCIAS BIBLIOGRÁFICAS}

BASTOS, Rejane Caixeta Gonçalves. INTRODUÇÃO À DINÂMICA DE SISTEMAS: proposta de disciplina a distância para curso de licenciatura em biologia, com uso de modelos qualitativos. 2014. 119 f. Dissertação (Mestrado) - Curso de Programa de Pós Graduação em Ensino de Ciências, Universidade de Brasília, Brasília-df, 2014.

BREDEWEG, B.; LIEM, J.; BEEK, W.; LINNEBANK, F.; GRACIA, J.; LOZANO, E.; WIßNER, M.; BÜHLING, R.; SALLES, P.; NOBLE, R.; ZITEK, A.; BORISOVA, P.;

CHIN, Doris B.; DOHMEN, Ilsa M.; SCHWARTZ, Daniel L. Young Children Can Learn Scientific Reasoning with Teachable Agents. Ieee Transactions On Learning Technologies, Usa, v. 6, n. 03, p.248-257, jul. 2013. Trimestral.

MIODUSER, D. (2013). DynaLearn - An Intelligent Learning Environment for Learning Conceptual Knowledge. AI Magazine, 34 (4): 46-65.

DORNAS, Waleska C. et al. Aterosclerose Experimental em Coelhos. Arquivos Brasileiros de Cardiologia, Minas Gerais, n. 95, p.272-278, 2010.

FELTRINI, Gisele Morisson. Aplicação de Modelos Qualitativos à Educação Científica de Surdos. 2009. 221 f. Dissertação (Mestrado) - Curso de Programa de Pós Graduação em Ensino de Ciências, Universidade de Brasília, Brasília-df, 2009.

FORBUS, K. (1984) Qualitative Process Theory. Artificial Intelligence 24: 85-168.

JOHNSON, W.Lewis; RICKEL, W.Jeff; LESTER, James C.. Animated Pedagogical Agents: Face-toFace Interaction in Interactive Learning Environments. International Journal Of Artificial

Intelligence In Education, v. 11, n. 1, p.47-78, 2000.

LEELAWONG, Krittaya; BISWAS, Gautam. Designing Learning by Teaching Agents: The Betty's Brain System. International Journal Of Artificial Intelligence In Education,Usa, v. 18, n. 3, p.181208, out. 2008.

MIODUSER, D. et al. Final report on DynaLearn evaluation studies. DynaLearn, EC FP7 STREP project 231526, Deliverable D7.4, 2012.

RESENDE, Mônica Maria Pereira. AVALIAÇÃo DO USO DE MODELOS QUALITATIVOS COMO INSTRUMENTO DIDÁTICO NO ENSINO DE CIÊNCIAS PARA ESTUDANTES SURDOS E OUVINTES. 2010. 162 f. Dissertação (Mestrado) - Curso de Programa de Pós Graduação em Ensino de Ciências, Universidade de Brasília, Brasília-df, 2010..

SALLES, P. and BREDEWEG, B. 2006. Modelos conceituais baseados em Raciocínio Qualitativo. Proceedings of the Workshop Informática e Aprendizagem em Organizações, G.M. da Nóbrega (ed.), pages 1-11, Brasília, Brazil, 9 November, 2006.

WIßNER, M.; HÄRING, M.; BÜHLING, R.; BEEK, W.; LINNEBANK, F.; LIEM, J.; BREDEWEG, B. \& ANDRÉ, E. Basic Help and Teachable Agent. DynaLearn, EC FP7 STREP project 231526, Deliverable D5.3, 2010. 


\section{APÊNDICES}

\section{Apêndice I - Texto e modelo 'Boom de Algas'}

Quadro 1

\section{Modelo" Bloom de Algas"}

Uma cidade fica perto do Lago. A cidade produz esgotos, que caem no Lago e causam poluição. A poluição por esgotos favorece o crescimento da população de um tipo de algas, que produzem um veneno (toxina) que fica dissolvido na água do lago. Essas toxinas reduzem o tamanho da população de peixes. O tratamento de esgotos pode resolver esse problema.

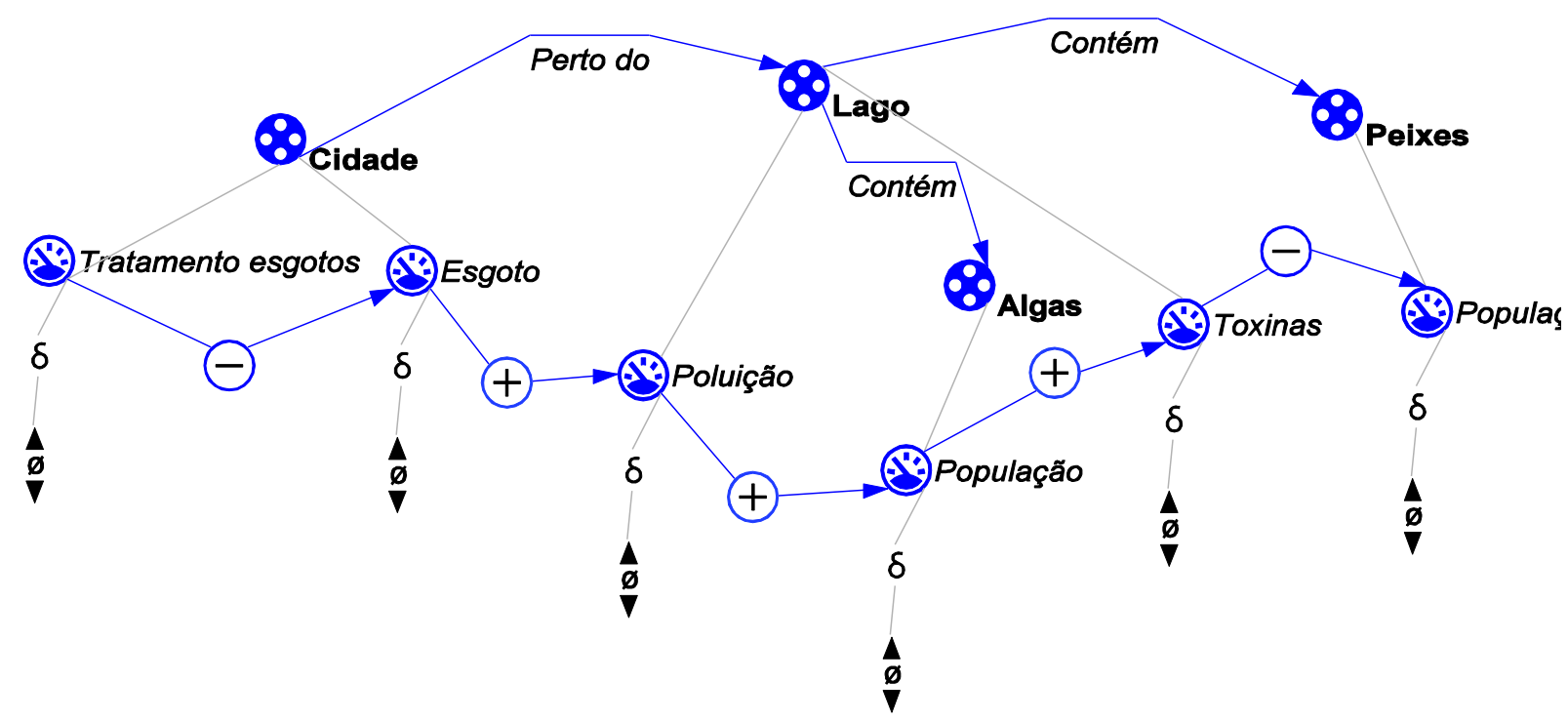

\section{$\underline{\text { Apêndice II - Texto e modelo 'Madeireiros x Ambientalistas' }}$}

Quadro 2

\section{Madeira ou Biodiversidade?}

"Grupo de defesa da natureza quer impedir que uma empresa madeireira retire árvores de uma floresta, para salvar as lagoas onde vive uma espécie rara de anfíbio. Os diretores da empresa dizem que as lagoas e a quantidade de anfíbios não podem ser mais importantes do que a sociedade, os empregos gerados com a venda da madeira e o dinheiro arrecadado com impostos.

O grupo de defesa da natureza argumenta que os anfíbios são parte importante da biodiversidade natural e que se as árvores forem retiradas, as lagoas secam, e sem elas, os anfíbios morrem e os insetos proliferam. Ao se alimentarem, os anfíbios consomem grande quantidade de insetos. Assim, os anfíbios contribuem também para reduzir insetos-praga que transmitem doenças para plantas, diminuindo a quantidade de produtos da floresta. Com as árvores preservadas, a sociedade ganha mais empregos na exploração de produtos da floresta e da biodiversidade, e tem melhor qualidade de vida." 


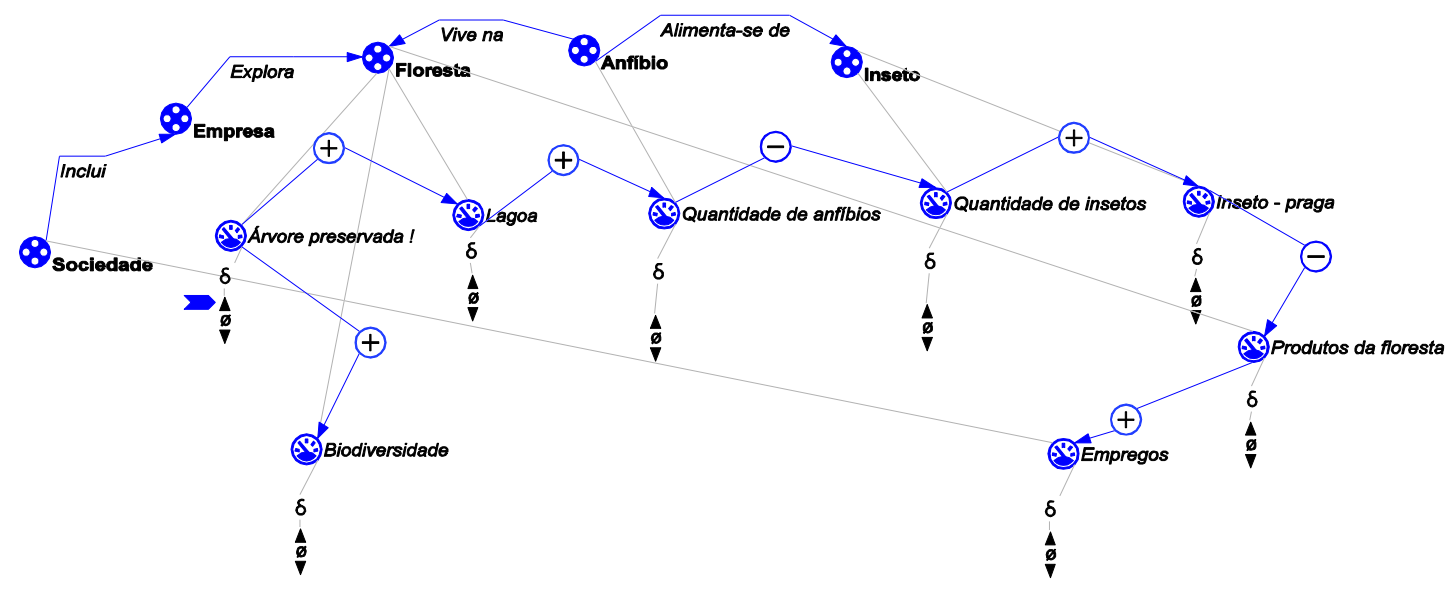

Fig. 11 - Modelo 'Madeireiros x Ambientalistas'

\section{$\underline{\text { Apêndice III - Slides para apresentação do agente aprendiz }}$}
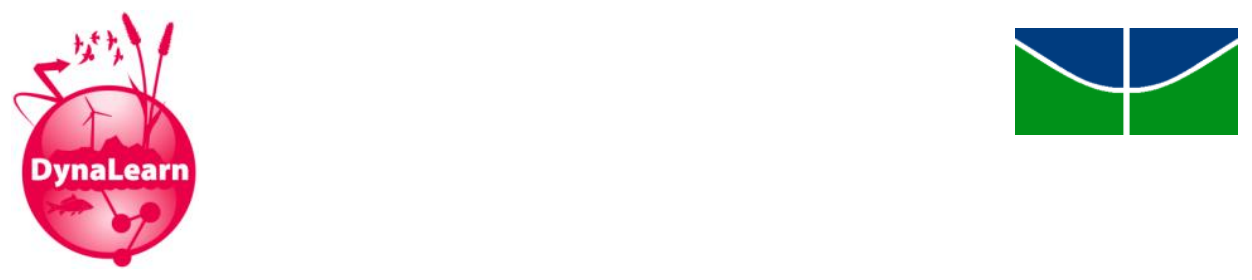

\section{$O$ agente aprendiz: Biodiversidade ou Madeira?}




\section{Agente Aprendiz}

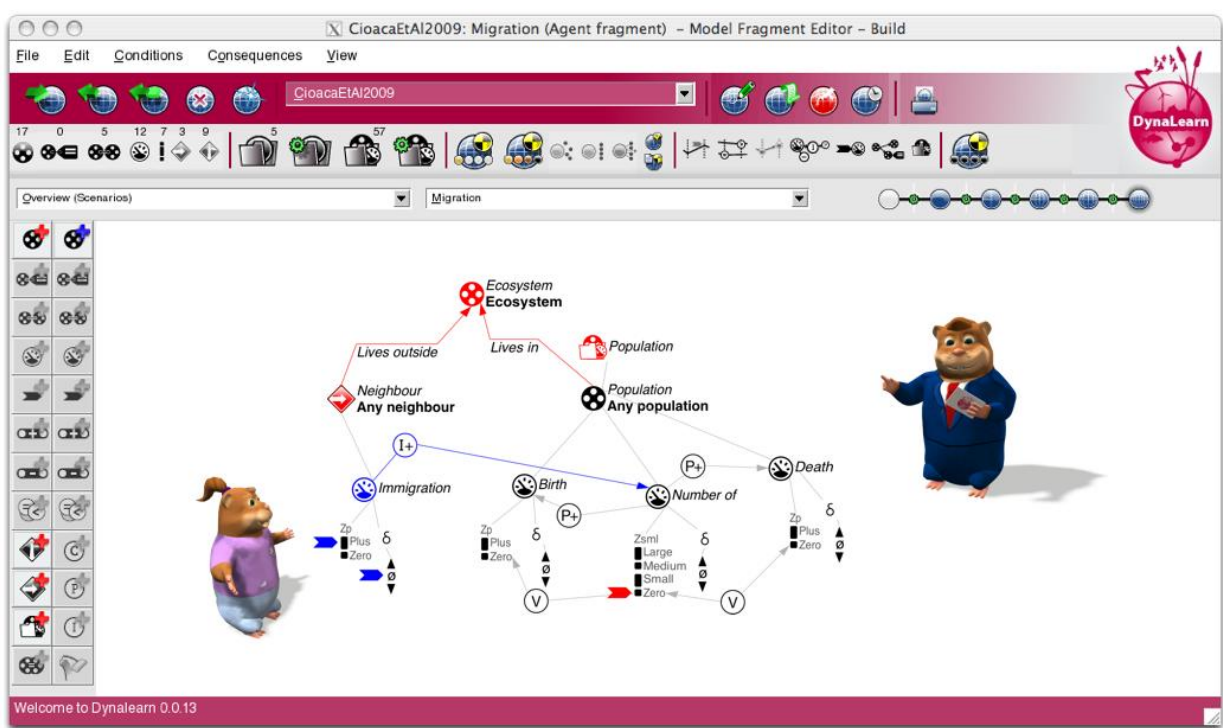

\section{Hamster se apresentando}

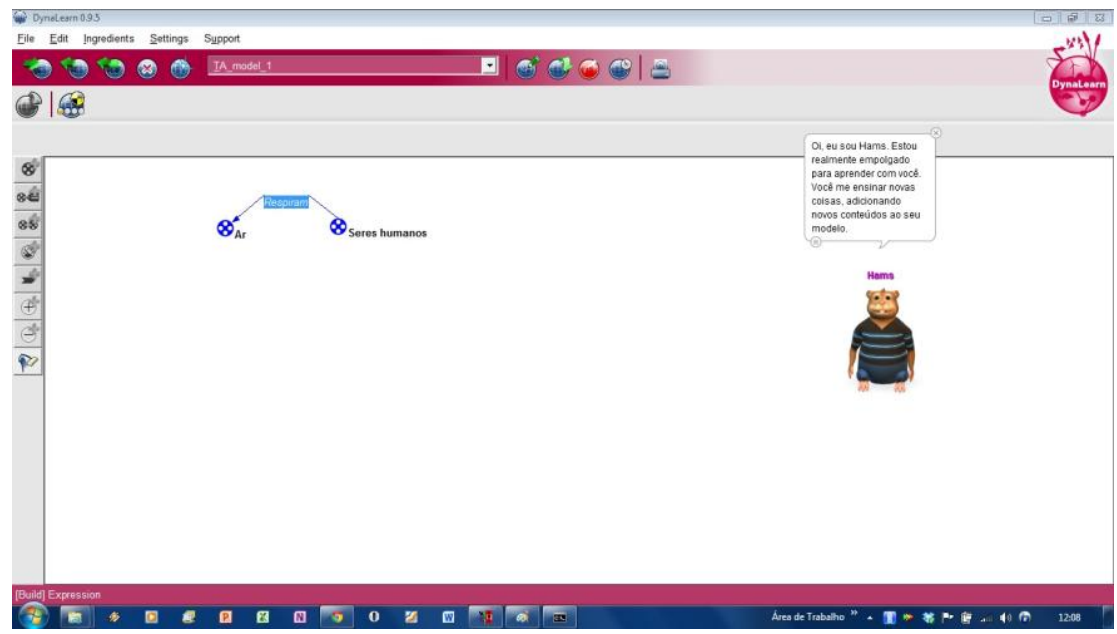




\section{Professor se apresenta}

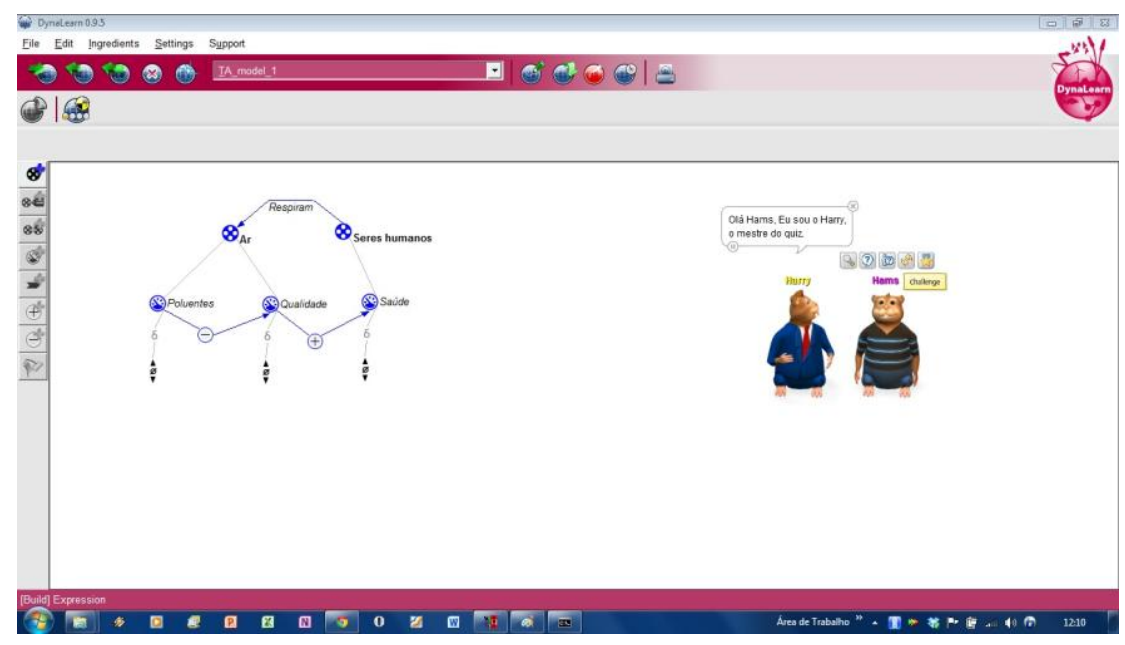

Erro na influência

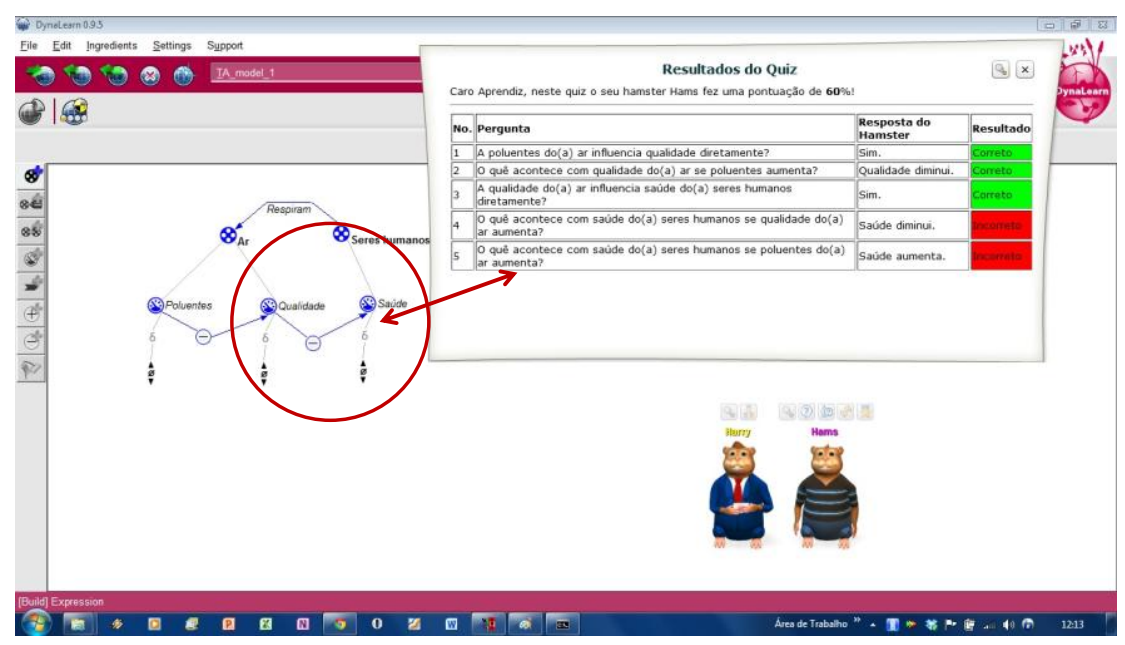


Erro na associação quantidade-entidade

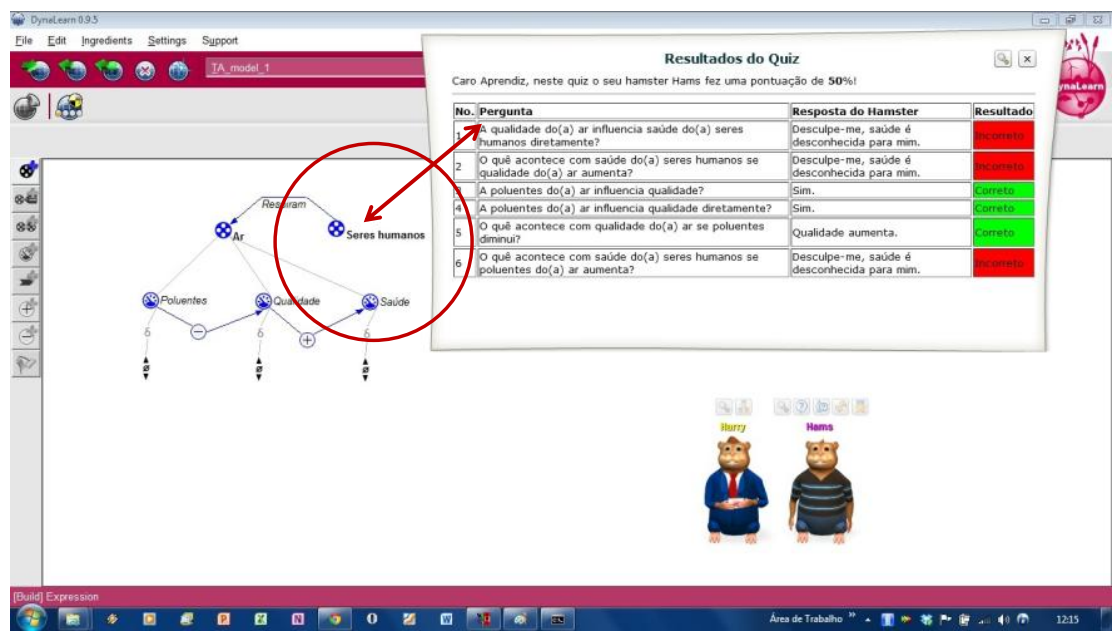

Tudo certo!

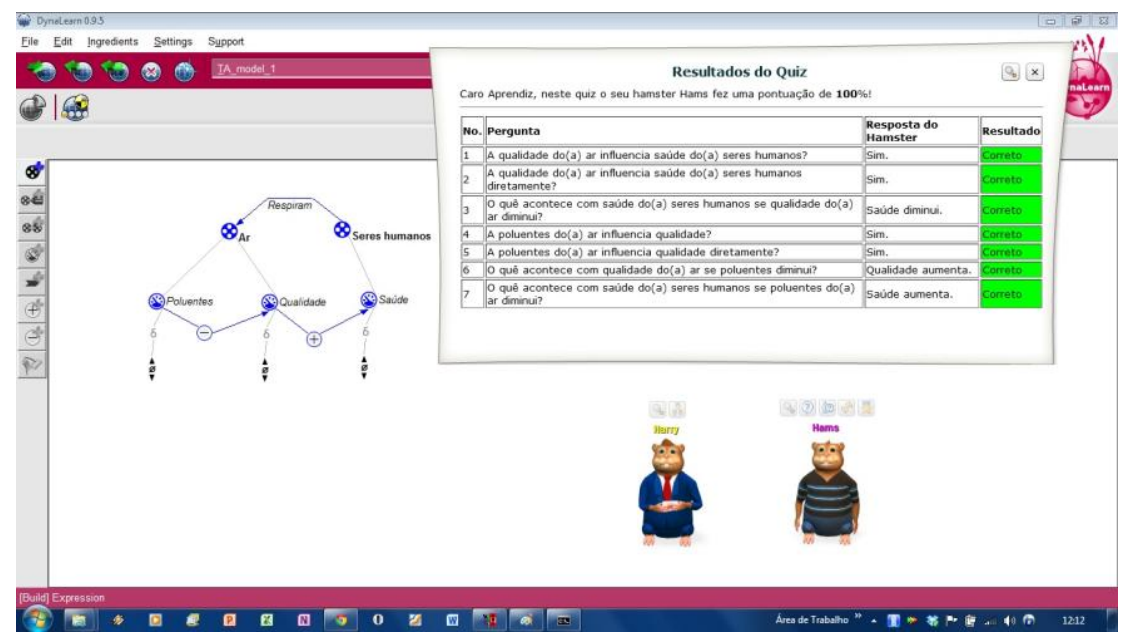




\section{Texto: Madeira ou Biodiversidade?}

"Grupo de defesa da natureza quer impedir que uma empresa madeireira retire árvores de uma floresta, para salvar as lagoas onde vive uma espécie rara de anfíbio. Os diretores da empresa dizem que as lagoas e a quantidade de anfíbios não podem ser mais importantes do que a sociedade, os empregos gerados com a venda da madeira e o dinheiro arrecadado com impostos.

O grupo de defesa da natureza argumenta que os anfíbios são parte importante da biodiversidade natural e que se as árvores forem retiradas, as lagoas secam, e sem elas, os anfíbios morrem e os insetos proliferam. Ao se alimentarem, os anfíbios consomem grande quantidade de insetos. Assim, os anfíbios contribuem também para reduzir insetos-praga que transmitem doenças para plantas, diminuindo a quantidade de produtos da floresta. Com as árvores preservadas, a sociedade ganha mais empregos na exploração de produtos da floresta e da biodiversidade, e tem melhor qualidade de vida."

\section{Texto: Madeira ou Biodiversidade?}

"Grupo de defesa da natureza quer impedir que uma empresa madeireira retire árvores de uma floresta, para salvar as lagoas onde vive uma espécie rara de anfíbio. Os diretores da empresa dizem que as lagoas e a quantidade de anfíbios não podem ser mais importantes do que a sociedade, os empregos gerados com a venda da madeira e o dinheiro arrecadado com impostos.

O grupo de defesa da natureza argumenta que os anfíbios são parte importante da biodiversidade natural e que se as árvores forem retiradas, as lagoas secam, e sem elas, os anfíbios morrem e os insetos proliferam. Ao se alimentarem, os anfíbios consomem grande quantidade de insetos. Assim, os anfíbios contribuem também para reduzir insetos-praga que transmitem doenças para plantas, diminuindo a quantidade de produtos da floresta. Com as árvores preservadas, a sociedade ganha mais empregos na exploração de produtos da floresta e da biodiversidade, e tem melhor qualidade de vida." 


\section{ANFÍBIOS: sapos, rãs, pererecas}
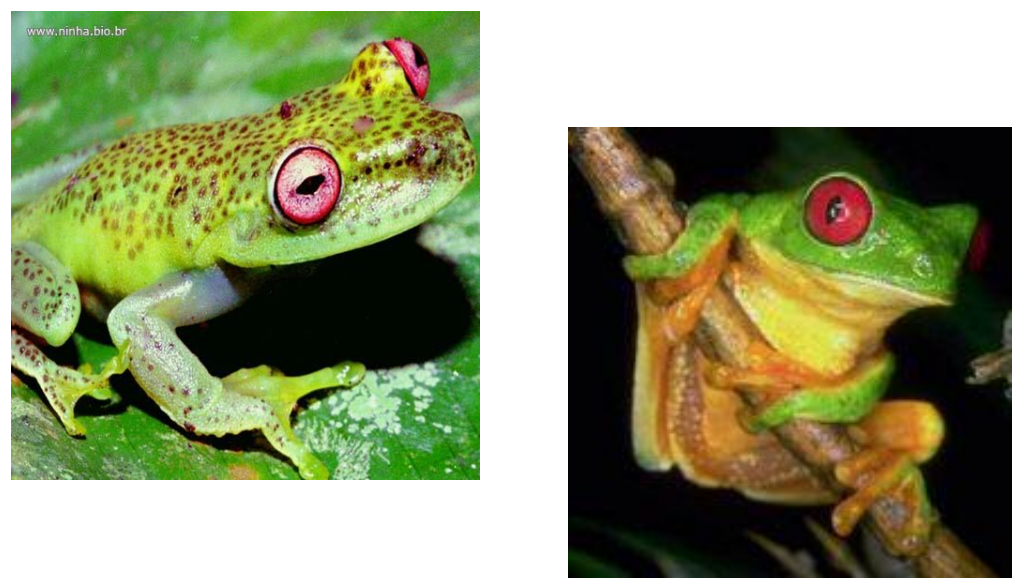

Insetos-praga: causam danos nas plantas
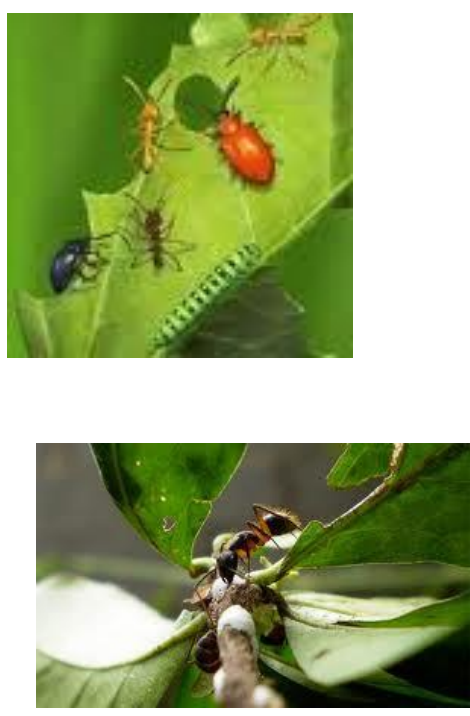
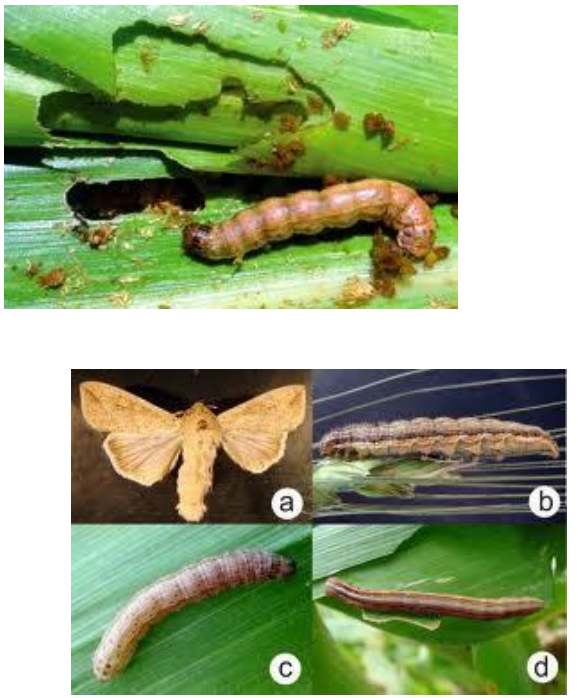
Usos da Madeira

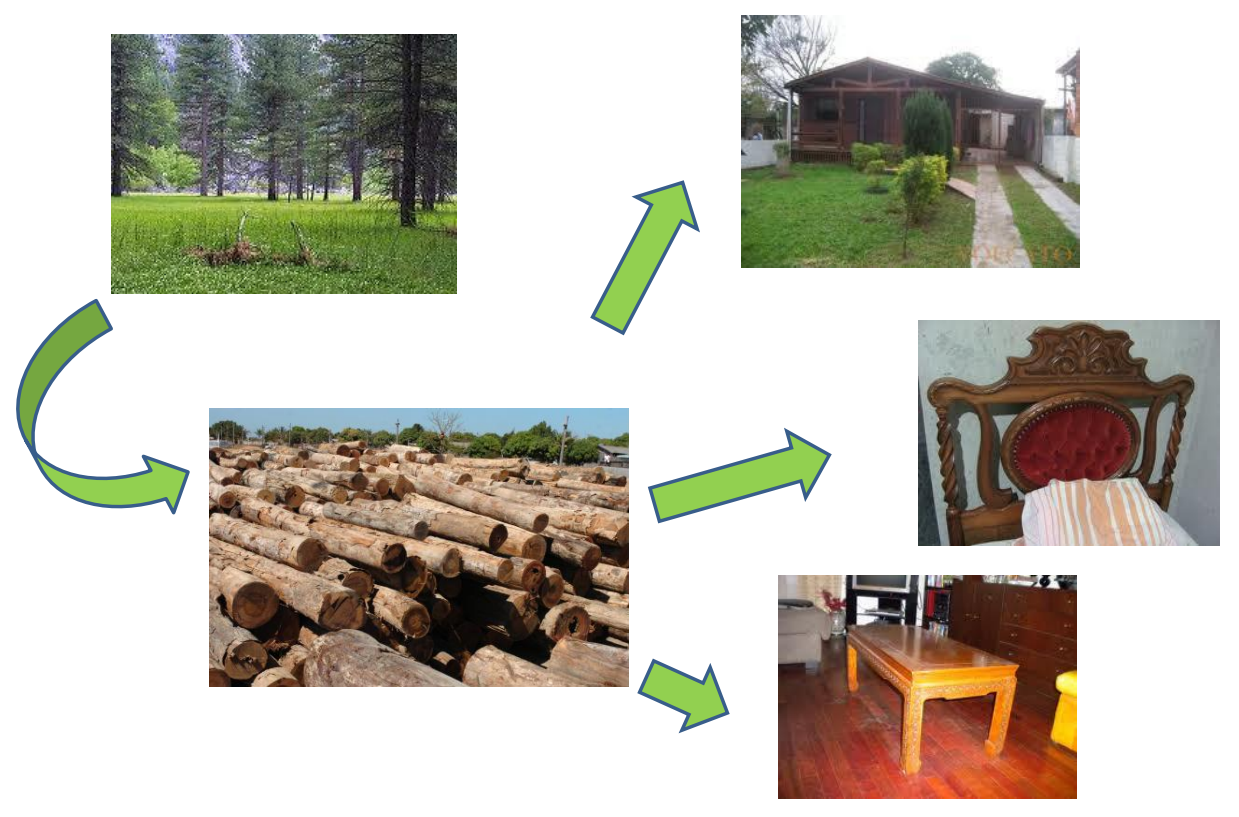

Produtos florestais

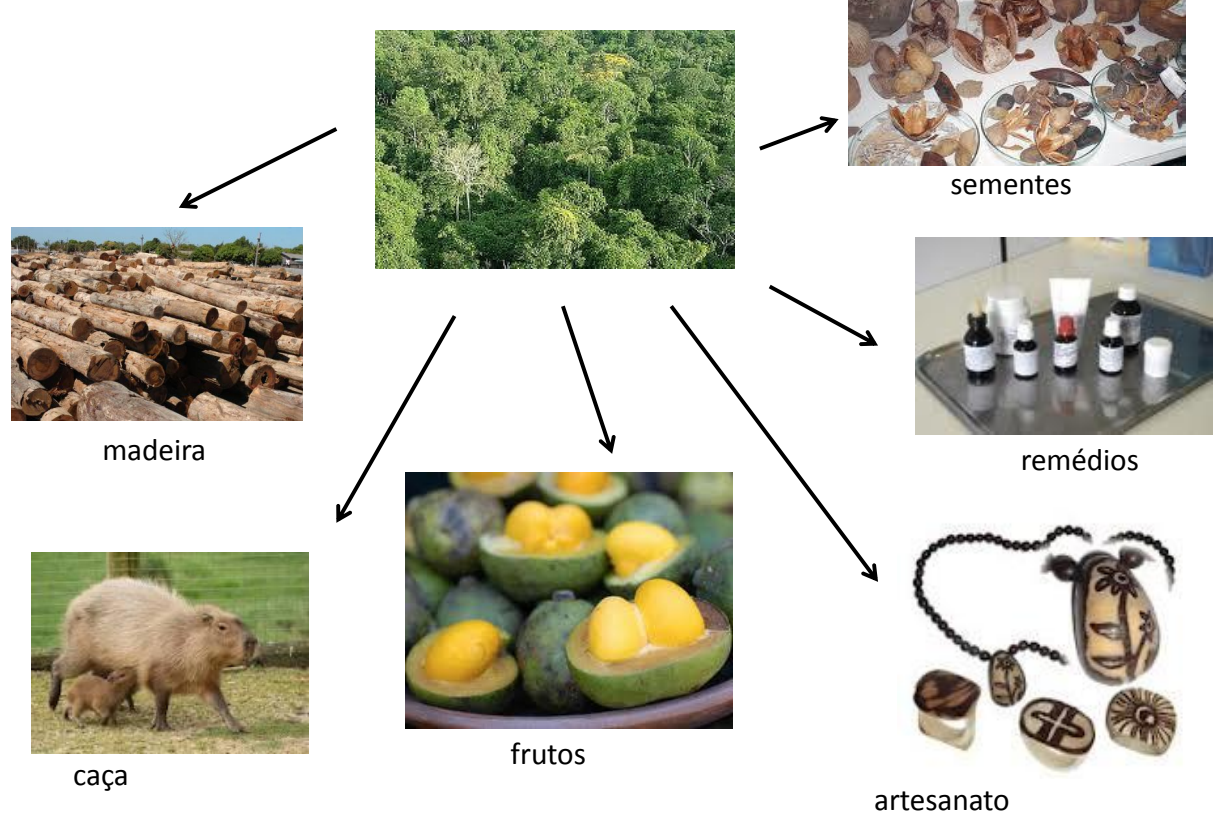




\section{Estrutura do modelo}

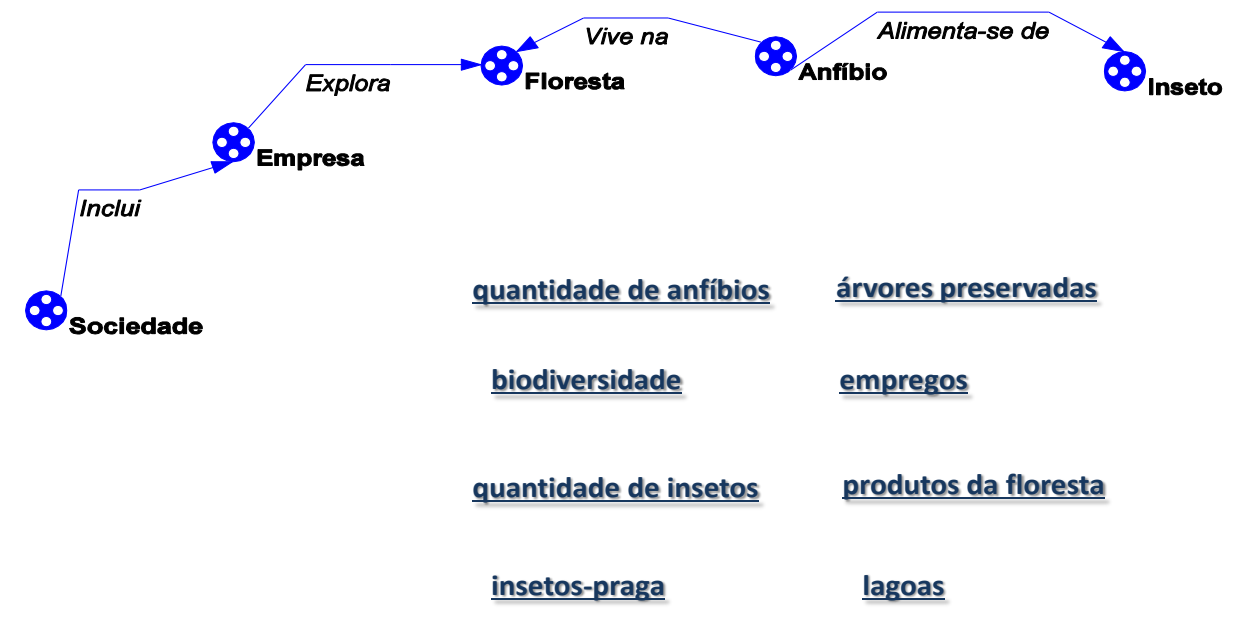

\section{Apêndice IV - Salvando um modelo no modo Agente Aprendiz}

Clique em 'Open model From file

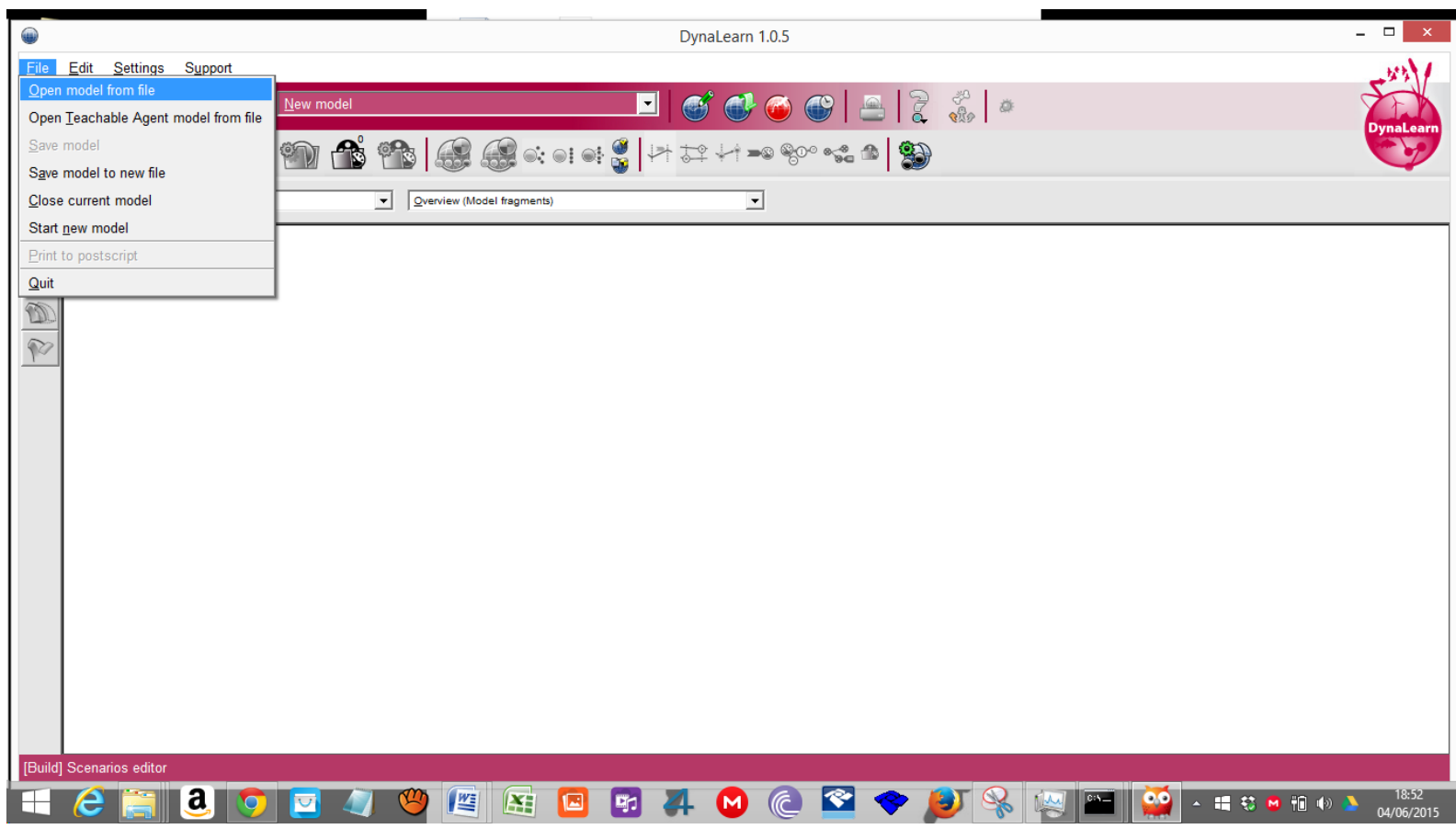

Navegue até o local em que se encontra o arquivo do modelo salvo no modo LS2 


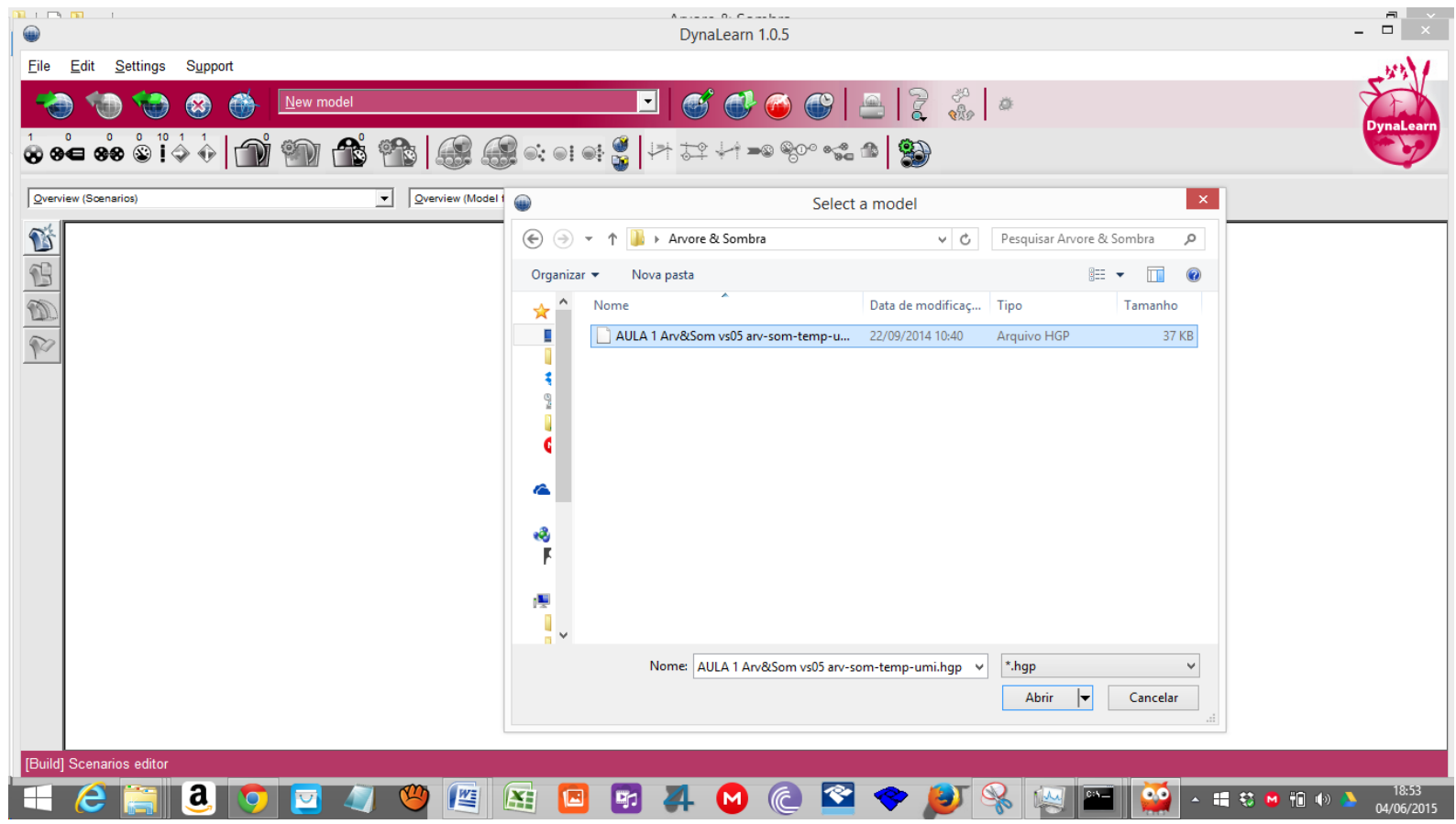

Vá em 'Support' e clique em 'Mark as TA model'

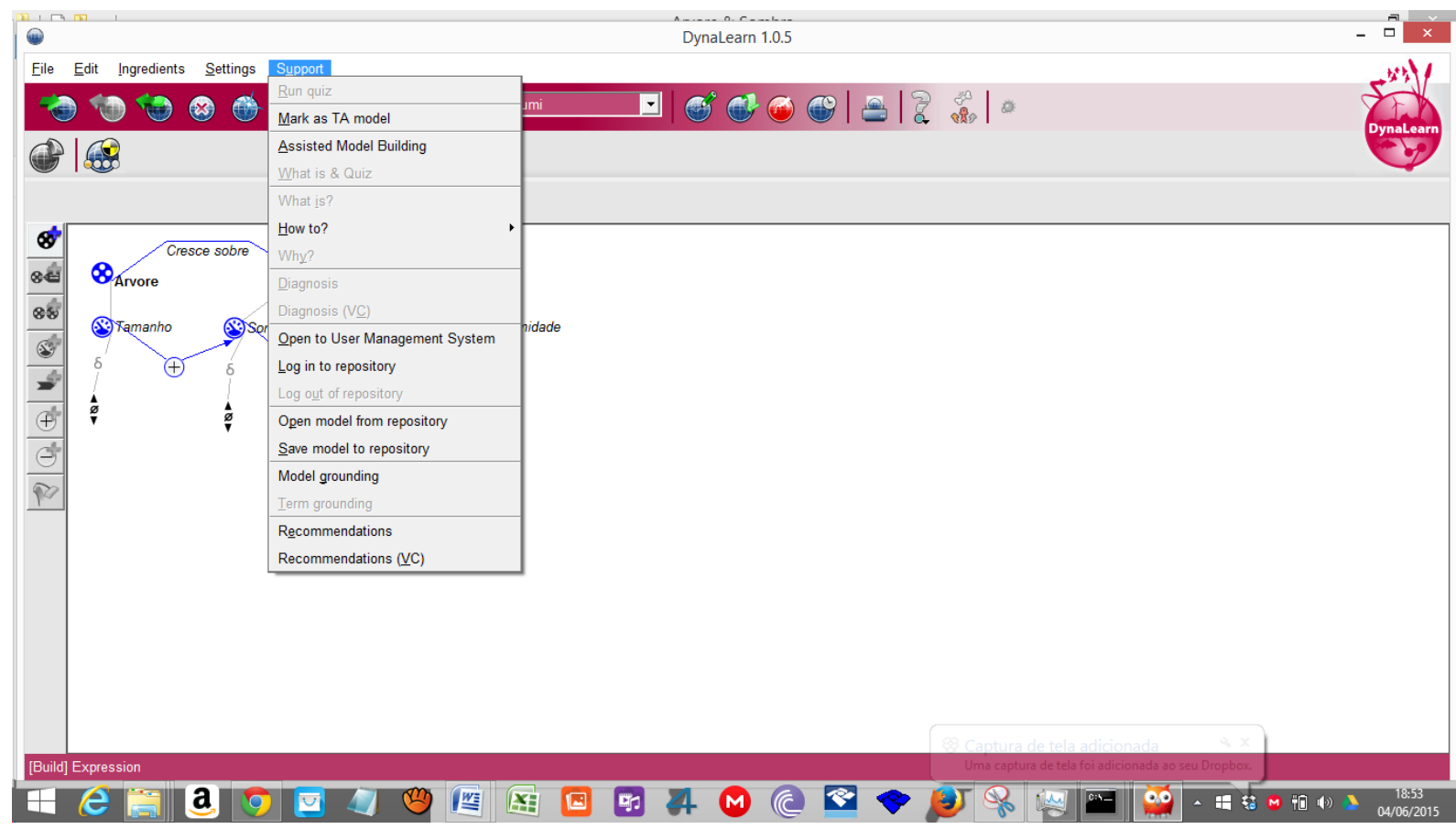

Salve o modelo que já encontra no modo Agente Virtual 


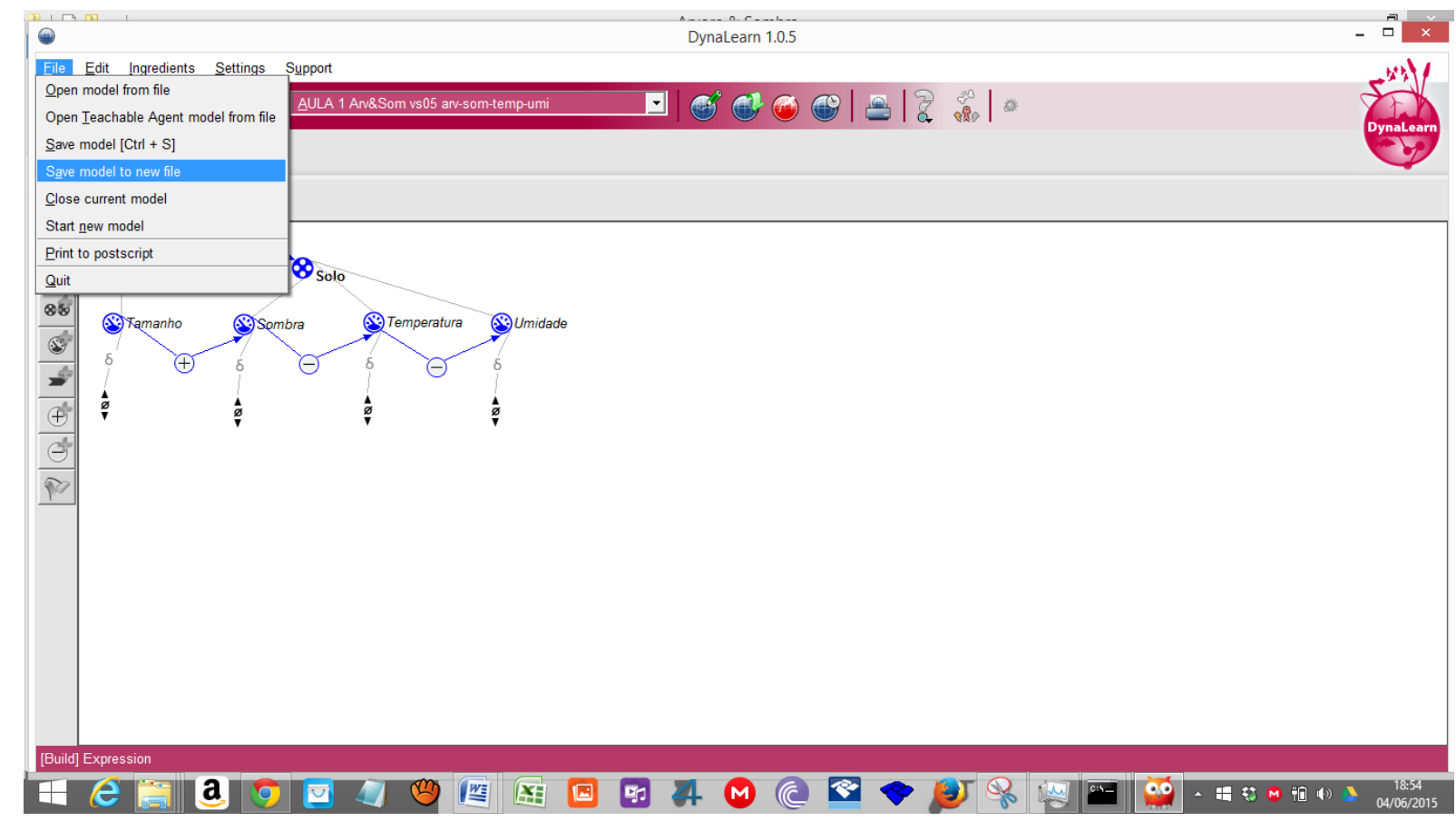

\section{Apêndice V - Apresentando o modelo da 'Aterosclerose'}

\section{a. A estrutura do sistema}

No modelo foi assuida a representação dos principais eventos relacionados à aterosclerose a fim de realizar discussõs sobre as causas, consequências e tratamento (ou prevenção) desta doença, ligada, principalmente, ao sistema circulatório humano.

A estrutura do sistema no modelo é representada pelas entidades "Ser humano", "Artéria", "Coração", "Cérebro" e "Pernas" (veja-se figura 12).

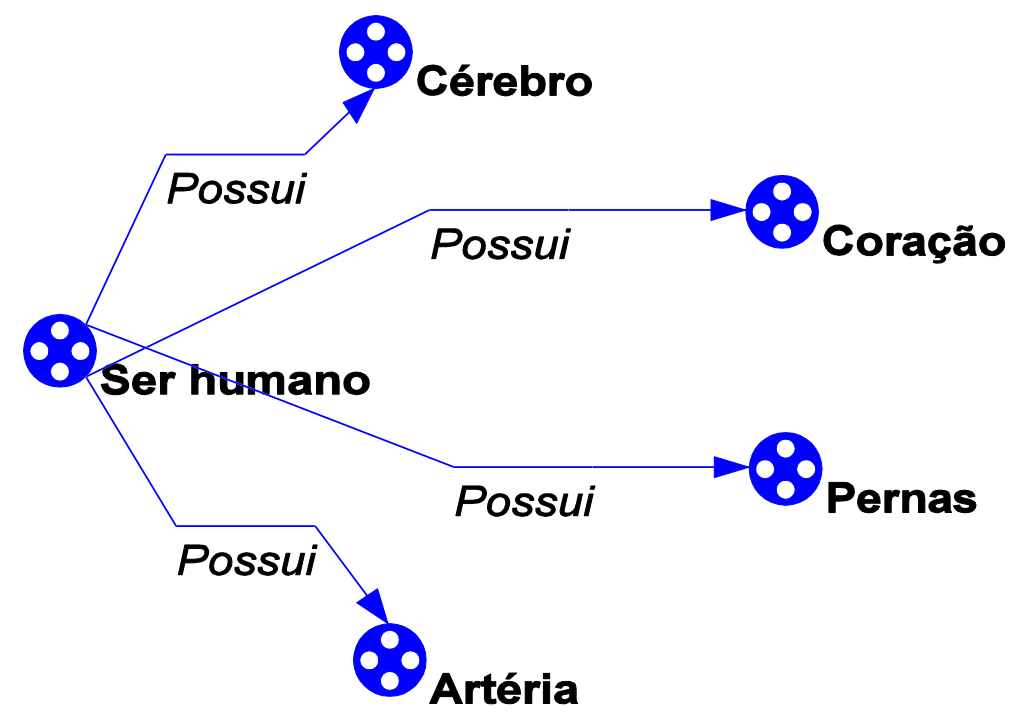

Figura 12. Árvore de entidades

b. Variáveis 
Cada entidade foi associada a variáveis (quantidades), que expressam características interessantes para o problema estudado. As variáveis utilizadas no modelo estão representadas no quadro abaixo.

Quadro - Representação das variáveis.

\begin{tabular}{|c|c|c|}
\hline Entidade & Variáveis & Significado \\
\hline \multirow[t]{3}{*}{ Ser humano } & $\begin{array}{l}\text { Alimentos pobres em } \\
\text { colesterol ruim. }\end{array}$ & $\begin{array}{l}\text { Medida da quantidade de ingestão de alimentos com } \\
\text { pouco ou nenhum colesterol ruim. }\end{array}$ \\
\hline & $\begin{array}{l}\text { Ingestão de colesterol } \\
\text { ruim. }\end{array}$ & $\begin{array}{l}\text { Medida da quantidade de ingestão de alimentos com } \\
\text { colesterol ruim. }\end{array}$ \\
\hline & Remédios. & $\begin{array}{l}\text { Medida da quantidade ideal de ingestão de remédios } \\
\text { próprios para o tratamento ou prevenção da } \\
\text { aterosclerose. }\end{array}$ \\
\hline \multirow[t]{3}{*}{ Artéria } & Ateromas. & $\begin{array}{l}\text { Medida da quantidade de ateromas formados nas } \\
\text { artérias do cérebro, coração ou pernas. }\end{array}$ \\
\hline & Passagem de sangue. & $\begin{array}{l}\text { Medida da quantidade de passagem de sangue nas } \\
\text { artérias. }\end{array}$ \\
\hline & Coágulos. & $\begin{array}{l}\text { Medida da quantidade de coágulos presentes nas } \\
\text { artérias do cérebro, coração ou pernas. }\end{array}$ \\
\hline Coração & Infarto & $\begin{array}{l}\text { Medida da quantidade de infartos que podem ocorrer } \\
\text { no coração. }\end{array}$ \\
\hline Cérebro & Derrame cerebral & $\begin{array}{l}\text { Medida da quantidade de derrames que podem ocorrer } \\
\text { no cérebro. }\end{array}$ \\
\hline Pernas & Trombose & $\begin{array}{l}\text { Medida da quantidade de tromboses que podem } \\
\text { ocorrer no pernas. }\end{array}$ \\
\hline
\end{tabular}

\section{c. Sub modelos}

Os modelos podem ser fracionados em modelos menores, que representam trechos com cadeias de causalidade. Serão descritos abaixo alguns desses submodelos, e os modelos completos são apresentados a seguir. Foi utilizado abaixo a sigla $S M$ que significa "submodelo".

\section{d. Um exemplo de cadeia de causalidade}




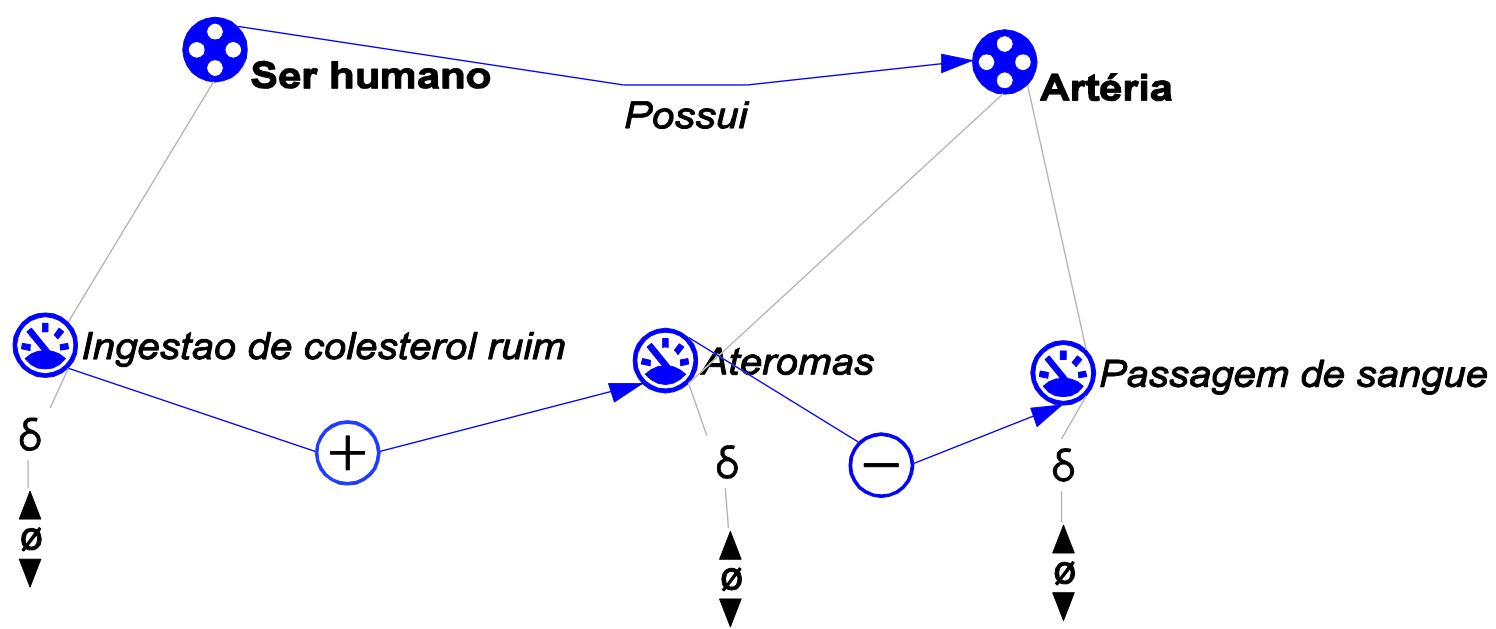

Fig. 13 - SM 01: 'Ingestão de colesterol ruim' influencia 'Ateromas' que influencia 'Passagem de sangue'.

O SM 01 demonstra a cadeia de causalidade entre as variáveis 'Ingestão de colesterol ruim', a formação de 'Ateromas' e a 'Passagem de sangue' nas artérias. Conforme a figura acima, a seta “+”" direcionada da 'Ingestão de colesterol ruim' para 'Ateromas', representa que quanto maior for a ingestão de colesterol ruim, mais ateromas serão formados nas artérias humanas e quanto menor a ingestão deste colesterol, menos ateromas serão formados.

A seta "_" direcionada de 'Ateromas' para a 'Passagem de sangue' representa que quanto maior for a formação de ateromas nas artérias, menor será o potencial de passagem de sangue nestes vasos sanguíneos, pois estes terão seu calibre reduzido. Esta seta negativa, significa ainda, que a diminuição na formação de ateromas nas artérias, aumentará o potencial de passagem de sangue nestas. Considerando duas entidades "A" e "B" em que há uma seta direcionada da primeira para a segunda, poderemos observar o seguinte: o sinal "+ " representa variação igual, ou seja, se uma variável aumenta a outra tembém aumenta. Se uma diminui a outra também. O sinal “_“ representa variação oposta, ou seja, se uma variável aumenta a outra irá diminuir. Se uma diminui a outra irá aumentar. 


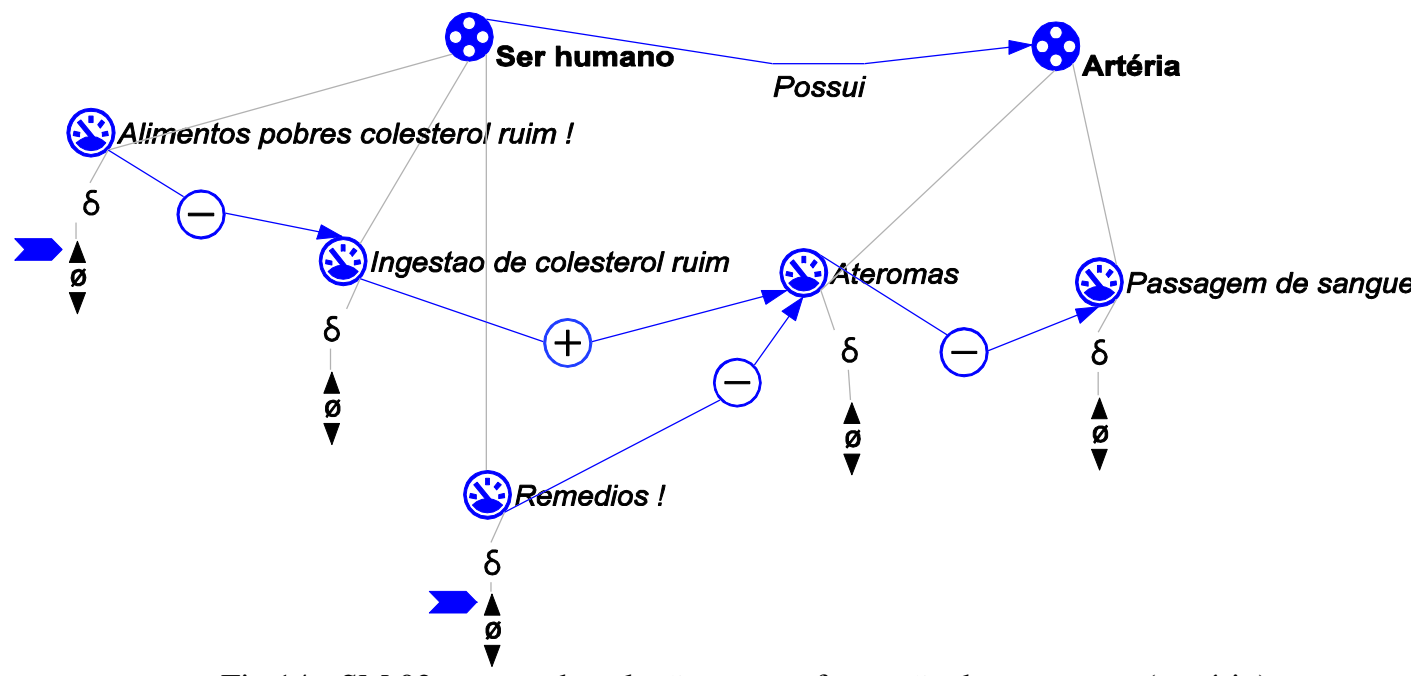

Fig.14 - SM 02: propondo soluções para a formação dos ateromas (cenário)

A figura acima representa a mesma cadeia de causalidade mostrada na figura anterior, porém, neste caso, foi modelado uma proposta de solução para a formação dos ateromas que reduzem a passagem de sangue nas artérias do corpo humano, pela adição das variáveis "Alimentos pobres em colesterol ruim" e "Remédios". A primeira sugere mudança nos hábitos alimentares ao propor que o aumento da ingestão de alimentos pobres em colesterol ruim, diminuem a ingestão de alimentos com o colesterol ruim. A segunda propõe que remédios podem agir diretamente sobre a formação dos ateromas, diminuindo estes.

\section{f. Fazendo simulações com o LS2}

A figura abaixo mostra como ocorre uma simulação em LS2 para o sub modelo 01, para um cenário em que a derivada da variável 'Ingestão de colesterol ruim' esteja marcada como aumentando.

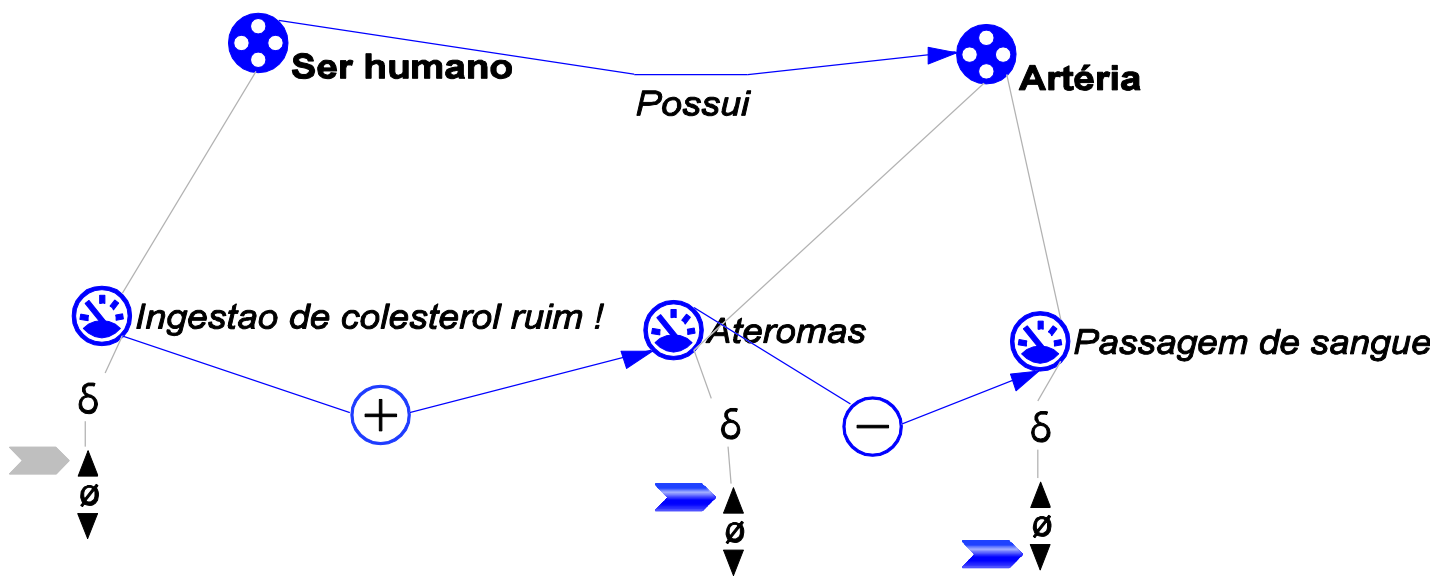

Fig. 15 - Simulação em LS2 sem o TA

O aluno pode marcar a derivada aumentando, da variável 'Ingestão de colesterol ruim' e 'solicitar' ao programa que rode a simulação (o valor inicial da simulação -cenário - está 
assinalado na cor cinza). O resultado será apresentado na cor azul, que no caso será aumentando para a variável 'Ateromas' e diminuído para a variável 'Passagem de sangue'.

A figura abaixo representa o resultado da simulação referente ao cenário do SM 02 mostrado na figura 14.

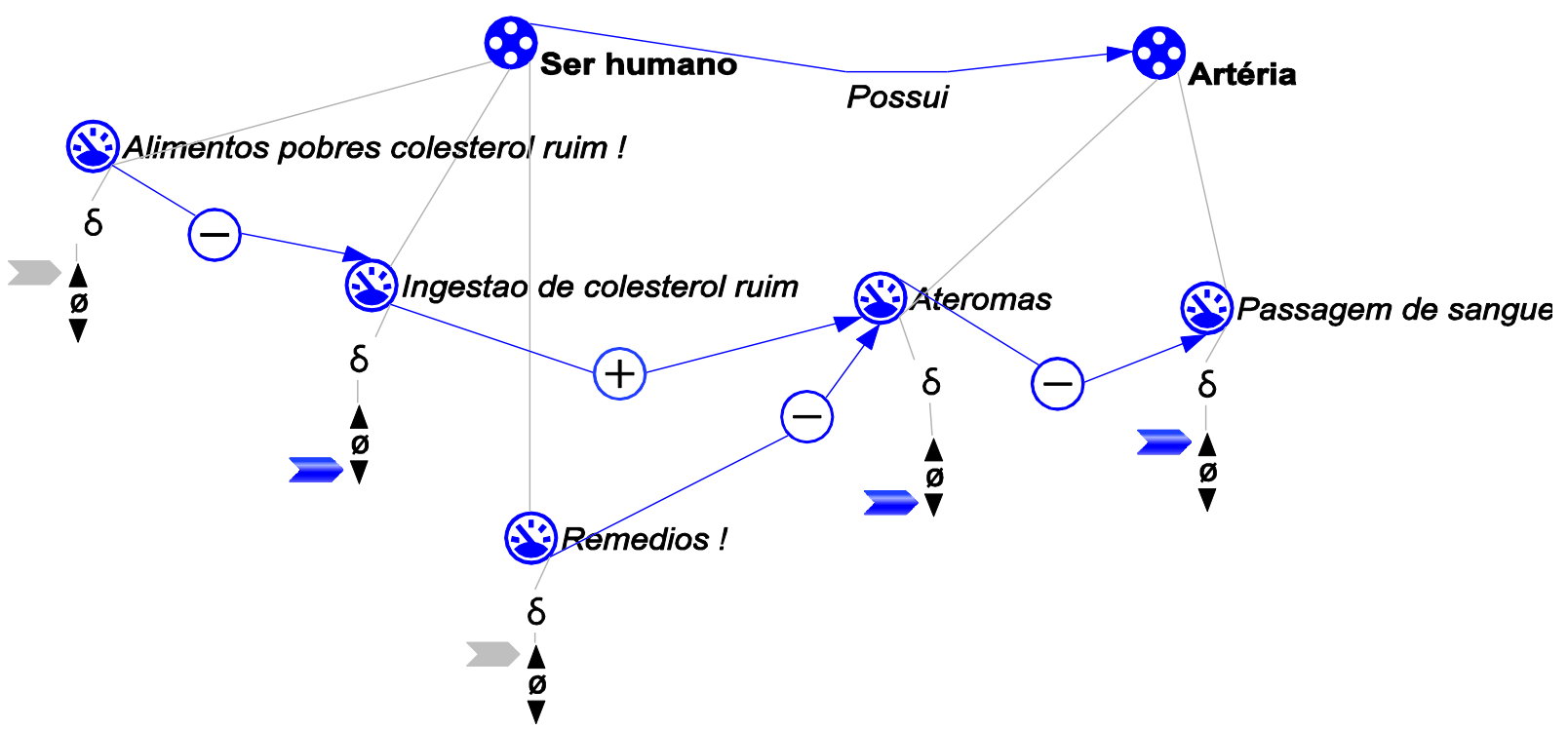

Fig. 16 - Propondo soluções para a formação dos ateromas (simulação)

A ingestão de alimentos pobres em colesterol ruim causa um efeito negativo na ingestão de colesterol ruim, que diminui o que por sua vez diminui a formação das placas de ateromas nas artérias humanas, favorecendo o aumento na passagem de sangue pelas artérias. Os remédios agem diretamente nos ateromas, diminuindo a formação destes.

\section{g. Simulação em LS2 com o TA}

A mesma simulação representada na figura 15 e já descrita pode ser feita com o uso do TA. Para isso, basta consultar o mestre do quiz, o Harry. Ele fará questionamentos sobre as influências positivas ou negativas entre as variáveis do modelo. Veja-se o exemplo abaixo: 

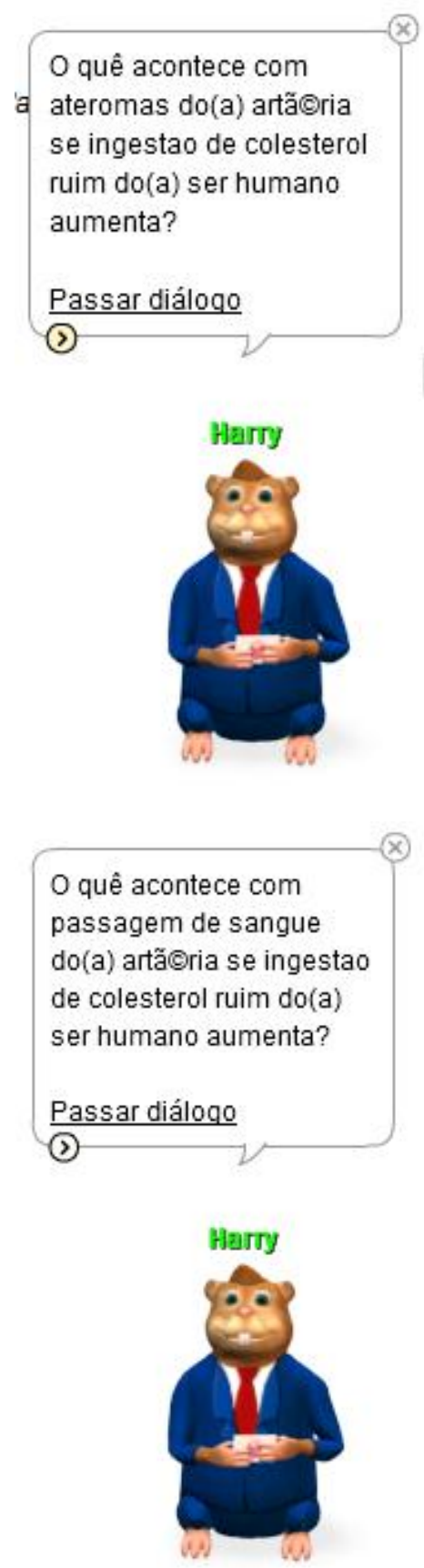

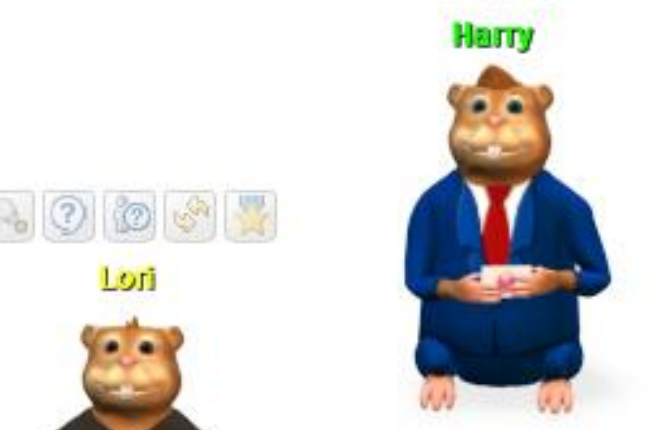

Ateromas aumenta.

(2)

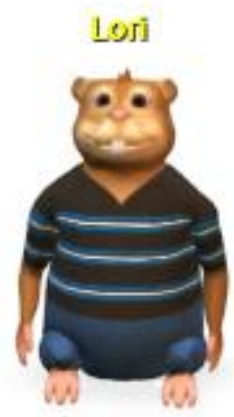

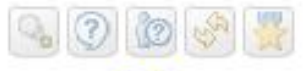

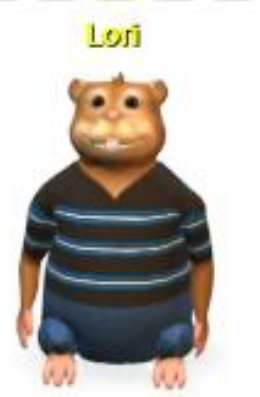

Passagem de sangue diminui.

(2)

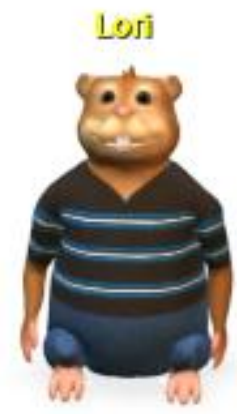

Fig. 17 - Simulação em LS2 com o TA

Pela análise e observação do diálogo ocorrido entre o mestre do quiz e o agente aprendiz, as simulações são feitas. Ressalta-se que as perguntas de simulações feitas no modo TA são feitas de modo aleatório, a critério do próprio programa, a fim de evitar que os alunos apenas decorem respostas. Essa aleatoriedade induz o aluno a ter que raciocinar sobre a dinâmica entre o mestre do quiz e o Pet aprendiz, de modo que o aluno possa fazer previsões e análises sobre o sistema modelado. 


\section{$\underline{\text { Apêndice VI - Modelo do aparelho reprodutor masculino }}$}

\section{a. A estrutura do sistema}

A figura abaixo mostra a árvore de entidades que representa a estrutura do sistema reprodutor masculino.

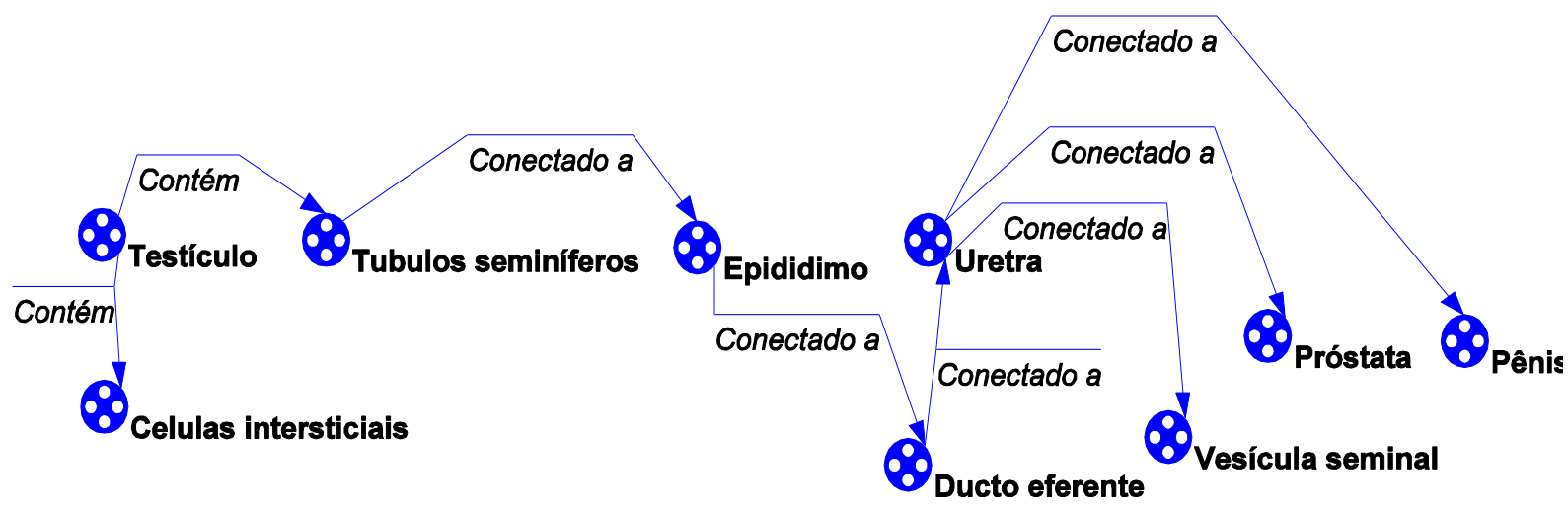

Fig. 18. Árvore de entidades

Neste modelo foi assumida a representação dos principais eventos relacionados ao funcionamento do sistema reprodutor masculino a fim de realizar discussõs sobre o assunto. Para tal foram usadas nove entidades que representam a estrutura do sistema - 'Testículo', 'Células Intersticiais', 'Túbulos seminíferos', 'Epidídimo', 'Ducto eferente', 'Uretra', 'Vesícula seminal', 'Próstata' e 'Pênis'.

\section{b. Variáveis}

Cada entidade foi associada a variáveis, que expressam características interessantes para o problema estudado. As variáveis utilizadas no modelo estão representadas no quadro abaixo: 
Quadro - Representação das quantidades.

\begin{tabular}{|c|c|c|}
\hline Entidade & Quantidade & Significado \\
\hline Testículo & ------ & ------ \\
\hline $\begin{array}{l}\text { Células } \\
\text { Intersticiais }\end{array}$ & Testosterona & $\begin{array}{l}\text { Medida da quantidade de testosterona } \\
\text { produzida nas células intersticiais dos } \\
\text { testículos. }\end{array}$ \\
\hline \multirow[t]{2}{*}{$\begin{array}{l}\text { Túbulos } \\
\text { seminíferos }\end{array}$} & Divisões celulares & $\begin{array}{l}\text { Medida da quantidade de divisões } \\
\text { celulares que ocorrem nos túbulos } \\
\text { seminíferos. }\end{array}$ \\
\hline & Gônias & $\begin{array}{l}\text { Medida da quantidade de gônias que } \\
\text { se formam nos túbulos seminíferos. }\end{array}$ \\
\hline Epidídimo & Espermatozoides & $\begin{array}{l}\text { Medida da quantidade de } \\
\text { espermatozoides presentes no } \\
\text { epidídimo. }\end{array}$ \\
\hline Ducto eferente & Espermatozoides & $\begin{array}{l}\text { Medida da quantidade de } \\
\text { espermatozoides presentes no ducto } \\
\text { eferente. }\end{array}$ \\
\hline Uretra & Sêmen & $\begin{array}{l}\text { Medida da quantidade de sêmen } \\
\text { presentes na uretra. }\end{array}$ \\
\hline Vesícula seminal & Secreção líquida & $\begin{array}{l}\text { Medida da quantidade de secreção } \\
\text { líquida produzida pela vesícula } \\
\text { seminal. }\end{array}$ \\
\hline Próstata & Secreção líquida & $\begin{array}{l}\text { Medida da quantidade de secreção } \\
\text { líquida produzida pela próstata. }\end{array}$ \\
\hline Pênis & Ejaculação & $\begin{array}{l}\text { Medida da quantidade de ejaculação } \\
\text { realizada pelo pênis. }\end{array}$ \\
\hline
\end{tabular}

\section{c. Sub modelos}


A figura abaixo mostra o SM que representa a formação do sêmen na uretra do aparelho reprodutor masculino humano.

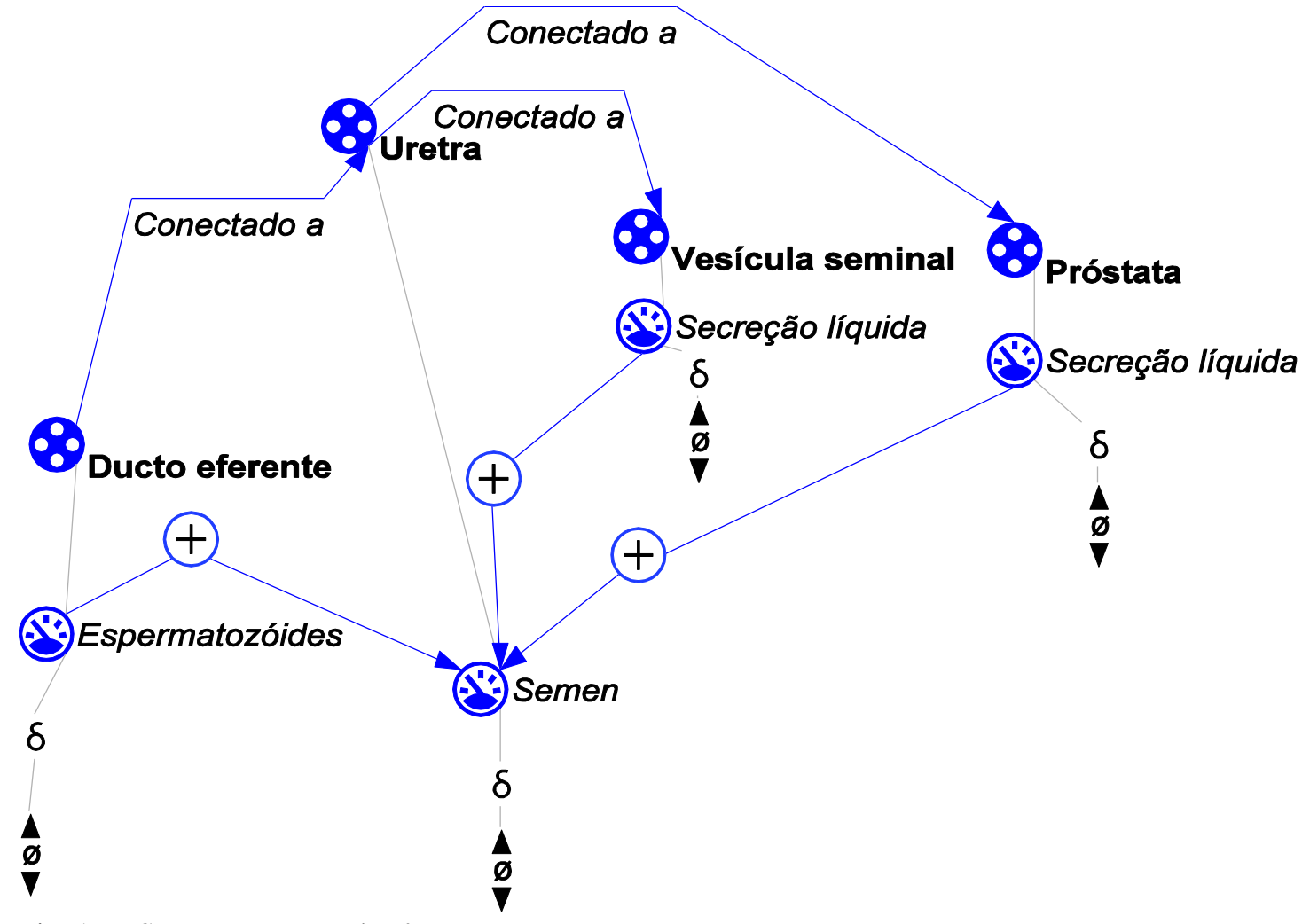

Fig. 19 - SM - Formação do sêmen

Conforme a figura 19, a seta “+” direcionada das variáveis 'Espermtozoides' para 'Semen', representa que quanto maior for a quantidade de espermatozoides nos ductos eferentes do aparelho reprodutor masculino, maior será a quantidade de sêmen na uretra. Da mesma forma, quanto menor a quantidade do primeiro, menor será a do segundo. Comportamento semelhante é notado em relação às variáveis 'Secreção líquida' da vesícula e 'Secreção líquida' da próstata em relação à variável 'Semen'.

\section{d. Representando a vasectomia e propondo discussões}




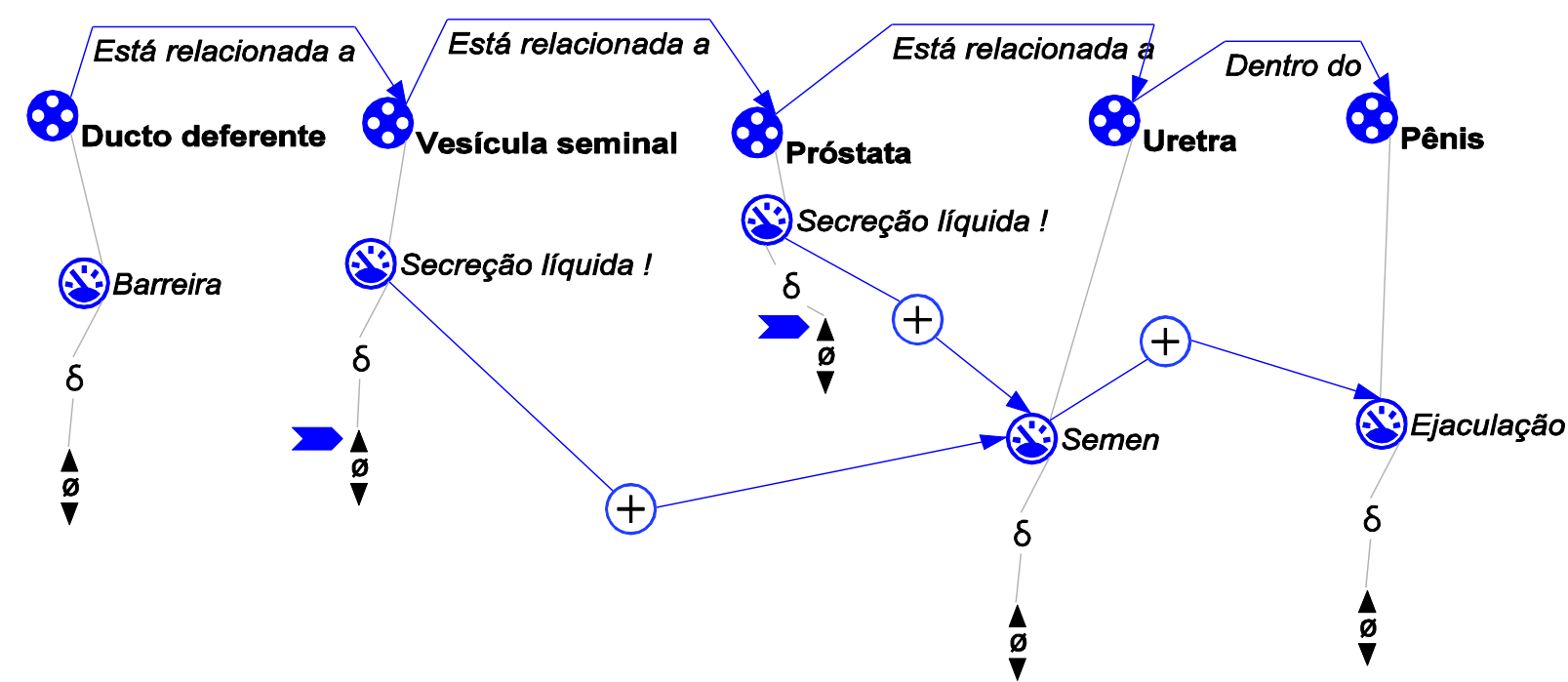

Fig.20 - SM -Formação do sêmen sem espermatozoides (cenário)

A Figura 20 representa a mesma cadeia de causalidade mostrada na figura anterior, porém, neste cenário, foi modelada uma situação para ser discutida, sobre a presença de uma barreira nos ductos deferentes, ou seja, a vasectomia, em que os espermatozoides se tornam ausentes neste tubo. Neste caso, observa-se a formação do sêmen pelos líquidos das vesículas seminais e próstata, mas sem espermatozoides. $\mathrm{O}$ resultado da simulação proposta nesta figura está representada na Figura 21.

\section{e. Fazendo simulações com o LS2}

A figura abaixo mostra como ocorre uma simulação em LS2 para um cenário referente ao SM representado na Figura 20.

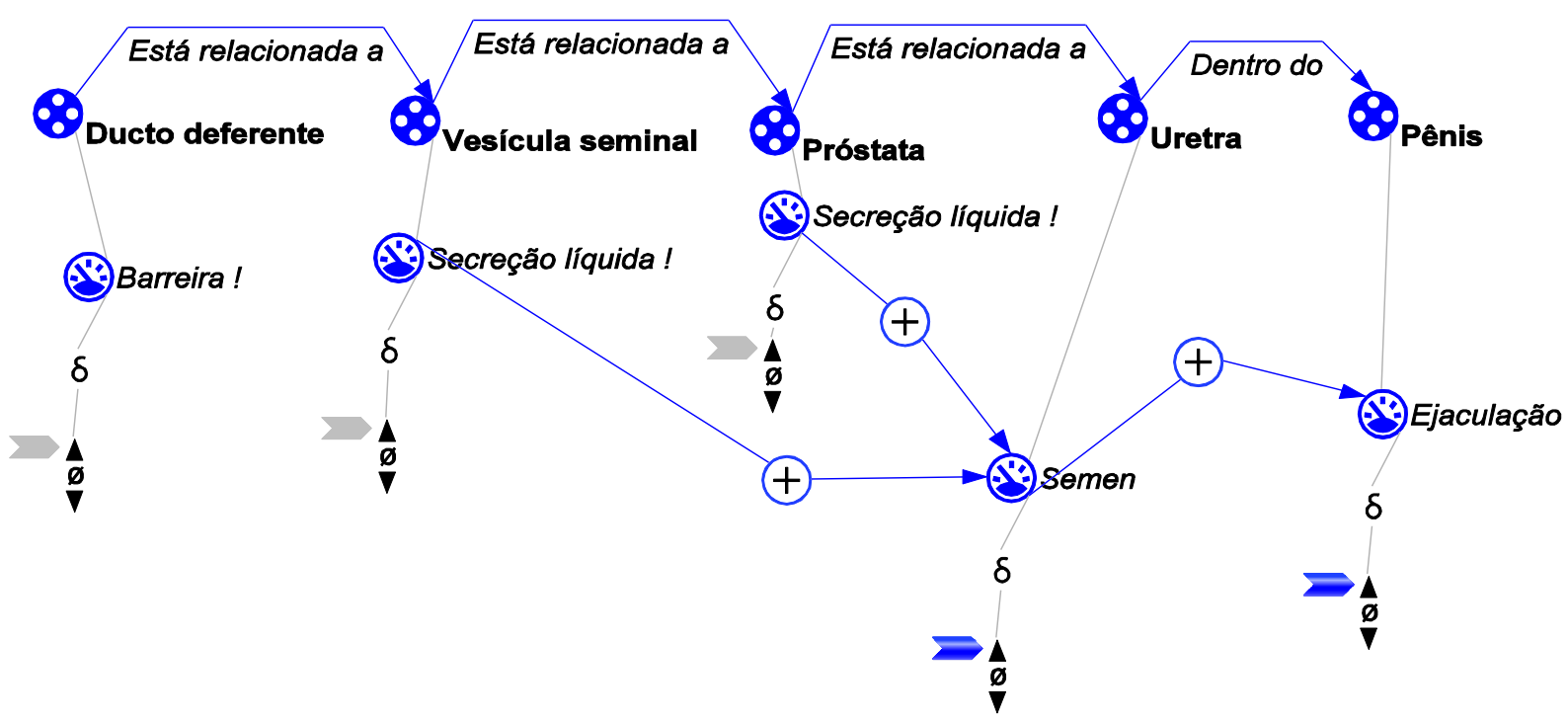

Fig. 21 - SM - Formação do sêmen sem espermatozoides (simulação) 
O aluno pode marcar a derivada aumentando, da variável 'Barreira' e 'Secreção líquida' e rodar a simulação no programa. O resultado será aumentando para todas as variáveis do cenário.

A figura abaixo representa a simulação para um cenário de um SM em que não houve a vasectomia, ou seja, sem a presença da variável 'Barreira'. Neste caso o sêmen produzido terá, na sua constituição, os espermatozoides.

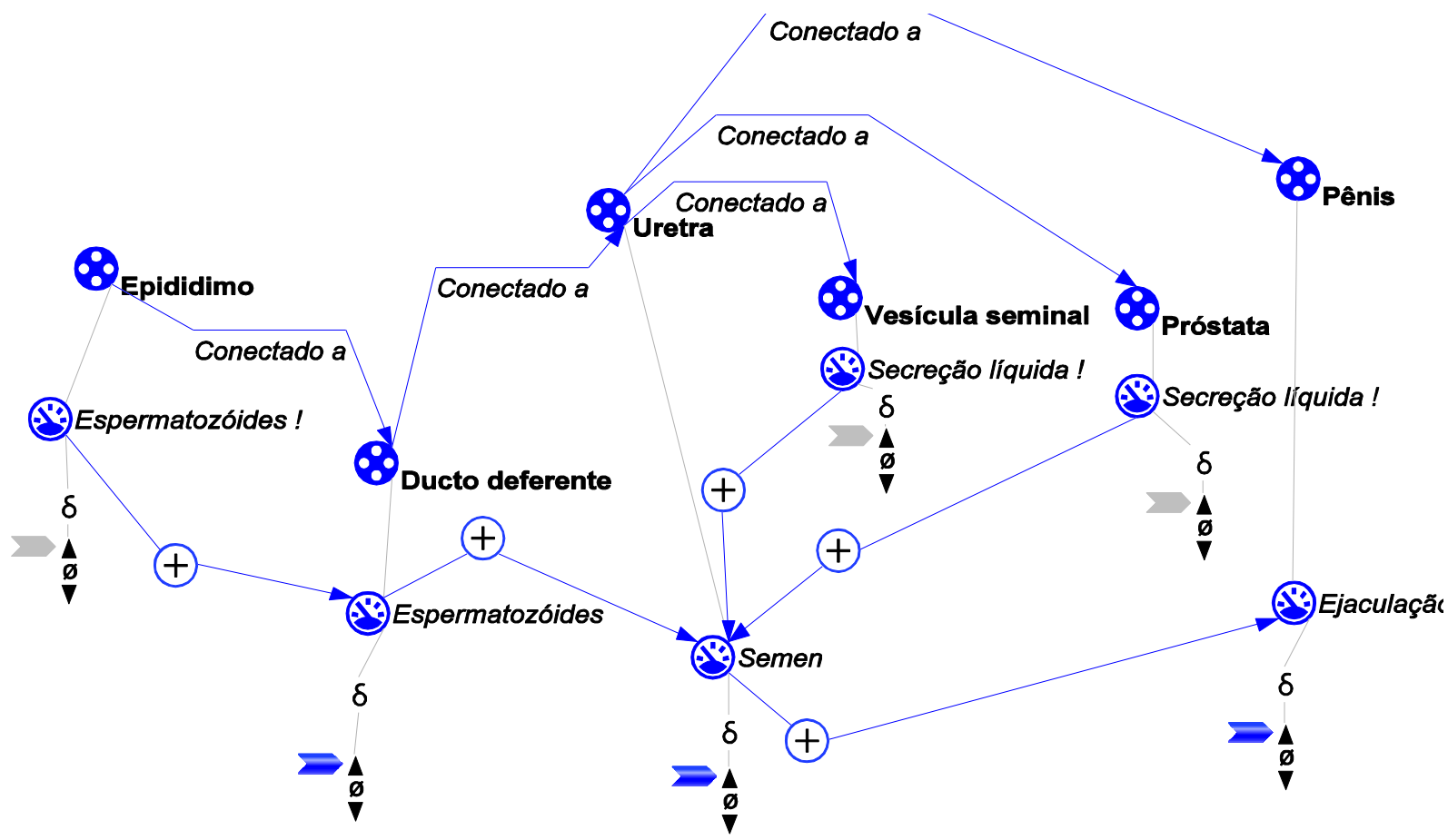

Fig. 22 - SM - Formação do sêmen com espermatozoides (simulação)

\section{f. Simulação em LS2 com o TA}

As mesmas simulações representadas nas Figuras 21 e 22 podem ser feitas com o uso do TA, como foi explicado no modelo da aterosclerose. 


\section{$\underline{\text { Apêndice VII - Texto e modelo sobre a placenta }}$}

\section{a. A estrutura do sistema}

No modelo foi assumida a representação dos principais eventos relacionados às funções da placenta do sistema reprodutor feminino humano a fim de realizar discussõs sobre o assunto. Para tal foram usadas sete entidades - 'Mãe', ' Sistema digestor', 'Sistema excretor', 'Sistema respoiratório', 'Placenta', 'Embrião', 'Sangue do embrião' que representam a estrutura do sistema no modelo como mostra a figura abaixo:

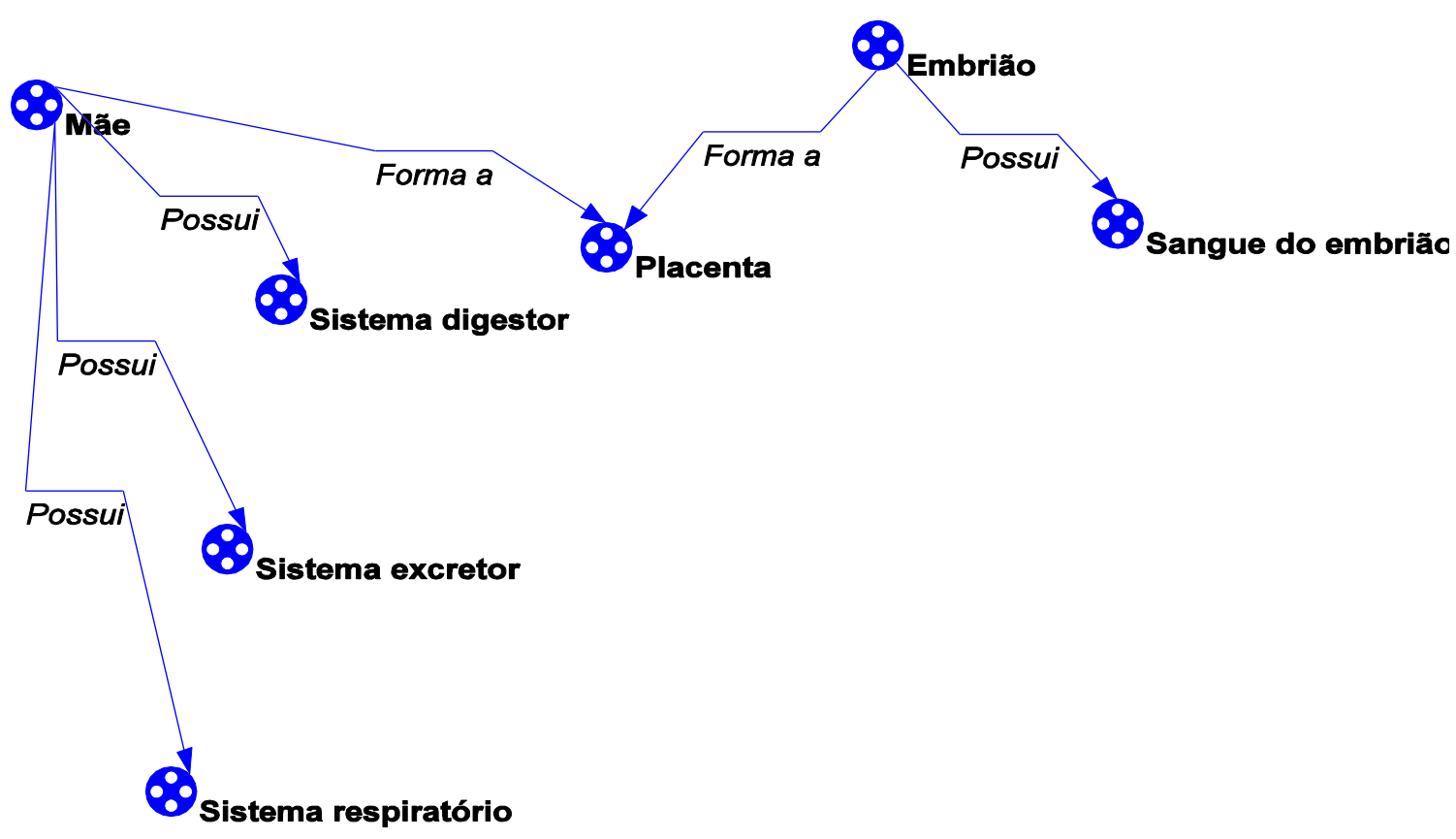

Figura 23. Árvore de entidades

\section{b. Variáveis}

Quadro - Representação das variáveis.

\begin{tabular}{|l|l|l|}
\hline Entidade & Variável & Significado \\
\hline Mãe & ------ & ----- \\
\hline
\end{tabular}




\begin{tabular}{|c|c|c|}
\hline Sistema digestor & Nutrientes & $\begin{array}{l}\text { Medida da quantidade de nutrientes presentes } \\
\text { no sistema digestor materno. }\end{array}$ \\
\hline Sistema excretor & Excretas & $\begin{array}{l}\text { Medida da quantidade de excretas presentes no } \\
\text { sistema excretor materno. }\end{array}$ \\
\hline \multirow[t]{2}{*}{ Sistema respiratório } & Oxigênio & $\begin{array}{l}\text { Medida da quantidade de oxigênio presente no } \\
\text { sistema respiratório materno. }\end{array}$ \\
\hline & Gás carbônico & $\begin{array}{l}\text { Medida da quantidade de gás carbônico } \\
\text { presente no sistema respiratório materno. }\end{array}$ \\
\hline \multirow[t]{4}{*}{ Placenta } & Difusão de nutrientes & $\begin{array}{l}\text { Medida da quantidade de nutrientes presente } \\
\text { na placenta materna. }\end{array}$ \\
\hline & Difusão de excretas & $\begin{array}{l}\text { Medida da quantidade de excretas presente na } \\
\text { placenta materna. }\end{array}$ \\
\hline & Difusão de oxigênio & $\begin{array}{l}\text { Medida da quantidade de oxigênio presente na } \\
\text { placenta materna. }\end{array}$ \\
\hline & Difusão de gás carbônico & $\begin{array}{l}\text { Medida da quantidade de gás carbônico } \\
\text { presente na placenta materna. }\end{array}$ \\
\hline Embrião & -------- & -------- \\
\hline \multirow[t]{4}{*}{ Sangue do embrião } & Nutrientes & $\begin{array}{l}\text { Medida da quantidade de nutrientes presentes } \\
\text { no sangue do embrião. }\end{array}$ \\
\hline & Excretas & $\begin{array}{l}\text { Medida da quantidade de excretas presentes no } \\
\text { sangue do embrião. }\end{array}$ \\
\hline & Oxigênio & $\begin{array}{l}\text { Medida da quantidade de oxigênio presente no } \\
\text { sangue do embrião. }\end{array}$ \\
\hline & Gás carbônico & $\begin{array}{l}\text { Medida da quantidade de gás carbônico } \\
\text { presente no sangue do embrião. }\end{array}$ \\
\hline
\end{tabular}

\section{c. Sub modelos}

A figura abaixo representa as trocas gasosas que ocorrem entre o sistema respiratório do corpo materno e o sangue do embrião. 

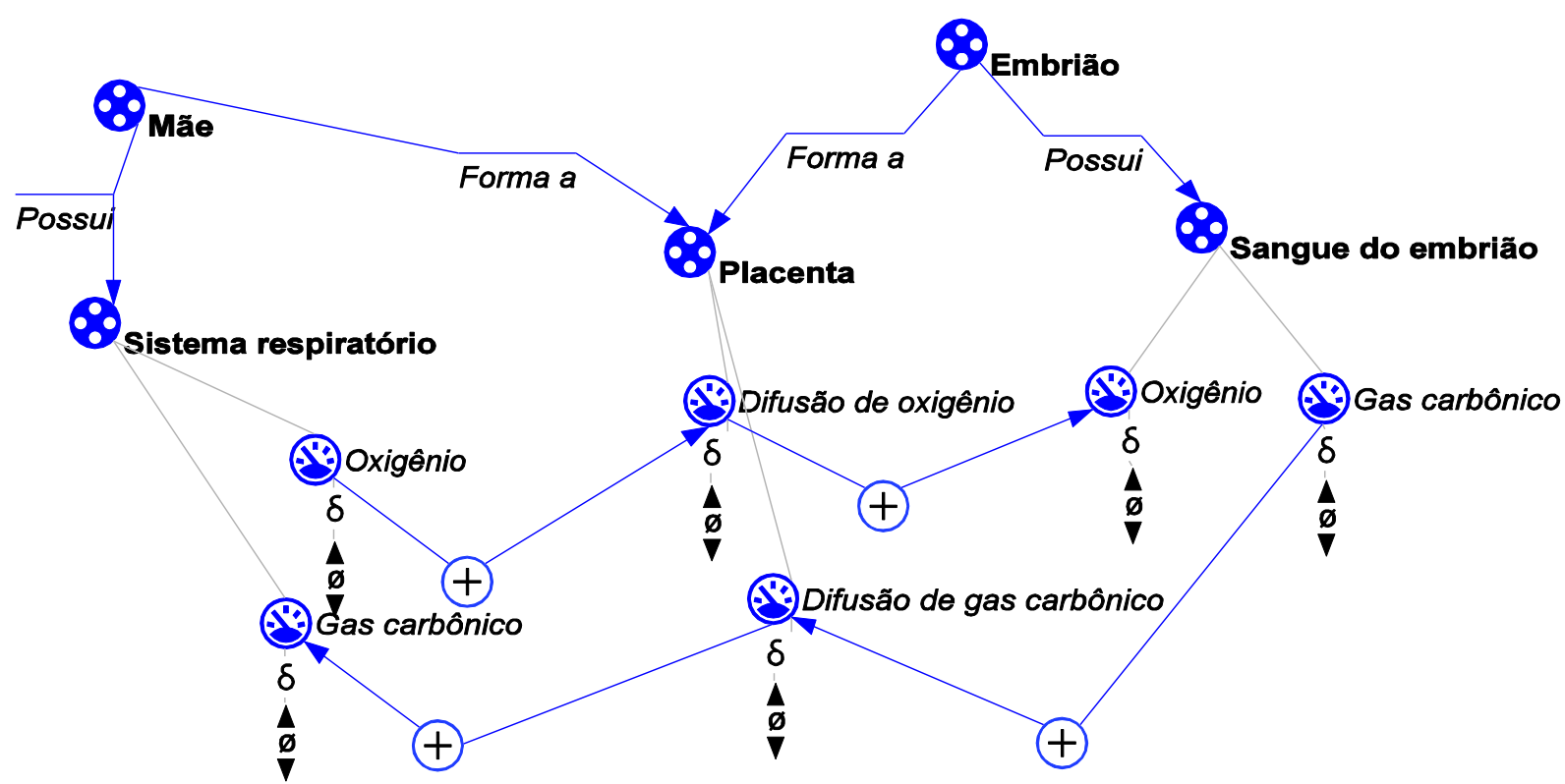

Fig. 24 - SM - Trocas gasosas entre corpo materno e embrião

Conforme a figura, a variável 'Oxigênio' da entidade 'Sistem respiratório' influencia positivamente a variável 'Difusão de oxigênio' da entidade 'Placenta' que por sua vez infuencia, também positivamente, a variável 'Oxigênio' da entidade 'Sangue do embrião'. Comportamento semelhante é observado em relação às variáveis 'Gas carbônico' - 'Difusão de gas carbônico' e 'Gas carbônico'.

\section{e. Fazendo simulações com o LS2}

A figura abaixo demonstra uma simulação em LS2 para um cenário do SM representado na figura anterior.
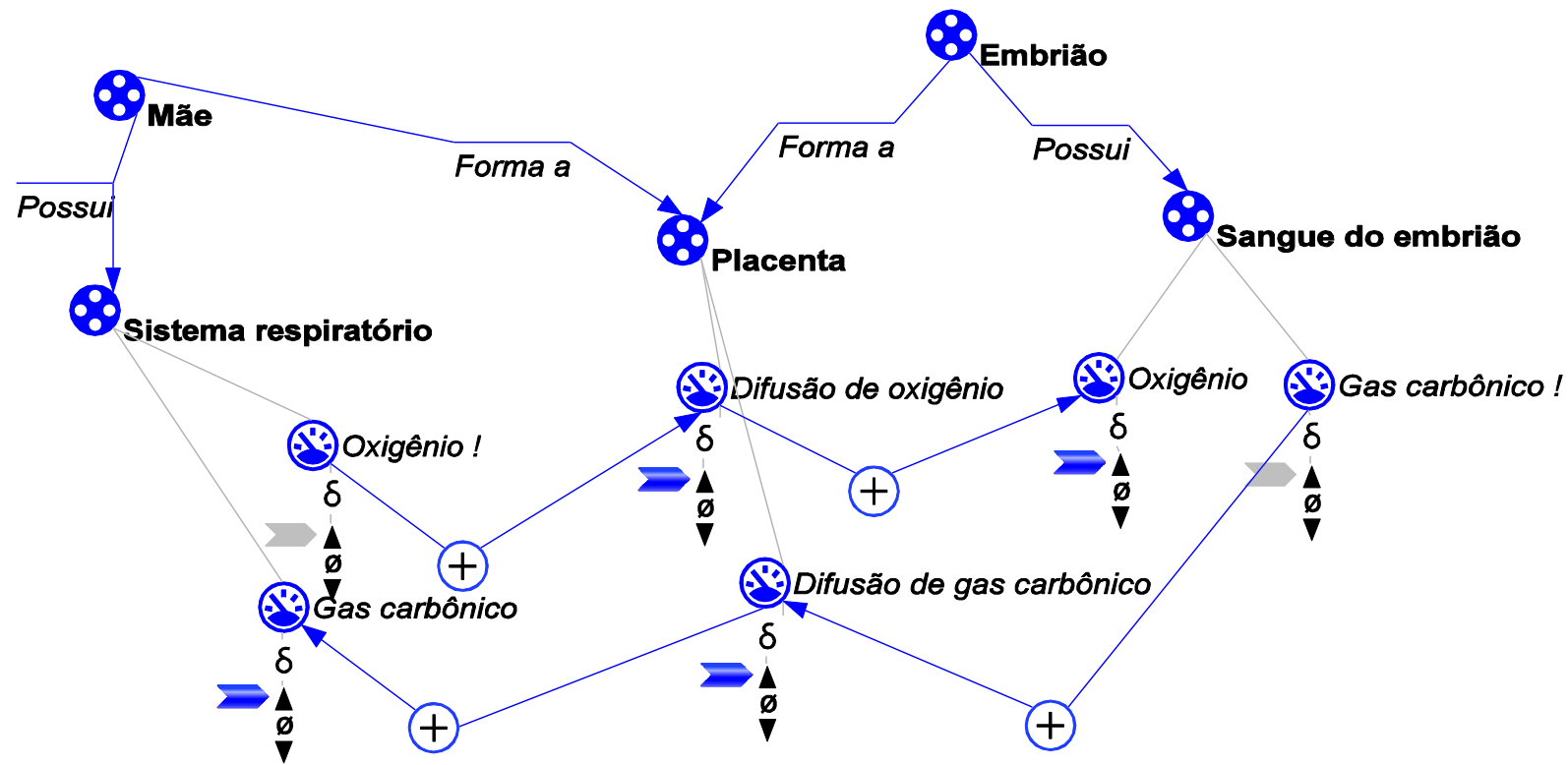

Fig. 25 - SM - Trocas gasosas entre corpo materno e embrião (simulação) 
O aluno pode marcar a derivada aumentando, das variáveis 'Oxigênio' da entidade 'Sistema respiratório' e 'Gás carbônico' da entidade 'Sangue do embrião' e rodar a simulação no programa. O resultado (comportamento das variáveis) para o aumento do oxigênio será: 'Difusão de oxigênio' da entidade 'Placenta' aumentando, 'Oxigênio' da entidade 'Sangue do embrião' aumentando. A consequência do aumento do gás carbônico no comportamento das variáveis do cenário será: 'Difusão de gás carbônico' da entidade 'Placenta' aumentando e 'Gás carbônico' da entidade 'Sistema respiratório' aumentando.

\section{f. Simulação em LS2 com o TA}

As mesmas simulações representadas na Figura 19 podem ser feitas com o uso do TA, como foi explicado.

\section{Apêndice VIII - Outros Modelos, Cenários s Simulações}

1 - Cenários e simulações - modelo da aterosclerose.

Figuras Aterosclerose "Sem Tratamento"

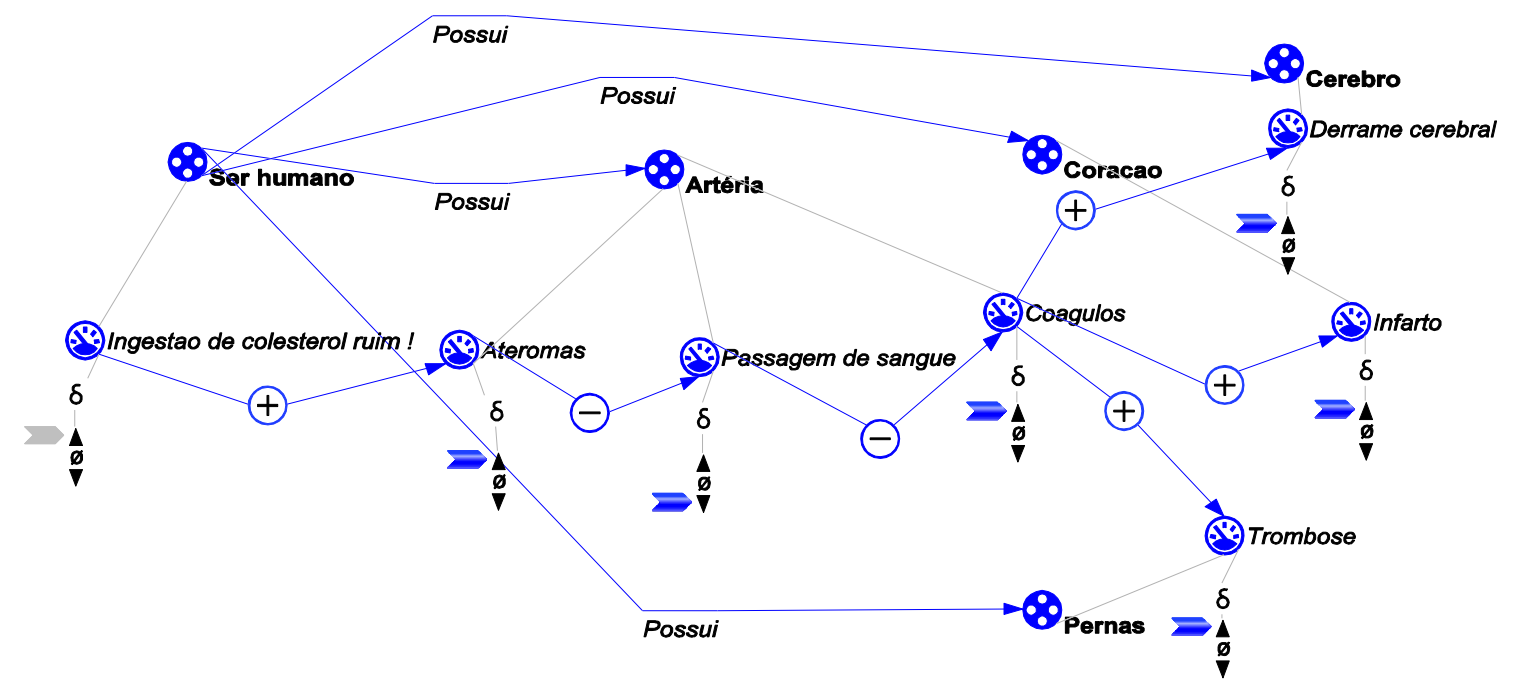

Expressão "sem tratamento" colesterol crescendo 


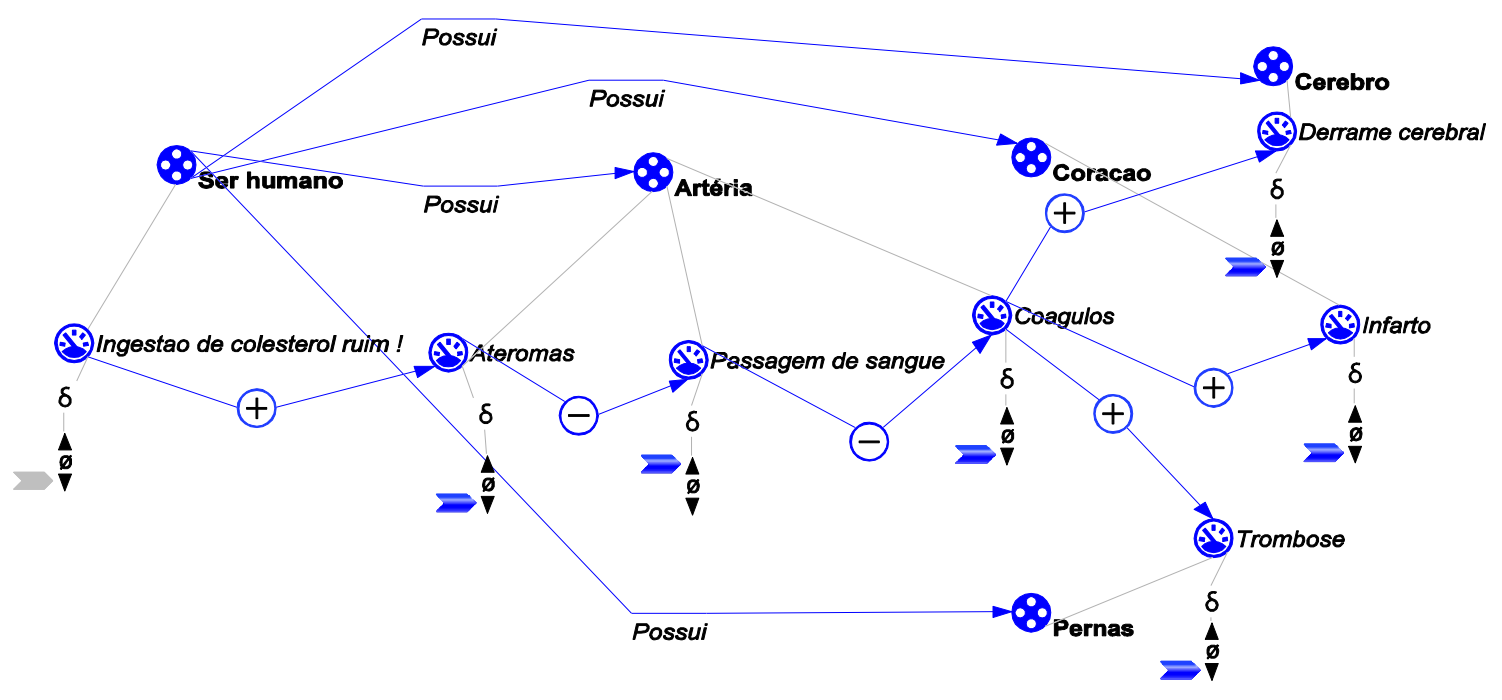

Expressão “sem tratamento" colesterol decrescendo

Figuras Aterosclerose "Com Tratamento"

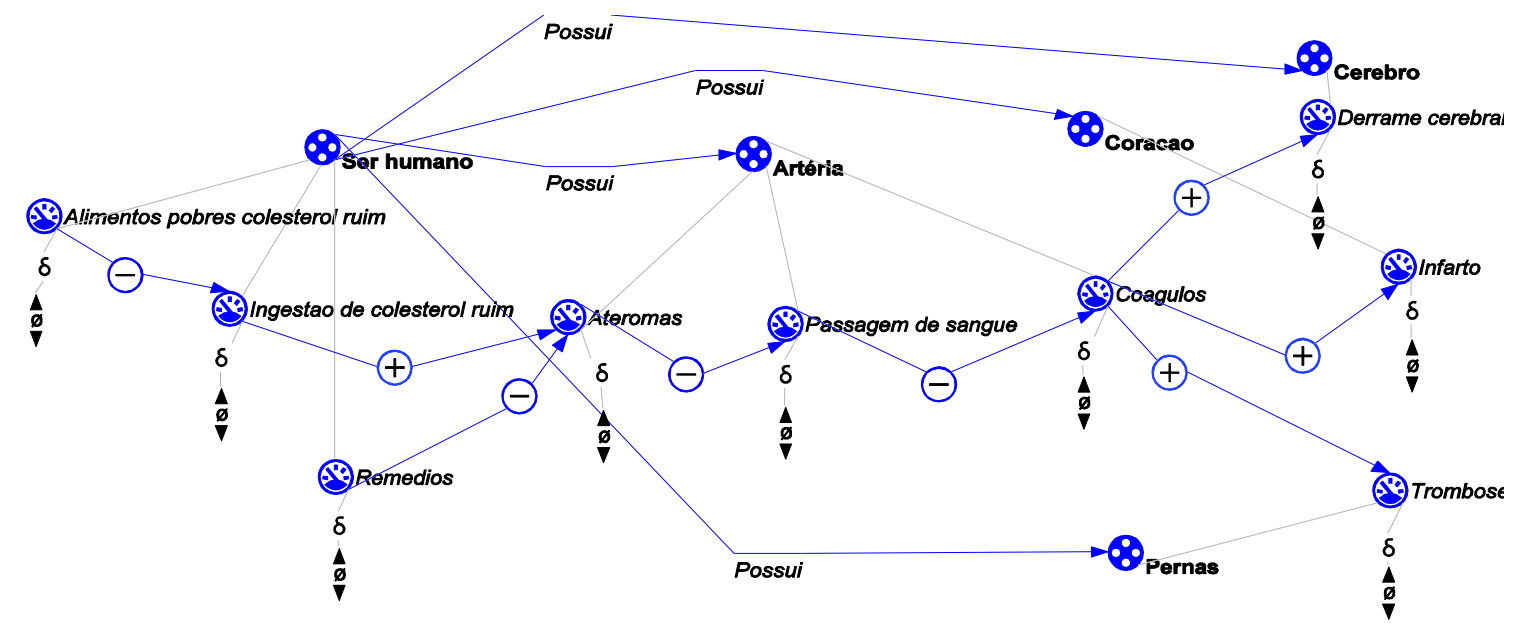

Expressão “com tratamento" 


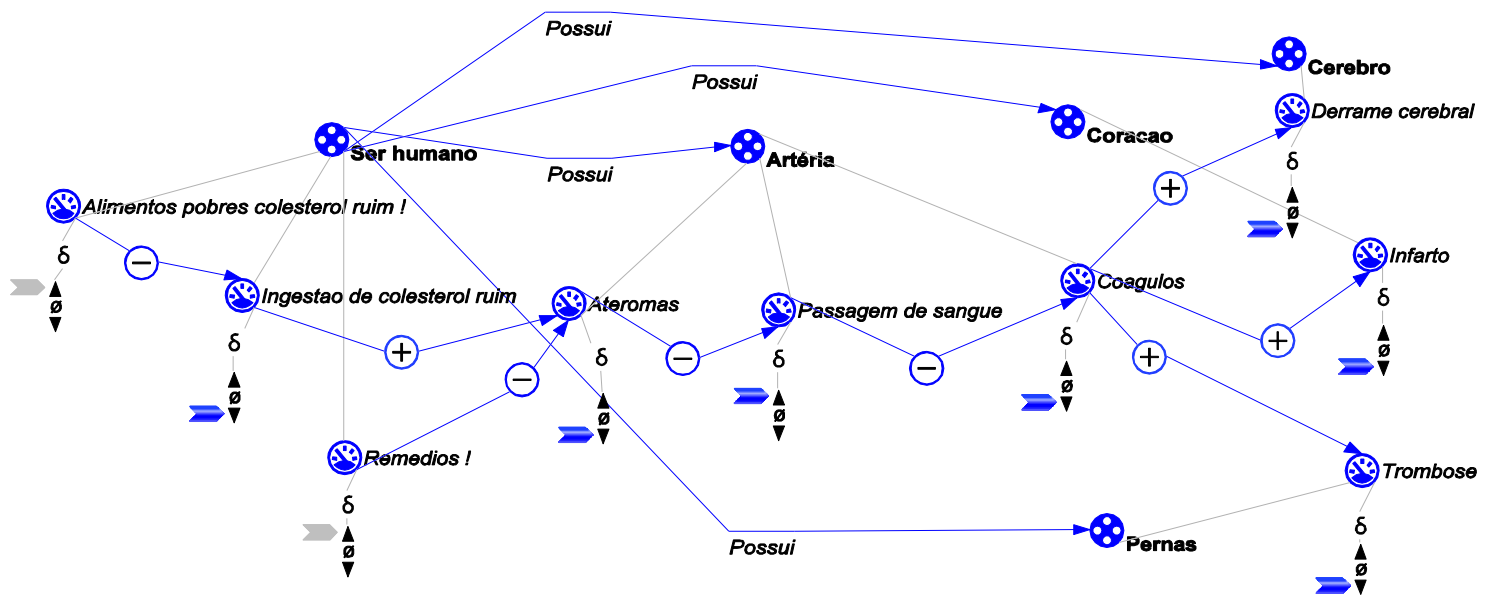

Simulação "com tratamento" baseado em alimentos bons e remédios aumentando

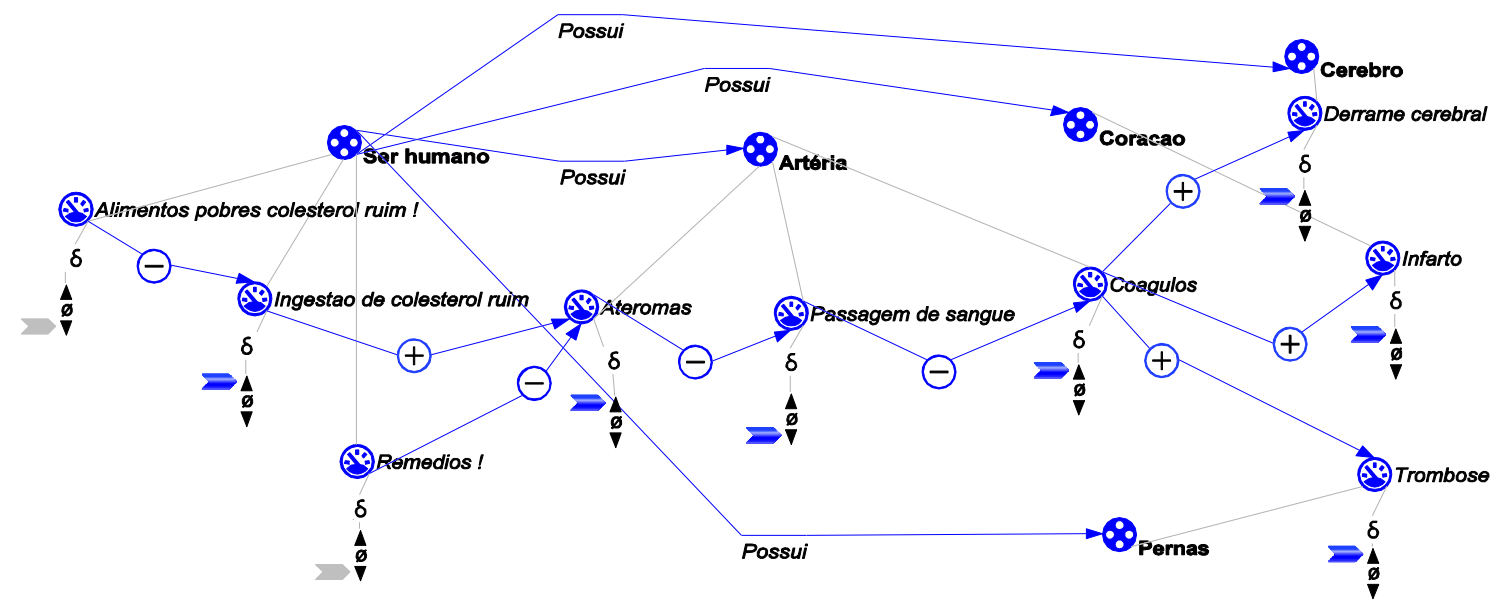

Simulação "com tratamento" baseado em alimentos bons e remédios diminuindo

2 - Cenários e simulações - modelo do aparelho reprodutor masculino. 


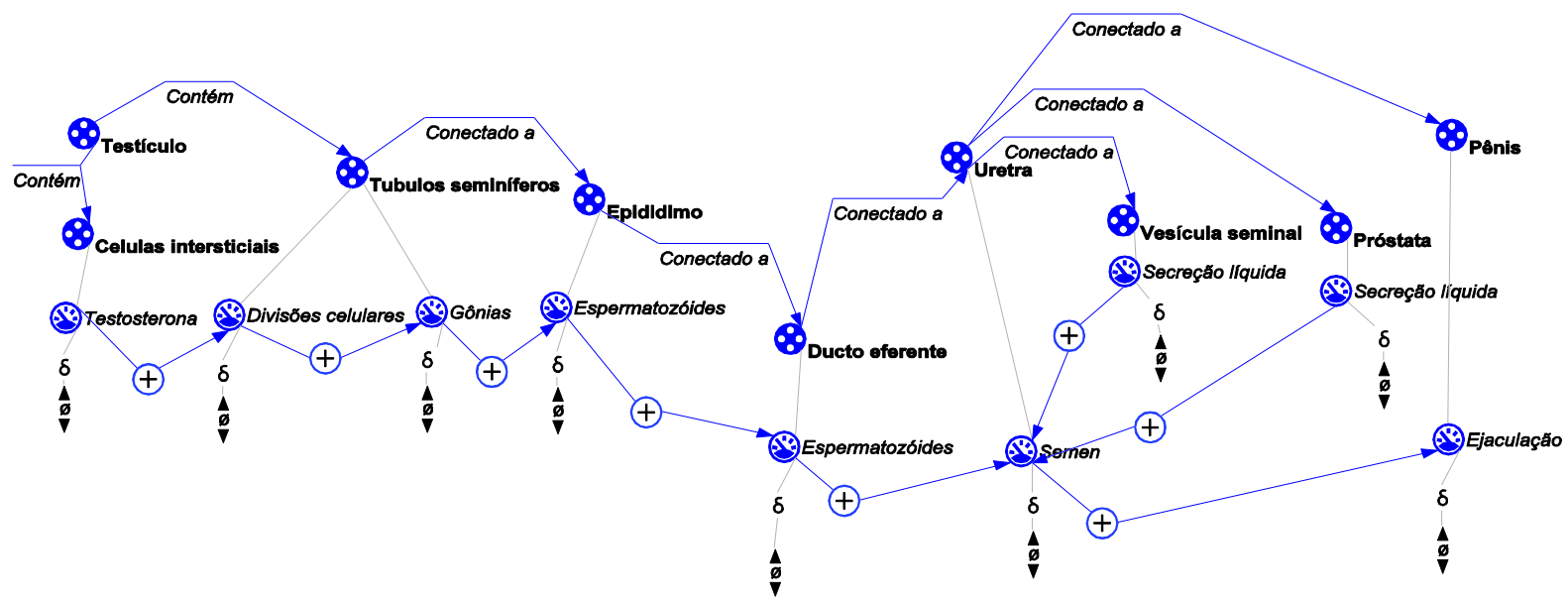

Expressão do modelo Aparelho reprodutor masculino

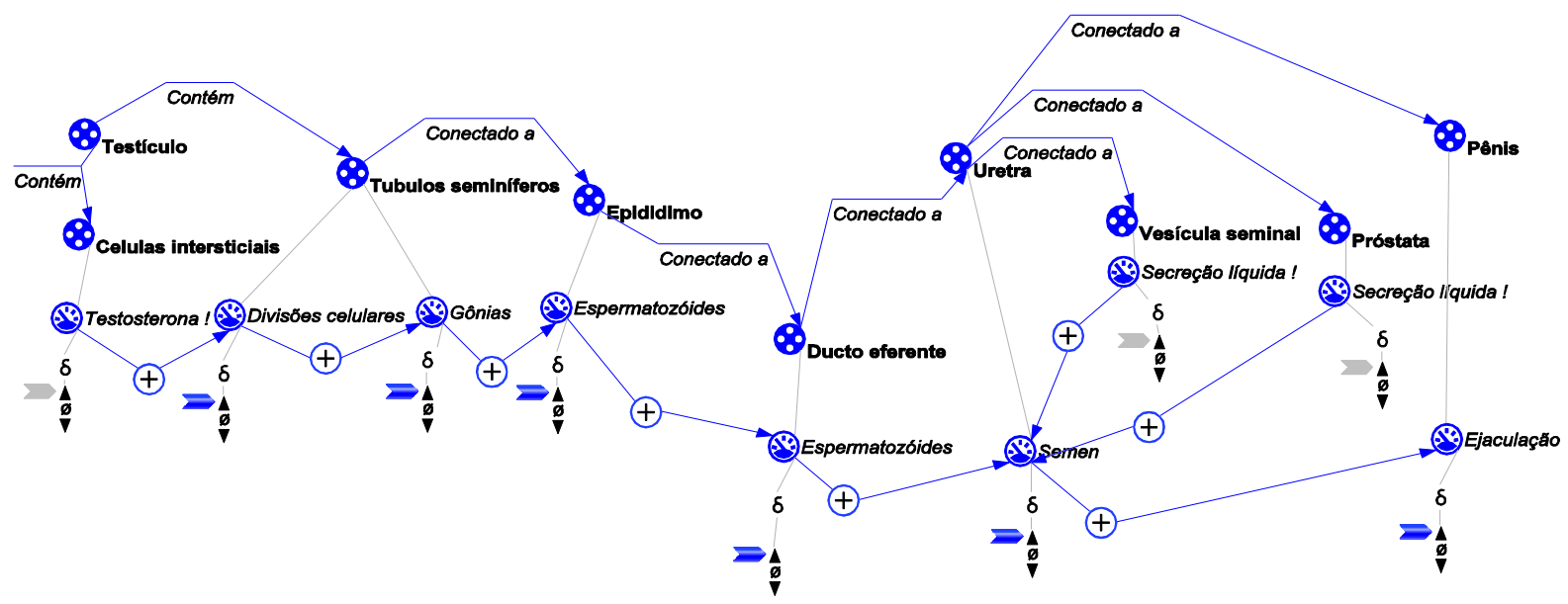

Simulação com produção de testosterona e secreção líquida aumentando

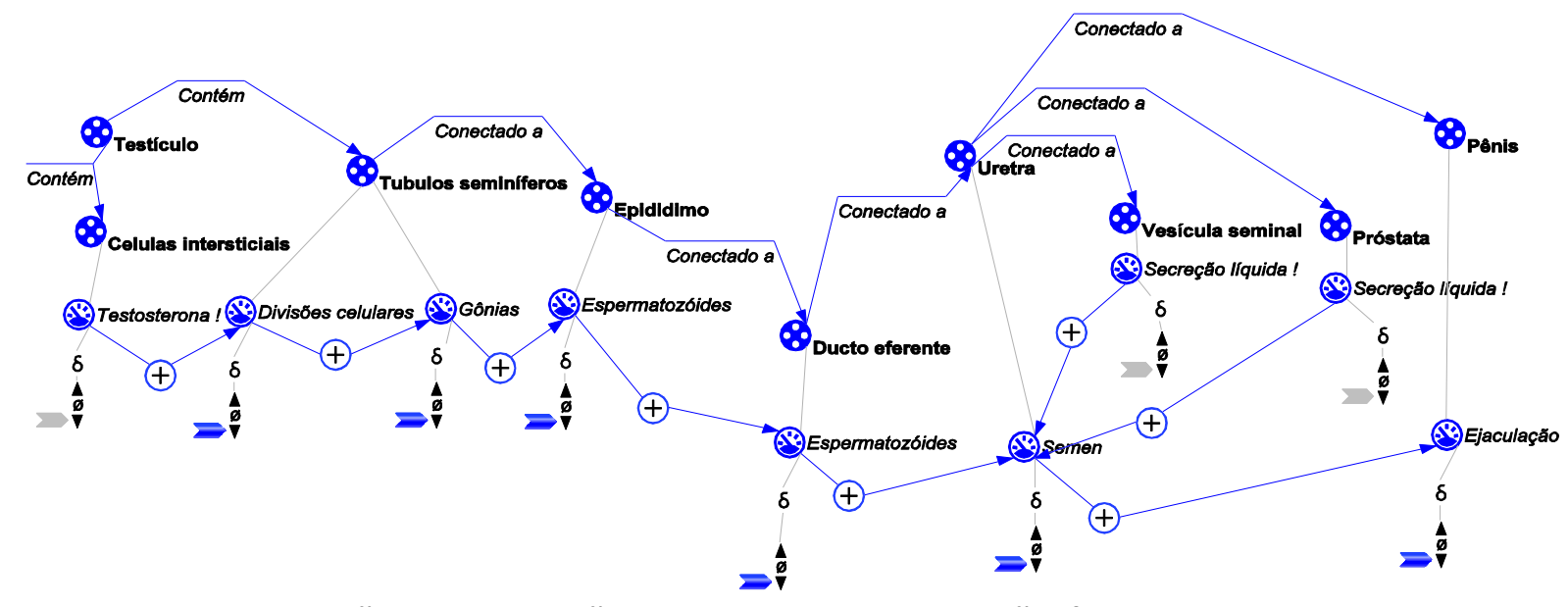

Simulação com produção de testosterona e secreção líquida diminuindo 


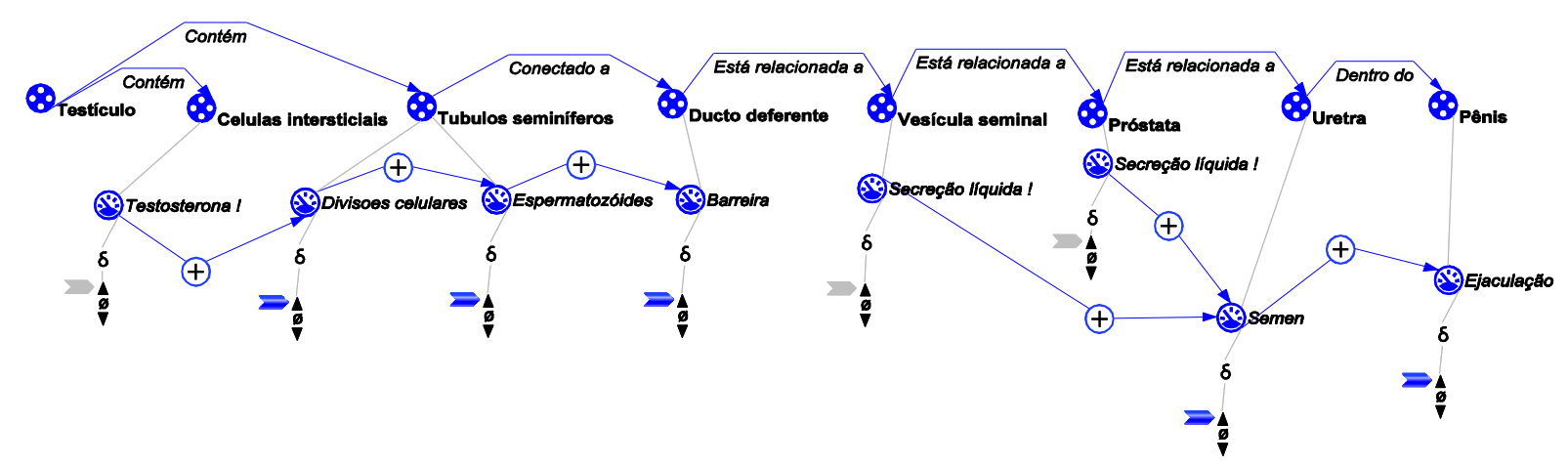

Simulação vasectomia: testosterona e secreções líquidas aumentando

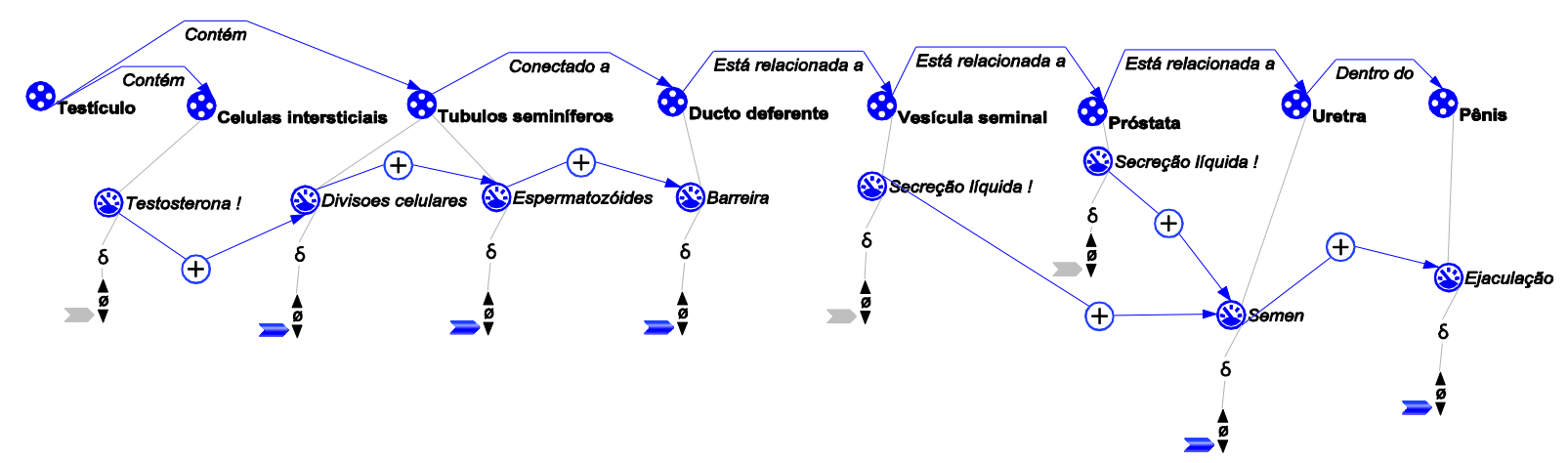

Simulação vasectomia: testosterona e secreções líquidas diminuindo 
3 - Cenários e simulações - modelo da placenta.
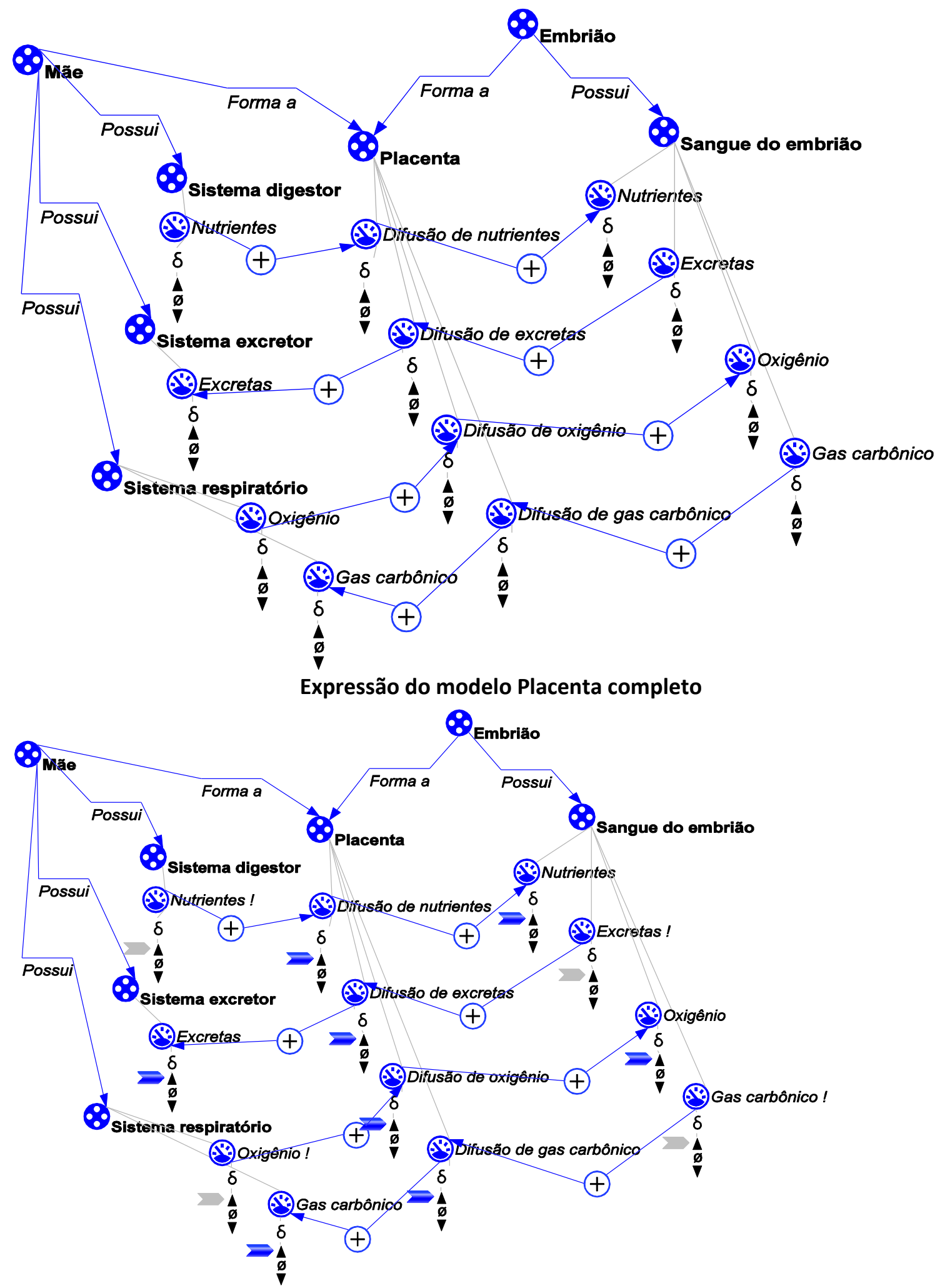

Simulação: Nutrientes e Oxigênio da mãe aumentando. Isso faz com que Excretas e Gás carbônico do sangue do embrião também estejam aumentando. 


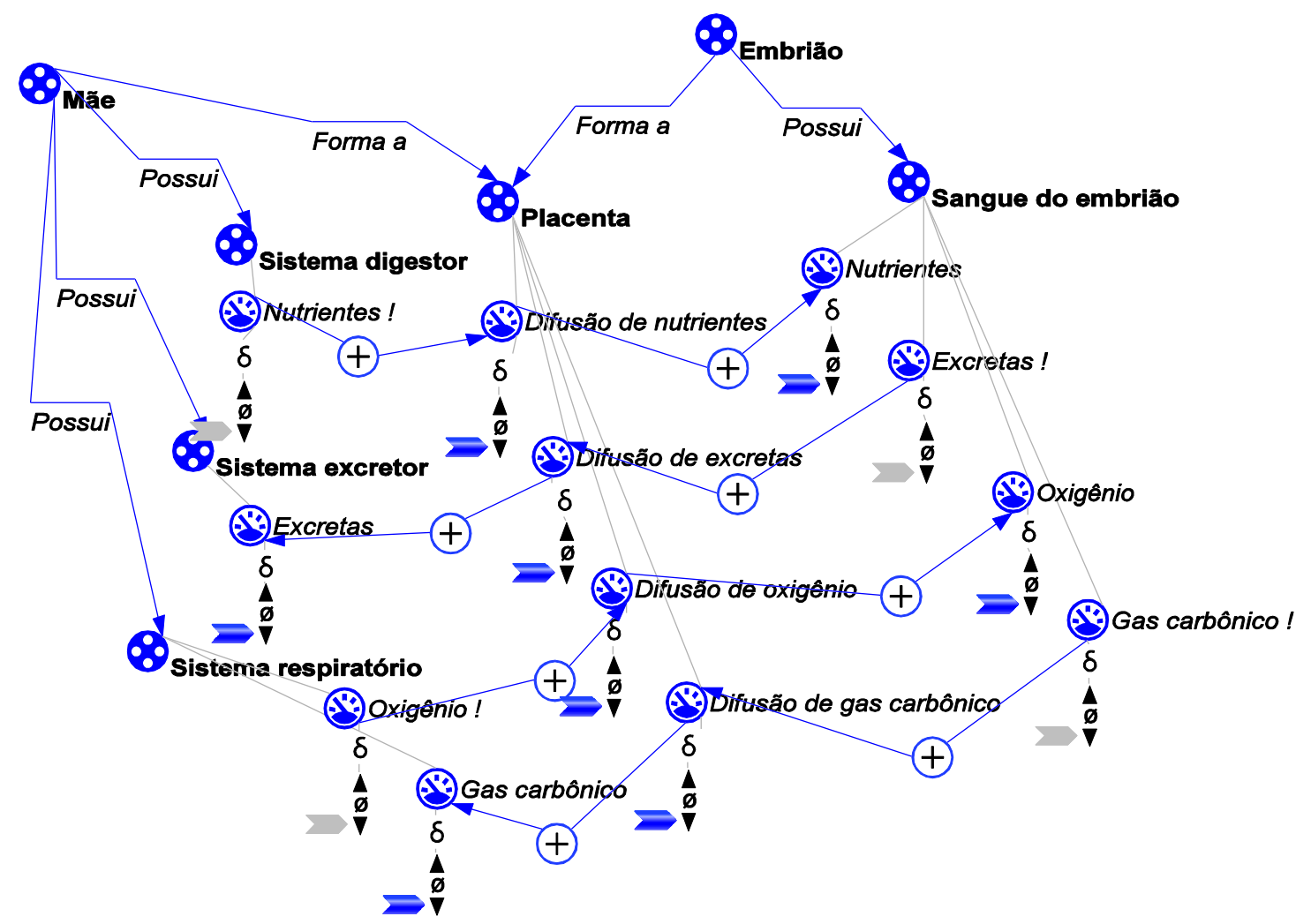

Simulação: Nutrientes e Oxigênio da mãe diminuindo. Excretas e Gás carbônico do sangue do embrião também estejam diminuindo. 